\title{
THERMAL PERFORMANCE OF EXTERIOR ROOF LEVEL AMENITY SPACE IN A COLD CLIMATE - A QUANTITATIVE GUIDANCE TOOL FOR LANDSCAPE DESIGN
}

\author{
By \\ William Alfred Jesse Williamson \\ Architectural Technology (Co-op), Sheridan College, 2002 \\ Honours Bachelor of Arts, University of Toronto, 2013 \\ (Architectural Studies - Design \& Environmental Studies) \\ An MRP presented to Ryerson University \\ in partial fulfillment of the \\ requirements for the degree of \\ Master of Building Science \\ in the Department of Architectural Science \\ Toronto, Ontario, Canada, 2017 \\ (C) William Alfred Jesse Williamson 2017
}




\section{Author's Declaration for Electronic Submission of a MRP}

I hereby declare that I am the sole author of this MRP. This is a true copy of the MRP, including any required final revisions.

I authorize Ryerson University to lend this MRP to other institutions or individuals for the purpose of scholarly research.

I further authorize Ryerson University to reproduce this MRP by photocopying or by other means, in total or in part, at the request of other institutions or individuals for the purpose of scholarly research. I understand that my MRP may be made electronically available to the public. 


\begin{abstract}
THERMAL PERFORMANCE OF EXTERIOR ROOF LEVEL AMENITY SPACE IN A COLD CLIMATE A QUANTITATIVE GUIDANCE TOOL FOR LANDSCAPE DESIGN
\end{abstract}

William Alfred Jesse Williamson

Master of Building Science, 2017

Department of Architectural Science, Ryerson University

There are no known studies to quantify the effects of amenity space landscape structures located over habitable space as related to thermal performance. There are three main objectives for investigation in this MRP; Objective 1 - Thermal analysis of on-slab wall types, Objective 2 (O2) - Thermal analysis of example amenity space using results from 01 , and Objective 3 (O3) - Recommended details that 'work' thermally and functionally.

A quantitative methodology was utilized using 1D manual calculation (Glaser method) and 2D computer simulation (THERM) to study three CIP concrete wall conditions and variations which include; 1.0 ) base line condition, 2.0) modified condition, and 3.0) ultimate condition. Simulation results of $\mathrm{O}$ indicated that design of landscape walls could improve thermal performance by $55 \%, 02$ found that there was an improvement of $60.5 \%$ between the worst and best performing conditions, and 03 recommended two wall variations to be utilized in landscape design which perform thermally and functionally.

\title{
Keywords
}

Thermal bridges, condominiums, MURBS, amenity space, landscape design, green roof, THERM 


\section{Acknowledgments}

In 2009 I decided to continue my post-secondary education, it has been a long journey, and I am pleased to be complete this latest portion.

I would like to thank my advisor Dr. Miljana Horvat for her advice and guidance to complete this report, my wife Joanne for her patience and support, my classmates at Ryerson for working with me and helping me when needed, and my colleagues/supervisors at IBI Group for being flexible, sympathetic, and for tolerating my time off to study. Another thank you to all my friends and extended family for their support and understanding in my desire to see this through.

So long, and thanks for all the fish. (Douglas Adams, 1984). 


\section{Table of Contents}

Author's Declaration for Electronic Submission of a MRP ....................................................................... ii

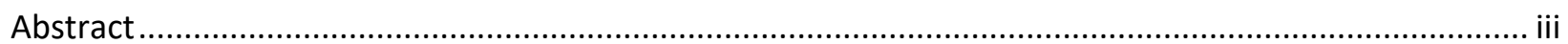

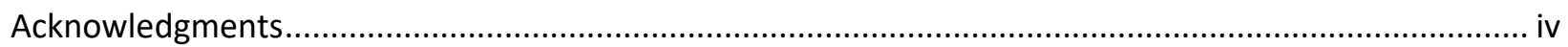

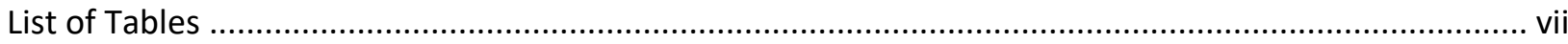

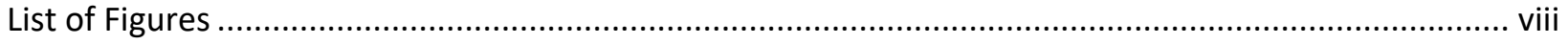

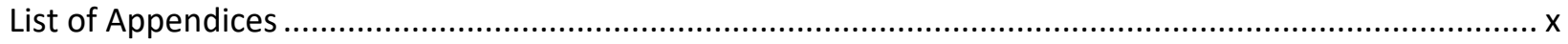

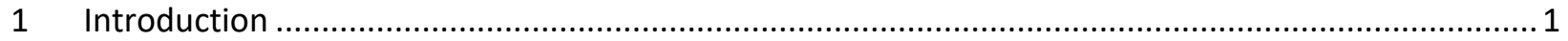

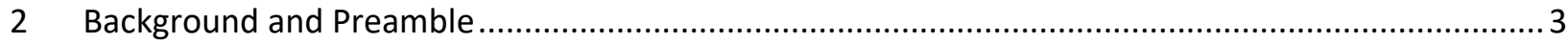

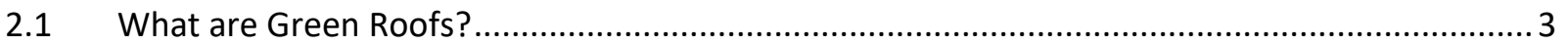

2.2 Heat Transfer in Green Roofs - What is Thermal Conduction? .................................................5

2.3 What is Landscape Amenity Space above Habitable Space? ..................................................... 7

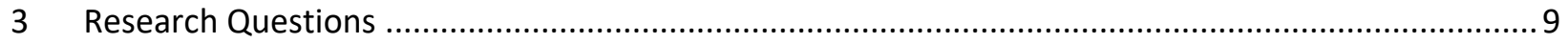

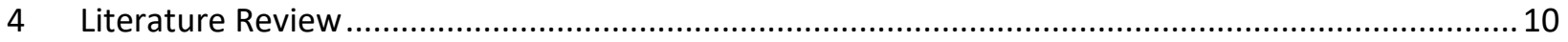

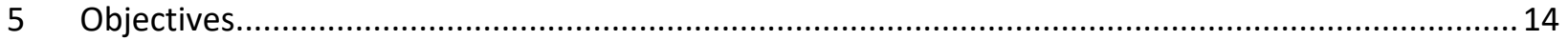

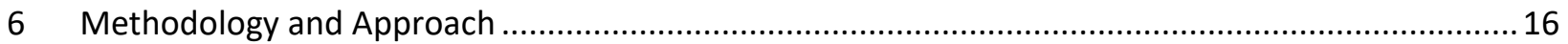

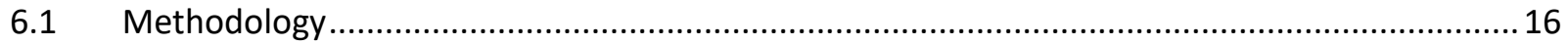

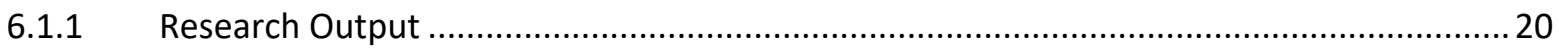

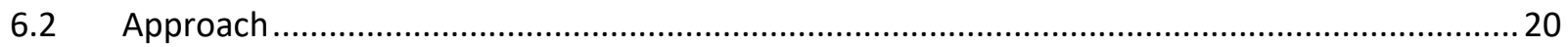

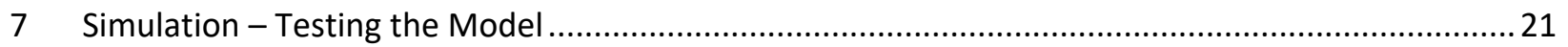

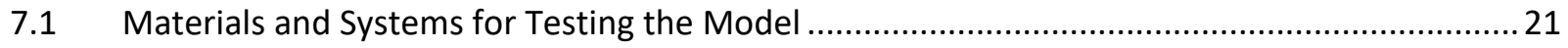

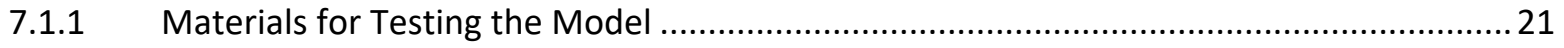

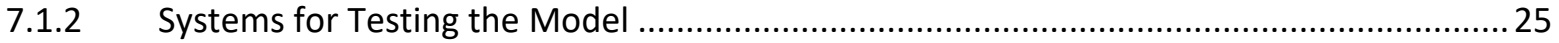

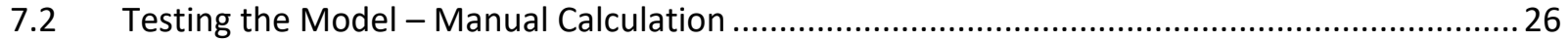

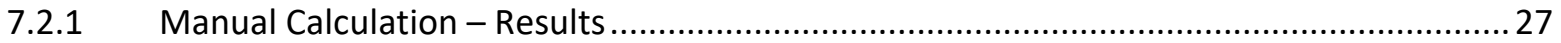

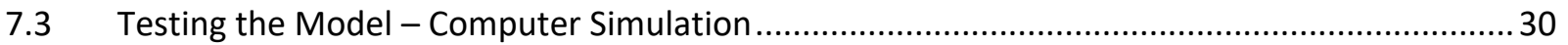

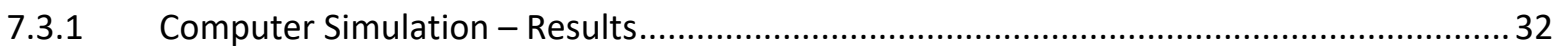

7.4 Testing the Model - Manual Calculation and Computer Simulation Analysis .............................34

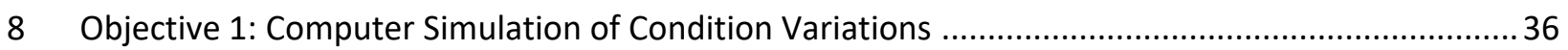

8.1 Condition Variations and Systems for Computer Simulation .................................................. 36

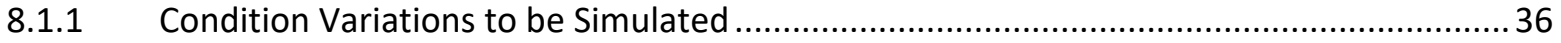

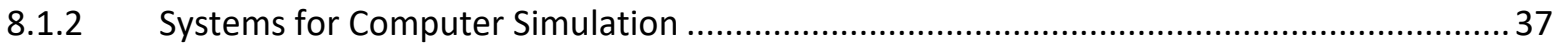




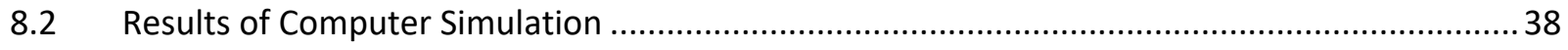

8.2.1 Results and Comparative Analysis of Computer Simulation .............................................. 39

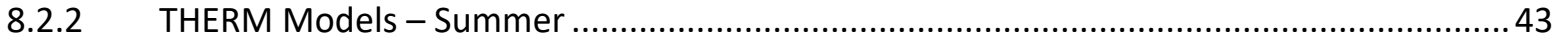

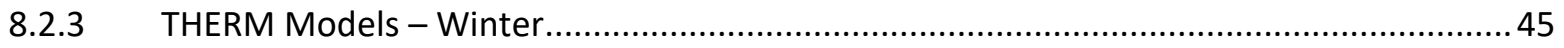

8.2.4 THERM Models - Additional Depictions ...................................................................... 46

9 Objective 2: Thermal Analysis of Example Amenity Space .......................................................... 48

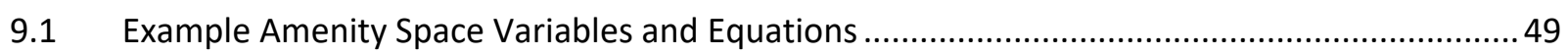

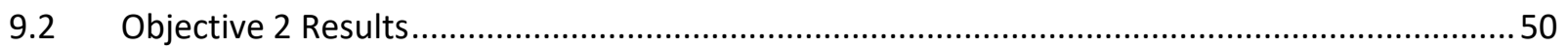

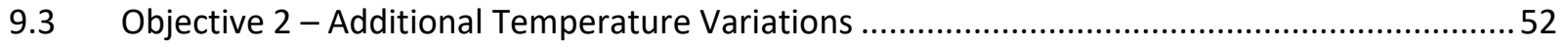

9.3.1 Objective 2 - Additional Temperature Variation Results ............................................5 52

10 Objective 3: Recommendations, Details that 'Work', and Future Work .....................................53

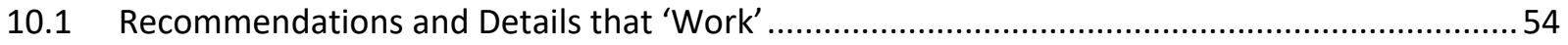

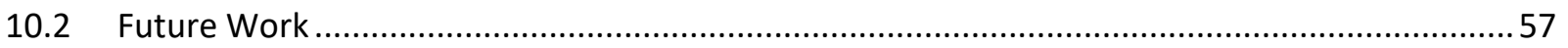

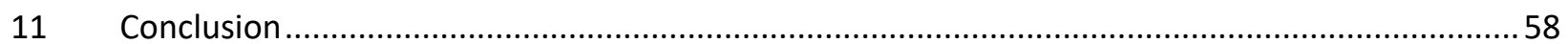

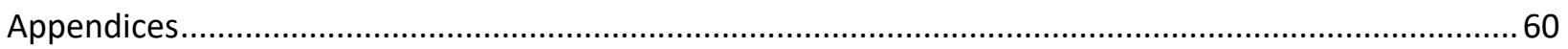

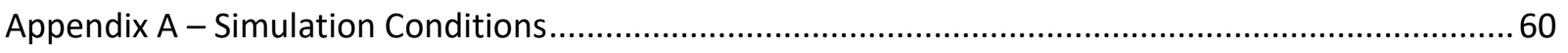

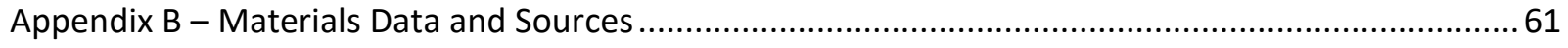

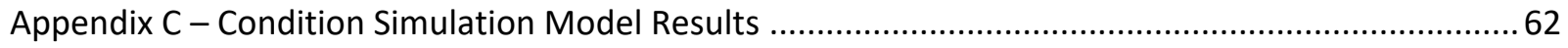

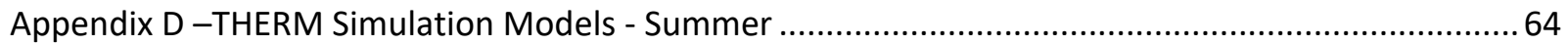

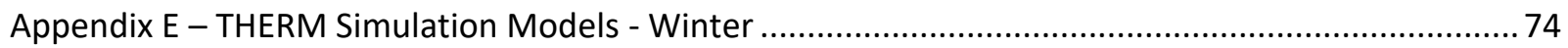

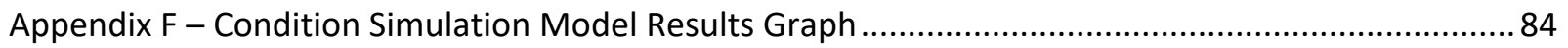

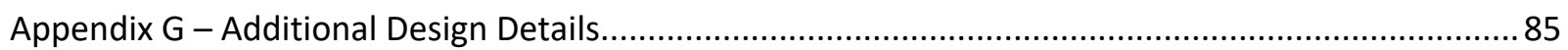

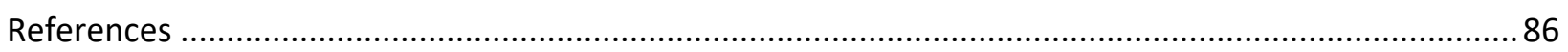




\section{List of Tables}

Table 2-1 - Green Roof Types, modified with metric units (Green Roof Technology, 2016) ...................... 4

Table 6-1 - Conditions and Descriptions of Models for Computer Simulation ........................................19

Table 7-1 - Table 5; Typical Apparent Thermal Conductivity Values for Soils, W/(m·K) (ASHRAE, 2009).. 23

Table 7-2 - Materials and Conductivity/Conductance for Manual Calculations and THERM ...................25

Table 7-3 - Manual Calculation, Summer - System 1 Paving .................................................................28

Table 7-4 - Manual Calculation, Summer - System 2 Wall ..................................................................... 28

Table 7-5 - Manual Calculation, Summer - System 3 Soil .................................................................. 28

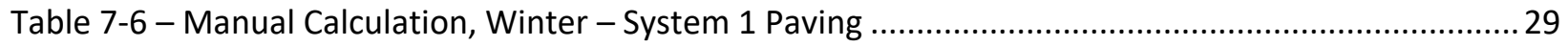

Table 7-7 - Manual Calculation, Winter - System 2 Wall..................................................................... 29

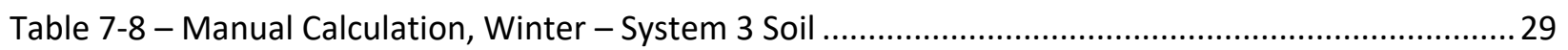

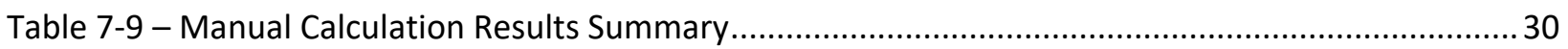

Table 7-10 - Computer Simulation Results Summary ….................................................................... 33

Table 7-11 - Manual Calculation and Computer Simulation Results Summary ....................................... 35

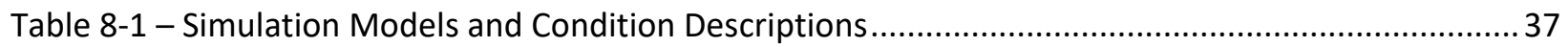

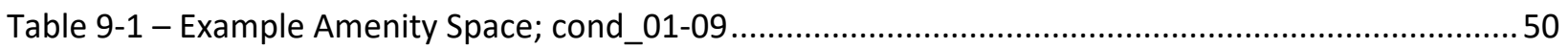

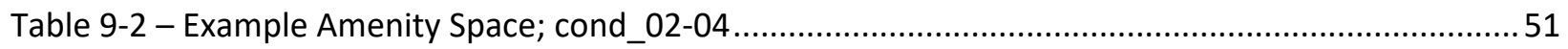

Table 9-3 - Example Amenity Space; cond_03-01 …............................................................................ 51

Table 9-4 - Example Amenity Space; cond_02-04 with Additional Temperature Variations.....................53

Table 10-1 - Condition 2.0 Design Detail Summary; Comments and Recommendations........................56

Table 10-2 - Condition 3.0 Design Detail Summary; Comments and Recommendations..........................56

Table 12-1 - Simulation Models and Condition Descriptions ...............................................................60

Table 12-2 - Materials and conductivity/conductance for manual calculations and THERM..................6 61

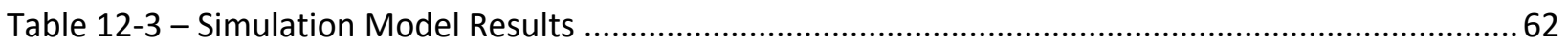




\section{List of Figures}

Figure $1.1-300 \mathrm{~mm}$ Wide CIP Concrete and Metal Wall with Thermal Bridge ....................................... 2

Figure 1.2 - 150mm Wide CIP Concrete Wall with Thermal Bridge ........................................................ 2

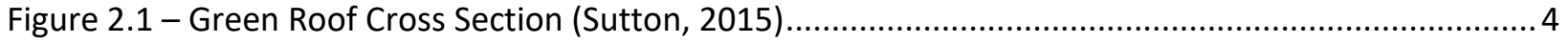

Figure 2.2 - The Energy Balance for a Green Roof (Theodosiou, 2009) …............................................ 5

Figure 2.3 - Conductive Heat Flow Through Copper (Cengel, 2007) .................................................... 6

Figure 2.4 - Conductive Heat Flow Through Silicon (Cengel, 2007) .................................................... 6

Figure 2.5 - Amenity Space Example (Urban Toronto [a], 2016) ...................................................... 8

Figure 2.6 - Amenity Space Example (Urban Toronto [b], 2016) ........................................................ 8

Figure 2.7 - Example Condominium Building with Podium Level Amenity Space (Sheftell, 2016) ............. 9

Figure 2.8 - Wind Flow and Pressure on a Building (Hutcheon \& Handegord, 1995) ............................... 9

Figure 4.1 - Detail 21; Insulated Concrete Roof with a Concrete Curb or Wall Bypassing the Roof

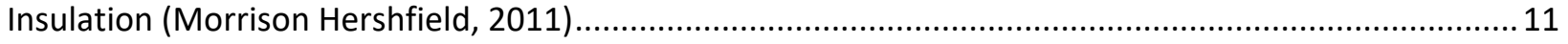

Figure 4.2 - Schöck Isokorb ${ }^{\circledR}$ Type CM for Concrete Balconies (Lawton \& Roppel, 2014)....................... 12

Figure 4.3 - Placement of Schöck Isokorb ${ }^{\circledR}$ in the Assembly (Lawton \& Roppel, 2014) .......................... 12

Figure 5.1 - Example Landscape Plan of Amenity Space and Intensive Green Roof ............................... 15

Figure 6.1 - Detailed Section Drawings of Three Thermal Conditions …............................................. 17

Figure 6.2 - Simplified Section Drawings of Three Thermal Conditions for Simulation ............................17

Figure 7.1 - Figure 6; Trends of Apparent Thermal Conductivity for Moist Soils (ASHRAE, 2009) ............23

Figure 7.2 - Systems for Testing the Manual and Computer Simulation Models ..................................26

Figure 7.3 - Condition 1.6 Systems Separated - Standard w/ No Wall Insulation, Summer ...................... 31

Figure 7.4 - Condition 1.6 Systems Separated - Standard w/ No Wall Insulation, Winter ....................... 31

Figure 7.5 - Condition 1.6 Systems Combined - Standard w/ No Wall Insulation, Summer .....................32

Figure 7.6 - Condition 1.6 Systems Combined - Standard w/ No Wall Insulation, Winter ....................... 32

Figure 7.7 - U-factor Model Comparison - Manual Calculation and Computer Simulation (CS) ............... 34

Figure 7.8 - U-factor Model Comparison - Manual Calculation and Computer Simulation (CS) ............... 35

Figure 8.1 - Systems for the Computer Simulation Models .............................................................. 38

Figure 8.2 - Condition 1 Results for Summer and Winter Simulation .................................................. 40

Figure 8.3 - Condition 2 Results for Summer and Winter Simulation .................................................. 41

Figure 8.4 - Condition 3 Results for Summer and Winter Simulation .................................................. 42

Figure 8.5 - Conditions 1, 2, and 3 Combined Results for Summer and Winter Simulation ..................... 43 


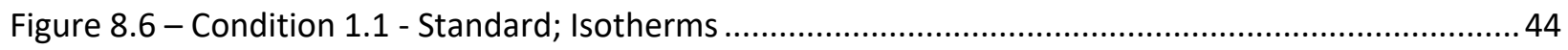

Figure 8.7 - Condition 1.1 - Standard; Flux Vectors …....................................................................... 44

Figure 8.8 - Condition 2.1 - Improved; Isotherms …................................................................................ 44

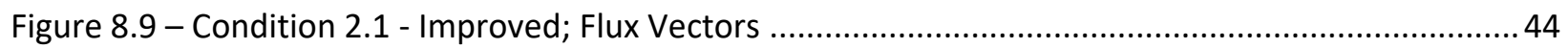

Figure 8.10 - Condition 3.1 - Ultimate; Isotherms .......................................................................... 44

Figure 8.11 - Condition 3.1 - Ultimate; Flux Vectors ............................................................................ 44

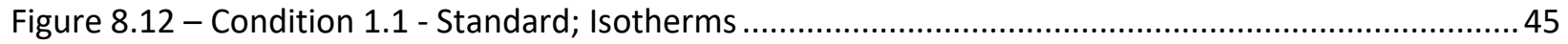

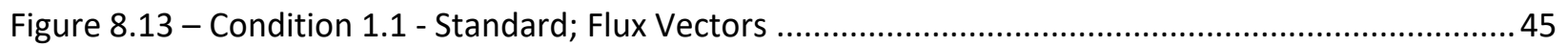

Figure 8.14 - Condition 2.1 - Improved; Isotherms ........................................................................ 45

Figure 8.15 - Condition 2.1 - Improved; Flux Vectors …................................................................... 45

Figure 8.16 - Condition 3.1 - Ultimate; Isotherms............................................................................. 46

Figure 8.17 - Condition 3.1 - Ultimate; Flux Vectors .......................................................................... 46

Figure 8.18 - Condition 1.1 - Standard, Summer; Heat Flux Magnitude and Legend ............................. 47

Figure 8.19 - Condition 1.1 - Standard, Winter; Heat Flux Magnitude and Legend................................. 47

Figure 8.20 - Condition 1.2 - Standard @ Reinforcing, Winter; Heat Flux Magnitude and Legend ...........47

Figure 8.21 - Condition 1.1 - Standard, Winter; Infrared and Legend ................................................ 47

Figure 8.22 - Condition 3.1 - Ultimate, Summer; Infrared and Legend ................................................ 48

Figure 8.23 - Condition 3.1 - Ultimate, Winter; Infrared and Legend ................................................... 48

Figure 9.1 - Example Landscape Plan with Thermal Zones for Analysis.................................................. 49

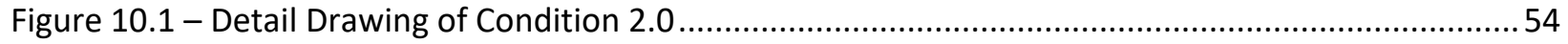

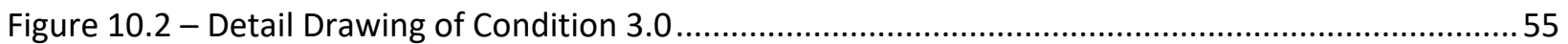




\section{List of Appendices}

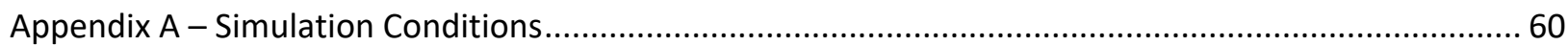

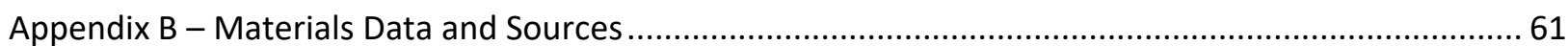

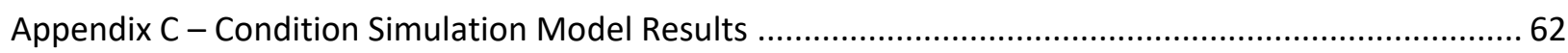

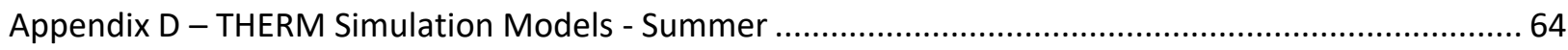

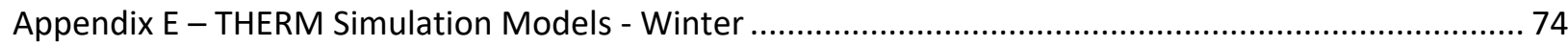

Appendix F - Condition Simulation Model Results Graph ............................................................... 84

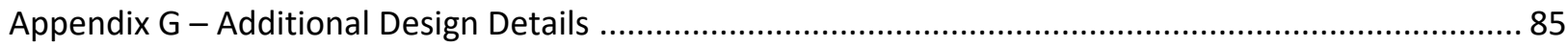




\section{Introduction}

Within the City of Toronto and Greater Toronto Area (GTA), there are hundreds of condominiums, multiuse residential buildings (MURBS), and apartment buildings recently constructed or currently under construction, and this trend has been ongoing for approximately 15 years (Canada Mortgage and Housing Corporation, 2013). Recent statistics from Canada Mortgage and Housing Corporation (CMHC) state that from January 2016 to October 2016 there were 16,178 units which started construction under the 'Apt and Other' category within the Toronto Census Metropolitan Area (CMA) (Canada Mortgage and Housing Corporation, 2016). Also from the same source, in 2016 there were 12,773 units in 'Apt and Other' category of which construction was completed. The previous year 2015, in the Toronto CMA there were 17,054 units which started construction and 29,326 units were completed (Canada Mortgage and Housing Corporation, 2016). If it is presumed that there is an average of 450 units per residential condominium/apartment building, the number of buildings completed in 2015 and in 2016 so far would be \pm 93.5 (if it is calculated as $(12,733+29,326) / 450=93.46)$.

Particularly in dense urban environments, there is an increased need to provide usable greenspace for residents and visitors alike. Not all landscape amenity space may be defined as greenspace, as the actual function of said space can vary drastically, but the act of adding vegetation where it is usually not available can have a positive impact on an urban inhabitant's health. There is increasing evidence showing that naturalised environments, or greenspace, located in urban areas are critical to the psychological health of humans and can help to increase feelings of well-being (Almusaed, 2011). Studies have shown that just by simply being near vegetation or naturalized areas, people often feel a calming sense, energized, and an uplifted spirit (Gullone, 2000).

City of Toronto by-laws mandate the required amenity space (interior and/or exterior) as a minimum area measured in square metres (sq. $\mathrm{m}$ or $\mathrm{m}^{2}$ ) that is to be provided as part of a new condominium development (City of Toronto, 2014). Due to this fact, the majority of these residential and/or mixeduse structures have exterior green roof and amenity space installed for the exclusive use of the residents, which would often be located on a podium or roof top level above habitable space. Landscape elements such as planter walls, planter boxes, and trellis features are typically connected structurally to the roof slab to provide lateral strength, regardless of the slab type or roof material. 
A visual walk around the city will confirm that the most common structural material in Toronto, particularly for mid to high rise building types such as condominiums and apartment buildings, partly due to its flexibility and unique physical properties, is cast-in-place (CIP) concrete. One of the drawbacks of CIP concrete is its thermal properties, with a conductivity of $1.40 \mathrm{~W} / \mathrm{m} \cdot \mathrm{K}$ it is on the higher end for typical building materials (ASHRAE, 2009). The conductivity of CIP Concrete is surpassed by carbon steel at $43.0 \mathrm{~W} / \mathrm{m} \cdot \mathrm{K}$, which is a material often used for reinforcing of concrete structures (The Engineering Toolbox, 2016). From a landscape architectural perspective, the impacts of green roof amenity space on thermal performance are largely overlooked, unknown, or are unconsidered factors during the design process. Therefore, landscape structures are typically secured to the slab without the use of insulation breaks, which create thermal bridges, examples of this condition can be seen in Figure 1.1 and Figure 1.2 below. In Figure 1.1 the thermal bridge can be seen through the connecting $300 \mathrm{~mm}$ wide CIP concrete wall and the top of CIP concrete slab. In Figure 1.2, which was a site plan application (SPA) phase detail, the landscape designer completely missed including the roof slab insulation in their wall detail, the detail also shows a thermal bridge at the $150 \mathrm{~mm}$ wide CIP concrete wall and the top of slab, even if the insulation was included in the original detail.

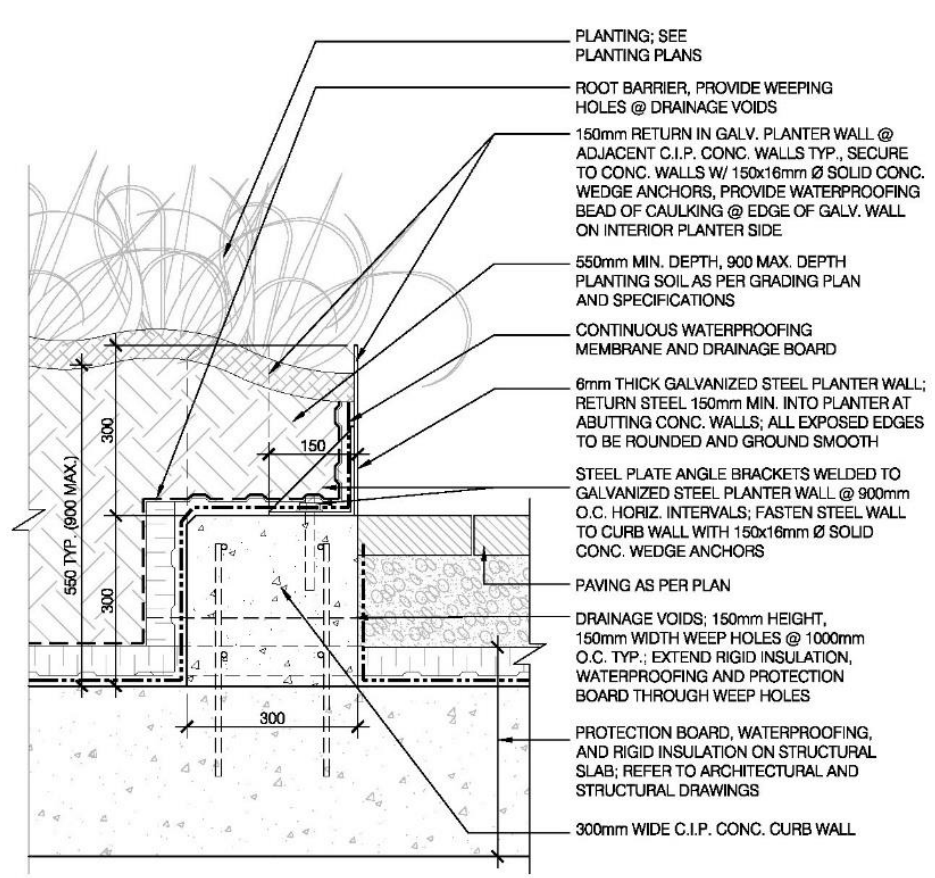

Figure 1.1-300mm Wide CIP Concrete and Metal Wall with Thermal Bridge

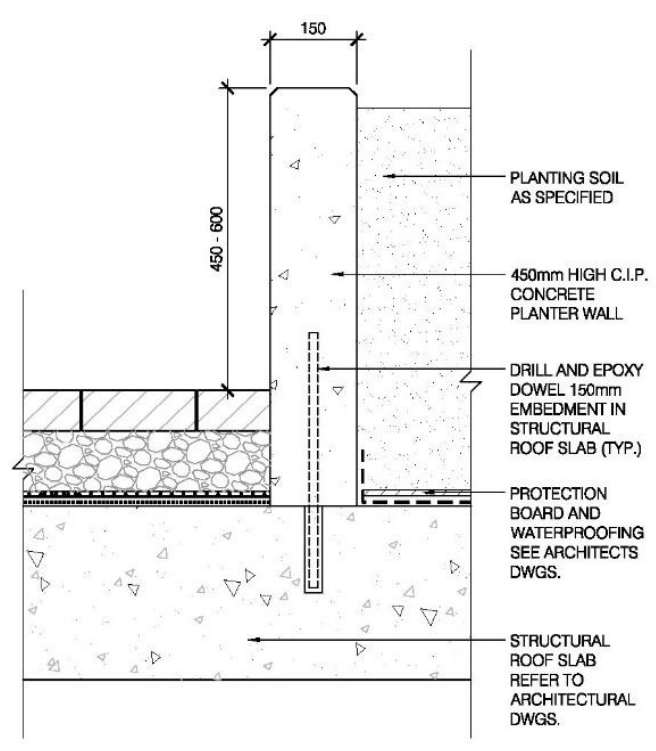

Figure 1.2 - 150mm Wide CIP Concrete Wall with Thermal Bridge 
There are no known studies to quantify these effects. This research proposes to study the impacts of amenity space green roof design with thermal bridges and to propose working solutions that can be applied in real-world conditions. Another aspect of this report is to create a potential teaching tool for landscape designers and landscape architects, helping them to be cognisant of how their field of work can negatively or positively impact a building's thermal performance.

\section{Background and Preamble}

There are a few basic concepts and principles to discuss in order for landscape designers, architectural designers, and anyone else that is unfamiliar with these topics to understand the scope and reasons behind creating this report. This section is important to fill in any introductory 'gaps' in the reader's knowledge and to define how the topics listed below are to be understood in this paper. The questions/sections to be explored further include; a) What are Green Roofs?, b) Heat Transfer in Green Roofs - What is Thermal Conduction?, and c) What is Landscape Amenity Space above Habitable Space?

\subsection{What are Green Roofs?}

There are three main types of green roofs; extensive, semi-intensive, and intensive (see Table 2-1 below). Each type of green roof can have many different variations in each category including soil types, drainage layers, filter mediums, and planting varieties (Sutton, 2015). Figure 2.1 below depicts an example of a green roof cross section, showing the typical layers that should be detailed. Figure 2.1 depicts a standard roofing system (where the waterproofing is located above the insulation layer), the details in this research project utilize an inverted roofing system (where the waterproofing is located below the insulation layer). The most basic difference between extensive and intensive green roofs is the depth of the growing medium, also called engineered substrate or planting soil (Sutton, 2015). In an existing building, the primary reason to select an extensive green roof system is often structural related. At 73.2 to $122.1 \mathrm{~kg} / \mathrm{sq} . \mathrm{m}$ ( 15 to $25 \mathrm{lbs} / \mathrm{sq} . \mathrm{ft}$ ), extensive green roofs are better suited for retrofit applications where both dead and live loads are a concern (Green Roof Technology, 2016). Whereas, in a new building an intensive green roof can be accommodated for structurally during the design phase and can allow the landscape designer to select a greater variation in a planting palette. However, structural conditions and/or concerns are not the only consideration in selecting a green roof type. 
Other variables include overall suitability for the project, cost, aesthetics, water retention or stormwater management capacity, and maintenance (Weiler \& Scholz-Barth, 2009). In an extensive green roof the growing medium is typically around $75 \mathrm{~mm}$ to $125 \mathrm{~mm}$ thick and it is planted with sedum, mosses, or small grasses (see Table 2-1 below). Whereas, an intensive green roof will often have growing medium depths of $175 \mathrm{~mm}$ to $600 \mathrm{~mm}$ for shrubs, grasses, and perennials and upwards of $900 \mathrm{~mm}$ to $1200 \mathrm{~mm}$ depth or greater for large shrubs and trees (Green Roof Technology, 2016). Semi-intensive green roofs tend to be in the ranges between extensive and intensive with depths of $125 \mathrm{~mm}$ to $175 \mathrm{~mm}$ for the growing medium and could be planted with sedum, ornamental grasses, or perennials (see Table 2-1 below).

Table 2-1 - Green Roof Types, modified with metric units (Green Roof Technology, 2016)

\begin{tabular}{|c|c|c|c|}
\hline & Extensive Green Roofs & Semi-Intensive Green Roofs & Intensive Green Roofs \\
\hline Overall Depth & $75-125 \mathrm{~mm}$ (3 - 5 inches) & $125-175 \mathrm{~mm}$ (5-7 inches) & $175-600+\mathrm{mm}$ (7 - 24+ inches) \\
\hline Weight max. & $73.2-122.1 \mathrm{~kg} / \mathrm{m}^{2}\left(15-25 \mathrm{lbs} / \mathrm{ft}^{2}\right)$ & $122.1-195.3 \mathrm{~kg} / \mathrm{m}^{2}\left(25-40 \mathrm{lbs} / \mathrm{ft}^{2}\right)$ & $170.9-390.6+\mathrm{kg} / \mathrm{m}^{2}\left(35-80+\mathrm{lbs} / \mathrm{ft}^{2}\right)$ \\
\hline Plants & $\begin{array}{c}\text { Mosses, Sedums, Succulents, Herbs } \\
\text { and few Grasses }\end{array}$ & $\begin{array}{c}\text { Selected Perennials, Sedums, } \\
\text { ornamental Grasses, Herbs and } \\
\text { little Shrubs }\end{array}$ & $\begin{array}{c}\text { Perennials, Lawn, Putting green, Shrubs } \\
\text { and Trees, rooftop farming }\end{array}$ \\
\hline Irrigation & no, not recommended & partially, as-needed & yes, automatic/flood \\
\hline Maintenance & low & medium & high \\
\hline Use & Living machine & Diversity, habitat & Garden, Park \\
\hline Costs & low & medium & high \\
\hline
\end{tabular}

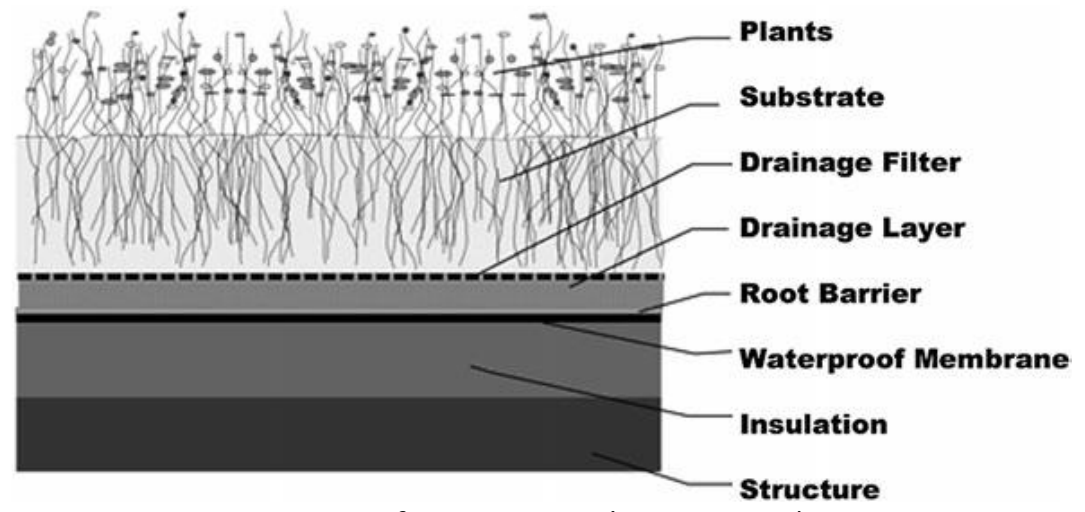

Figure 2.1 - Green Roof Cross Section (Sutton, 2015) 
For the purpose of this study, the focus will be on intensive green roofs with a soil depth of $\pm 700 \mathrm{~mm}$ only. Intensive green roofs were selected for this study because they are often used in amenity space design and can facilitate a wider variety of wall designs as well as many different varieties of vegetation. The next section/question will provide a simplified description of heat transfer in green roofs focusing on what is relevant to the approach of this research paper.

\subsection{Heat Transfer in Green Roofs - What is Thermal Conduction?}

The actual heat transfer mechanisms in green roofs are quite complicated (see Figure 2.2 below), and are subject to various external and internal variables such as geographical location, elevation, solar radiation, precipitation, wind and pressure, vegetation density, building mechanical devices (internal air conditioning), and occupant use, to name a few (Sutton, 2015). There are many ongoing and previously completed studies within various scientific fields to quantify performance variables of green roofs both mathematically and experimentally, but these studies are usually focused on the actual green roofs themselves (Theodosiou, 2009). Though this report is focused on how landscape structures affect thermal performance of a building in amenity space areas, the adjacency of green roof and paving systems cannot be ignored. Due to this fact and because the topic of green roofs is relevant to this research, some studies will be explored further in the literature review portion of this report (see Section 4 below).

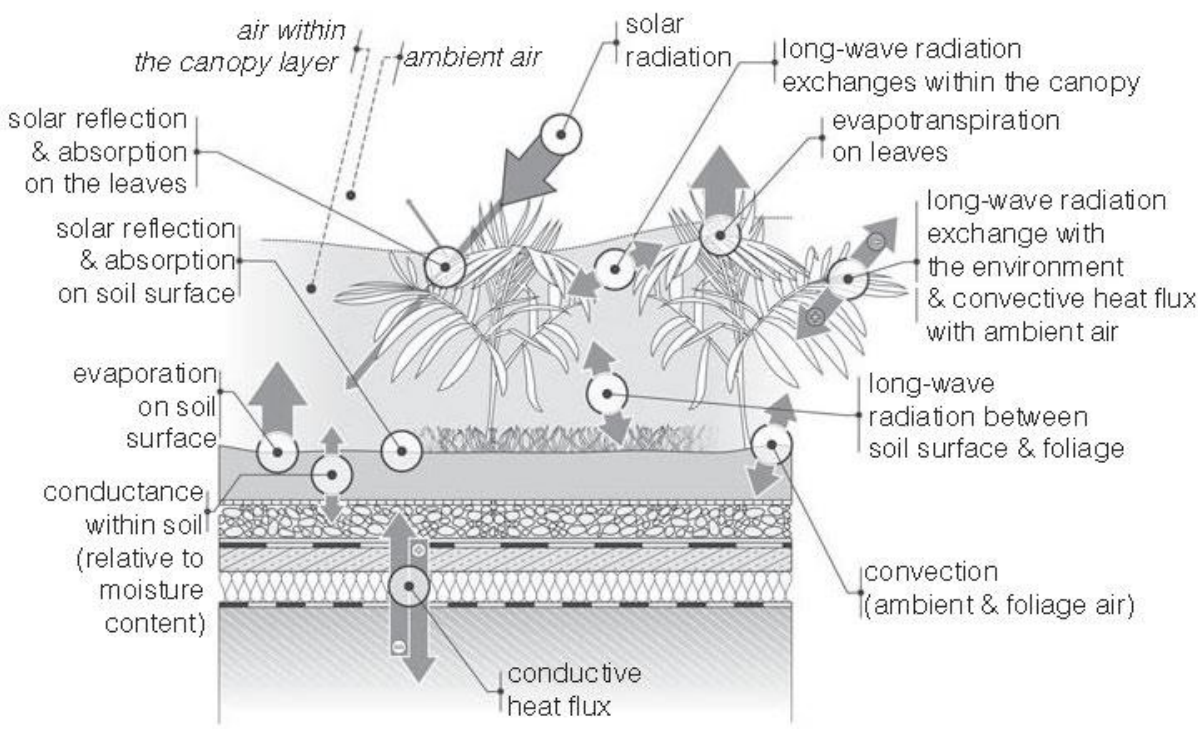

Figure 2.2 - The Energy Balance for a Green Roof (Theodosiou, 2009) 
The study of heat transfer in buildings is a focus of the field of building science, or building physics. There are three primary physical methods which facilitate heat transfer within a building; conduction, convection, and radiation (Hens, 2007). Conduction is the heat transfer mechanism of focus in this study, it relates directly to thermal bridges and the green roof landscape amenity design in this report. Cengel (2007) defines conduction as "The transfer of energy from the more energetic particles of a substance to the adjacent less energetic ones as a result of interactions between the particles" and "The rate of heat conduction through a solid is directly proportional to its thermal conductivity". The rate of heat transfer by conduction between building elements are defined by a materials conductivity [k] (see Figure 2.3 and Figure 2.4 below) or resistance $\left[R_{s i}\right]$ values. The units for conductivity are defined as $\mathrm{W} / \mathrm{m} \cdot \mathrm{K}$ and for resistance are defined as $\mathrm{m}^{2} \cdot \mathrm{K} / \mathrm{W}$ (Cengel, 2007). Basically, the higher the $\mathrm{k}$ value for a given material, the greater the heat transmission will be through conduction, and the higher the $\mathrm{R}_{\mathrm{si}}$ value for a given material the lower the heat transmission is through conduction. Thermal conductivity is also related to temperature. Generally in gases conductivity increases as the temperature increases, whereas in liquids and solids conductivity tends to decrease as temperature increases (Cengel, 2007).

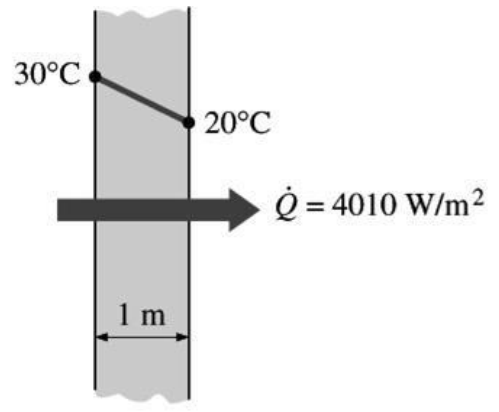

(a) Copper $\left(k=401 \mathrm{~W} / \mathrm{m} \cdot{ }^{\circ} \mathrm{C}\right)$ Figure 2.3-Conductive Heat Flow Through Copper (Cengel, 2007)

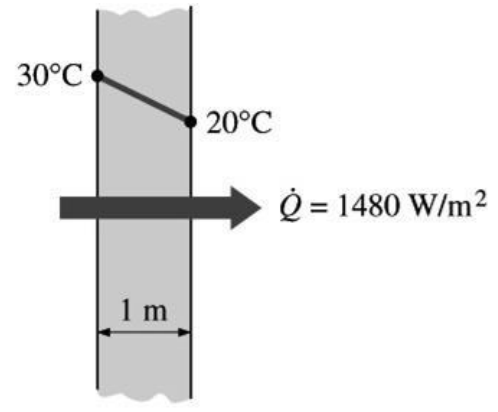

(b) Silicon $\left(k=148 \mathrm{~W} / \mathrm{m} \cdot{ }^{\circ} \mathrm{C}\right)$

Figure 2.4-Conductive Heat Flow Through Silicon (Cengel, 2007)

The software application THERM, which is utilized for this study, provides an output with a numerical heat transfer coefficient value called a U-factor or U-value (Mitchell, et al., 2013). The units defined for $\mathrm{U}$-factor values are $\mathrm{W} / \mathrm{m}^{2} \cdot \mathrm{K}$. Essentially, the lower the U-factor value, the higher the resistance values are within the system. Cengel (2007) defines this value as "The rate of heat loss through a unit surface area of a window per unit temperature difference between the indoors and the outdoors is called the Ufactor". THERM was initially designed to analyse the thermal performance of windows, but is often employed for other building analysis purposes as it can be customized to simulate a wide variety of twodimensional (2D) applications where thermal bridges are a concern (Lawrence Berkeley National 
Laboratory, 2016). Other aspects of the program THERM will be explored further in other sections of this report (see Section 6.1 below).

The relationship of thermal conductivity, thermal conductance, and resistance can be defined by the equations and units below:

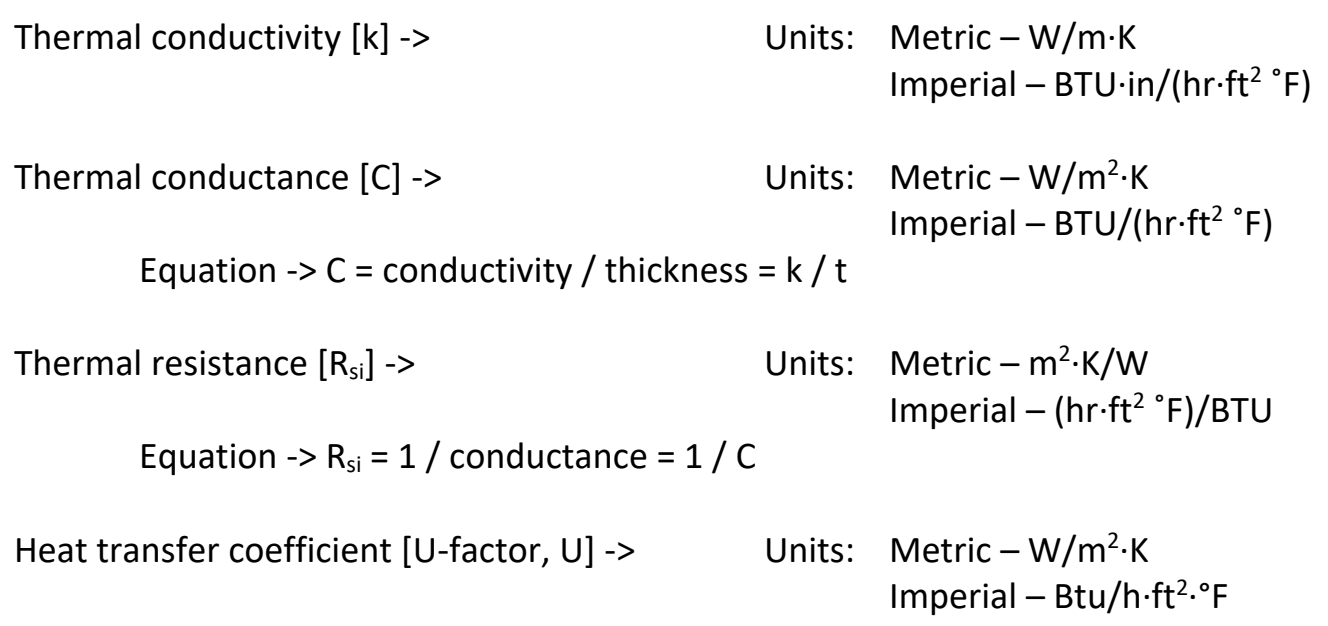

This section describing thermal conductance should highlight why it is not advisable to use materials with high conductivity in building envelope construction, particularly if there is no continuous insulating layer to break the thermal connection from the interior to the exterior or from the exterior to the interior. The next section describes landscape amenity space and habitable space.

\subsection{What is Landscape Amenity Space above Habitable Space?}

Building Science Corporation (2016) defines habitable space as "Building space intended for continual human occupancy. Such space generally includes areas used for living, sleeping, dining and cooking, but does not generally include bathrooms, toilets, hallways, storage areas, closets, or utility rooms". For the purpose of this report, the definition of habitable space is expanded to include any interior air conditioned space in a building as mentioned above and also including any circulation or storage areas where there is potential for interior and exterior thermal differences. This essentially means that habitable space requires the necessity of an enclosed or continuous thermal barrier to regulate internal and external temperature variation and reduce unwanted heat transmission. 


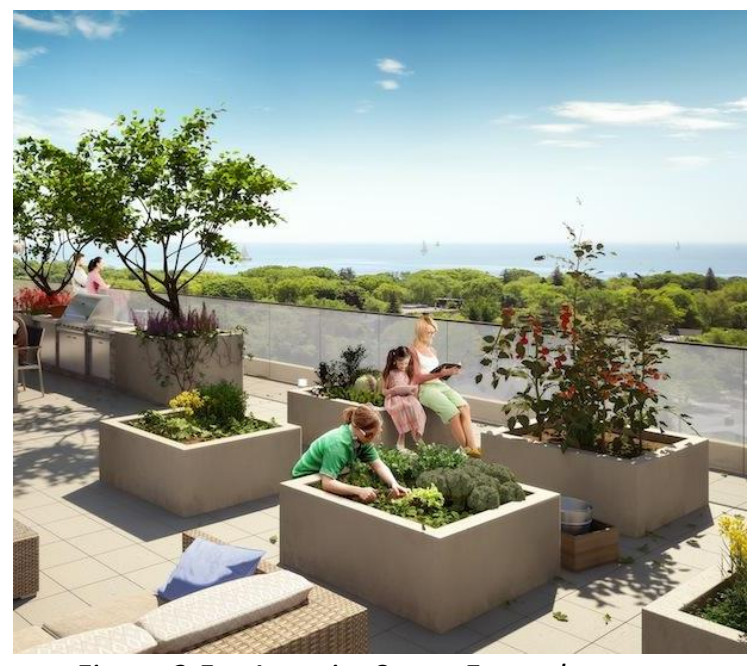

Figure 2.5 - Amenity Space Example (Urban Toronto [a], 2016)

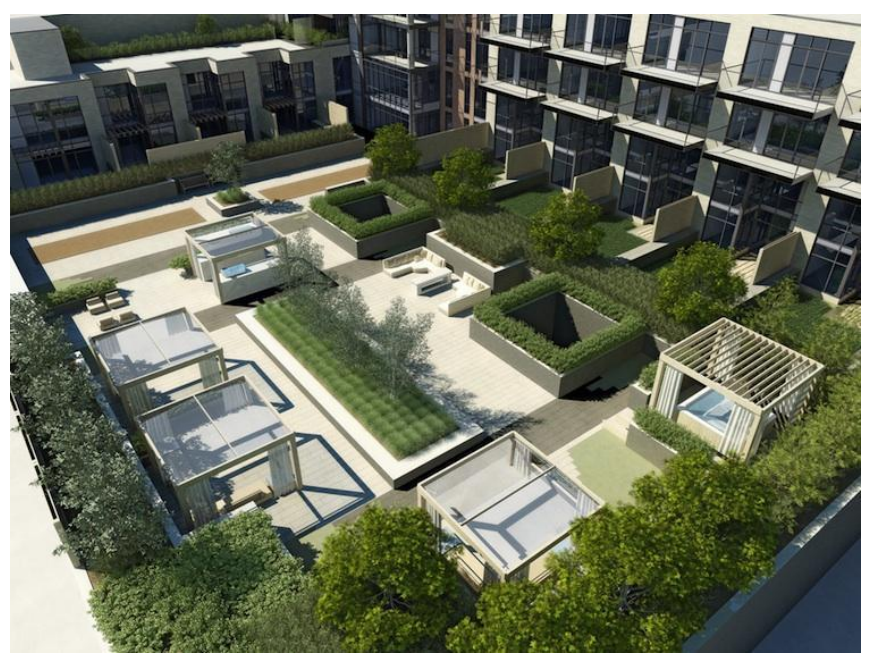

Figure 2.6-Amenity Space Example (Urban Toronto [b], 2016)

Landscape amenity space refers to any exterior roof top area of which is accessible to a building's residents and typically provided for their exclusive use (see Figure 2.5 and Figure 2.6 above). Particularly in dense urban environments, amenity space becomes increasingly important as easy access to safe parks, green space, or clean and uncrowded facilities can be limited. Amenity space often includes, but is certainly not limited to, areas for eating, socializing, lounging, swimming, sun tanning, barbequing, sporting facilities, etc., and usually incorporates a green roof component of some sort. These exterior spaces are typically located on a podium level, often between three to five storeys high, or located on a roof top level in low to midrise buildings (ex. $<20$ storeys) due to high wind loads and uplift pressure at higher roof levels (see Figure 2.7 and Figure 2.8 below). High velocity winds and uplift pressures can create dangerous and uncomfortable conditions, particularly at the edges of high rise buildings, which is why amenity space is often relegated to the lower levels of a building and/or proper precautions must be taken to ensure occupant safety at higher levels (Sutton, 2015). For this report, the example amenity space (see Section 5, Figure 5.1 below, p. 15) is assumed to be at the roof top level above the podium and located between 3 to 5 storeys in height. 


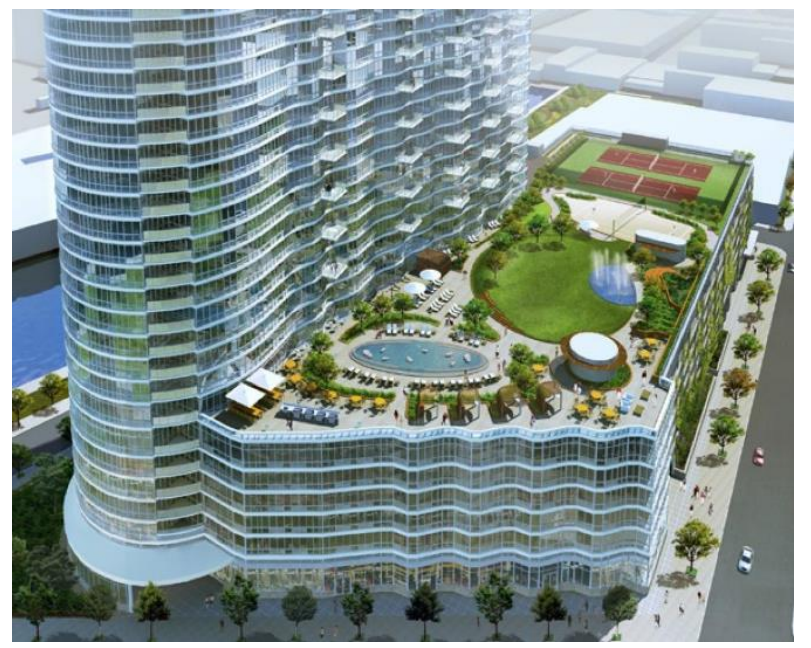

Figure 2.7-Example Condominium Building with Podium Level Amenity Space (Sheftell, 2016)

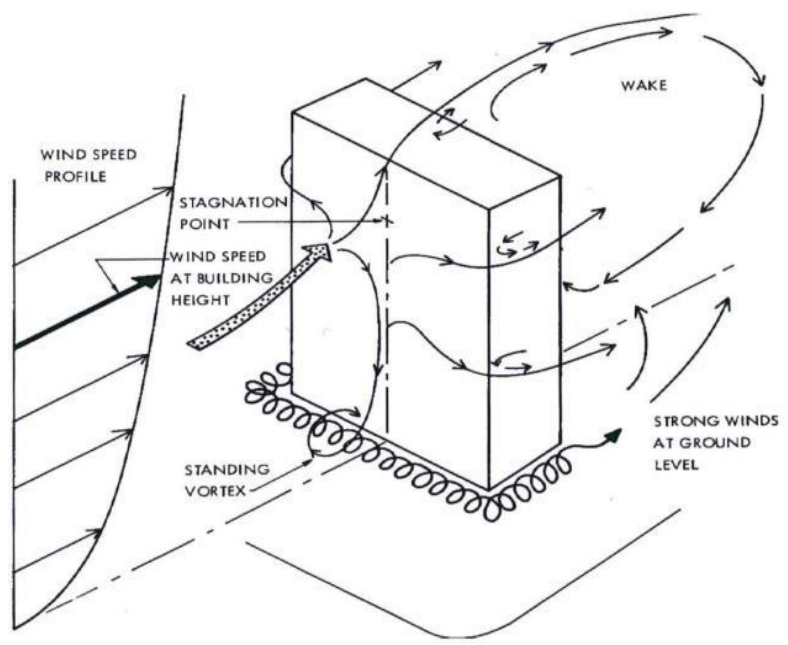

Figure 2.8 - Wind Flow and Pressure on a Building (Hutcheon \& Handegord, 1995)

However, though the focus of this report is on condominium or apartment building exterior amenity space in particular. The topic is relevant to other typologies such as office buildings, hotels, or other commercial structures that include at-grade plazas (ex. CIBC building at Yonge St and Queen St E in downtown Toronto) or any other usable roof top areas, if they are located above habitable space and thus requiring thermal protection. As such, the recommendations in this report could be applied to a broader area of application than strictly landscape amenity space for condominiums and/or apartment buildings. The next section includes questions that were formulated to guide this research.

\section{Research Questions}

In order to confront the issues relating to the proposed scope of this report, a list of research questions was generated to further define the direction in which to proceed:

1. Is improved thermal design of green roof landscape structures able to assist in regulating building energy performance?

2. Can an integrative approach to green roof design help to involve landscape designers in decisions relating to building energy performance? 


\section{Literature Review}

As noted in the introduction section above, there are no known studies to quantify the effects of landscape walls incorporating thermal bridges and their impacts on amenity space green roof designs. This represents a gap in the existing scientific knowledge on the topic of thermal bridges, a part of which is intended to be completed by the creation of this report. There exists significant literature on green roofs of all types (ex. extensive, semi-intensive, and intensive), some of which will be discussed. There also exists significant literature on quantifying the impact of thermal bridges in building details; walls, windows, doors, balconies, parapets, foundations, to name a few, some of which will also be discussed in this section where they are relevant to this study. Literature relating to manual calculation methods and computer simulation software will also be briefly explored. There is a section in this report (see Section 7.1.1 below, p. 21) which explains specific materials and their properties as they relate to the simulations in this study, so an overview of thermal materials science will not be discussed here. Due to the large quantity of literature on the topics to be reviewed in this section, only a select few documents will be explored as they are relevant and this section is not intended to represent an exhaustive review of all existing topics. The primary focus of this literature review (where possible) will be focused on thermal properties as it effects CIP concrete landscape walls, which is the focus of this research paper.

The Morrison Hershfield (2011) report titled Thermal Performance of Building Envelope Details for Midand High-Rise Buildings (1365-RP) contains one example of a thermal study which is similar to Condition 1 (see Section 6.1 below, p. 16, for more information), and they attained a U-value of $0.65 \mathrm{~W} / \mathrm{m}^{2} \cdot \mathrm{K}$ for their condition labelled as 'Detail 21' (see Figure 4.1 below). As quoted from their report "Detail 21 is an insulated concrete roof with a concrete curb or wall bypassing the roof insulation. The thermal

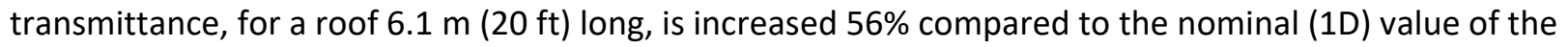
roof" (Morrison Hershfield, 2011). Their detail is quite similar to the non-thermally broken wall conditions to be considered in this report, but as can be seen in Figure 4.1 below, they do not include roof ballast, an intensive green roof, or a paving surface in their simulation. 


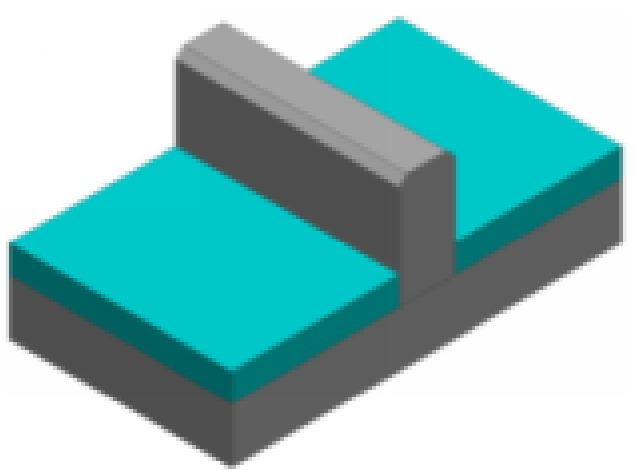

Figure 4.1 - Detail 21; Insulated Concrete Roof with a Concrete Curb or Wall Bypassing the Roof Insulation (Morrison Hershfield, 2011)

In his research project relating to thermal transmission in balcony slabs, Murad's (2015) computer simulation models found that utilizing Schöck Isokorb ${ }^{\circledR}$ was able to reduce $7 \%$ overall energy loss for the study building (Murad, 2015). The content in this report provides an indication of the effects of thermal bridging in green roof areas, as the roof slab surface area is small compared to the surface area of a building's façade and/or balcony protrusions. Therefore, roof areas in a building likely represent a minimal percentage of overall energy flow (ex. even less than 7\%). However, the overall percentage of a buildings energy flow due to landscape walls is not the particular concern or focus of this report and it will also not be calculated. What is important is to find areas where energy flow is happening, and to reduce and/or minimize them as much as possible in order to fill in one more gap in the thermal performance of a buildings envelope.

Lawton \& Roppel (2014) write a Morrison Hershfield report on details and analysis of thermal bridges including manual calculation formulae, the report is relating to an existing product used to provide thermal breaks on balconies. The manufacturer is Schöck and the product is Isokorb type CM (p. 20 of their report), which is claimed to be able to reduce the thermal conductivity [k] in balcony slabs by $92 \%$ (see Figure 4.2 and Figure 4.3 below). They also refer to utilizing the International Standard (ISO) 14683 document which contains manual calculation methods for thermal bridges of various types for their report (International Organization for Standardization (ISO), 2015). Isokorb ${ }^{\circledR}$ of all types utilize stainless steel for the reinforcing portion running through the rigid insulated thermal break. This is because stainless steel has a lower conductivity value at $16.00 \mathrm{~W} / \mathrm{m} \cdot \mathrm{K}$ than carbon steel at $43.00 \mathrm{~W} / \mathrm{m} \cdot \mathrm{K}$, thereby reducing the thermal bridging effect of reinforcing. Schöck Isokorb rigid insulation (RI) thickness can be customized to suit an application and the required thermal conditions requested by the designer (Schöck USA Inc., 2015). It is possible that by customizing an Isokorb product, if it was needed for a 
landscape application, that it would increase the price per unit, and this is a factor that would have to be considered during the design phase.

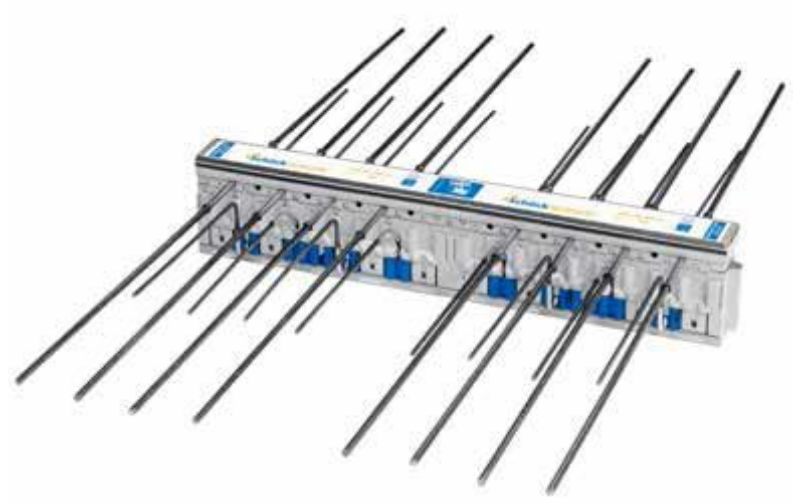

Figure 4.2 - Schöck Isokorb ${ }^{\circledR}$ Type CM for Concrete Balconies (Lawton \& Roppel, 2014)

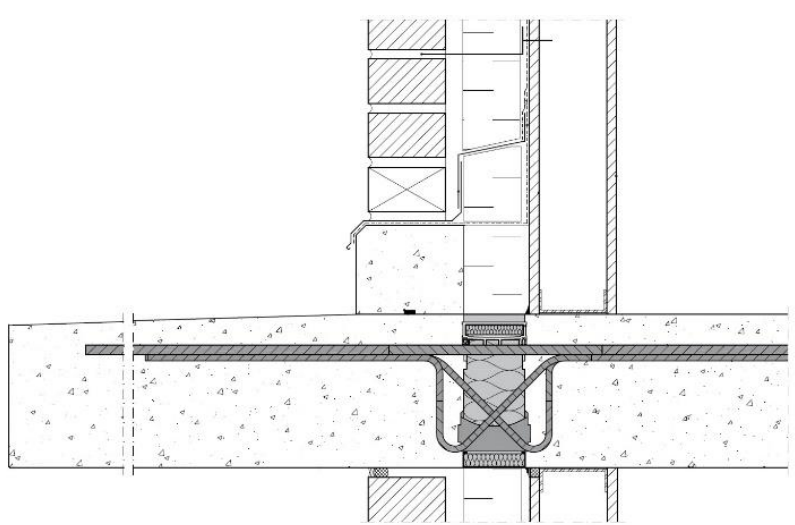

Figure 4.3 - Placement of Schöck Isokorb ${ }^{\circledR}$ in the Assembly (Lawton \& Roppel, 2014)

The Becker \& Wang (2011) study titled Green Roof Heat Transfer and Thermal Performance Analysis provides a summary of green roof thermal performance as well as including experimental data to reinforce their research results. Their report was focused on quantifying the effects of conductive heat transfer of retrofitted green roofs installed on existing buildings in downtown Pittsburgh, Pennsylvania. The results of their study found that on the first green roof, Hamerschlag Hall during 2009 and 2010, an average of $26 \%$ less heat was lost during the heating months from the installed green roof than was lost from the control roof with conventional roofing located at Porter Hall (Becker \& Wang, 2011). They also found for the same years in the green roof and control roof at Allegheny County Office Building (ACOB), there was an average of $8.2 \%$ reduction in heat loss in heating months and a $75 \%$ reduction in heat gain in cooling months. Their results indicate that the installed green roofs reduced conductive heat gain and loss, and thus can provide positive benefits in urban locations. They note that further studies must be completed to analyze other modes of heat transfer and building energy modeling to assess actual economic savings (Becker \& Wang, 2011).

Oberndorfer et al. (2007) highlights the importance and impact of green roofs in urban areas. Their report cites the specific benefits of green roof technology including stormwater management and reduction, improvement in air quality, regulation of building temperatures, reduction in urban heat island effect, and increased urban wildlife habitat (Oberndorfer, et al., 2007). They expand these topics further and discuss the history of green roofs, compare types of green roofs, explore ecosystem services 
provided, discuss urban habitat values, postulate community and landscape properties, and conclude with a section outlining future research directions. In future work, they conclude that research should focus on plant selection for various climate regions, methods to improve air and water quality, robust cost-benefit models to advise if the technology is effective, and more research on the role of biodiversity in living-roof performance (Oberndorfer, et al., 2007). Though the focus of this research paper does not necessarily apply specifically to urban areas, MURBS and apartment buildings tend to be built primarily in high density urban areas.

Though manual 2D thermal bridge calculations are out of the scope of this report, a few articles were found that could be useful for possible future work relating to this topic and to test the 2D computer simulation models. In Blomberg's (1996) thesis titled Heat conduction in two and three dimensions: Computer modelling of building physics applications, he describes numerical formulations to be utilized for computer simulations. He also outlines that "the robust method of explicit finite differences" is the method utilized for the computer simulations in which closely follows the physical equations (Blomberg, 1996). This is an older paper, so some of the methods may be somewhat outdated or unrefined, but it is quite exhaustive in describing the process of thermal bridge calculations and methodology, so it is worth a mention here. Nyberg (2011) wrote a thesis titled Thermal bridges at foundations: Evaluation of heat calculation methods, which contains examples of two-dimensional (2D) and three-dimensional (3D) manual calculation methods that are then compared to HEAT2 and HEAT3 computer simulations. The purpose stated for his report was to "analyze and verify the specific calculation methods used in SS-EN ISO 13370:2007 and SS-EN ISO 10211:2007 to calculate heat loss to the ground" and to "minimize the spread and error of the results" (Nyberg, 2011). It was noted that there was 5\% deviation when comparing the 2D and 3D models, but when certain dimensional parameters were modified, the deviations between the two models increased to $10 \%$ (Nyberg, 2011). It was suggested that standardizing variables and future work could help to reduce these variations.

ISO/DIS (2015) standard 14683 which "deals with simplified methods for determining heat flows through linear thermal bridges which occur at junctions of building elements", contains formulae and standards to calculate linear thermal bridges. The ISO report is titled Thermal bridges in building construction - Linear thermal transmittance - Simplified methods and default values, and it contains manual calculation methods for thermal bridges of various types including roofs, balconies, corners, intermediate floors, internal walls, slab-on ground floors, suspended ground floors, pillars, and window 
and door openings (International Organization for Standardization (ISO), 2015). This is a different ISO standard as studied by Nyberg (2011), but the amount of varied details studied makes it a potential source of manual calculation methods for future work related to this report. Lastly, Hutcheon \& Handegord (1995) in their book Building Science for a Cold Climate, provide materials data and calculation methods for the Glaser method as utilized to test the computer model in this report. They define their seminal book as "a growing body of knowledge increasingly being defined as 'building science'" (Hutcheon \& Handegord, 1995). This book is still specified as required reading at Ryerson University in the Building Science department, highlighting the importance of the information contained therein. The next section below outlines the three objectives of this report.

\section{Objectives}

To quantify thermal performance and provide indications of energy movement in landscape amenity space areas when located over habitable space with a focus on 'typical' and 'modified' structural details (ex. CIP concrete walls) and intensive green roof. The overall research goal is to provide scalable results for analytical use in amenity space and green roof design.

In this report there will be three main objectives for investigation:

- Objective $1(01)$ - Thermal analysis of on-slab wall types

- Objective $2(\mathrm{O} 2)$ - Thermal analysis of example amenity space using results from $\mathrm{O} 1$

- Objective $3(\mathrm{O} 3)$ - Recommended details that 'work' thermally and functionally

A simplified landscape plan that is representative of a 'typical' amenity space design (located in downtown Toronto) has been created to provide a quantifiable metric of a possible real world application for this study (see Figure 5.1 below). The study area is defined with a dashed line and a note, it can be described as extending from the outside face of the building to the inside face of all the parapet walls. It could be said that a theoretical plan as shown below would bring up too many other design questions relating to the buildings program, function, envelope, use, to name a few. To provide some legitimacy to the conceptual 'typical' amenity space provided in this report, it should be noted that it is actually quite similar to the design of a future building planned in the west end of Toronto, the author is one of the current landscape designers in the early stages of the project. 


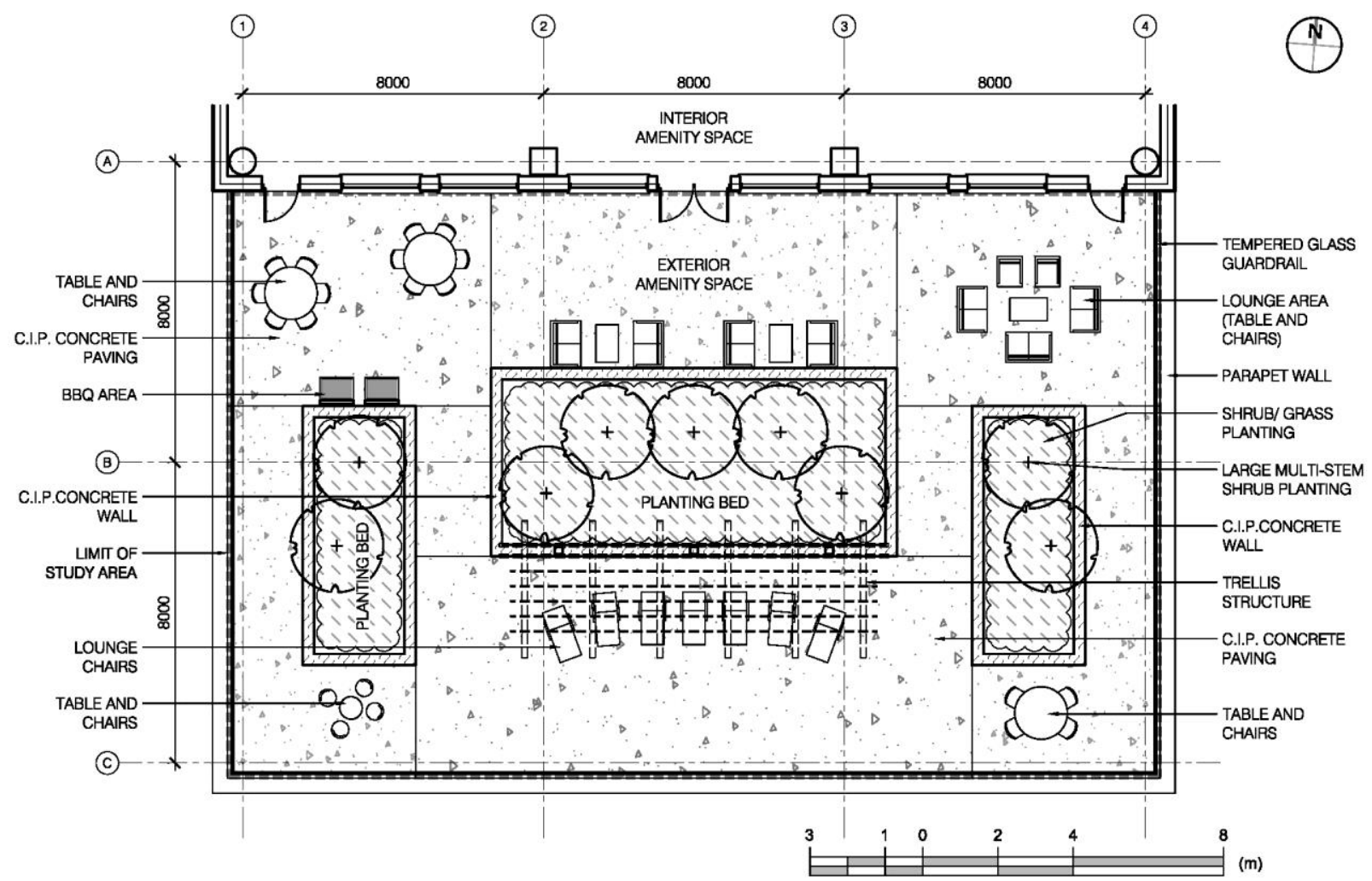

Figure 5.1 - Example Landscape Plan of Amenity Space and Intensive Green Roof

Total Area $=386.9 \mathrm{~m}^{2}$, Conc. wall $=67.6$ lin. $\mathrm{m}\left(20.3 \mathrm{~m}^{2}\right)$, Paving (conc.) $=291.5 \mathrm{~m}^{2}$, Planting bed $=75.1 \mathrm{~m}^{2}$

This report at its foundation is a research project but it also contains significant design aspects, and should be considered an investigation into both research and design. Generally, if completed properly, there is much less ambiguity within scientific research projects, which must follow the scientific method precisely and they must also be replicable. While design on the other hand, much like art, is subjective and can be open to interpretation. All efforts will be made to remove any ambiguity within this report and any background information will be provided to validate or explain the ideas postulated within. The following section outlines the methodology and approach for this research paper. 


\section{Methodology and Approach}

\subsection{Methodology}

It is proposed to employ a quantitative methodology using manual calculation (Glaser method) and computer simulation (THERM) of thermal conditions to create measurable and scalable metrics for use in landscape amenity space and green roof design (Hutcheon \& Handegord, 1995). The Glaser method will be used for one-dimensional (1D) thermal conditions, appropriate manual calculation methods for $2 \mathrm{D}$ thermal bridges are out of the scope of this study. The software choice for this study is THERM 6.3.46 created by Lawrence Berkeley National Laboratory (Lawrence Berkeley National Laboratory, 2016). The particular version selected is not the most current version, but was the National Fenestration Rating Council (NFRC) certified version of the software (which expired on 2016-05-01 for new certification and re-certification while writing this report) (National Fenestration Rating Council, 2016). A review of the differences between THERM 6.3.46 and THERM 7.4.3, the current version, indicated that the updates to the software were not particularly related to the focus of this research, so it was decided to continue with version 6.3.46 (Lawrence Berkeley National Laboratory, 2016). Other software such as HEAT2 by BLOCON Sweden was considered, but the strength of the THERM application is that it has the required functions for this study, utilizes external standards validation, is free to use, and has a relatively simple learning curve (Lawrence Berkeley National Laboratory, 2016).

This study proposes to consider three thermal conditions of landscape walls (design details) over an inverted roof system for comparative analysis (see Figure 6.1 and Figure 6.2 below):

- Condition 1 - Standard: CIP concrete roof slab with doweled in CIP concrete retaining wall

- Condition 2 - Improved: CIP concrete roof slab with doweled in thermally broken CIP concrete retaining wall

○ It is proposed to implement the product Schöck Isokorb ${ }^{\circledR}$, a similar product, or a design that has a similar effect of the product, possibly using standard high density rigid insulation with holes punctured for reinforcing to pass through at an appropriate spacing (Schöck USA Inc., 2015). Schöck Isokorb ${ }^{\circledR}$ is designed for use in a few different building applications including thermally broken parapets and balconies, there is little reason to assume that it would not be appropriate for this study condition or real world application (Lawton \& Roppel, 2014). 
- Condition 3 - Ultimate: CIP concrete roof slab with thermally broken CIP concrete retaining wall

- For this condition the layout of the wall in plan would typically require a shape with at least 3 to 4 sides to create lateral support as there is no doweled connection to the slab.
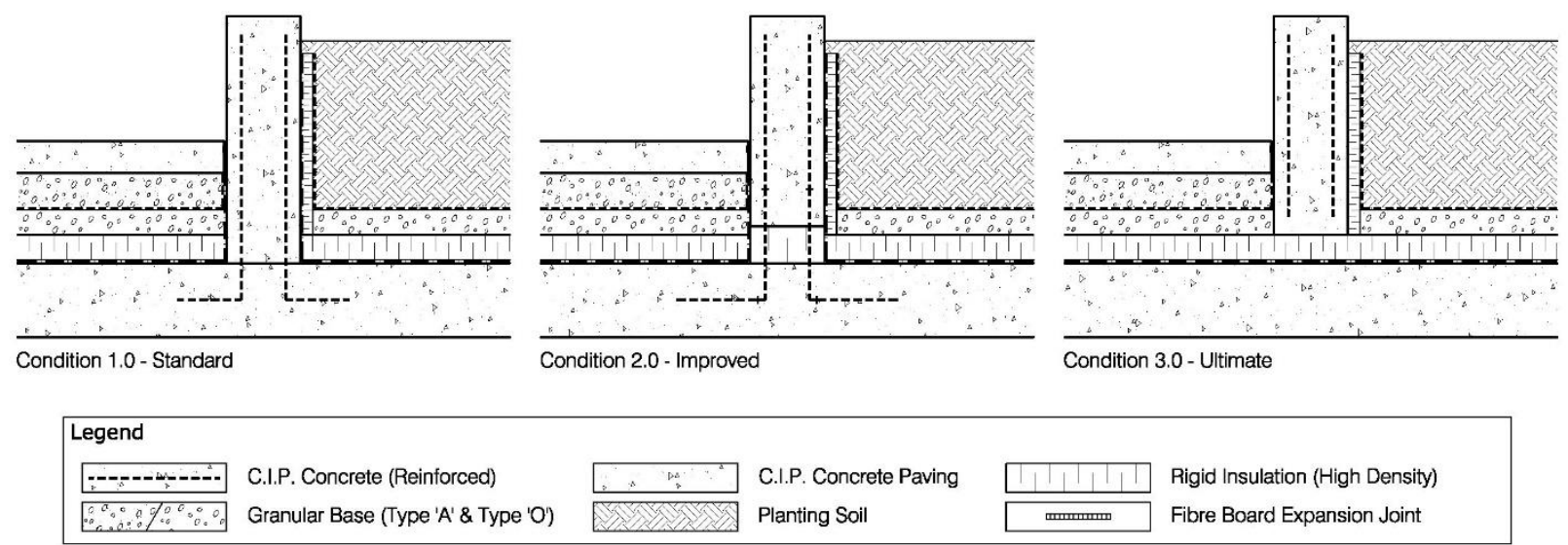

Figure 6.1 - Detailed Section Drawings of Three Thermal Conditions

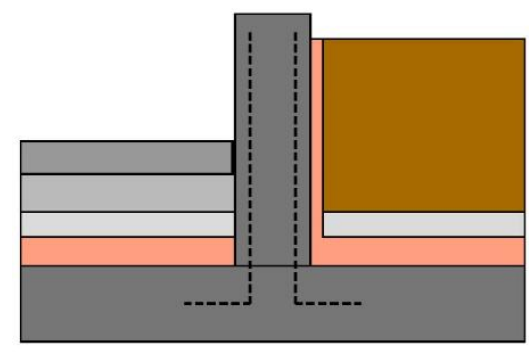

Condition 1.0 - Standard

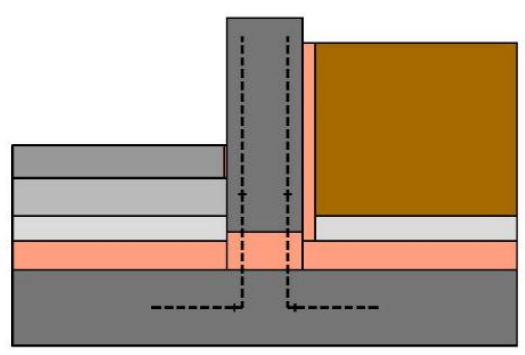

Condition 2.0 - Improved

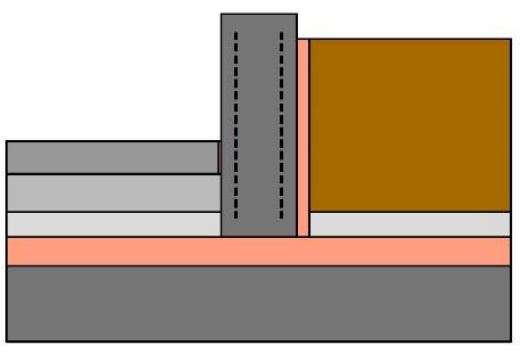

Condition 3.0 - Ultimate

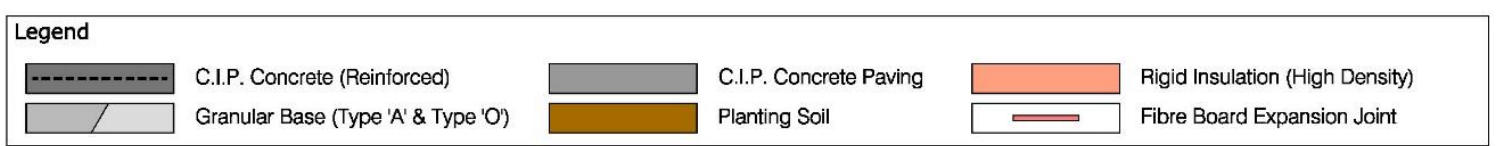

Figure 6.2 - Simplified Section Drawings of Three Thermal Conditions for Simulation

Static winter and summer conditions are selected for this study, as it is considered that this is when some of the greatest temperature variations would generally occur. The atmospheric temperature conditions of the study (static), where $\mathrm{T}=$ temperature, are:

- Summer;
- Interior condition; $\mathrm{T}_{\mathrm{si}}=23^{\circ} \mathrm{C}$
- Exterior condition; $\mathrm{T}_{\text {so }}=27^{\circ} \mathrm{C}$

- Winter;
- Interior condition; $\mathrm{T}_{\mathrm{wi}}=23^{\circ} \mathrm{C}$
- Exterior condition; $\mathrm{T}_{\mathrm{wo}}=-15^{\circ} \mathrm{C}$ 
Further to this, dynamic temperature variations are not included in this study, only the static summer and winter conditions as outlined are selected for simulation. However, because radiation is also not considered in this study, an additional range of more extreme temperature variations will be explored in Objective 2 to further assess the thermal performance of the example landscape amenity space design (see Section 9.3 below, p. 52). Basically, the example amenity space in a real-world condition would be exposed to heating by solar radiation during daylight hours and subsequent cooling during the evening and overnight hours, the intensity of which will vary depending on geographical location, temperature, orientation, and exposure. The reason for including further temperature variations in 02 as examples is to simply assess, with the simulation tools as utilized, how radiation or more extreme weather conditions could affect thermal performance and to provide an additional metric for contemplation.

The conditions outlined above should be thought of as; 1.0 ) a base line condition, 2.0) a modified condition, and 3.0) ways to avoid thermal bridges completely (see Figure 6.1 and Figure 6.2 above). The variations of these conditions will be described in this section. In Table 6-1 below, the three thermal conditions are expanded to create and describe variations to be utilized in the Objective 1 computer simulations (see Section 8 below). There are a few items varied for these conditions and they include; reinforcing, the slab insulation thickness $(100 \mathrm{~mm}, 125 \mathrm{~mm}$, and $150 \mathrm{~mm}$ thick), the wall insulation layer (50 mm, $25 \mathrm{~mm}$ thick, and none), CIP concrete wall width or thickness ( $300 \mathrm{~mm}, 200 \mathrm{~mm}, 250 \mathrm{~mm}$, and $400 \mathrm{~mm}$ wide), and a variation on the paving surface ( $70 \mathrm{~mm}$ thick precast concrete unit paving on a 25 $\mathrm{mm}$ thick sand setting bed). These condition variations are designated based on the author's knowledge and personal experience with landscape design and amenity space design. For example, in Condition X.1 (see Table 6-1 below), $100 \mathrm{~mm}$ thickness is often used for the rigid insulation layer at the slab and it can provide an approximate $R_{s i}$ value of 3.52 ( $R 20$ in imperial), which of course varies by manufacturer (Owens Corning, 2011). In Ontario, the minimum $\mathrm{R}_{\mathrm{si}}$ value to be provided in an assembly is mandated by the Ontario Building Code (OBC) (Ontario Ministry of Housing, 2015).

Due to the complexity of estimating reinforcing in a wall to suit all conditions, the quantity of which is dependent on various factors (retaining height of the wall, thickness of the wall, specific structural engineer to review drawings, etc.), it was decided to not include it in the majority of the simulations but to assess it as one variable in each condition. Condition X.2 was created to simulate the effects of reinforcing in the wall in order to compare it to Condition X.1 and assess how reinforcing can create additional thermal bridging and focus heat flux. In Conditions X.3 and X.4 the architect or building 
envelope consultant may decide to specify a thicker insulation layer to provide a higher $R_{s i}$ value which these conditions employ, the landscape wall thickness remains the same at $300 \mathrm{~mm}$ wide. Conditions $X .5$ and X.6 are variations of the wall insulation values at $25 \mathrm{~mm}$ thickness and none. Rigid insulation along the interior face of the planter wall is applied to reduce frost susceptibility of vegetation during cold weather and to help protect established root systems during the winter months. Conditions X.7, X.8, and X.9 are variations of the wall from $300 \mathrm{~mm}$ to $200 \mathrm{~mm}, 250 \mathrm{~mm}$, and $400 \mathrm{~mm}$ in width, due to the fact that landscape designers often employ various widths for both function and aesthetics. The final Condition variation X.10 substitutes the CIP concrete paving with precast concrete unit paving, another typical paving material often seen in landscape design.

Table 6-1 - Conditions and Descriptions of Models for Computer Simulation

\begin{tabular}{|c|c|}
\hline \multicolumn{2}{|c|}{ Conditions and Descriptions of Models for Computer Simulation } \\
\hline \multicolumn{2}{|c|}{ Name } \\
\hline Condition 1.0 - Standard (Design Detail) & Condition 2.0 - Improved (Design Detail) \\
\hline Condition 1.1 - Standard & Condition 2.1 - Improved \\
\hline Condition 1.2 - Standard@ Reinforcing & Condition 2.2 - Improved @ Reinforcing \\
\hline Condition 1.3 - Standard w/ 125mm Slab Insulation & Condition 2.3 - Improved w/ 125mm Slab Insulation \\
\hline Condition 1.4 - Standard w/ 150mm Slab Insulation & Condition 2.4 - Improved w/ 150mm Slab Insulation \\
\hline Condition 1.5 - Standard w/ 25mm Wall Insulation & Condition 2.5 - Improved w/ 25mm Wall Insulation \\
\hline Condition 1.6 - Standard w/ No Wall Insulation & Condition 2.6 - Improved w/ No Wall Insulation \\
\hline Condition 1.7 - Standard w/ 200mm Wide Wall & Condition 2.7 - Improved w/ 200mm Wide Wall \\
\hline Condition 1.8 - Standard w/ 250mm Wide Wall & Condition 2.8 - Improved w/ 250mm Wide Wall \\
\hline Condition 1.9 - Standard w/ 400mm Wide Wall & Condition 2.9 - Improved w/ 400mm Wide Wall \\
\hline Condition 1.10 - Standard w/ Precast Conc. Paving & Condition 2.10 - Improved w/ Precast Conc. Paving \\
\hline \multicolumn{2}{|l|}{ Condition 3.0 - Ultimate (Design Detail) } \\
\hline \multicolumn{2}{|l|}{ Condition 3.1 - Ultimate } \\
\hline \multicolumn{2}{|l|}{ Condition 3.2 - Ultimate @ Reinforcing } \\
\hline \multicolumn{2}{|l|}{ Condition 3.3 - Ultimate $\mathrm{w} / 125 \mathrm{~mm}$ Slab Insulation } \\
\hline \multicolumn{2}{|l|}{ Condition 3.4 - Ultimate $w / 150 \mathrm{~mm}$ Slab Insulation } \\
\hline \multicolumn{2}{|l|}{ Condition 3.5 - Ultimate $\mathrm{w} / 25 \mathrm{~mm}$ Wall Insulation } \\
\hline \multicolumn{2}{|l|}{ Condition 3.6 - Ultimate w/ No Wall Insulation } \\
\hline \multicolumn{2}{|l|}{ Condition 3.7 - Ultimate $\mathrm{w} / 200 \mathrm{~mm}$ Wide Wall } \\
\hline \multicolumn{2}{|l|}{ Condition 3.8 - Ultimate $\mathrm{w} / 250 \mathrm{~mm}$ Wide Wall } \\
\hline \multicolumn{2}{|l|}{ Condition 3.9 - Ultimate w/ 400mm Wide Wall } \\
\hline Condition 3.10 - Ultimate w/ Precast Conc. Paving & \\
\hline
\end{tabular}

It should also be stated that different light conditions (ex. sunlight, shade cover from trees, shade from other buildings, etc.), soil moisture content, and granular moisture content, although important for green roof and amenity space design, will not be included in these simulations. These condition variations as described are simulated to quantify the effects of amenity space landscape structures over habitable space. 


\subsubsection{Research Output}

The quantified research output for this report is summarized below:

- Manual calculations for the one simple thermal condition and comparisons of results to computer simulation of the same and a similar condition.

- Computer simulations of the three thermal conditions and quantitative comparisons of results.

○ Sub-conditions or variations (ex. different wall widths/heights) and comparisons.

- Recommended green roof and landscape details that perform well thermally and functionally.

- Discuss limitations, economic issues, and potential problems.

- Summary listing reasons and support to adopt 'enhanced' details.

\subsection{Approach}

This study employs an interdisciplinary and integrative approach including architecture and building science (the author), landscape architecture (the author), as well as preliminary structural considerations (the author), to realize the emphasis and focus of this research. The author's personal experience in post-secondary education and in the workforce is integral to the scope of the research direction and approach. The majority of the analysis and results will be sole sourced (the author), with additional input from cited literature references to confirm and validate unfamiliar or unknown concepts where required.

Interdisciplinary focus of approach:

- Landscape architecture - design of amenity space, detailing of original, improved, and ultimate thermal conditions while accommodating building science and structural considerations

- Building science (BS) - analyses thermal conditions, coordinate and correlate data

- Structural design - preliminary structural design of all wall conditions based on known variables 


\section{Simulation - Testing the Model}

The initial stage to simulating the three proposed conditions and their variations is to create a manual calculation of a sample model which is broken up into 1D systems (see section 7.2 below) that can be used to compare with the accuracy of the 1D and 2D computer simulation (see section 7.3 below). For this study it was decided to use the model named 'cond_01-06', which is listed as 'Standard w/ No Wall Insulation' (see Section 8.1.1, Table 8-1 below, p. 37). This condition (cond_01-06) was selected as the test model because it does not include the planter wall insulation, which would unnecessarily complicate the division of the systems and would likely not add much of benefit to the final results of the comparison test. After considering these factors, the testing was completed in two stages; 1) to manually calculate the 1D model using the Glaser Method and 2) to split the computer model into both $1 \mathrm{D}$ and $2 \mathrm{D}$ systems and simulate to compare to the manual model. The first step is to define the materials and conductivity values to be used in the manual and computer simulations in Section 7.1 below.

\subsection{Materials and Systems for Testing the Model}

To create any simulation, either manual or computer, assumptions must be made to simplify the model and to extrapolate where needed in order to resolve any unknown variables. Table 7-2 below (p. 25) is a list of materials and their thermal properties as relevant to the simulation models. Chapter 26 titled "Heat, Air, and Moisture Control in Building Assemblies-Material Properties" in ASHRAE Fundamentals 2009 includes material conductivity data for various typical building materials (ASHRAE, 2009). To be consistent, the ASHRAE fundamentals chapter will be used to delineate as many values as possible for this report, and other sources and extrapolation will be adapted to fill in the gaps as required. In order to define the conductivity [k] values for a few of the less common or undefined building materials, a few assumptions were made and are as described and defined in the section below.

\subsubsection{Materials for Testing the Model}

Material assumptions and selections for testing the model and further simulations are described in this section. For CIP concrete, the $\mathrm{k}$ value does not include reinforcing steel. As previously outlined, reinforcing variables are too difficult to define for the specific purpose of this study. Reinforcing 
variables can depend on factors such as wall height, wall thickness, density required, and spacing. Due to this fact, reinforcing is not considered in the majority of the models and was only simulated to compare cond_0X-01 and cond_0X-02 in each condition series to ascertain the effects of one example reinforcing layout. Studies were completed to compare walls at non-reinforced cross sections and at reinforcing cross sections including; cond_01-01, cond_01-02, cond_02-01, cond_02-02, cond_03-01, and cond_03-02 (see Section 8.1.1, Table 8-1, p. 37).

Granular 'A' values were extrapolated from ASHRAE Fundamentals (2009) and Koliji's (2013) Geotechdata.info website. It was decided to select the limestone $\mathrm{k}$ value of $1.2 \mathrm{~W} / \mathrm{m} \cdot \mathrm{K}$ from ASHRAE material conductivity data tables (Chapter 26) and void density derived from Geotechdata.info at 30\% for granular ' $A$ '. It was then calculated to find $\mathrm{k}$ at $0.84 \mathrm{~W} / \mathrm{m} \cdot \mathrm{K}$ for Granular ' $\mathrm{A}$ ', air or moisture content were not included in the value (Koliji, 2013). Granular ' $A$ ' void content is slightly lower than granular ' $O$ ' (clear stone), as outlined below, due to the presence of fines.

Granular 'O' (Clear Stone) values were also extrapolated from ASHRAE (2009) and Koliji's (2013) Geotechdata.info website. It was decided to again select the limestone k value of $1.2 \mathrm{~W} / \mathrm{m} \cdot \mathrm{K}$ from ASHRAE material conductivity data tables (Chapter 26) and void density derived from Geotechdata.info at $35 \%$ for granular ' $\mathrm{O}$ '. It was then calculated to find $\mathrm{k}$ at $0.78 \mathrm{~W} / \mathrm{m} \cdot \mathrm{K}$ for Granular ' $\mathrm{O}$ ', air or moisture content were also not included in the value (Koliji, 2013). Granular ' $O$ ' (clear stone) void content is slightly higher than granular ' $A$ ' due to the absence of fines.

When considering soil, there is also no simple k value to assign, it is a highly inconsistent material dependent on many variables including moisture and the specific soil type. Soil is also composed of materials with different conductivity values; gravel, sand, silt, clay, and peat (Sutton, 2015).

Conductivity values are also dependent on moisture content, mineral composition, particle sizes, organic components, density/compaction, temperature, and solar exposure, to name a few (Becker \& Wang, 2011). Based on the variables of these properties, soil conductivities ranging between $0.15 \mathrm{~W} / \mathrm{m} \cdot \mathrm{K}$ to 4.0 W/m.K have been assigned to various soil types as in ASHRAE (2009) and The Engineering Toolbox (2016). For the purpose of this report a value of $0.95 \mathrm{~W} / \mathrm{m} \cdot \mathrm{K}$ has been assumed based on Table 7-1 below (Table 5 from ASHRAE Fundamentals) under loams defining the lower end value for summer conditions and the higher end value of $2.25 \mathrm{~W} / \mathrm{m} \cdot \mathrm{K}$ for winter conditions (ASHRAE, 2009). 
Table 7-1 - Table 5; Typical Apparent Thermal Conductivity Values for Soils, $W /(m \cdot K)(A S H R A E, 2009)$

\begin{tabular}{lccc}
\hline & \multicolumn{2}{c}{ Recommended Values for Design } \\
\cline { 3 - 4 } & Normal Range & Low $^{\mathbf{b}}$ & High $^{\mathbf{c}}$ \\
\hline Sands & 0.6 to 2.5 & 0.78 & 2.25 \\
Silts & 0.9 to 2.5 & 1.64 & 2.25 \\
Clays & 0.9 to 1.6 & 1.12 & 1.56 \\
Loams & 0.9 to 2.5 & 0.95 & 2.25 \\
\hline
\end{tabular}

${ }^{a}$ Reasonable values for use when no site- or soil-specific data are available.

${ }^{b}$ Moderately conservative values for minimum heat loss through soil (e.g., use in soil heat exchanger or earth-contact cooling calculations). Values are from Salomone and Marlowe (1989).

${ }^{\mathrm{c}}$ Moderately conservative values for maximum heat loss through soil (e.g., use in peak winter heat loss calculations). Values are from Salomone and Marlowe (1989).

Another factor to support these different $\mathrm{k}$ values in summer and winter for soil is moisture and ice content. From The Engineering Toolbox (2016), a conductivity value for water is defined as $0.58 \mathrm{~W} / \mathrm{m} \cdot \mathrm{K}$ and for ice the conductivity value is $2.18 \mathrm{~W} / \mathrm{m} \cdot \mathrm{K}$. What this implies is that due to water content the conductivity of soil could be lowered and with ice content it could be increased, hence the lower k value assigned to summer condition and higher $\mathrm{k}$ value assigned to winter conditions as described above and in Table 7-2 (p. 25) listing materials for the simulation. Figure 7.1 below further highlights the effects of moisture content in different types of soil as well as providing evidence of the importance of grading (drainage) in soil affecting thermal conductivity.

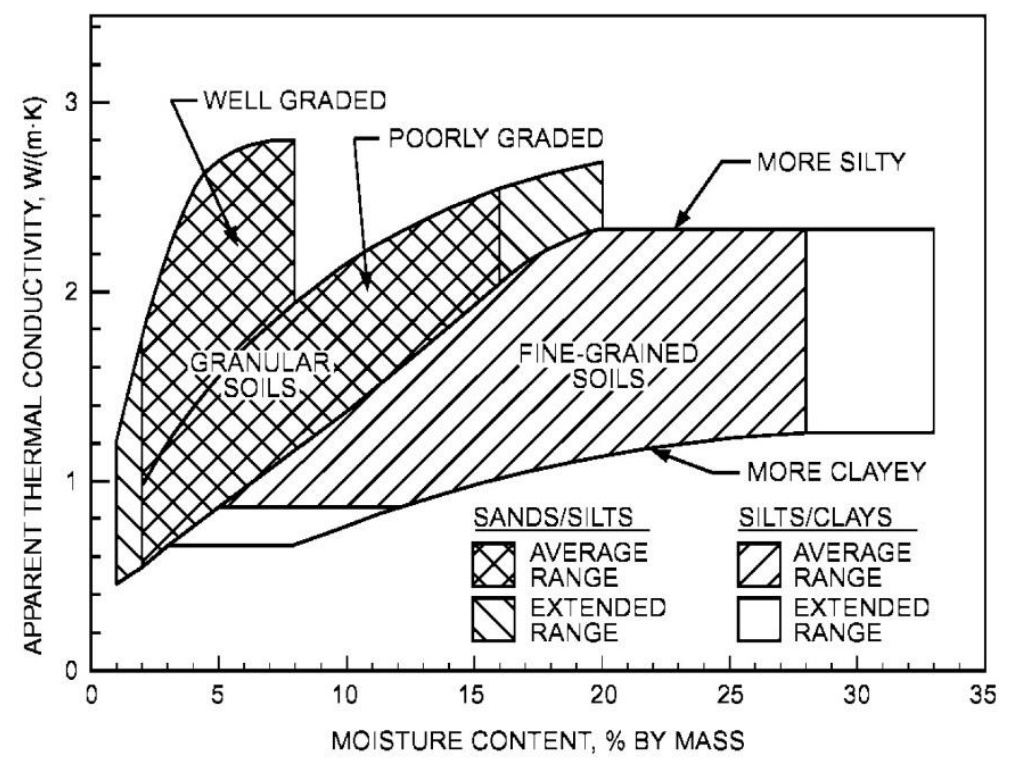

Figure 7.1 - Figure 6; Trends of Apparent Thermal Conductivity for Moist Soils (ASHRAE, 2009) 
Regarding soil, it should be noted that the depth of the growing medium and soil characteristics (ex. particle size, moisture content, air content, organic content, granular/sand content, density/compaction, etc.), as mentioned above, will affect the thermal properties of the layer and because of this the more dynamic nature of growing medium properties is also outside of the scope of this report.

For the extruded polystyrene (XPS) rigid foam insulation, two different ASHRAE $k$ values were selected for the wall and slab insulation, the lower value of $0.022 \mathrm{~W} / \mathrm{m} \cdot \mathrm{K}$ was assigned to the slab insulation and $0.03 \mathrm{~W} / \mathrm{m} \cdot \mathrm{K}$ for the wall insulation (ASHRAE, 2009). Considering the typical sequence of construction, the landscape contractor and associated landscape trades would usually install the wall rigid insulation after the slab insulation and would likely use a different product as specified by landscape designers or provided by landscape contractors. In a built project, it is also possible that the wall rigid insulation could be the same type and specification as the slab insulation. However, for the purpose of this report and thermal design issues, it was decided to place $k$ value precedence on the slab insulation.

Other wall materials than what are defined in this section could conceivably provide better $\mathrm{k}$ values than CIP concrete, for example natural stone gravity walls, walls with stone cladding, or solid wood walls. A few wall thicknesses will be explored as it is common for the thickness to vary depending on the aesthetics or function of the CIP concrete wall as designed, however for this report other wall materials or walls with cladding are not considered

As with most computer simulations, there a few building materials not included in this study to simplify the model. To simplify the condition models for the simulations in this study, waterproofing, protection board, filter fabric, and root barrier layers are not included. Due to the minimal thickness and/or porosity of these materials it was not assumed that they would contribute drastically to thermal performance for this study. As outlined in Section 6.1 above (p. 16), dynamic temperature variations are also not included in this study. THERM does not contain dynamic simulation capabilities, so any other temperature variations would have to be manually input and the amount of time required to perform the multitude of separate simulations makes the task out of the scope of this report. 
Concerning the explanations outlined in this section, the compiled list of simulation materials, descriptions, and conductivity/conductance values are defined in Table 7-2 below.

Table 7-2 - Materials and Conductivity/Conductance for Manual Calculations and THERM

\begin{tabular}{|c|c|c|c|c|}
\hline Material Name & Thickness & Conductivity $[\mathrm{K}]$ & Conductance $[\mathrm{C}]$ & Description \\
\hline Units & $\mathrm{mm}$ & {$[\mathrm{W} / \mathrm{m} * \mathrm{~K}]$} & {$[\mathrm{W} / \mathrm{m} 2 * \mathrm{~K}]$} & \\
\hline CIP Concrete Paving, Broom Finish & 130 & 0.93 & & Paving \\
\hline CIP Concrete Slab & 300 & 1.40 & & Structural slab \\
\hline CIP Concrete Wall & Varies & 1.40 & & Structural wall \\
\hline Expansion Joint, Mineral Board & 10 & 0.25 & & Asphalt impregnated, Felt \\
\hline Exterior Surface Coefficient & $N / A$ & & 22.70 & Summer, exterior surfaces \\
\hline Exterior Surface Coefficient & $\mathrm{N} / \mathrm{A}$ & & 34.00 & Winter, exterior surfaces \\
\hline Granular 'A' & 150 & 0.84 & & Base layer, $30 \%$ void content \\
\hline Granular 'O', Clear Stone & 100 & 0.78 & & Drainage layer at slab, $35 \%$ void content \\
\hline Interior Surface Coefficient & $N / A$ & & 9.26 & Summer and winter, interior surfaces \\
\hline Precast Concrete Unit Pavers & 70 & 0.93 & & Brick, building \\
\hline Rigid Insulation (XPS), Slab & 100 & 0.022 & & High density \\
\hline Rigid Insulation (XPS), Wall & 50 & 0.03 & & High density \\
\hline Sand & 25 & 0.33 & & Dry \\
\hline Soil, Icy & \pm 700 & 2.25 & & Winter condition, loams \\
\hline Soil, Moist & \pm 700 & 0.95 & & Summer condition, loams \\
\hline Steel, Carbon $1 \%$ & 10 & 43.00 & & Reinforcing \\
\hline Steel, Stainless & 10 & 16.00 & & Reinforcing \\
\hline
\end{tabular}

Note, these materials are utilized for all simulations, manual and computer, within this report.

\subsubsection{Systems for Testing the Model}

In order to calculate the 1D conductive heat flux through the roof structure and landscape walls, the roof was divided vertically to define the following systems (see Figure 7.2 below):

- System 1 - Paving: Air (Exterior), Concrete Paving, Granular 'A', Granular 'O' (Clear Stone), Rigid Insulation, Concrete Slab, Air (Interior)

- System 2 - Wall: Air (Exterior), Concrete Wall, Concrete Slab, Air (Interior)

- System 3 - Soil: Air (Exterior), Planting Soil, Granular 'O' (Clear Stone), Rigid Insulation, Concrete Slab, Air (Interior) 


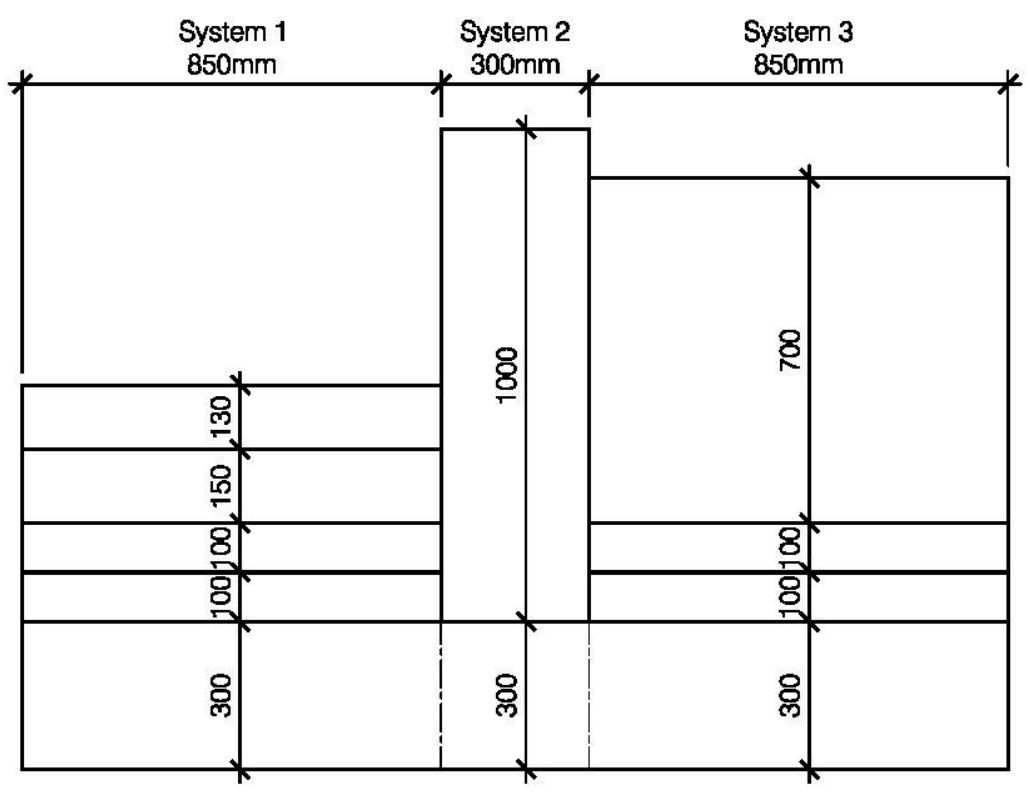

Figure 7.2 - Systems for Testing the Manual and Computer Simulation Models

Note that, in the systems outlined above, the width (shown under the system headings) of each system is not a factor in the 1D manual calculations, as they only consider the material thickness to determine the conductivity and/or resistance of a given material. For the computer simulation, the same systems will be utilized, but the study will be completed for both 1D and 2D variations to assess how the addition of another dimension can affect the heat flow through a condition split into systems. First, some of assumptions and equations of the manual calculations are outlined in the section below.

\subsection{Testing the Model - Manual Calculation}

For the manual calculation a few assumptions and exclusions were made to simplify the 2D model into a 1D model. The numerical model is simplified with the assumptions outlined below;

- Steady state conditions.

- Solar radiation is not considered.

- Heat flux (flow) is taken as uni-directional, perpendicular to the air flow.

- Interior room temperature is 23 degrees Celsius. 
Heat Transfer through Conduction Variables;

$\mathrm{k}=$ Conductivity

$\mathrm{C}=$ Conductance

$\mathrm{R}_{\mathrm{si}}=$ Resistance

$\mathrm{T}_{0}=$ Temperature outside

$\mathrm{T}_{\mathrm{i}}=$ Temperature inside

$\Delta \mathrm{t}=$ Temperature difference

$\mathrm{U}=$ Overall heat transfer coefficient

Heat Transfer through Conduction;

The heat transfer values through the roof slab will be calculated using the equations below:

$$
\begin{array}{ll}
\text { Conductance }->\mathrm{C}=\mathrm{k} / \mathrm{I} & {\left[\mathrm{W} / \mathrm{m}^{2} \cdot \mathrm{K}\right]} \\
\text { Resistance }->\mathrm{R}=1 / \mathrm{C} & {\left[\mathrm{m}^{2} \cdot \mathrm{K} / \mathrm{W}\right]} \\
\text { Temperature difference } \rightarrow \Delta t_{1}=\frac{R_{1}}{R_{\text {tot }}}\left(t_{\text {out }}-t_{\text {in }}\right) & {\left[{ }^{\mathrm{K}}\right]} \\
\text { Overall heat transfer coefficient }->\mathrm{U}=1 / \mathrm{R}_{\text {tot }} & {\left[\mathrm{W} / \mathrm{m}^{2} \cdot \mathrm{K}\right]} \\
\text { Overall heat transfer } \rightarrow \mathrm{q}_{\text {total }}=\mathrm{U}_{\mathrm{x}} \cdot \mathrm{A} \cdot\left(\mathrm{T}_{\mathrm{i}}-\mathrm{T}_{\mathrm{o}}\right) & {\left[\mathrm{W} / \mathrm{m}^{2}\right]}
\end{array}
$$

The variables, equations, and material values defined in the sections above are then input into a spreadsheet program to simulate the thermal properties of each system using the Glaser method (Hutcheon \& Handegord, 1995). The results of these manual calculations are shown in Section 7.2.1 below.

\subsubsection{Manual Calculation - Results}

The manual calculation results for each system (systems as outlined in Section 7.1.2 above) and atmospheric variations are shown in the tables below. As outlined above, the temperature variables used in the manual calculations for the summer conditions are $\mathrm{T}_{\mathrm{si}}=23^{\circ} \mathrm{C}$ for interior and $\mathrm{T}_{\mathrm{so}}=27^{\circ} \mathrm{C}$ for exterior. 
Table 7-3 - Manual Calculation, Summer - System 1 Paving

\begin{tabular}{|c|c|c|c|c|c|c|c|}
\hline No. & Element [units] & Lenth $[\mathrm{m}]$ & $\begin{array}{c}\text { Conductivity } \\
{[\mathrm{W} / \mathrm{m} \cdot \mathrm{K}]}\end{array}$ & $\begin{array}{c}\text { Conductance } \\
{\left[\mathrm{W} / \mathrm{m}^{2} \cdot \mathrm{K}\right]}\end{array}$ & $\begin{array}{c}\text { Resistance } \\
{\left[\mathrm{m}^{2} \cdot \mathrm{K} / \mathrm{W}\right]}\end{array}$ & $\begin{array}{l}\text { Change in } \\
\text { Temp. }\left[{ }^{\circ} \mathrm{K}\right]\end{array}$ & Temperature $\left[{ }^{\circ} \mathrm{C}\right]$ \\
\hline 1 & Exterior Surface & - & - & 34.0000 & 0.0294 & -0.0220 & 27 \\
\hline 2 & Concrete, Paving & 0.1300 & 0.93 & 7.1538 & 0.1398 & -0.1046 & 26.9780 \\
\hline 3 & Granular 'A' & 0.1500 & 0.84 & 5.6000 & 0.1786 & -0.1337 & 26.8733 \\
\hline 4 & Granular 'O', Clear & 0.1000 & 0.78 & 7.8000 & 0.1282 & -0.0960 & 26.7397 \\
\hline 5 & Rigid Insulation, Slab & 0.1000 & 0.022 & 0.2200 & 4.5455 & -3.4025 & 26.6437 \\
\hline 6 & Concrete, Slab & 0.3000 & 1.40 & 4.6667 & 0.2143 & -0.1604 & 23.2412 \\
\hline 7 & Interior Surface & - & - & 9.2600 & 0.1080 & -0.0808 & 23.0808 \\
\hline \multicolumn{5}{|r|}{ Total } & 5.3437 & -4.0000 & 23 \\
\hline & & & & $A_{p}=$ & 1.0000 & $\mathrm{~m}^{2}$ & \\
\hline & & & & $\mathrm{U}_{\mathrm{p}}=$ & 0.1871 & $\mathrm{~W} / \mathrm{m}^{2} \cdot \mathrm{K}$ & \\
\hline & & & & $q_{p}=$ & -0.7485 & $\mathrm{~W} / \mathrm{m}^{2}$ & \\
\hline
\end{tabular}

Table 7-4 - Manual Calculation, Summer - System 2 Wall

\begin{tabular}{|c|c|c|c|c|c|c|c|}
\hline No. & Element [units] & Lenth [m] & $\begin{array}{l}\text { Conductivity } \\
{[\mathrm{W} / \mathrm{m} \cdot \mathrm{K}]}\end{array}$ & $\begin{array}{c}\text { Conductance } \\
{\left[\mathrm{W} / \mathrm{m}^{2} \cdot \mathrm{K}\right]}\end{array}$ & $\begin{array}{c}\text { Resistance } \\
{\left[\mathrm{m}^{2} \cdot \mathrm{K} / \mathrm{W}\right]}\end{array}$ & $\begin{array}{l}\text { Change in } \\
\text { Temp. }\left[{ }^{\circ} \mathrm{K}\right]\end{array}$ & $\begin{array}{c}\text { Temperature } \\
{\left[{ }^{\circ} \mathrm{C}\right]}\end{array}$ \\
\hline 1 & Exterior Surface & - & - & 34.0000 & 0.0294 & -0.1104 & 27 \\
\hline 2 & Concrete, Wall & 1.0000 & 1.40 & 1.4000 & 0.7143 & -2.6803 & 26.8896 \\
\hline 3 & Concrete, Slab & 0.3000 & 1.40 & 4.6667 & 0.2143 & -0.8041 & 24.2093 \\
\hline 4 & Interior Surface & - & - & 9.2600 & 0.1080 & -0.4052 & 23.4052 \\
\hline \multicolumn{5}{|r|}{ Total } & 1.0660 & -4.0000 & 23 \\
\hline & & & & $A_{w}=$ & 1.0000 & $\mathrm{~m}^{2}$ & \\
\hline & & & & $\mathrm{U}_{\mathrm{w}}=$ & 0.9381 & $\mathrm{~W} / \mathrm{m}^{2} \cdot \mathrm{K}$ & \\
\hline & & & & $\mathrm{q}_{\mathrm{w}}=$ & -3.7524 & $\mathrm{~W} / \mathrm{m}^{2}$ & \\
\hline
\end{tabular}

Table 7-5 - Manual Calculation, Summer - System 3 Soil

\begin{tabular}{|c|c|c|c|c|c|c|c|}
\hline No. & Element [units] & Lenth [m] & $\begin{array}{c}\text { Conductivity } \\
{[\mathrm{W} / \mathrm{m} \cdot \mathrm{K}]}\end{array}$ & $\begin{array}{c}\text { Conductance } \\
{\left[\mathrm{W} / \mathrm{m}^{2} \cdot \mathrm{K}\right]}\end{array}$ & $\begin{array}{c}\text { Resistance } \\
{\left[\mathrm{m}^{2} \cdot \mathrm{K} / \mathrm{W}\right]}\end{array}$ & $\begin{array}{l}\text { Change in } \\
\text { Temp. }\left[{ }^{\circ} \mathrm{K}\right]\end{array}$ & $\begin{array}{c}\text { Temperature } \\
{\left[{ }^{\circ} \mathrm{C}\right]} \\
\end{array}$ \\
\hline 1 & Exterior Surface & - & - & 34.0000 & 0.0294 & -0.0201 & 27 \\
\hline 2 & Soil, Dry & 0.7000 & 0.84 & 1.2000 & 0.8333 & -0.5690 & 26.9799 \\
\hline 3 & Granular 'O', Clear & 0.1000 & 0.78 & 7.8000 & 0.1282 & -0.0875 & 26.4110 \\
\hline 4 & Rigid Insulation, Slab & 0.1000 & 0.022 & 0.2200 & 4.5455 & -3.1034 & 26.3234 \\
\hline 5 & Concrete, Slab & 0.3000 & 1.40 & 4.6667 & 0.2143 & -0.1463 & 23.2200 \\
\hline 6 & Interior Surface & - & - & 9.2600 & 0.1080 & -0.0737 & 23.0737 \\
\hline \multicolumn{5}{|r|}{ Total } & 5.8587 & -4.0000 & 23 \\
\hline & & & & $A_{s}=$ & 1.0000 & $\mathrm{~m}^{2}$ & \\
\hline & & & & $\mathrm{U}_{\mathrm{s}}=$ & 0.1707 & $\mathrm{~W} / \mathrm{m}^{2} \cdot \mathrm{K}$ & \\
\hline & & & & $\mathrm{q}_{\mathrm{s}}=$ & -0.6827 & $\mathrm{~W} / \mathrm{m}^{2}$ & \\
\hline
\end{tabular}


The temperature variables used in the manual calculations for the winter conditions are $T_{w i}=23^{\circ} \mathrm{C}$ for interior and $\mathrm{T}_{\mathrm{wo}}=-15^{\circ} \mathrm{C}$ for exterior.

Table 7-6 - Manual Calculation, Winter - System 1 Paving

\begin{tabular}{|c|c|c|c|c|c|c|c|}
\hline No. & Element [units] & Lenth $[\mathrm{m}]$ & $\begin{array}{c}\text { Conductivity } \\
\mathrm{k}[\mathrm{W} / \mathrm{m} \cdot \mathrm{K}]\end{array}$ & $\begin{array}{c}\text { Conductance } \\
{\left[\mathrm{W} / \mathrm{m}^{2} \cdot \mathrm{K}\right]}\end{array}$ & $\begin{array}{c}\text { Resistance } \\
{\left[\mathrm{m}^{2} \cdot \mathrm{K} / \mathrm{W}\right]}\end{array}$ & $\begin{array}{c}\text { Change in } \\
\text { Temp. }\left[{ }^{\circ} \mathrm{K}\right]\end{array}$ & $\begin{array}{c}\text { Temperature } \\
{\left[{ }^{\circ} \mathrm{C}\right]}\end{array}$ \\
\hline 1 & Exterior Surface & - & - & 34.0000 & 0.0294 & 0.2092 & -15 \\
\hline 2 & Concrete, Paving & 0.1300 & 0.93 & 7.1538 & 0.1398 & 0.9940 & -14.7908 \\
\hline 3 & Granular 'A' & 0.1500 & 0.84 & 5.6000 & 0.1786 & 1.2699 & -13.7968 \\
\hline 4 & Granular 'O', Clear & 0.1000 & 0.78 & 7.8000 & 0.1282 & 0.9117 & -12.5270 \\
\hline 5 & Rigid Insulation, Slab & 0.1000 & 0.022 & 0.2200 & 4.5455 & 32.3235 & -11.6153 \\
\hline 6 & Concrete, Slab & 0.3000 & 1.40 & 4.6667 & 0.2143 & 1.5238 & 20.7082 \\
\hline 7 & Interior Surface & - & - & 9.2600 & 0.1080 & 0.7679 & 22.2321 \\
\hline & & & & Total & 5.3437 & 38.0000 & 23 \\
\hline & & & & $\mathrm{A}_{p}=$ & 1.0000 & $\mathrm{~m}^{2}$ & \\
\hline
\end{tabular}

Table 7-7-Manual Calculation, Winter - System 2 Wall

\begin{tabular}{|c|c|c|c|c|c|c|c|}
\hline No. & Element [units] & Lenth $[\mathrm{m}]$ & $\begin{array}{l}\text { Conductivity } \\
\mathrm{k}[\mathrm{W} / \mathrm{m} \cdot \mathrm{K}]\end{array}$ & $\begin{array}{c}\text { Conductance } \\
{\left[\mathrm{W} / \mathrm{m}^{2} \cdot \mathrm{K}\right]}\end{array}$ & $\begin{array}{c}\text { Resistance } \\
{\left[\mathrm{m}^{2} \cdot \mathrm{K} / \mathrm{W}\right]}\end{array}$ & $\begin{array}{l}\text { Change in } \\
\text { Temp. }\left[{ }^{\circ} \mathrm{K}\right]\end{array}$ & $\begin{array}{c}\text { Temperature } \\
{\left[{ }^{\circ} \mathrm{C}\right]} \\
\end{array}$ \\
\hline 1 & Exterior Surface & - & - & \begin{tabular}{|l|}
34.0000 \\
\end{tabular} & 0.0294 & 1.0485 & -15 \\
\hline 2 & Concrete, Wall & 1.0000 & 1.40 & 1.4000 & 0.7143 & 25.4630 & -13.9515 \\
\hline 3 & Concrete, Slab & 0.3000 & 1.40 & 4.6667 & 0.2143 & 7.6389 & 11.5114 \\
\hline 4 & Interior Surface & - & - & 9.2600 & 0.1080 & 3.8497 & 19.1503 \\
\hline \multicolumn{5}{|r|}{ Total } & 1.0660 & 38.0000 & 23 \\
\hline & & & & $A_{w}=$ & 1.0000 & $\mathrm{~m}^{2}$ & \\
\hline & & & & $\mathrm{U}_{\mathrm{w}}=$ & 0.9381 & $\mathrm{~W} / \mathrm{m}^{2} \cdot \mathrm{K}$ & \\
\hline & & & & $\mathrm{q}_{\mathrm{w}}=$ & 35.6481 & $\mathrm{~W} / \mathrm{m}^{2}$ & \\
\hline
\end{tabular}

Table 7-8 - Manual Calculation, Winter - System 3 Soil

\begin{tabular}{|c|c|c|c|c|c|c|c|}
\hline No. & Element [units] & Lenth $[\mathrm{m}]$ & $\begin{array}{l}\text { Conductivity } \\
\mathrm{k}[\mathrm{W} / \mathrm{m} \cdot \mathrm{K}]\end{array}$ & $\begin{array}{c}\text { Conductance } \\
{\left[\mathrm{W} / \mathrm{m}^{2} \cdot \mathrm{K}\right]}\end{array}$ & $\begin{array}{c}\text { Resistance } \\
{\left[\mathrm{m}^{2} \cdot \mathrm{K} / \mathrm{W}\right]}\end{array}$ & $\begin{array}{l}\text { Change in } \\
\text { Temp. }\left[{ }^{\circ} \mathrm{K}\right]\end{array}$ & $\begin{array}{c}\text { Temperature } \\
{\left[{ }^{\circ} \mathrm{C}\right]} \\
\end{array}$ \\
\hline 1 & Exterior Surface & - & - & 34.0000 & 0.0294 & 0.1908 & -15 \\
\hline 2 & Soil, Dry & 0.7000 & 0.84 & 1.2000 & 0.8333 & 5.4051 & -14.8092 \\
\hline 3 & Granular 'O', Clear & 0.1000 & 0.78 & 7.8000 & 0.1282 & 0.8316 & -9.4041 \\
\hline 4 & Rigid Insulation, Slab & 0.1000 & 0.022 & 0.2200 & 4.5455 & 29.4823 & -8.5726 \\
\hline 5 & Concrete, Slab & 0.3000 & 1.40 & 4.6667 & 0.2143 & 1.3899 & 20.9097 \\
\hline 6 & Interior Surface & - & - & 9.2600 & 0.1080 & 0.7004 & 22.2996 \\
\hline \multicolumn{5}{|r|}{ Total } & 5.8587 & 38.0000 & 23 \\
\hline & & & & $A_{s}=$ & 1.0000 & $m^{2}$ & \\
\hline & & & & $\mathrm{U}_{\mathrm{s}}=$ & 0.1707 & $\mathrm{~W} / \mathrm{m}^{2} \cdot \mathrm{K}$ & \\
\hline & & & & $q_{s}=$ & 6.4861 & $\mathrm{~W} / \mathrm{m}^{2}$ & \\
\hline
\end{tabular}


Table 7-9-Manual Calculation Results Summary

\begin{tabular}{|c|c|c|c|}
\hline \multicolumn{4}{|c|}{ THERM U-factor Model Comparison, Winter and Summer } \\
\hline Model & U-factor & Projection & \% Error Energy Norm. \\
\hline Units & {$[\mathrm{W} / \mathrm{m} 2 * \mathrm{~K}]$} & & \\
\hline \multicolumn{4}{|l|}{ Manual Calculation } \\
\hline cond_01-06_s_total & 0.4320 & & \\
\hline cond_01-06_s_paving & 0.1871 & $1 \mathrm{D}$ & Not applicable \\
\hline cond_01-06_s_soil & 0.1707 & $1 \mathrm{D}$ & Not applicable \\
\hline cond_01-06_s_wall & 0.9381 & $1 \mathrm{D}$ & Not applicable \\
\hline cond_01-06_w_total & 0.4320 & & \\
\hline cond_01-06_w_paving & 0.1871 & $1 \mathrm{D}$ & Not applicable \\
\hline cond_01-06_w_soil & 0.1707 & $1 \mathrm{D}$ & Not applicable \\
\hline cond_01-06_w_wall & 0.9381 & $1 \mathrm{D}$ & Not applicable \\
\hline Averaged/Interpolated & & & \\
\hline
\end{tabular}

As was expected when considering basic heat transfer principles, the lowest U-factor values can be seen in the insulated portions of the systems, while the highest U-values are through the uninsulated CIP concrete wall system (see Table 7-2 above). For comparison purposes, the U-values were averaged for each system and seasonal variation, and the results are the same for both at $0.432 \mathrm{~W} / \mathrm{m}^{2} \cdot \mathrm{K}$. After reporting these results, the 1D manual calculation numbers will be compared to the 1D and 2D results from the computer simulations in the next section.

\subsection{Testing the Model - Computer Simulation}

For the computer simulation test, the study was completed for both 1D (separated) and 2D (combined) variations. This was completed to assess if the 1D model matches the manual calculation and to further ascertain how the addition of another dimension (2D) can affect the heat flux through the systems and what the overall result could be. Figure 7.3 and Figure 7.4 below depict the isotherms of the separated simulated models for each system (paving, wall, and soil) in summer and winter conditions respectively. 

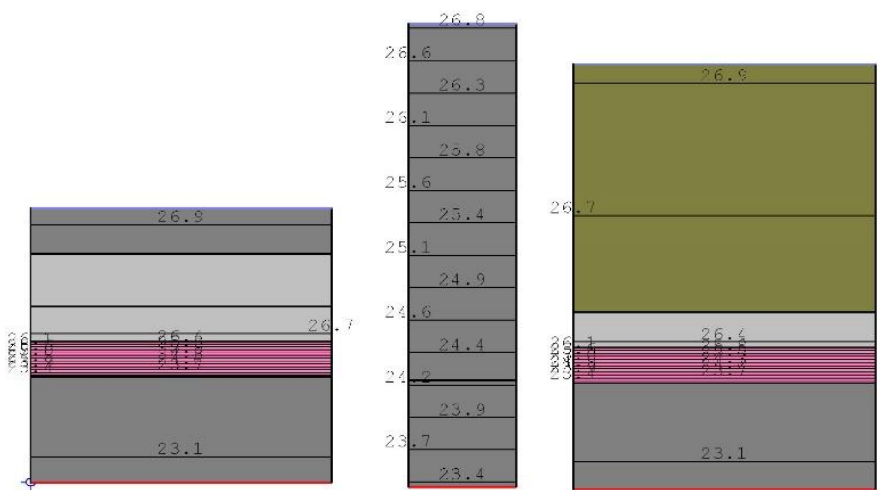

Figure 7.3 - Condition 1.6 Systems Separated - Standard w/ No Wall Insulation, Summer
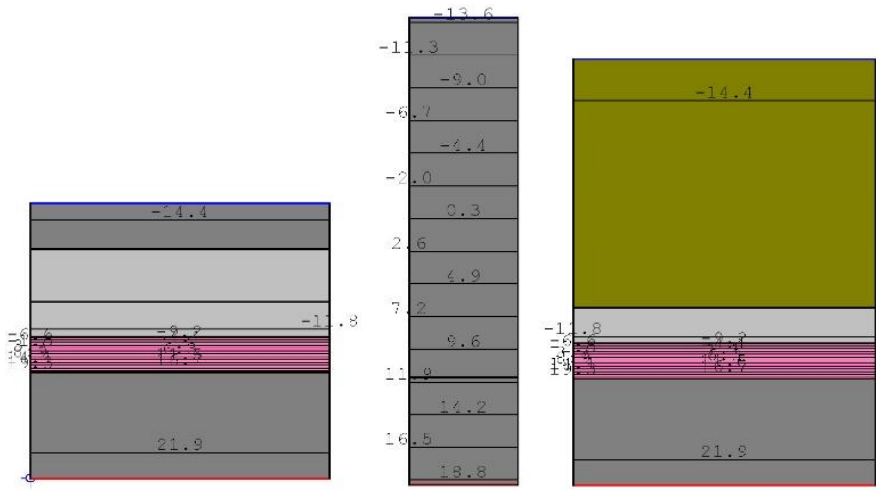

Figure 7.4 - Condition 1.6 Systems Separated - Standard w/ No Wall Insulation, Winter

Figure 7.5 and Figure 7.6 below depict the isotherms from the simulated models for each system (paving, wall, and soil) combined as one 2D model for both summer and winter conditions respectively. As mentioned previously, these conditions were simulated as combined models to ascertain how the adjacency of 2D elements affect the heat flux of each system (when compared to the 1D separated models, see Figure 7.3 and Figure 7.4 above). 


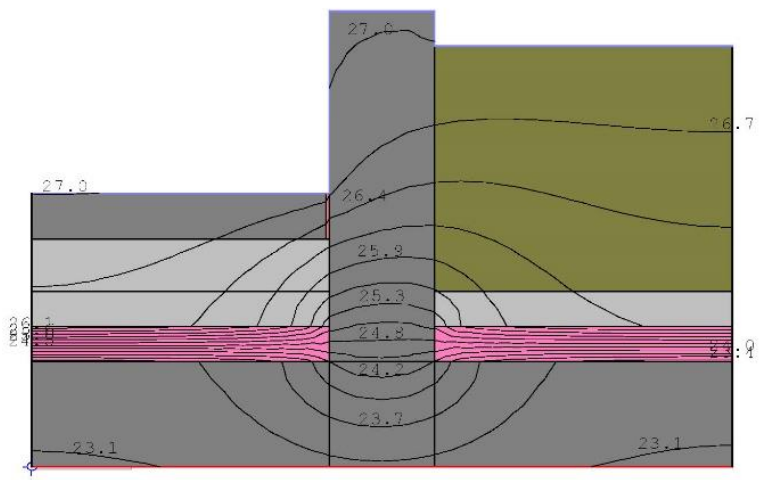

Figure 7.5 - Condition 1.6 Systems Combined - Standard w/ No Wall Insulation, Summer

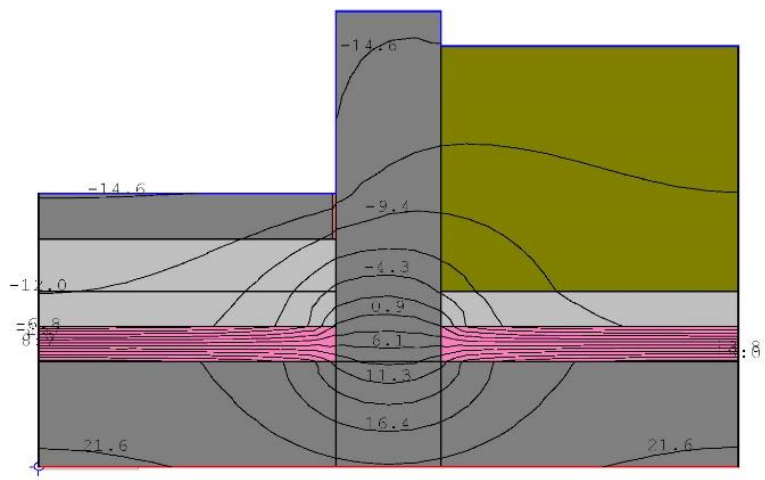

Figure 7.6 - Condition 1.6 Systems Combined - Standard w/ No Wall Insulation, Winter

After simulating these separated and combined system models for Condition 1.6 (cond_01-06) the results will be compared and assessed in the next section.

\subsubsection{Computer Simulation - Results}

Similar to the manual calculations, and again as expected, the lowest $U$-factor values can be seen in the insulated portions of the systems, while the higher U-values are in the CIP concrete wall system. For comparison purposes, the $\mathrm{U}$-values in the separated computer model were also averaged, and the results are $0.4284 \mathrm{~W} / \mathrm{m}^{2} \cdot \mathrm{K}$ for summer and $0.4375 \mathrm{~W} / \mathrm{m}^{2} \cdot \mathrm{K}$ for winter (see Table 7-10 below). If this is compared to the $0.432 \mathrm{~W} / \mathrm{m}^{2} \cdot \mathrm{K}$ for summer and winter in the manual calculation, the results only differ by $0.83 \%$ for summer and $1.25 \%$ for winter. Based on these results, it is relatively safe to say that the $1 \mathrm{D}$ manual and computer simulation models are accurate in comparison to each other. However, if a reason was to be postulated for the variation, it is likely with the way that THERM subdivides the model into a finite element mesh. The process of creating an element mesh for thermal modeling is similar to how 3D modeling programs of games create simplified visual representations of rounded and curved shapes by subdividing them into many triangular, square, or distorted polygonal shaped objects (Edelsbrunner, 2001). When viewed from a distance or zoomed out on a computer screen, the 3D mesh object would appear to be smooth, depending on the density of the mesh. In computer simulated thermal modeling, finite element mesh subdivides the model into smaller portions which can be more easily calculated, the results of which are then combined to give a final result. 
Table 7-10 - Computer Simulation Results Summary

\begin{tabular}{|c|c|c|c|}
\hline \multicolumn{4}{|c|}{ THERM U-factor Model Comparison, Winter and Summer } \\
\hline \multirow[t]{2}{*}{ Model } & U-factor & Projection & \% Error Energy Norm. \\
\hline & {$[\mathrm{W} / \mathrm{m} 2 * \mathrm{~K}]$} & & \\
\hline \multicolumn{4}{|l|}{ Seperated Model (CS) } \\
\hline cond_01-06_s_total & 0.4284 & Averaged & \\
\hline cond_01-06_s_paving & 0.1866 & Total Length & $0.00 \%$ \\
\hline cond_01-06_s_soil & 0.1731 & Total Length & $0.00 \%$ \\
\hline cond_01-06_s_wall & 0.9254 & Total Length & $0.00 \%$ \\
\hline cond_01-06_w_total & 0.4375 & Averaged & \\
\hline cond_01-06_w_paving & 0.1871 & Total Length & $0.00 \%$ \\
\hline cond_01-06_w_soil & 0.1874 & Total Length & $0.00 \%$ \\
\hline cond_01-06_w_wall & 0.9381 & Total Length & $0.00 \%$ \\
\hline \multicolumn{4}{|l|}{ Combined Model (CS) } \\
\hline cond_01-06_s_total & 0.4665 & Total Length & $8.75 \%$ \\
\hline cond_01-06_s_paving & 0.4101 & Total Length & $8.75 \%$ \\
\hline cond_01-06_s_soil & 0.3954 & Total Length & $8.75 \%$ \\
\hline cond_01-06_s_wall & 0.8274 & Total Length & $8.75 \%$ \\
\hline cond_01-06_w_total & 0.5000 & Total Length & $9.31 \%$ \\
\hline cond_01-06_w_paving & 0.4323 & Total Length & $9.31 \%$ \\
\hline cond_01-06_w_soil & 0.4299 & Total Length & $9.31 \%$ \\
\hline cond_01-06_w_wall & 0.8904 & Total Length & $9.31 \%$ \\
\hline Averaged/Interpolated & & & \\
\hline
\end{tabular}

In the computer simulated (CS) combined model, the results of each system vary quite substantially from the separated CS model (see Figure 7.7 below). The results of the paving and soil systems (cond_01-06_x_paving and cond_01-06_x_soil) vary in the range of 54.0\% to $56.0 \%$ while the wall systems (cond_01-06_x_wall) are in the range of $6.0 \%$ to $12.0 \%$ in difference. The range of the variation between these two simulations and their systems is likely due to differences of physically separating the 1D model (Figure 7.3 and Figure 7.4 above, p. 31) and then comparing those results to the 2D combined models (Figure 7.5 and Figure 7.6 above, p. 32). The total or average U-factor for both the separated and combined (cond_01-06_x_total) models varies in the range of $8.0 \%$ to $12.5 \%$. Based on these values, it can be seen that there is much less variation in the averaged and total U-factor values (cond_01-06_x_total) when compared and there is much more variation seen in the systems (cond_0106_x_paving, cond_01-06_x_soil, and cond_01-06_x_wall) when compared to each other in the separated and combined CS models. 


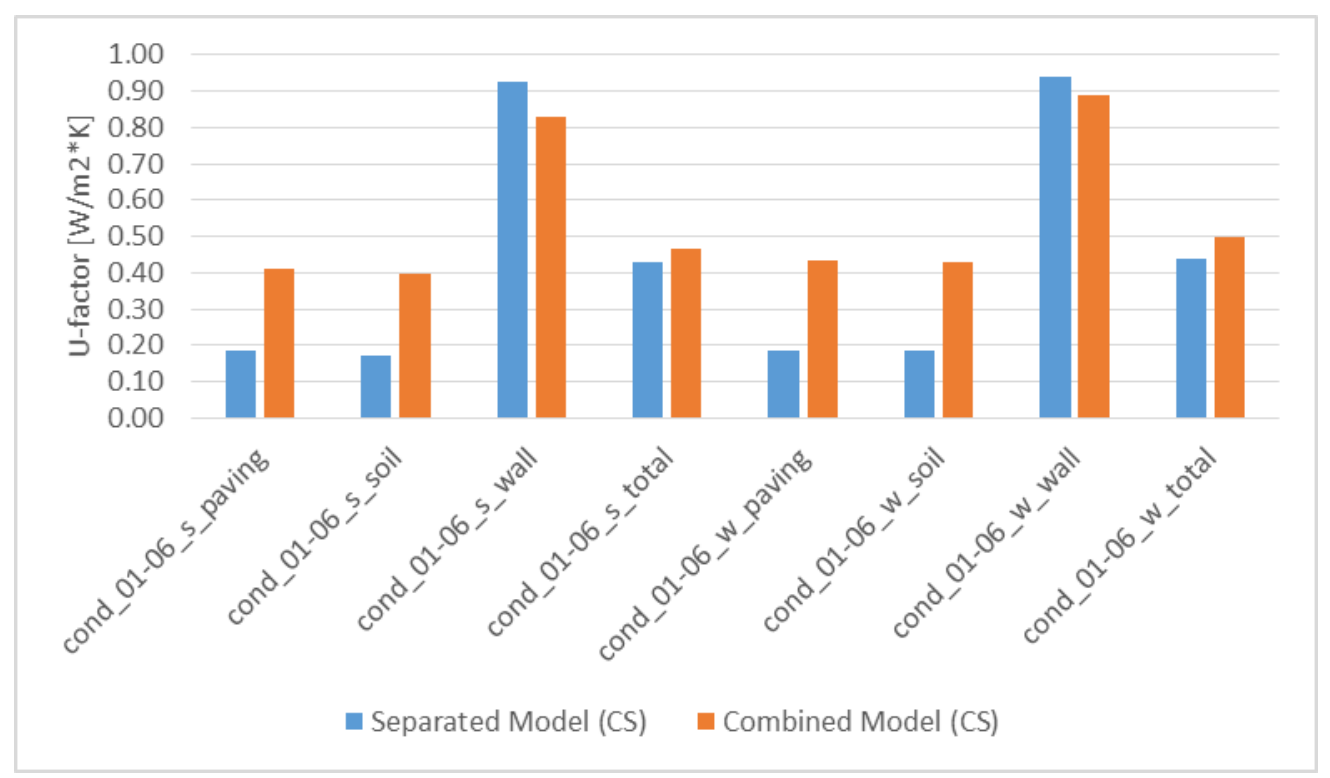

Figure 7.7 - U-factor Model Comparison - Manual Calculation and Computer Simulation (CS)

\subsection{Testing the Model - Manual Calculation and Computer Simulation Analysis}

The compiled results of the manual calculations and computer simulations from the previous sections are shown in Table 7-11 and Figure 7.8 below. The differences between the manual calculations and separated model CS as previously discussed are also shown in Figure 7.8. There is minimal variation in Manual Calculation and Separated Model (CS) categories under cond_01-06_s_total and cond_0106_w_total. The primary differences can be seen when comparing the Manual Calculation and Separated Model (CS) category results to the Combined Model (CS) category results under cond_0106_s_total and cond_01-06_w_total. The compared differences of those models are in the range of $8.0 \%$ to $12.5 \%$ and are believed to be derived from system adjacency and $2 \mathrm{D}$ heat flux through the wall structure/system which is graphically depicted as isotherms in Figure 7.5 and Figure 7.6 above (see Section 7.3, p. 30). 
Table 7-11 - Manual Calculation and Computer Simulation Results Summary

\begin{tabular}{|c|c|c|c|}
\hline \multicolumn{4}{|c|}{ THERM U-factor Model Comparison, Winter and Summer } \\
\hline Model & U-factor & Projection & \% Error Energy Norm. \\
\hline \multicolumn{4}{|c|}{ Units $\quad[\mathrm{W} / \mathrm{m} 2 * \mathrm{~K}]$} \\
\hline \multicolumn{4}{|c|}{ Manual Calculation } \\
\hline cond_01-06_s_total & 0.4320 & & \\
\hline cond_01-06_s_paving & 0.1871 & 1D & Not applicable \\
\hline cond_01-06_s_soil & 0.1707 & $1 \mathrm{D}$ & Not applicable \\
\hline cond_01-06_s_wall & 0.9381 & $1 \mathrm{D}$ & Not applicable \\
\hline cond_01-06_w_total & 0.4320 & & \\
\hline cond_01-06_w_paving & 0.1871 & $1 \mathrm{D}$ & Not applicable \\
\hline cond_01-06_w_soil & 0.1707 & $1 \mathrm{D}$ & Not applicable \\
\hline cond_01-06_w_wall & 0.9381 & $1 \mathrm{D}$ & Not applicable \\
\hline \multicolumn{4}{|l|}{ Seperated Model (CS) } \\
\hline cond_01-06_s_total & 0.4284 & Averaged & \\
\hline cond_01-06_s_paving & 0.1866 & Total Length & $0.00 \%$ \\
\hline cond_01-06_s_soil & 0.1731 & Total Length & $0.00 \%$ \\
\hline cond_01-06_s_wall & 0.9254 & Total Length & $0.00 \%$ \\
\hline cond_01-06_w_total & 0.4375 & Averaged & \\
\hline cond_01-06_w_paving & 0.1871 & Total Length & $0.00 \%$ \\
\hline cond_01-06_w_soil & 0.1874 & Total Length & $0.00 \%$ \\
\hline cond_01-06_w_wall & 0.9381 & Total Length & $0.00 \%$ \\
\hline \multicolumn{4}{|l|}{ Combined Model (CS) } \\
\hline cond_01-06_s_total & 0.4665 & Total Length & $8.75 \%$ \\
\hline cond_01-06_s_paving & 0.4101 & Total Length & $8.75 \%$ \\
\hline cond_01-06_s_soil & 0.3954 & Total Length & $8.75 \%$ \\
\hline cond_01-06_s_wall & 0.8274 & Total Length & $8.75 \%$ \\
\hline cond_01-06_w_total & 0.5000 & Total Length & $9.31 \%$ \\
\hline cond_01-06_w_paving & 0.4323 & Total Length & $9.31 \%$ \\
\hline cond_01-06_w_soil & 0.4299 & Total Length & $9.31 \%$ \\
\hline cond_01-06_w_wall & 0.8904 & Total Length & $9.31 \%$ \\
\hline Averaged/Interpolated & & & \\
\hline
\end{tabular}

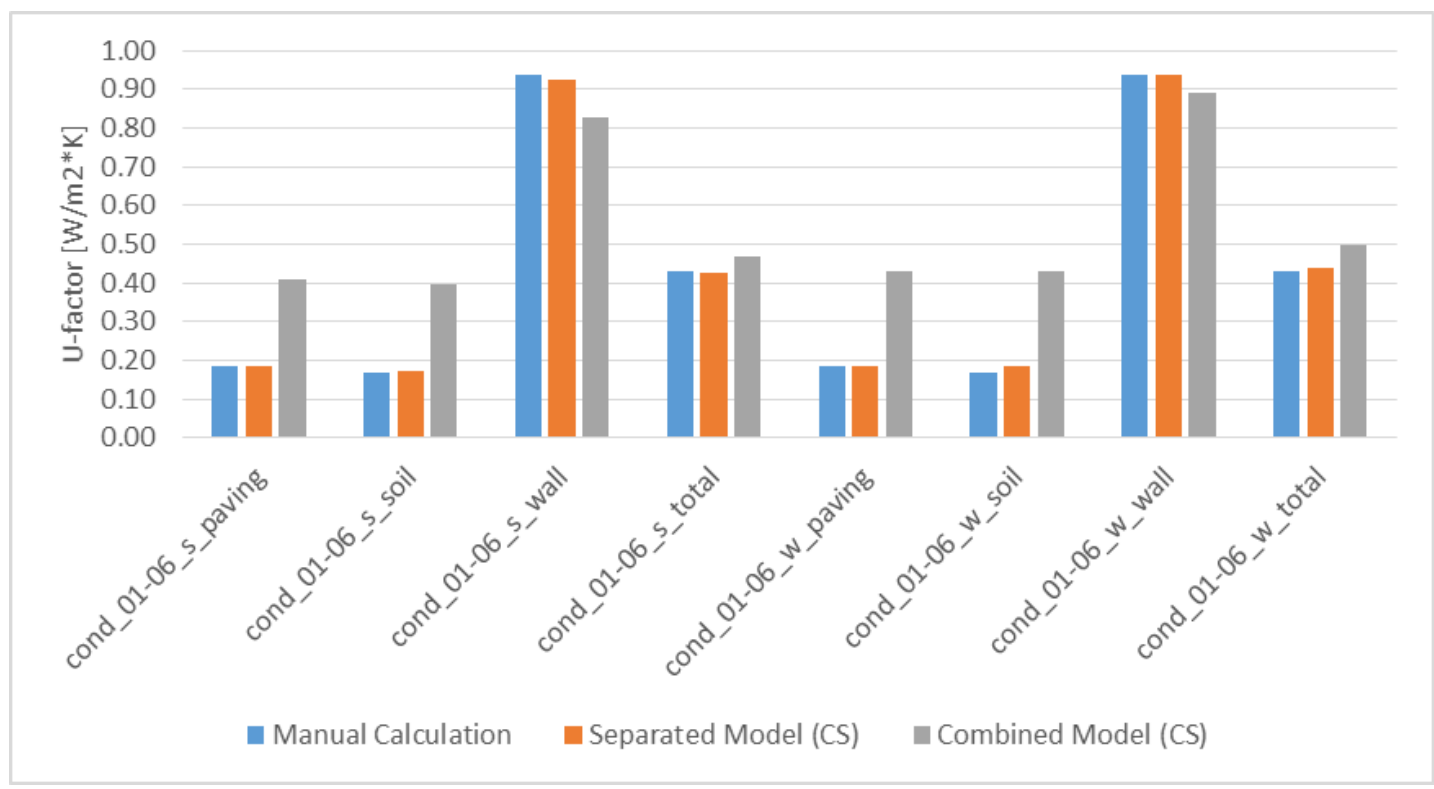

Figure 7.8-U-factor Model Comparison - Manual Calculation and Computer Simulation (CS) 
Based on the compiled results in Figure 7.8, testing the model appears to be successful in confirming the validity of the computer models. The next portion of this report, Objective 1 , will be to simulate all the conditions and variations outlined in Table 8-1, and to analyse the results.

\section{Objective 1: Computer Simulation of Condition Variations}

After confirming the relative accuracy of the models by manual calculation and computer simulation, this section is where the final simulations will be modeled and the results will be quantified, analysed, and compared.

\subsection{Condition Variations and Systems for Computer Simulation}

\subsubsection{Condition Variations to be Simulated}

As with the description of the conditions and variations in Section 6.1 Methodology (p. 16), the conditions for the computer simulation are reiterated below and given descriptive codes. Each condition variation will have a code such as 'cond_00-00_x_system'. Where 'cond' describes the model as a condition, the first set of ' 00 ' is the condition number, the second set of ' 00 ' is the variation, the ' $x$ ' it the seasonal variation where ' $s$ ' is summer and ' $w$ ' is winter, and 'system' is the system name or model description. In Table 8-1 below, the model names for the computer simulation are provided and described. The following Section 8.1.2 below describes the systems for the computer simulation. 
Table 8-1 - Simulation Models and Condition Descriptions

\begin{tabular}{l|l|l|}
$\begin{array}{l}\text { Simulation Model Name and Description } \\
\text { Model Name } \\
\text { cond_01-01 } \\
\text { cond_01-02 }\end{array}$ & Description & Standard \\
$\begin{array}{l}\text { Standard @ Reinforcing } \\
\text { cond_01-03 }\end{array}$ & Standard w/ 125mm Slab Insulation & $\begin{array}{l}\text { Summer and Winter } \\
\text { Summer and Winter }\end{array}$ \\
\hline cond_01-04 & Standard w/ 150mm Slab Insulation & Summer and Winter \\
\hline cond_01-05 & Standard w/ 25mm Wall Insulation & Summer and Winter \\
\hline cond_01-06 & Standard w/ No Wall Insulation & Summer and Winter \\
\hline cond_01-07 & Standard w/ 200mm Wide Wall & Summer and Winter \\
\hline cond_01-08 & Standard w/ 250mm Wide Wall & Summer and Winter \\
\hline cond_01-09 & Standard w/ 400mm Wide Wall & Summer and Winter \\
\hline cond_01-10 & Standard w/ Precast Conc. Paving & Summer and Winter \\
cond_02-01 & Improved & Summer and Winter \\
cond_02-02 & Improved @ Reinforcing & Summer and Winter \\
\hline cond_02-03 & Improved w/ 125mm Slab Insulation & Summer and Winter \\
\hline cond_02-04 & Improved w/ 150mm Slab Insulation & Summer and Winter \\
\hline cond_02-05 & Improved w/ 25mm Wall Insulation & Summer and Winter \\
\hline cond_02-06 & Improved w/ No Wall Insulation & Summer and Winter \\
\hline cond_02-07 & Improved w/ 200mm Wide Wall & Summer and Winter \\
\hline cond_02-08 & Improved w/ 250mm Wide Wall & Summer and Winter \\
\hline cond_02-09 & Improved w/ 400mm Wide Wall & Summer and Winter \\
\hline cond_02-10 & Improved w/ Precast Conc. Paving & Summer and Winter \\
cond_03-01 & Ultimate & Summer and Winter \\
cond_03-02 & Ultimate @ Reinforcing & Summer and Winter \\
\hline cond_03-03 & Ultimate w/ 125mm Slab Insulation & Summer and Winter \\
\hline cond_03-04 & Ultimate w/ 150mm Slab Insulation & Summer and Winter \\
\hline cond_03-05 & Ultimate w/ 25mm Wall Insulation & Summer and Winter \\
\hline cond_03-06 & Ultimate w/ No Wall Insulation & Summer and Winter \\
\hline cond_03-07 & Ultimate w/ 200mm Wide Wall & Summer and Winter \\
\hline cond_03-08 & Ultimate w/ 250mm Wide Wall & Summer and Winter \\
\hline cond_03-09 & Ultimate w/ 400mm Wide Wall & Summer and Winter \\
\hline cond_03-10 & Ultimate w/ Precast Conc. Paving & Summer and Winter \\
\hline & & \\
\hline
\end{tabular}

\subsubsection{Systems for Computer Simulation}

In order to simulate the 2D conductive heat flux through the roof structure and landscape walls, the conditions are broken up to define the following systems (see Figure 8.1 below):

- System 1 - Paving U-factor: Air (Exterior), Concrete Paving, Granular 'A', Granular 'O' (Clear Stone), Rigid Insulation, Concrete Slab, Air (Interior), and the left half of the planter wall

- System 2 - Planter U-factor: Air (Exterior), Planting Soil, Granular 'O' (Clear Stone), Rigid Insulation, Concrete Slab, Air (Interior), and the right half of the planter wall

- Overall U-factor - Both System 1 and System 2 combined and averaged 


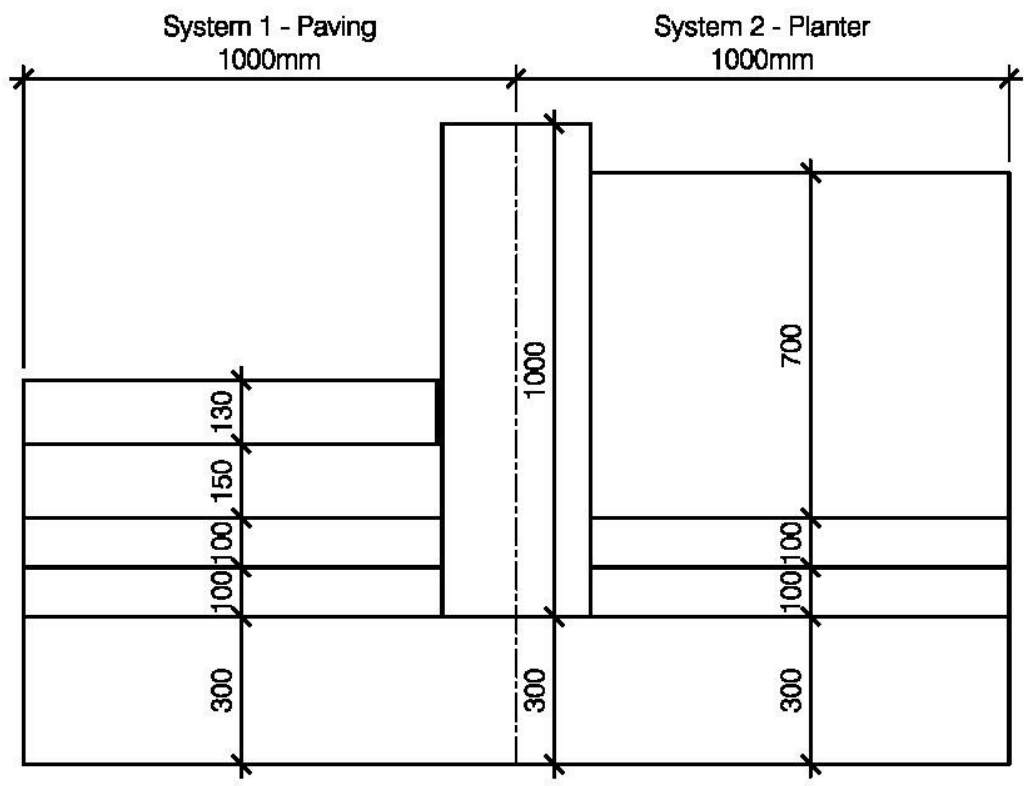

Figure 8.1 - Systems for the Computer Simulation Models

Figure 8.1 above depicts the systems for the Objective 1 computer simulation as described. The walls are divided at the midpoint and each system is named based on the adjacent paving or planter fields. These systems will also be utilized for Objective 2 as applied to the example landscape plan. The results of Objective 1 CS are compiled and analysed in the next section.

\subsection{Results of Computer Simulation}

The figures in Section 8.2.1 below graphically depict the U-factor values for all of the CS models and variations listed by condition designation (also see Appendix C - Condition Simulation Model Results, $\mathrm{p}$. 62). The figures in Section 8.2.2 and 8.2.3 are representative selected examples from the completed conditions with the 30 variations which are all depicted in Appendix D -THERM Simulation Models Summer (p. 64) and Appendix E - THERM Simulation Models - Winter (p. 74). THERM provides numerical simulation output of the condition models as a U-factor value and percentage (\%) error energy norm (EEN), which will be displayed in the charts. U-factor values were described in Section 2.2 above (p. 5). How EEN is derived is described by Mitchell et al. (2013) as "Upon the completion of the numerical simulation, the error estimator portion of the program makes local error estimates, and based on the error levels, refines troublesome regions of the model and recalculates the entire model. This procedure is repeated until no local regions show error levels higher than what is prescribed." EEN values are included in the charts below primarily for completeness purposes. Further to the CS models 
depicting isotherms and flux vectors below, additional CS models are created to depict interesting iterations of heat flux magnitude in condition variations.

\subsubsection{Results and Comparative Analysis of Computer Simulation}

The results of the simulation have shown that the models with the lowest and highest $\mathrm{U}$-factor values are generally what was expected when simply considering the design of the detail and the continuity of the insulation layer. As depicted in Figure 8.2, Figure 8.3, and Figure 8.4 below the lowest U-factor simulated, therefore the best performing thermally, was cond_02-04 and cond_03-04 at $0.1288 \mathrm{~W} / \mathrm{m}^{2} \cdot \mathrm{K}$ for summer and $0.1316 \mathrm{~W} / \mathrm{m}^{2} \cdot \mathrm{K}$ for winter. The highest $\mathrm{U}$-factor model, or the worst performing, was cond_01-09 at $0.4937 \mathrm{~W} / \mathrm{m}^{2} \cdot \mathrm{K}$ for summer and $0.5078 \mathrm{~W} / \mathrm{m}^{2} \cdot \mathrm{K}$ for winter. The mid-range U-factor value was simulated in model cond_03-01 at $0.1815 \mathrm{~W} / \mathrm{m}^{2} \cdot \mathrm{K}$ for summer and $0.1874 \mathrm{~W} / \mathrm{m}^{2} \cdot \mathrm{K}$ for winter. Note, that the models listed here as best and worst performers do not include cond_XX-02 (lighter colour bars), the reinforcing section simulations, in the interpretation. If the reinforcing sections are considered, the worst U-factor performer is cond_01-02 at $0.7116 \mathrm{~W} / \mathrm{m}^{2} \cdot \mathrm{K}$ for summer and 0.7310 $\mathrm{W} / \mathrm{m}^{2} \cdot \mathrm{K}$ for winter. This highlights the localized effects of doweled in steel reinforcing located in a structural wall, the model cond_01-01 which is the same section without reinforcing, has a U-factor value of $0.4464 \mathrm{~W} / \mathrm{m}^{2} \cdot \mathrm{K}$ for summer and $0.4596 \mathrm{~W} / \mathrm{m}^{2} \cdot \mathrm{K}$ for winter. What this implies is that, based on the standard condition model in this study (cond_XX-01), reinforcing can increase the localized heat flux by $\pm 37.0 \%$, which is quite substantial. 


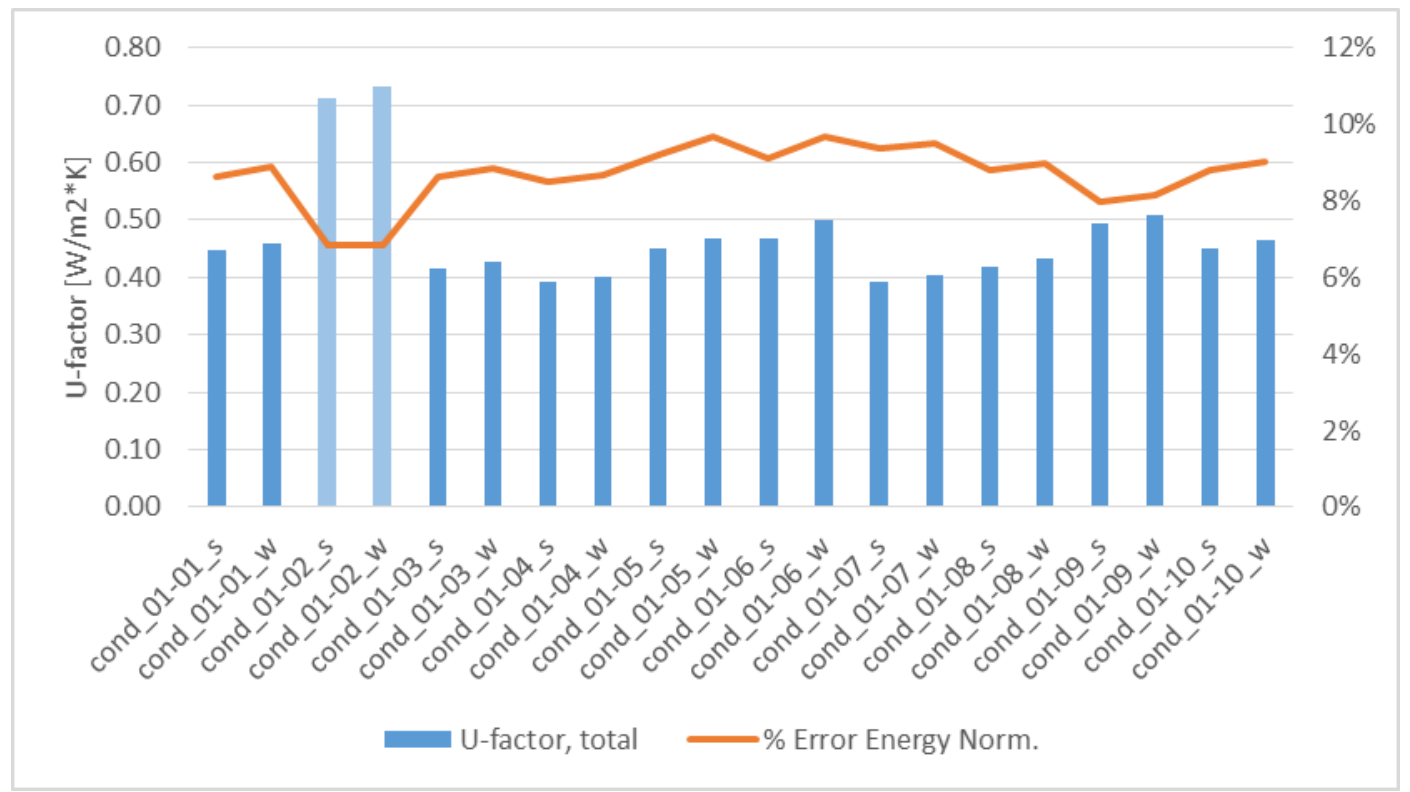

Figure 8.2 - Condition 1 Results for Summer and Winter Simulation

In Figure 8.2 above, it is evident that the range of variations did have a relatively significant impact on the U-factor values for this condition. All of the variations, excluding cond_01-02 at reinforcing (lighter colour bars), are in the range of $\pm 0.4 \mathrm{~W} / \mathrm{m}^{2} \cdot \mathrm{K}$ and $\pm 0.5 \mathrm{~W} / \mathrm{m}^{2} \cdot \mathrm{K}$, amounting to an approximately $20.0 \% \mathrm{U}$ factor difference between variations. Generally as expected, these values are of a magnitude that was anticipated. Meaning, the condition variations where there is more insulation (cond_01-03 and cond_01-04) have the lower U-factor values and the variations where the wall width is varied (cond_0107, cond_01-08, and cond_01-09) have lower or higher U-factor values in relation to the decreased or increased width of the wall, when compared to cond_01-01. An interesting result can be found in cond_01-05 and cond_01-06, the variations with $25 \mathrm{~mm}$ wall insulation and no wall insulation. It was found that in these two variations the U-factor value increased slightly, showing that the wall insulation can serve an additional purpose other than thermal protection of the vegetation. 


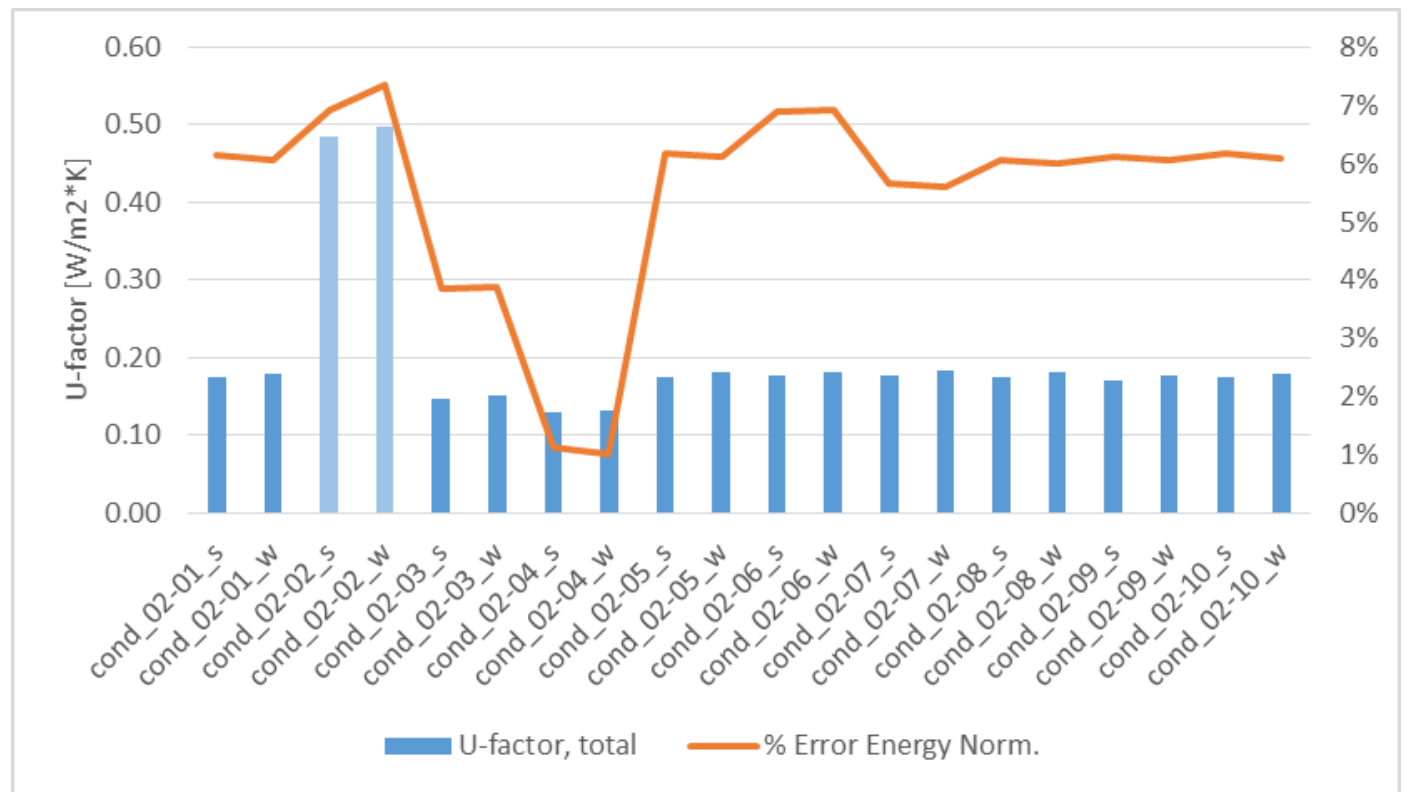

Figure 8.3 - Condition 2 Results for Summer and Winter Simulation

In Figure 8.3 above, it is evident that the range of variations did not have a significant impact on the Ufactor values for this condition. Most of the variations (excluding cond_02-02 at reinforcing), are in the range of $\pm 0.175 \mathrm{~W} / \mathrm{m}^{2} \cdot \mathrm{K}$ and $\pm 0.185 \mathrm{~W} / \mathrm{m}^{2} \cdot \mathrm{K}$, amounting to an approximately $5.0 \% \mathrm{U}$-factor difference between variations. Furthermore, cond_03-03 and cond_03-04 with thickened slab insulation show the lowest U-factor values for this condition in the range of $\pm 0.13 \mathrm{~W} / \mathrm{m}^{2} \cdot \mathrm{K}$ and $\pm 0.15 \mathrm{~W} / \mathrm{m}^{2} \cdot \mathrm{K}$. These results are somewhat similar to the range of values simulated in Condition 1, but with lower overall U-factors due to the thermal break provided under the planter walls. The initial idea behind the $150 \mathrm{~mm}$ thick rigid insulation thermal break was to increase the material thickness above the $100 \mathrm{~mm}$ slab insulation to help offset the additional heat flux that would be distributed through the doweled in reinforcing penetrations. From the results in the figure above, the $150 \mathrm{~mm}$ rigid insulation under the wall has helped to offset the overall heat flux in Condition 2 including the variations cond_02-05 to cond_02-10. 


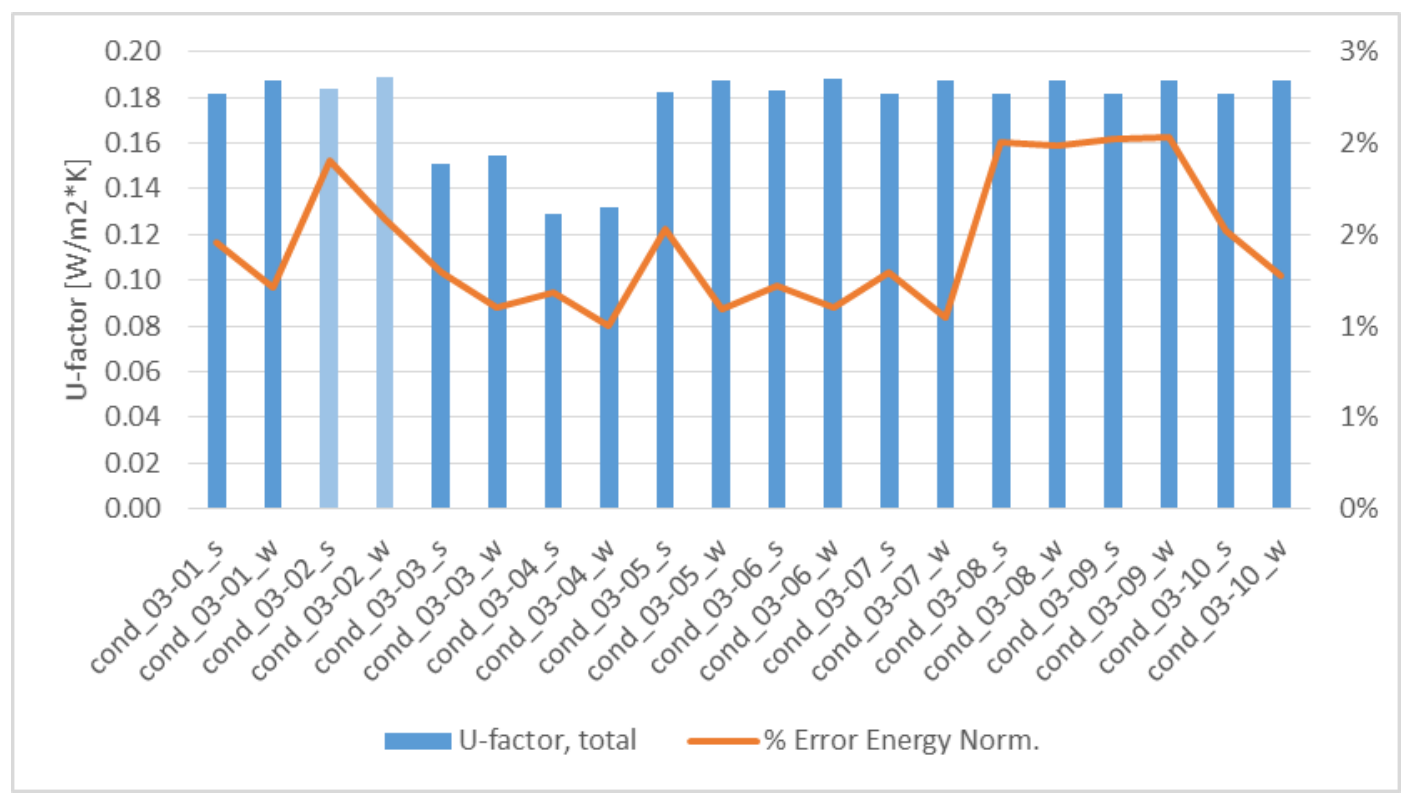

Figure 8.4 - Condition 3 Results for Summer and Winter Simulation

In Figure 8.4 above, as with Condition 2, the range of variations did not have a significant impact on the U-factor values for this condition. Excluding cond_02-02 at reinforcing as well as cond_03-03 and cond_03-04 with thickened slab insulation, most of the variations are similar in this condition and are in the range of $\pm 0.180 \mathrm{~W} / \mathrm{m}^{2} \cdot \mathrm{K}$ and $\pm 0.1875 \mathrm{~W} / \mathrm{m}^{2} \cdot \mathrm{K}$, amounting to an approximately $4.0 \% \mathrm{U}$-factor difference between variations. These results are also quite similar to the range of values simulated in Condition 2, but with even less variation due to the continuous $100 \mathrm{~mm}$ thick slab insulation layer. In fact, when comparing the average U-factor values of Condition 2 and Condition 3 an interesting output was realized, Condition 3 is actually slightly worse performing than Condition 2 . What this indicates is that in Condition 2 the uniform $150 \mathrm{~mm}$ thick rigid insulation under the CIP concrete walls actually helped to minimize or offset the thermal impact in other condition variations, thereby offering slightly better overall performance. Also for Condition 3, it was thought at the start of this research that there would be additional heat flux seen through the narrowed or widened wall variations (cond_03-07 to cond_03-09) due to surface contact with the insulating layer, but the difference in U-factor values in these variations was minimal as well. What actually occurred, was that the greatest U-factor differences in Condition 3 were due to the increased thickness of the slab insulation layer only. 


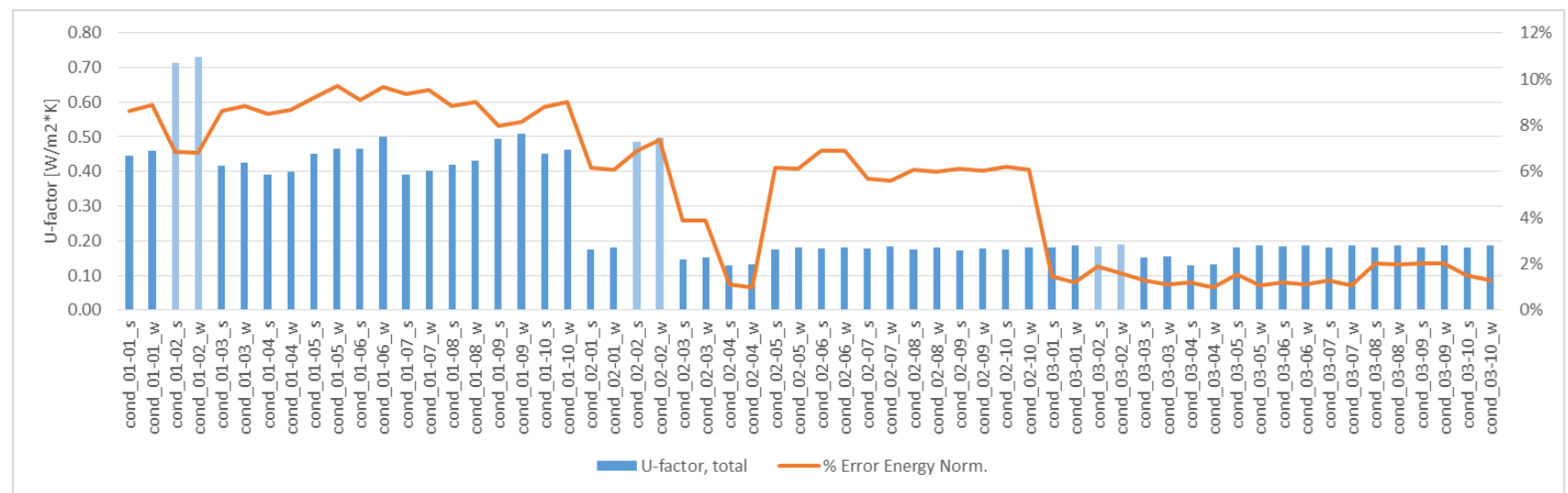

Figure 8.5 - Conditions 1, 2, and 3 Combined Results for Summer and Winter Simulation

In Figure 8.5 above, all of the results of the condition variations are compiled into one graph (also see enlarged version in Appendix F, p. 84). This compiled graph simply depicts how all the conditions and variations away from the standard Condition 1 are significant improvements in thermal performance. As Lawton \& Roppel (2014) outline, they describe the performance of 'efficient' details as "Fully insulated with only small conductive bypasses" with a U-value of $0.2 \mathrm{~W} / \mathrm{m}^{2} \cdot \mathrm{K}$, 'improved' details as "Thermally broken and intermittent structural connections" with a U-value of $0.35 \mathrm{~W} / \mathrm{m}^{2} \cdot \mathrm{K}$, and 'regular' details as "Under-insulated and continuous structural connections" with a U-value of $0.5 \mathrm{~W} / \mathrm{m}^{2} \cdot \mathrm{K}$. The range of U-values seen in the modeled Condition 2 and 3 fits into the 'efficient' category based on their analysis, while Condition 1 would fit into the 'regular' category. The next Sections 8.2.2 and 8.2.3 will depict graphically and summarise analytically the results of the more interesting or unique findings outlined in this section.

\subsubsection{THERM Models - Summer}

The figures below depict some of the summer condition variation models as captioned. For the model cond_01-01 (see Figure 8.6 and Figure 8.7), it can be seen in the isotherms and flux vectors graphics that the heat flux path is from exterior to interior and the majority of the heat flux is directly through the CIP concrete wall. In cond_02-01 (see Figure 8.8 and Figure 8.9) and cond_03-01 (see Figure 8.10 and Figure 8.11), the heat flux is reduced and more evenly distributed along the extents of the CS model, showing that improvements have been introduced. These graphics depict how the thermally broken wall helps to control and minimize heat flux through the slab structure. 


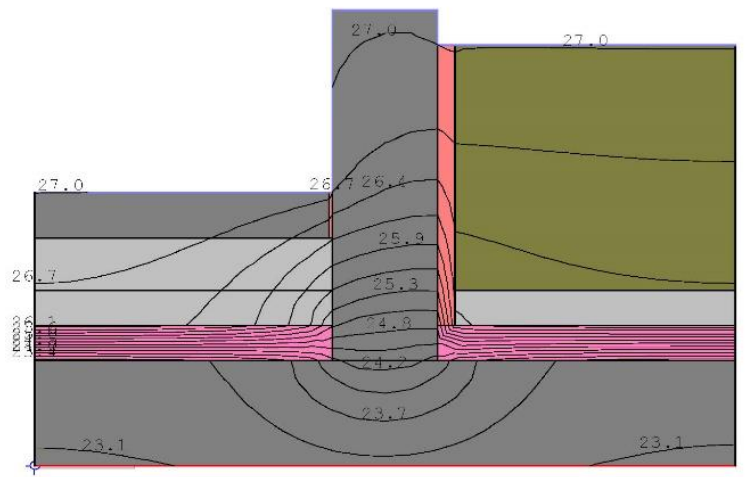

Figure 8.6 - Condition 1.1 - Standard; Isotherms

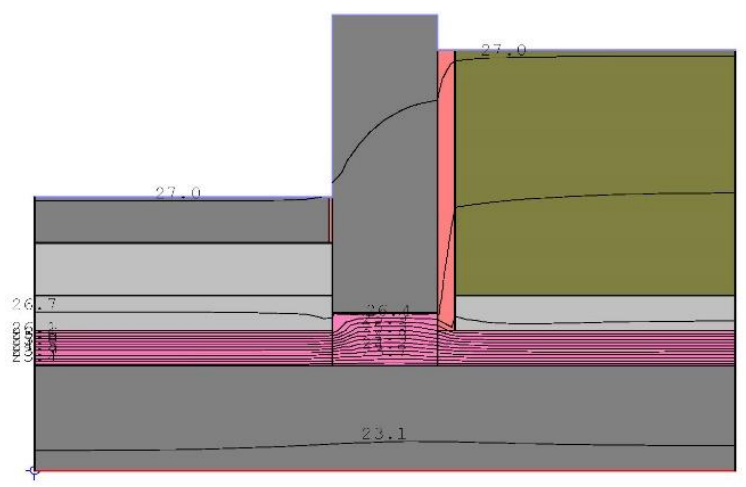

Figure 8.8-Condition 2.1 - Improved; Isotherms

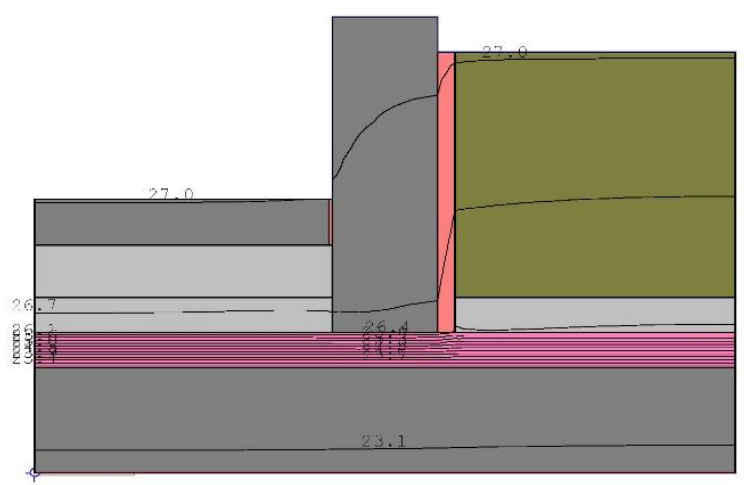

Figure 8.10-Condition 3.1 - Ultimate; Isotherms

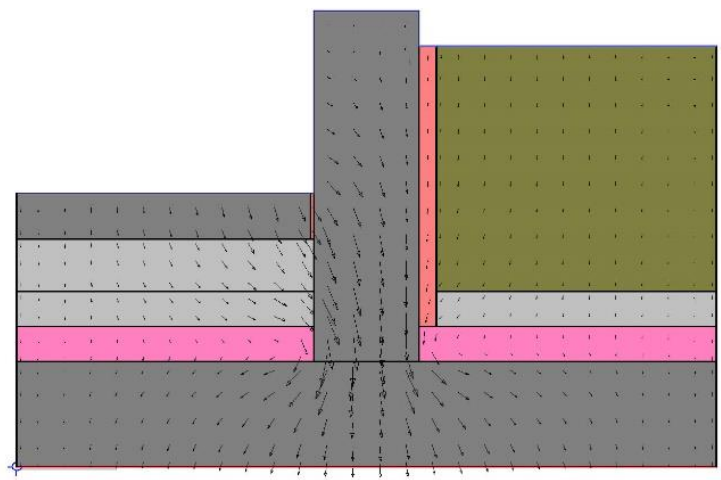

Figure 8.7-Condition 1.1 - Standard; Flux Vectors

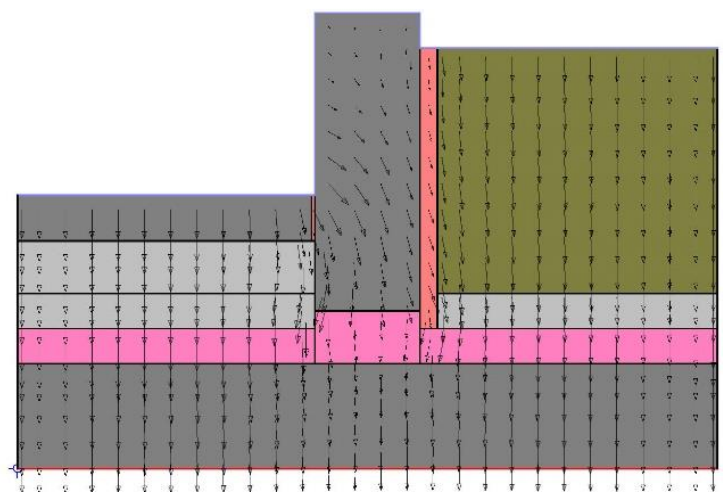

Figure 8.9-Condition 2.1 - Improved; Flux Vectors

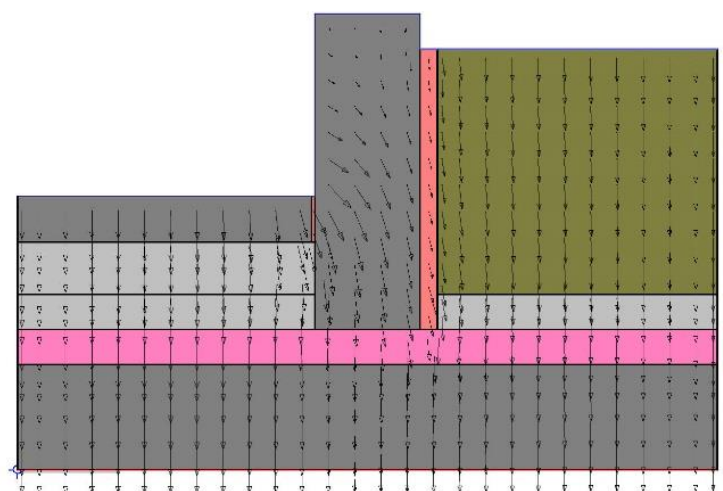

Figure 8.11 - Condition 3.1 - Ultimate; Flux Vectors 


\subsubsection{THERM Models - Winter}

The figures below depict some of the winter condition variation models as captioned. For the model cond_01-01 (see Figure 8.12 and Figure 8.13), it can be seen in the isotherms and flux vectors graphics that the heat flux path is from interior to exterior and the majority of the heat flux is directly through the CIP concrete wall. In cond_02-01 (see Figure 8.14 and Figure 8.15) and cond_03-01 (see Figure 8.16 and Figure 8.17), the heat flux is reduced and more evenly distributed along the extents of the CS model. As with the summer conditions, these graphics depict how the thermally broken wall helps to control and minimize heat flux through the slab structure.

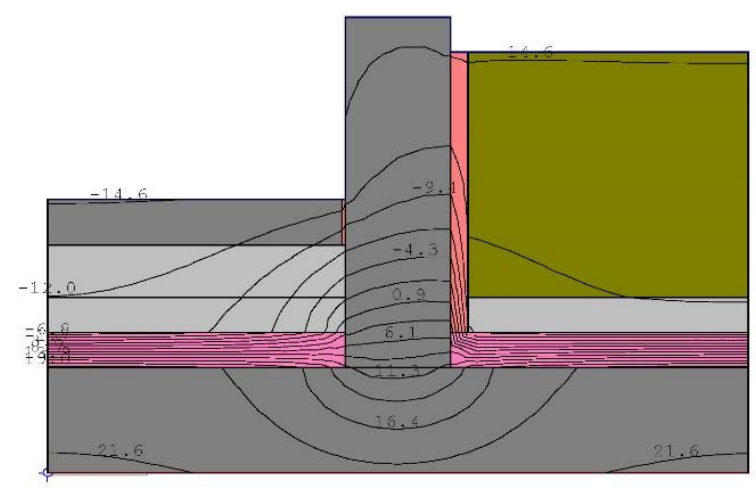

Figure 8.12 - Condition 1.1 - Standard; Isotherms

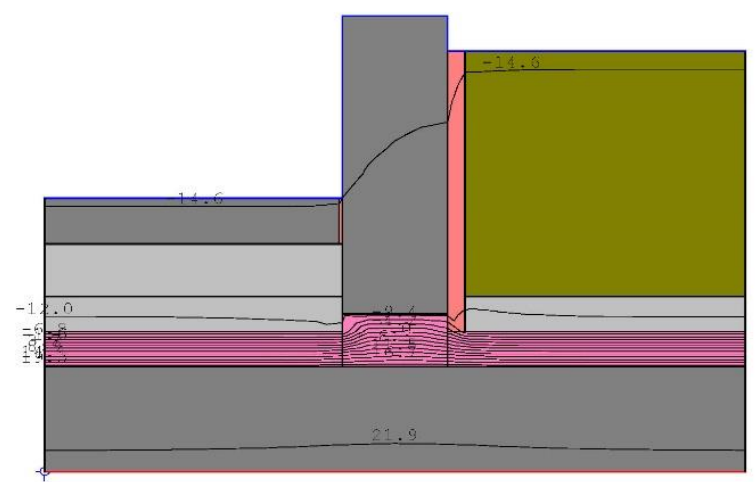

Figure 8.14 - Condition 2.1 - Improved; Isotherms

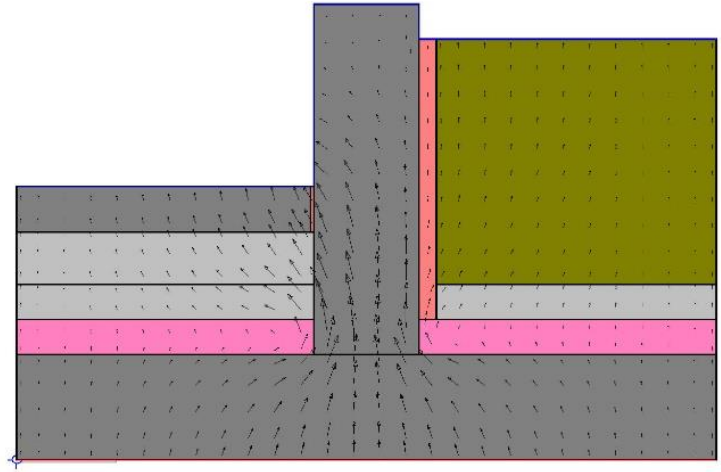

Figure 8.13-Condition 1.1 - Standard; Flux Vectors

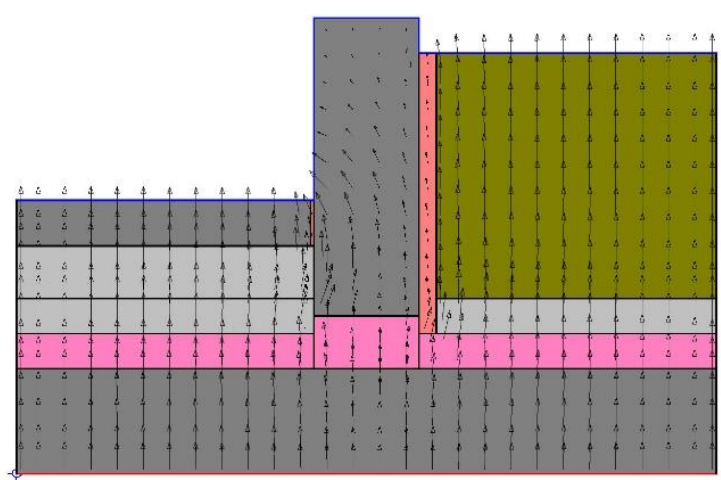

Figure 8.15 - Condition 2.1 - Improved; Flux Vectors 


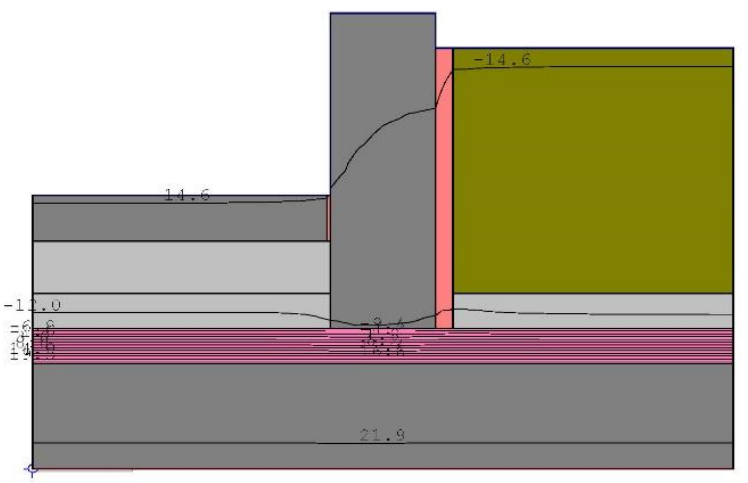

Figure 8.16-Condition 3.1 - Ultimate; Isotherms

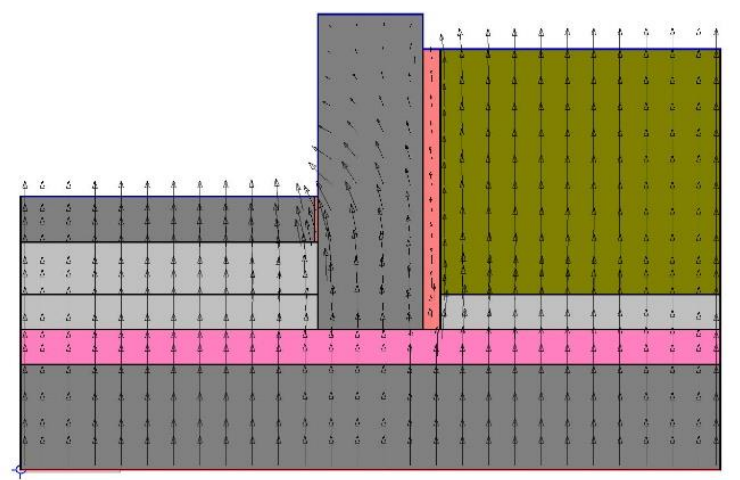

Figure 8.17-Condition 3.1 - Ultimate; Flux Vectors

\subsubsection{THERM Models - Additional Depictions}

The figures in this section contain additional graphical depictions of variation models as captioned.

Figure 8.18 and Figure 8.19 below depicts heat flux magnitude for the model cond_01-01 in summer and winter, the heat flux magnitude is focused at the uninsulated portion and through the CIP concrete wall. Figure 8.20 below depicts heat flux magnitude for the model cond_01-02 in winter, the heat flux magnitude is focused on the reinforcing steel with the highest conductivity value. Figure 8.21 below is an infrared representation of the temperature variation for the model cond_01-01 in winter, it depicts how the greatest temperature variation occurs at the broken insulation layer at the CIP concrete wall. Further to this, the temperature visualized at the top of concrete slab under the concrete wall is approximately $10^{\circ} \mathrm{C}$, while the temperature at the top of concrete slab under the rigid insulation is approximately $20^{\circ} \mathrm{C}$. Greater temperature variations seen over time when localized at the slab and wall junction area will place increased thermal stress on building elements including the CIP concrete, waterproofing layers, and insulation layers (Straube, 2012). Continuous thermal protection layers (as seen in Figure 8.22 and Figure 8.23 below, p. 48) help to reduce temperature variation across a building assembly and thereby increase the longevity of the materials, with an added benefit of minimizing internal localized hot or cold spots, which can cause condensation problems and/or negative affects to occupant comfort (Straube, 2012). 


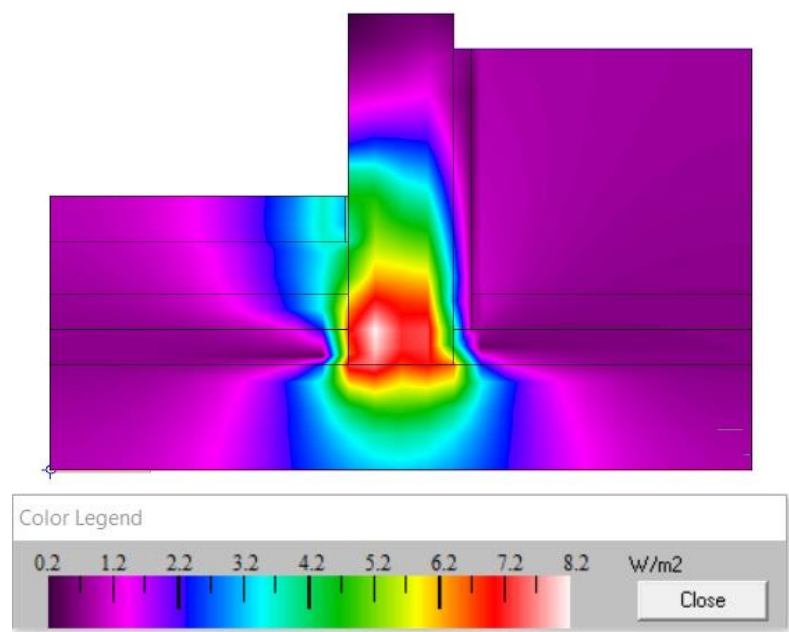

Figure 8.18 - Condition 1.1 - Standard, Summer; Heat Flux Magnitude and Legend

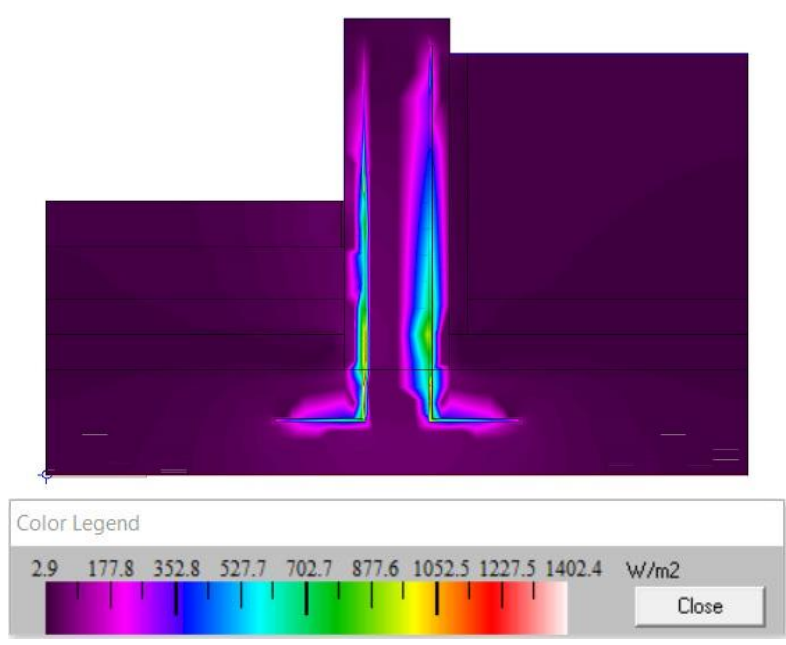

Figure 8.20-Condition 1.2 - Standard @ Reinforcing, Winter; Heat Flux Magnitude and Legend

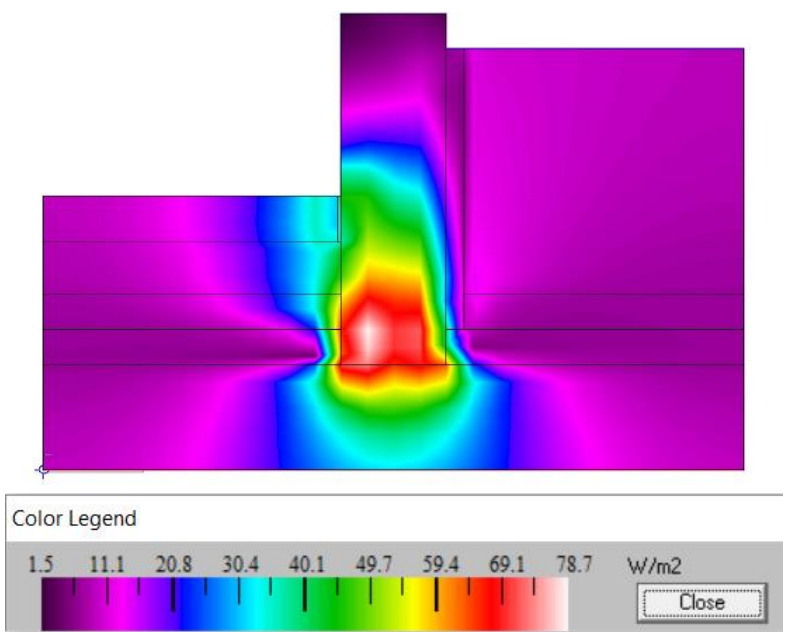

Figure 8.19 - Condition 1.1 - Standard,

Winter; Heat Flux Magnitude and Legend

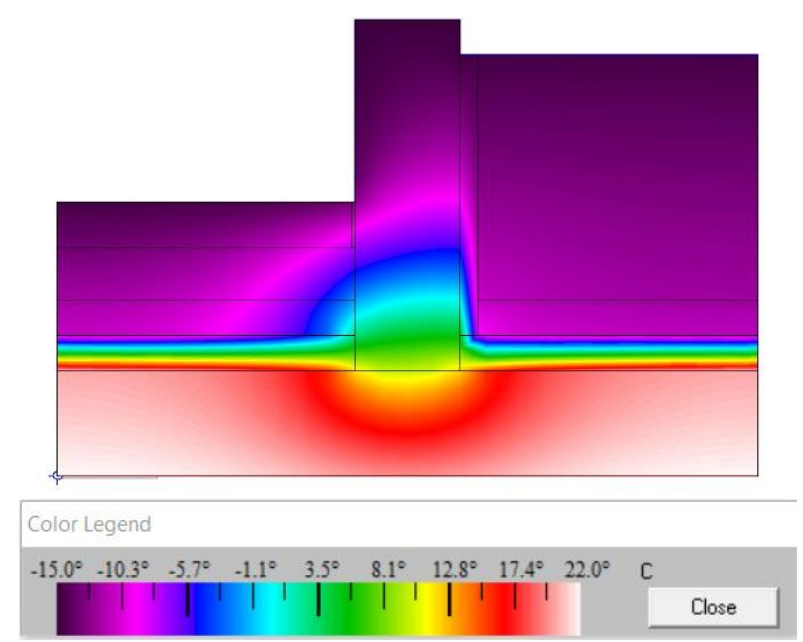

Figure 8.21 - Condition 1.1 - Standard, Winter; Infrared and Legend

Figure 8.22 and Figure 8.23 below are infrared representations of the temperature variation for the model cond_03-01 in summer and winter respectively, they depict how the majority of the temperature variation occurs at the continuous insulation layer at the top of the slab. 


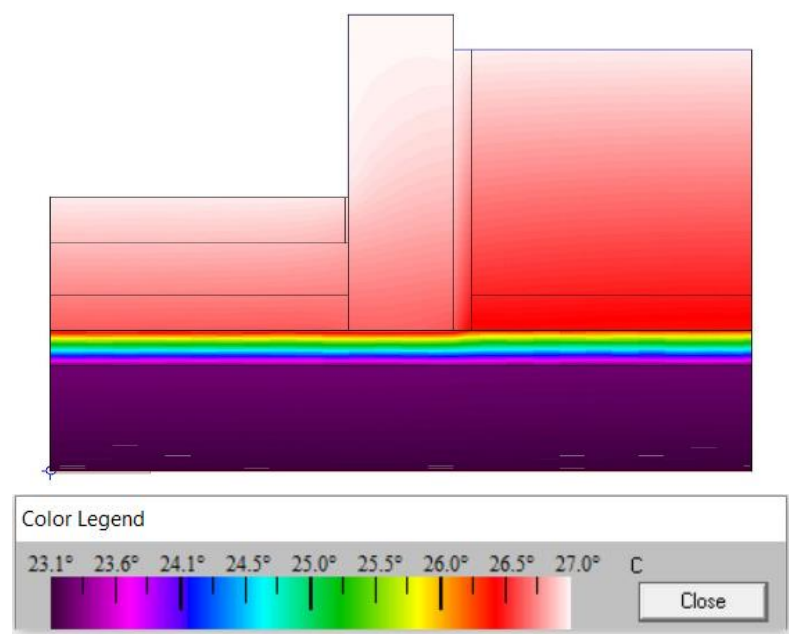

Figure 8.22 - Condition 3.1 - Ultimate, Summer; Infrared and Legend

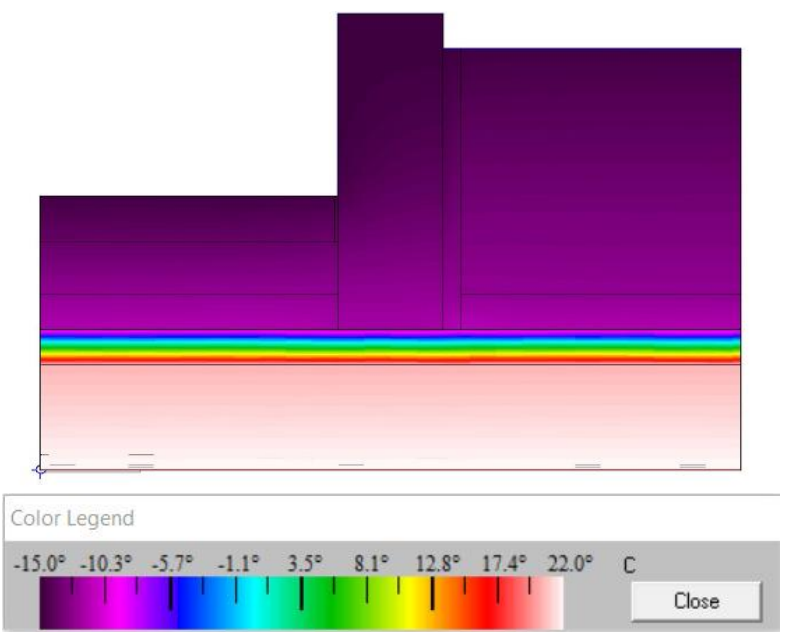

Figure 8.23 - Condition 3.1 - Ultimate, Winter; Infrared and Legend

The next section, Objective 2 will apply the results of Objective 1 to the example amenity space plan to assess a variety of thermal performance conditions.

\section{Objective 2: Thermal Analysis of Example Amenity Space}

When the results of the on-slab CIP wall thermal analysis are applied to the example amenity space plan (see Figure 5.1 above on p. 15 and Figure 9.1 below) it is possible to attain an estimation of the overall quantifiable effects of landscape design choices. For the purpose of the example plan thermal analysis the worst performing, best performing, and mid-range performing U-factor wall conditions will be assessed in that order, to provide a broad range of examples, while not requiring the need to assess and compare all of the simulated wall condition variations. Figure 9.1 below, indicates the example landscape plan showing the thermal zones for analysis to be used in Objective 2 (O2). These thermal zones are derived from the Objective $1(01)$ calculations and systems, they have been measured on the amenity space plan and are listed as such; paving field $\left(222.3 \mathrm{~m}^{2}\right)$, wall at paving $\left(79.6 \mathrm{~m}^{2}\right)$, wall at planter $\left(55.6 \mathrm{~m}^{2}\right)$, and planter field $\left(29.4 \mathrm{~m}^{2}\right)$. 


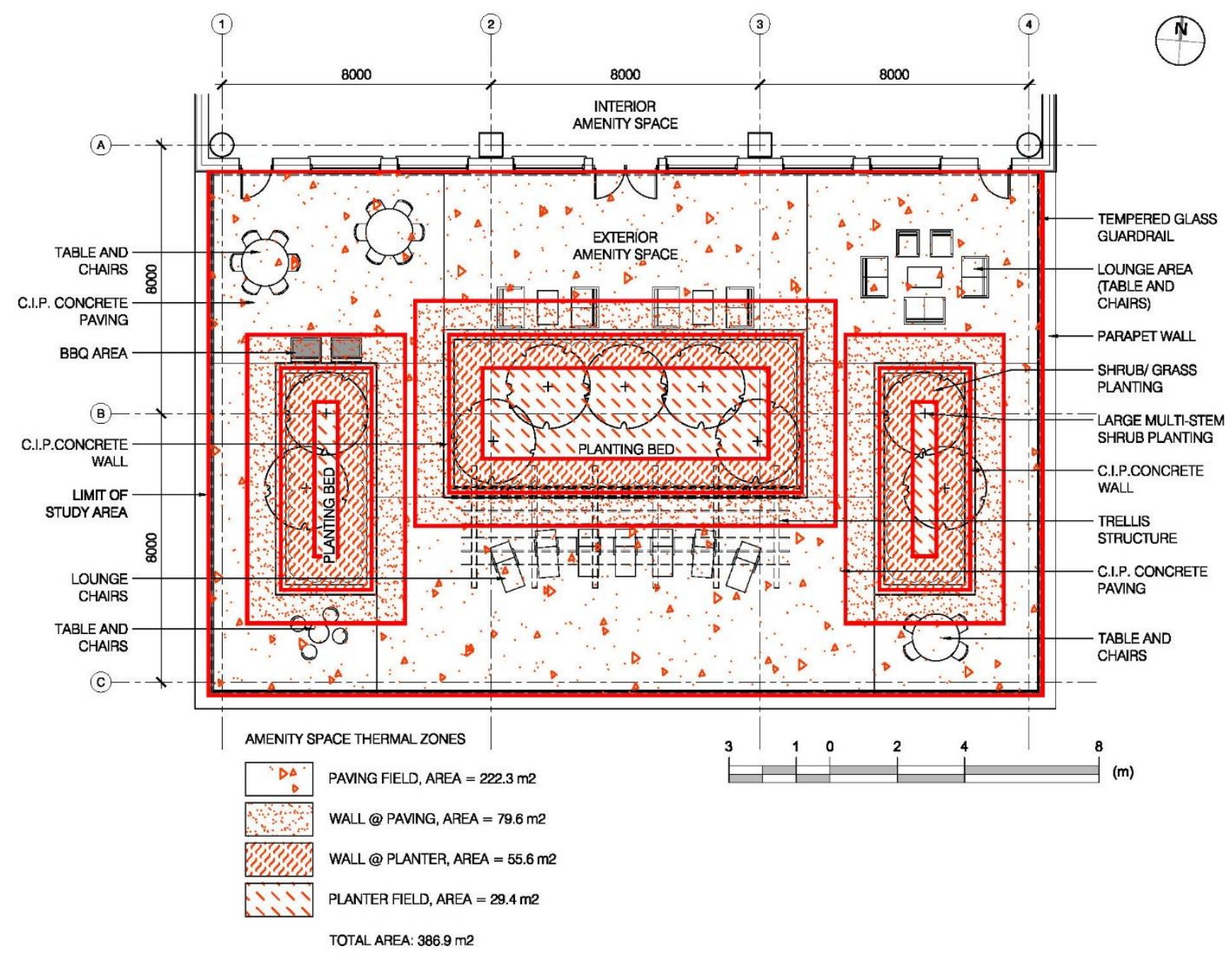

Figure 9.1 - Example Landscape Plan with Thermal Zones for Analysis

\subsection{Example Amenity Space Variables and Equations}

In order for the results in this section to be duplicated or applied to a different amenity space plan by an external reader, the variables and equations implemented to attain the Objective 2 results are summarized below.

Example Amenity Space Calculation Variables;

$$
\begin{aligned}
& A=\text { Area } \\
& U=U \text {-factor value (simulated in Objective } 1 \text { ) } \\
& q=\text { Heat Flux } \\
& Q=\text { Heat Flow } \\
& \%=\text { Heat Flow Percentage }
\end{aligned}
$$


Example Amenity Space Calculation;

The heat flow values for the example amenity space will be calculated using the equations below:

$$
\begin{array}{ll}
\text { Heat Flux } \rightarrow \mathrm{q}=\mathrm{U} \cdot 1 \cdot\left(\mathrm{T}_{\mathrm{i}}-\mathrm{T}_{\mathrm{o}}\right) & {\left[\mathrm{W} / \mathrm{m}^{2}\right]} \\
\text { Heat Flow } \rightarrow \mathrm{Q}=\mathrm{A} / \mathrm{q} & {[\mathrm{W}]} \\
\text { Percentage }->\%=\left(\mathrm{Q}_{\mathrm{x}} / \mathrm{Q}_{\text {total }}\right) \cdot 100 & {[\%]}
\end{array}
$$

The variables and equations defined in this section are then input into a spreadsheet program to simulate the thermal performance of the example amenity space using values from Objective 1 . The results of these calculations are shown in Section 9.2 below.

\subsection{Objective 2 Results}

The total heat flow for the 02 cond_01-09 amenity space (worst performing) is $510.60 \mathrm{~W}$ for summer and $4926.71 \mathrm{~W}$ for winter (see Table 9-1 below). The negative value shown for the summer conditions in these calculations is due to the formulation of the heat flux equation and indicates that the heat flow direction is from exterior to interior (see p. 64, Appendix D for additional graphical examples). The total heat flow for $\mathrm{O} 2$ cond_02-04 (tied with cond_03-04 as noted previously) amenity space is $200.98 \mathrm{~W}$ for summer and 1925.15 W for winter (see Table 9-2 below). These results indicate that there is an improvement of approximately 60.5\% between the worst (cond_01-09) and best (cond_02-04 and

\begin{tabular}{|c|c|c|c|c|c|}
\hline \multicolumn{6}{|c|}{ Example Amenity Space Thermal Calculations - cond_01-09_s } \\
\hline Zone & Area & U-factor, total & Heat Flux $[q]$ & Heat Flow Total [Q] & Heat Flow \% \\
\hline \multicolumn{6}{|c|}{$\left[\mathrm{W} / \mathrm{m}^{2} \cdot \mathrm{K}\right]$} \\
\hline Paving field & 222.3 & 0.2412 & -0.9648 & -214.4750 & $42.00 \%$ \\
\hline Wall @ paving & 79.6 & 0.5014 & -2.0056 & -159.6458 & $31.27 \%$ \\
\hline Wall @ planter & 55.6 & 0.4859 & -1.9436 & -108.0642 & $21.16 \%$ \\
\hline Planter field & 29.4 & 0.2416 & -0.9664 & -28.4122 & $5.56 \%$ \\
\hline & & & \multicolumn{2}{|r|}{-510.60} & $100 \%$ \\
\hline \multicolumn{6}{|c|}{ Example Amenity Space Thermal Calculations - cond_01-09_w } \\
\hline Zone & Area & U-factor, total & Heat Flux $[q]$ & Heat Flow Total [Q] & Heat Flow \% \\
\hline Units & {$\left[\mathrm{m}^{2}\right]$} & {$\left[\mathrm{W} / \mathrm{m}^{2} \cdot \mathrm{K}\right]$} & {$\left[\mathrm{W} / \mathrm{m}^{2}\right]$} & \multicolumn{2}{|c|}{$[\mathrm{W}]$} \\
\hline Paving field & 222.3 & 0.2420 & 9.1960 & 2044.2708 & $41.49 \%$ \\
\hline Wall @ paving & 79.6 & 0.5107 & 19.4066 & 1544.7654 & $31.35 \%$ \\
\hline Wall@ planter & 55.6 & 0.5049 & 19.1862 & 1066.7527 & $21.65 \%$ \\
\hline \multirow[t]{2}{*}{ Planter field } & 29.4 & 0.2425 & 9.2150 & 270.9210 & $5.50 \%$ \\
\hline & & & \multicolumn{2}{|r|}{4926.71} & $100 \%$ \\
\hline
\end{tabular}
cond_03-04) performing conditions.

Table 9-1 - Example Amenity Space; cond_01-09 
Table 9-2 - Example Amenity Space; cond_02-04

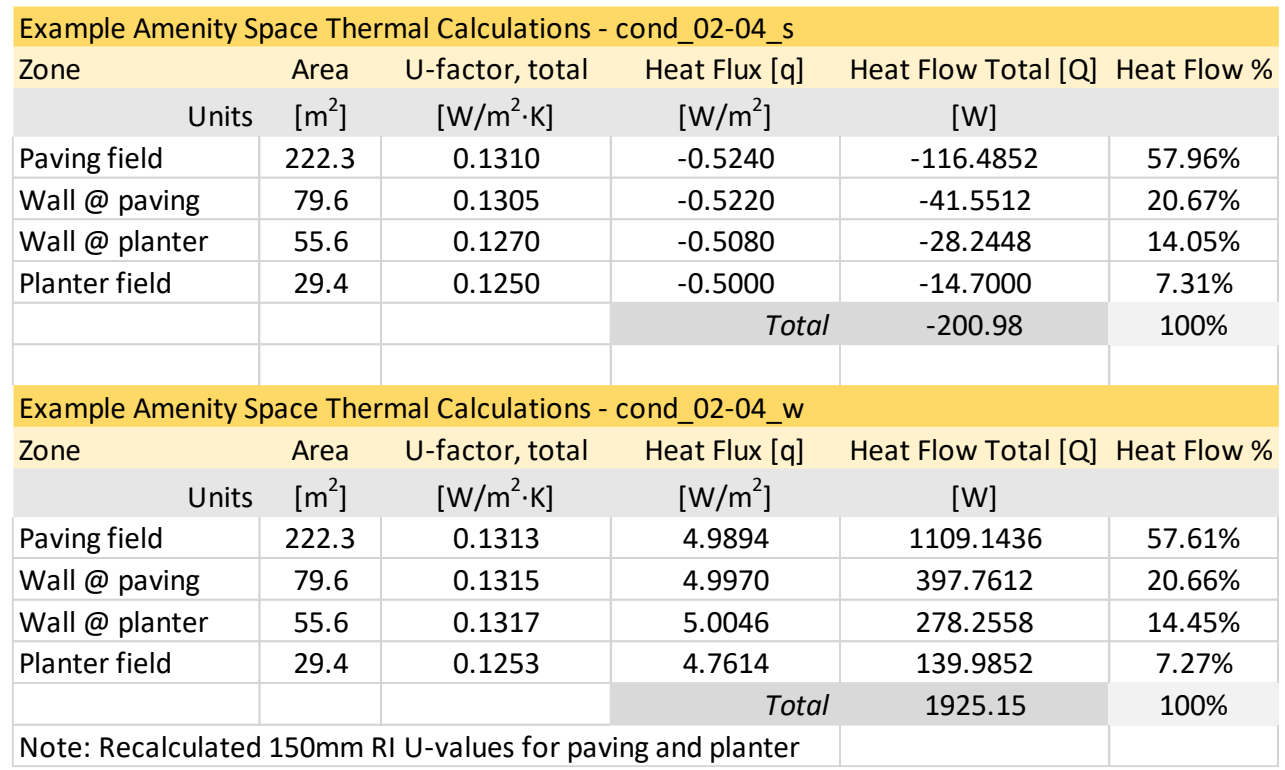

The total heat flow for $\mathrm{O} 2$ cond_03-01 amenity space (mid-range performing) is $341.43 \mathrm{~W}$ for summer and $3277.98 \mathrm{~W}$ for winter (see Table 9-3 below). These values place 02 cond_03-01_s results almost directly mid-range between cond_01-09_s and cond_02-04_s (cond_03-04_s) in regards to thermal performance. The winter results of $\mathrm{O} 2$ cond_03-01_w results are again almost directly mid-range between cond_01-09_w and cond_02-04_w (cond_03-04_w) in regards to thermal performance values.

Table 9-3 - Example Amenity Space; cond_03-01

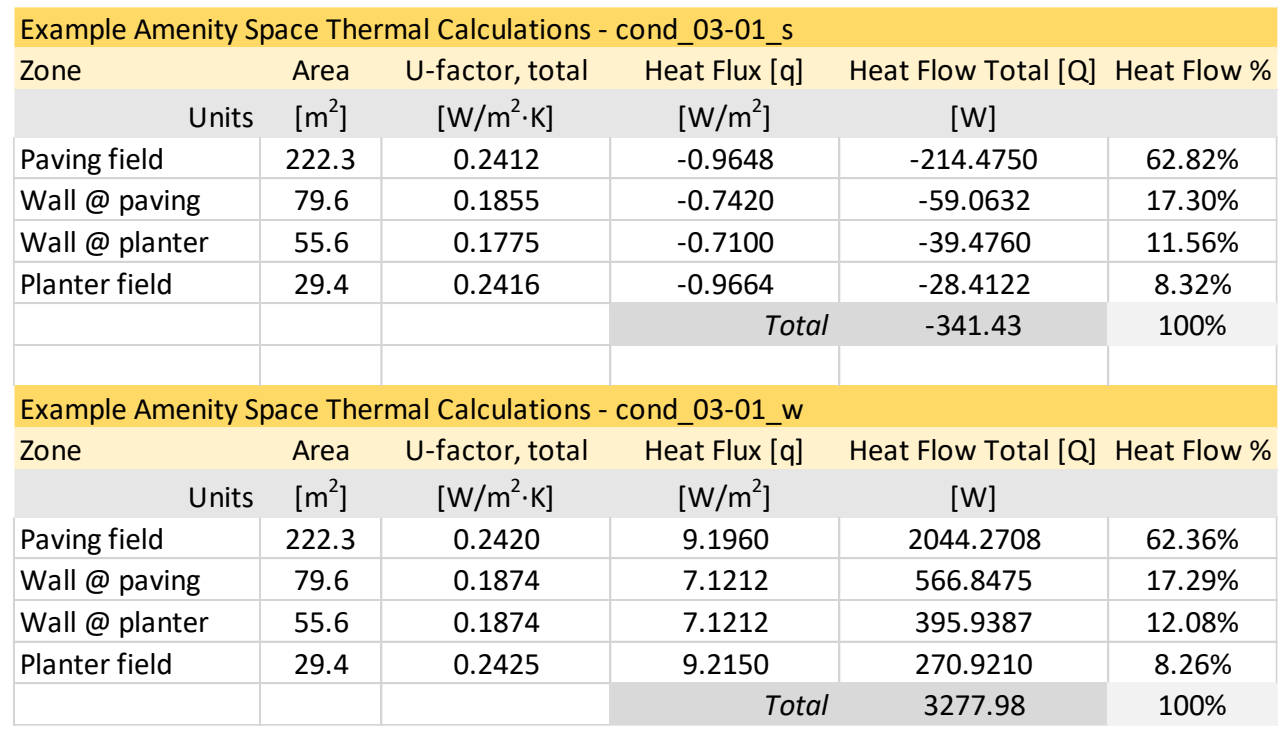


There is relatively little surprise in the results of the 02 example plan thermal performance calculations. The results are in line with what was seen in the condition model variations in 01 (see Section 8 above, p. 36). However, if the example amenity space layout was modified or redesigned, more planter walls were added and an insulation penetrating wall detail such as cond_01-09 was utilized, there would be increasingly worse heat transfer resistance shown in the $\mathrm{O} 2$ results. This again highlights the importance of selecting a cond_03-XX (or cond_02-XX) model variation for the landscape walls during the design phase, which provides more flexibility in increasing the linear length of planters in a given amenity space without drastically affecting thermal performance. In the section below, additional temperature variations will be explored for Objective 2 .

\subsection{Objective 2 -Additional Temperature Variations}

As outlined in Section 6.1 above (p. 16), additional temperature variations will be tested on the example amenity space in this section to simply assess the effects of solar radiation in the summer, night time cooling, or more extreme weather conditions in the winter. These additional static weather conditions will be applied to the best performing 01 condition variation model (cond_02-04, tied with cond_03-04) to further quantify thermal performance.

The additional temperature variations are outlined below;

- Summer;

O Interior condition; $\mathrm{T}_{\mathrm{si}}=23^{\circ} \mathrm{C}$

- Exterior condition; $\mathrm{T}_{\mathrm{so}}=45^{\circ} \mathrm{C}$

- Winter;

O Interior condition; $\mathrm{T}_{\mathrm{wi}}=23^{\circ} \mathrm{C}$

- Exterior condition; $\mathrm{T}_{\text {wo }}=-25^{\circ} \mathrm{C}$

\subsubsection{Objective 2 - Additional Temperature Variation Results}

The total heat flow for the more extreme version of 02 cond_02-04 (cond_03-04) amenity space is 1105.40 W for summer and 2431.76 W for winter (see Table 9-4 below) compared to the previous results of $200.98 \mathrm{~W}$ for summer and $1925.15 \mathrm{~W}$ for winter (see Section 9.2, Table 9-2 above, p. 51). The 
heat flow rate for this additional temperature variation is increased for the summer condition by $82.0 \%$ and is also increased for the winter condition by $20.8 \%$.

Table 9-4 - Example Amenity Space; cond_02-04 with Additional Temperature Variations

\begin{tabular}{|c|c|c|c|c|c|}
\hline \multicolumn{6}{|c|}{ Example Amenity Space Thermal Calculations - cond_02-04_s } \\
\hline \multirow[t]{2}{*}{ Zone } & Area & U-factor, total & Heat Flux $[q]$ & Heat Flow Total [Q] & Heat Flow \% \\
\hline & {$\left[\mathrm{m}^{2}\right]$} & {$\left[\mathrm{W} / \mathrm{m}^{2} \cdot \mathrm{K}\right]$} & {$\left[\mathrm{W} / \mathrm{m}^{2}\right]$} & {$[\mathrm{W}]$} & \\
\hline Paving field & 222.3 & 0.1310 & -2.8820 & -640.6686 & $57.96 \%$ \\
\hline Wall @ paving & 79.6 & 0.1305 & -2.8710 & -228.5316 & $20.67 \%$ \\
\hline Wall @ planter & 55.6 & 0.1270 & -2.7940 & -155.3464 & $14.05 \%$ \\
\hline \multirow[t]{2}{*}{ Planter field } & 29.4 & 0.1250 & -2.7500 & -80.8500 & $7.31 \%$ \\
\hline & & & \multicolumn{2}{|r|}{-1105.40} & $100 \%$ \\
\hline \multicolumn{6}{|c|}{ Example Amenity Space Thermal Calculations - cond_02-04_w } \\
\hline \multirow[t]{2}{*}{ Zone } & Area & U-factor, total & Heat Flux $[q]$ & Heat Flow Total [Q] & Heat Flow \% \\
\hline & {$\left[\mathrm{m}^{2}\right]$} & {$\left[\mathrm{W} / \mathrm{m}^{2} \cdot \mathrm{K}\right]$} & {$\left[\mathrm{W} / \mathrm{m}^{2}\right]$} & {$[\mathrm{W}]$} & \\
\hline Paving field & 222.3 & 0.1313 & 6.3024 & 1401.0235 & $57.61 \%$ \\
\hline Wall @ paving & 79.6 & 0.1315 & 6.3120 & 502.4352 & $20.66 \%$ \\
\hline Wall @ planter & 55.6 & 0.1317 & 6.3216 & 351.4810 & $14.45 \%$ \\
\hline \multirow[t]{2}{*}{ Planter field } & 29.4 & 0.1253 & 6.0144 & 176.8234 & $7.27 \%$ \\
\hline & & & Total & 2431.76 & $100 \%$ \\
\hline \multicolumn{4}{|c|}{ Note: Recalculated $150 \mathrm{~mm} \mathrm{RI} \mathrm{U-values} \mathrm{for} \mathrm{paving} \mathrm{and} \mathrm{planter}$} & & \\
\hline
\end{tabular}

These additional results are quite different from the initial cond_02-04 02 results above, they certainly indicate the effects of temperature variations and suggest the potential limitations of a static simulation. The results of the additional temperature variations included in this section indicate the importance of dynamic simulation to further improve the accuracy of thermal simulations and to help locate anomalies or spikes in the thermal performance data. However, this additional $\mathrm{O} 2$ result does not negate the simulated data that has been quantified in this paper, as the data is still relevant for comparative analysis and empirical examination within the outlined framework described in this study. Object 3 (03) below will provide recommendations on how to utilize landscape wall design details to improve thermal performance.

\section{Objective 3: Recommendations, Details that 'Work', and Future Work}

The results of Objective 1 and 2 are to form the basis of the wall design proposals to be outlined in this section, Objective 3 . This section is where landscape design details that should be implemented will be proposed, and comments and recommendations (compiled advantages and disadvantages) for each 
type assessed. It is also where details that perform thermally with the least heat flux will be shown, postulation of alternative details and recommendations, and additional materials will be discussed.

\subsection{Recommendations and Details that 'Work'}

In this section it is important to build on some of the simulated results of this study and to recommend detail(s) that 'work' both thermally and functionally. One of the motives behind the creation of this report was to raise awareness of provisions towards building thermal issues in landscape design. Other than the thermal considerations outlined in this report, amenity space landscape architects and landscape designers have to also be aware of program, function, economics, moisture/drainage problems, vegetation selection, sunlight exposure, and of course, aesthetics. Based on the thermal and technical research in this study, it is not recommended to utilize detail Condition 1.0 in landscape wall amenity space design. However in certain instances, a structural engineer or architect may not be willing to explore alternative wall designs based on site requirements, or due to a variety of other potential factors. If this is the case, it is up to the landscape designer, structural engineer, and architect to use all available knowledge to create a solution that satisfies all parties involved.

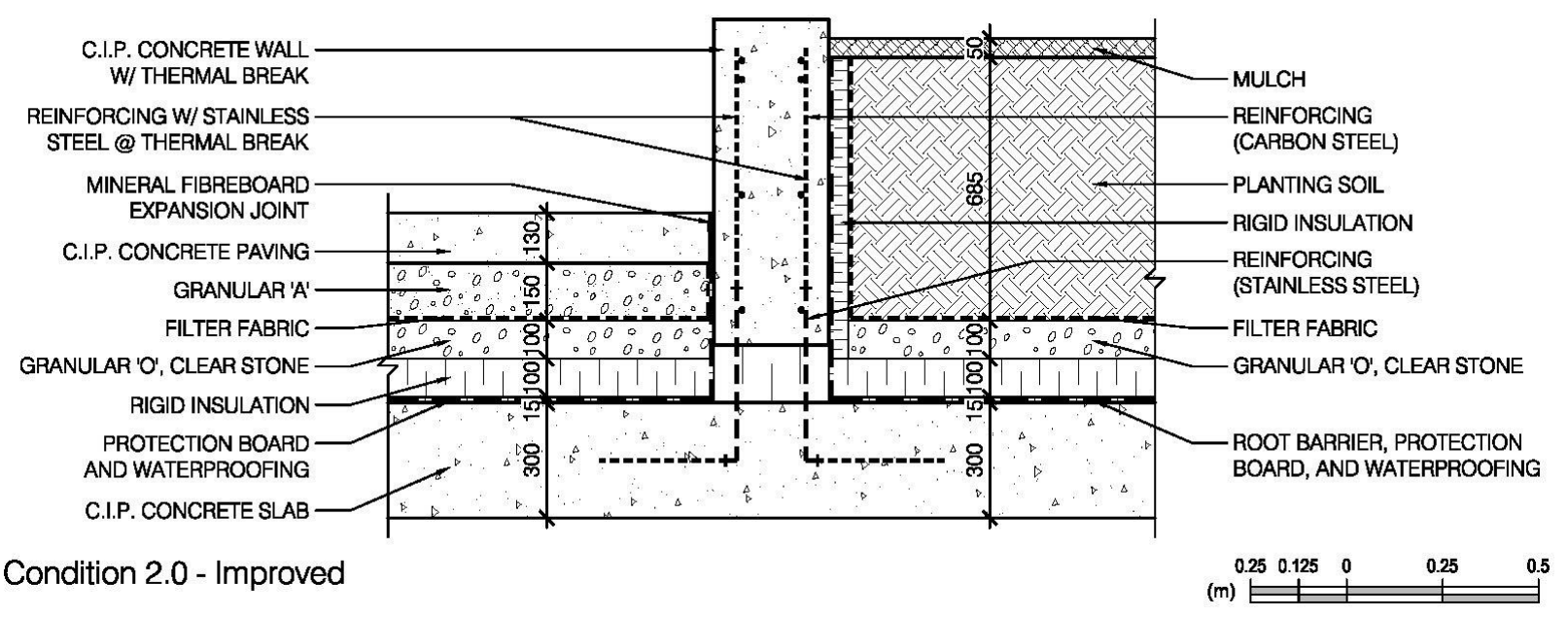

Figure 10.1 - Detail Drawing of Condition 2.0

To the author's knowledge, the proposed detail for Condition 2.0 (see Figure 10.1 above), or an iteration thereof, has yet to be installed in a constructed landscape project. Therefore, the validity of this condition as a working solution to landscape wall design is untested. However, in Lawton \& Roppel (2014) they outline the use of the Schöck Isokorb ${ }^{\circledR}$ product in CIP concrete parapet design (see Appendix 
G, p. 85), the design of which is relatively similar in both function and approach to the landscape wall design in this proposal. It is believed that the parapet application similar to Condition 2.0, with the exclusion of some specific landscape design functions still to be resolved (see Table 10-1 below), helps to validate the constructability and use of Condition 2.0 in a real-world application.

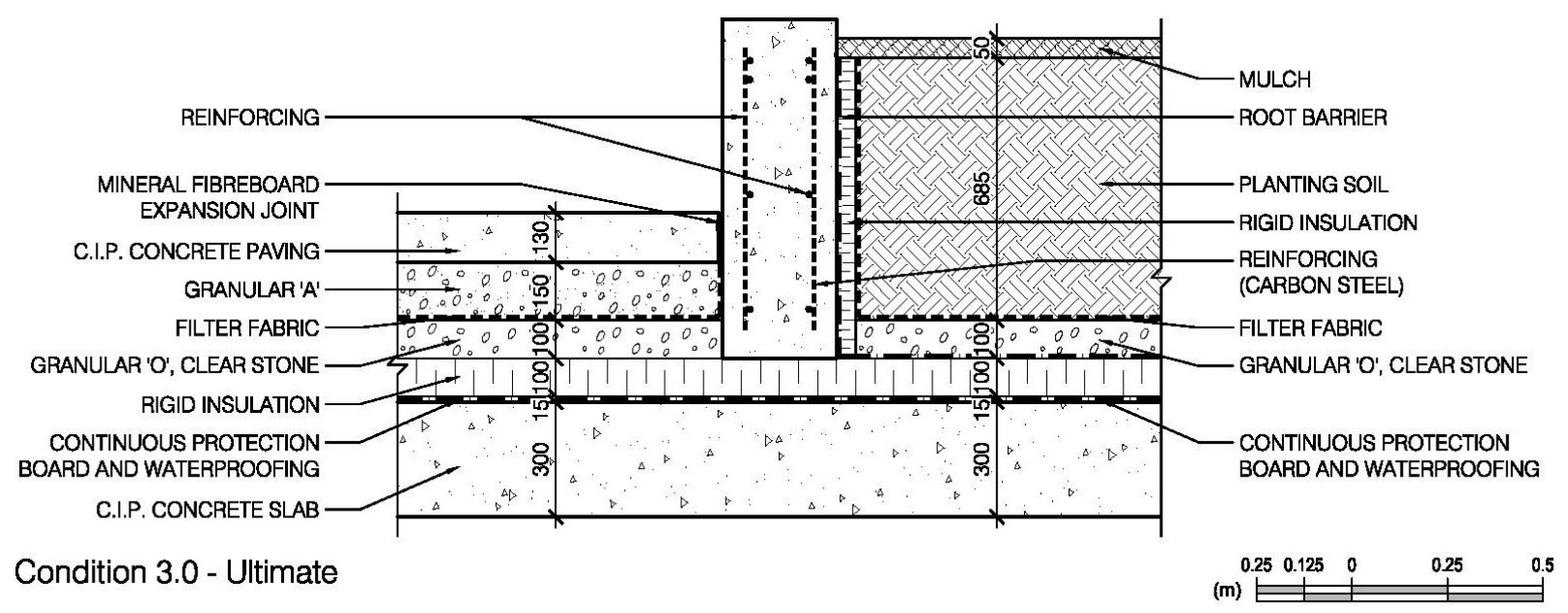

Figure 10.2 - Detail Drawing of Condition 3.0

Condition 3.0 is the 'ultimate' landscape wall detail to be recommended for use considering thermal performance, longevity, and continuity of insulation, waterproofing, and protection board layers (see Table 10-2 below). Essentially, Condition 3.0 keeps high conductivity elements separated by low conductivity elements and maintains the integrity of the waterproofing layer, thus as a simplified hypothesis, it meets the requirements of a thermally/functionally performing landscape amenity space wall. Though Condition 2.0 and 3.0 were some of the best performing thermally, there are a few other design aspects to be considered or resolved when selecting a specific wall detail. For example, in both Condition 2.0 and Condition 3.0 the granular ' $\mathrm{O}$ ' clear stone drainage layer could be replaced or accentuated with a drainage mat, or drainage plate, placed above the rigid insulation or at the slab level above the waterproofing (Sutton, 2015). Utilizing a drainage mat in lieu of a granular layer would also help to reduce the structural capacity requirements for the CIP concrete slab, thereby possibly reducing the overall cost of the roof design. A compiled list of comments and recommendations for each proposed wall detail are described in Table 10-1 and Table 10-2 below. 
Table 10-1 - Condition 2.0 Design Detail Summary; Comments and Recommendations

\begin{tabular}{|c|c|}
\hline \multicolumn{2}{|c|}{ Design Details Condition 2.0 - Summary } \\
\hline Item & Comments/Recommendations \\
\hline Thermal performance & Overall increased thermal performance but doweled reinforcing will cause reductions \\
\hline Waterproofing & $\begin{array}{l}\text { Minimal waterproofing penetrations, additional waterproofing layer can be extended } \\
\text { up wall, waterproofing layer is not fully continuous }\end{array}$ \\
\hline Insulation & $\begin{array}{l}\text { Insulation under the wall can be thickened to balance thermal losses from reinforcing, } \\
\text { doweled reinforcing creates thermal bridging }\end{array}$ \\
\hline Drainage & Slab drainage should be sloped away from walls \\
\hline Constructability & $\begin{array}{l}\text { Due to doweled connections and reinforcing layer at the base of the wall, } \\
\text { constructability will be more difficult }\end{array}$ \\
\hline Cost & Non-standard wall construction will have increased cost implications \\
\hline Structural capacity & $\begin{array}{l}\text { Doweled reinforcing will allow for increased wall heights, insulation structural } \\
\text { capacity will require engineering input }\end{array}$ \\
\hline Flexibility & Wall condition is suitable for most designs and plan layouts \\
\hline
\end{tabular}

Cond. 2.0;

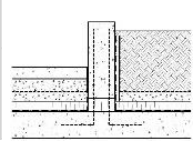

Table 10-2 - Condition 3.0 Design Detail Summary; Comments and Recommendations

\begin{tabular}{|c|c|}
\hline \multicolumn{2}{|c|}{ Design Details Condition 3.0 - Summary } \\
\hline Item & Comments/Recommendations \\
\hline Thermal performance & Overall increased thermal performance \\
\hline Waterproofing & $\begin{array}{l}\text { No waterproofing penetrations, waterproofing and protection board layers are } \\
\text { continuous }\end{array}$ \\
\hline Insulation & Insulation layer is continuous \\
\hline Drainage & $\begin{array}{l}\text { Slab drainage should be sloped away from walls, drainage layer could be extended } \\
\text { under the wall }\end{array}$ \\
\hline Constructability & $\begin{array}{l}\text { Construction is simplified due to separated elements, allows for easier scheduling to } \\
\text { coordinate with trades }\end{array}$ \\
\hline Cost & $\begin{array}{l}\text { Cost implications would be minimal, potential for remobilization upcharge from } \\
\text { trades }\end{array}$ \\
\hline Structural capacity & $\begin{array}{l}\text { Structural capacity is reduced, walls must be multiple sided in plan to provide lateral } \\
\text { support (ex. } 3 \text { to } 4 \text { sides or square/rectangular shaped) }\end{array}$ \\
\hline Flexibility & $\begin{array}{l}\text { Wall condition is suitable for most designs and plan layouts if lateral support is } \\
\text { provided }\end{array}$ \\
\hline
\end{tabular}

Cond. 3.0;

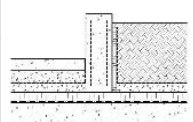

Note, these comments and recommendations are to be considered as a guideline in landscape amenity space wall design only. Landscape wall details, when designed to be constructed in a MURB or apartment building generally require consultation with the client, landscape architect or landscape designer, coordination with other disciplines (architecture, structural, electrical, and mechanical typically), and specific product selection (ex. rigid insulation, filter fabric, root barrier, drainage mat, 
lighting, etc.). These provisions are relatively standard requirements in any design project and interdisciplinary coordination should always be thought of as critical to their success. Also to reiterate, as it was already mentioned in Section 6 (p. 16), for Condition 3.0 the layout of the wall in plan would require a shape with at least 3 to 4 sides to create lateral support as there is no doweled connection to the slab. Another way that landscape designers accomplish a design result similar to Condition 3.0 is to specify precast concrete planters, often in square, rectangular, or round shapes either with a bottom or no bottom. These precast concrete planters could be placed on top of the paving layer, granular layer or drainage mat, or on top of the rigid insulation layer. Depending on the size of the precast planters they can produced as one-piece units or multi-piece units that are assembled on-site to provide larger sizes and variation. Essentially, precast concrete planter walls could perform most of the same functions as Condition 3.0 but their main limitation is often size (ex. planting area and soil depth or planting soil volume) and flexural strength (particularly in multi-piece units). Either selection, Condition 3.0 or precast walls, is a valid choice for landscape design that could perform thermally and functionally. However each has specific aspects to be deliberated by the designer, some of which have been covered in this report in order to assess as many options as are relevant to this study. The next section will outline ideas for potential studies to expand and/or continue what was produced in this report.

\subsection{Future Work}

Though this study does not focus on wall materials other than CIP concrete, it should be noted that incorporating other structural wall materials as well as cladded walls into the simulation conditions would be a value added interpretation of varied landscape amenity space conditions. As with most design professionals, landscape architects and landscape designers enjoy a diverse selection of materials to work with to enhance their design and realise their intended aesthetic. However, because of the relative simplicity to build, commonality of material to structure, modern aesthetic, and overall longevity of CIP concrete, it is a valid material of focus for this study. Further to this, and based on the results of $\mathrm{O} 2$ and $\mathrm{O} 3$, it would be a useful exercise to study the impact of reinforcing in all of the $\mathrm{O} 2$ wall conditions as additional variations. The simulation results as defined in this research have shown relatively little deviation between the thermal performance of the $\mathrm{O} 2$ and $\mathrm{O} 3$ condition variations due to the rigid insulation layer(s). By including reinforcing as in cond_XX-02 in new condition variations, an idea of the effects of reinforcing on thermal performance in Condition 2 could be more accurately 
assessed. Based on this analysis and the simulation results, it is also realized that simulating reinforcing would be useful exercise for Condition 1 variations as well.

Other wall materials could be included in further thermal analysis such as various types of natural stone (ex. granite, limestone, marble, etc.) or wood (ex. cedar, pine, ipe, wood composite, etc.). Additional wall thicknesses and wall heights could be studied, they are common factors to vary depending on aesthetics, function of the wall, or structural requirements (ex. aesthetic height of wall or soil depth for planting required). Temperature variations affect thermal conditions, it would be proposed to study other seasons and/or averaged weather patterns (ex. 12 per year with average temperature per month), or possibly dynamic weather simulated based on yearly measured data. Though Objective 2 simulates what amounts to a 'representative 3D' condition by applying the $2 \mathrm{D}$ wall details to what would amount to an extruded 3D model, it would be an interesting study to actually simulate the thermal conditions in a 3D software program. Additional research completed on this topic should include moisture and condensation analysis, as it is important to the function of a building and to the overall health of the occupants. Internal and external temperature variations have the potential to create moisture and condensation problems at certain points within a building envelope, particularly at thermal bridges (Straube, 2012). To confirm or validate the results in the study it would be useful to test some, or all of the models and variations, in another simulation software such as HEAT2 (for 2D simulation comparison) or HEAT3 (for 3D simulation).

\section{Conclusion}

The results of the three objectives $(01,02$, and 03$)$ in this report have shown that landscape wall details can prove effective in improving thermal performance of amenity space areas with intensive green roofs. O1 modeled thirty (30) condition variations with two (2) weather variations for each condition providing simulated U-factor values which were quantified in table format (see Section 8 above, p. 36 and Appendix C - Condition Simulation Model Results, p. 62 below). The results of $\mathrm{O} 1$ indicated that thermal design of landscape walls could improve thermal performance by approximately $55 \%$ when comparing cond_01-XX to cond_02-XX and cond_03-XX, though the percentage gained would vary somewhat depending on the specific condition variation that was compared. $\mathrm{O} 2$ analysed a selected three (3) of the condition variations, with a range of U-factor performance values (worst, best, and midrange), and applied the numbers to the landscape amenity plan in Figure 9.1 (see Section 9 above, p. 
48). As described above, the results of $O 2$ indicated that there was an improvement of approximately 60.5\% between the worst (cond_01-09) and best (cond_02-04 and cond_03-04) performing conditions. In the section containing $\mathrm{O} 3$, based on the results from $\mathrm{O} 1$ and $\mathrm{O} 2$, two (2) wall variations were selected and proposed as recommended details to be utilized in landscape design which also perform thermally and functionally (see Section 10 above, p. 53). By quantifying the results of the condition variations, a tool has been created which provides a relatively simple method which can be adapted to model the thermal performance of a landscape amenity space roof design.

The above sections highlight how landscape designers and architectural designers need to be cognisant of thermal bridges within landscape areas over habitable space, particularly in exterior amenity space, and to learn how to avoid designs that proliferate thermal heat gain or heat loss. The results of this study also indicate that there is need for an overall change in landscape wall designs to be thermally broken whenever it is possible. In the increasingly interdisciplinary and interconnected field of building design, it should no longer be solely the purview of architects and architectural designers to be aware of thermal issues related to building envelopes. This is not to say that landscape designers must be architects or take responsibility for their work, but that they should gain enough knowledge to at least be able to critically assess building interface details and to posit informed questions when required.

Architectural designers and architects must also be aware of these issues and educate or inform others if there is a particular area of concern. More attention placed towards landscape wall design also helps to protect the overall integrity of the insulation layer and waterproofing membrane. Increased thermal performance of building envelopes is an ongoing and ever improving field of study, it is hopeful that this report will add some valuable information, and provide a useful voice highlighting the significance of thermal design in a field where is it often overlooked. 


\section{Appendices}

\section{Appendix A - Simulation Conditions}

\section{Table 0-1 - Simulation Models and Condition Descriptions}

\begin{tabular}{|c|c|c|}
\hline \multicolumn{3}{|c|}{ Simulation Model Name and Description } \\
\hline Model Name & Description & Weather Variation \\
\hline cond_01-01 & Standard & Summer and Winter \\
\hline cond_01-02 & Standard@ Reinforcing & Summer and Winter \\
\hline cond_01-03 & Standard w/ 125mm Slab Insulation & Summer and Winter \\
\hline cond_01-04 & Standard w/ 150mm Slab Insulation & Summer and Winter \\
\hline cond_01-05 & Standard w/ 25mm Wall Insulation & Summer and Winter \\
\hline cond_01-06 & Standard w/ No Wall Insulation & Summer and Winter \\
\hline cond_01-07 & Standard w/ 200mm Wide Wall & Summer and Winter \\
\hline cond_01-08 & Standard w/ 250mm Wide Wall & Summer and Winter \\
\hline cond_01-09 & Standard w/ 400mm Wide Wall & Summer and Winter \\
\hline cond_01-10 & Standard w/ Precast Conc. Paving & Summer and Winter \\
\hline cond_02-01 & Improved & Summer and Winter \\
\hline cond_02-02 & Improved@ Reinforcing & Summer and Winter \\
\hline cond_02-03 & Improved w/ 125mm Slab Insulation & Summer and Winter \\
\hline cond_02-04 & Improved w/ 150mm Slab Insulation & Summer and Winter \\
\hline cond_02-05 & Improved w/ 25mm Wall Insulation & Summer and Winter \\
\hline cond_02-06 & Improved w/ No Wall Insulation & Summer and Winter \\
\hline cond_02-07 & Improved w/ 200mm Wide Wall & Summer and Winter \\
\hline cond_02-08 & Improved w/ 250mm Wide Wall & Summer and Winter \\
\hline cond_02-09 & Improved w/ 400mm Wide Wall & Summer and Winter \\
\hline cond_02-10 & Improved w/ Precast Conc. Paving & Summer and Winter \\
\hline cond_03-01 & Ultimate & Summer and Winter \\
\hline cond_03-02 & Ultimate @ Reinforcing & Summer and Winter \\
\hline cond_03-03 & Ultimate w/ 125mm Slab Insulation & Summer and Winter \\
\hline cond_03-04 & Ultimate w/ 150mm Slab Insulation & Summer and Winter \\
\hline cond_03-05 & Ultimate w/ 25mm Wall Insulation & Summer and Winter \\
\hline cond_03-06 & Ultimate w/ No Wall Insulation & Summer and Winter \\
\hline cond_03-07 & Ultimate $\mathrm{w} / 200 \mathrm{~mm}$ Wide Wall & Summer and Winter \\
\hline cond_03-08 & Ultimate $\mathrm{w} / 250 \mathrm{~mm}$ Wide Wall & Summer and Winter \\
\hline cond_03-09 & Ultimate w/ 400mm Wide Wall & Summer and Winter \\
\hline cond_03-10 & Ultimate w/ Precast Conc. Paving & Summer and Winter \\
\hline
\end{tabular}




\section{Appendix B - Materials Data and Sources}

\section{Table 0-2 - Materials and conductivity/conductance for manual calculations and THERM}

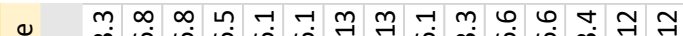

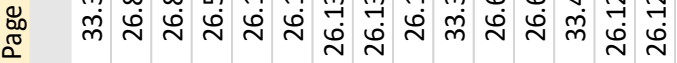

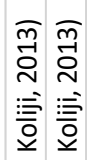

তิ

흉

言 狺

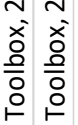

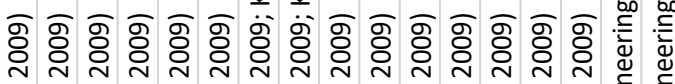

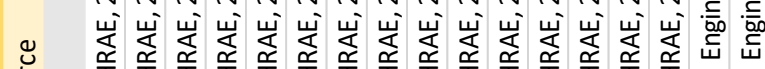

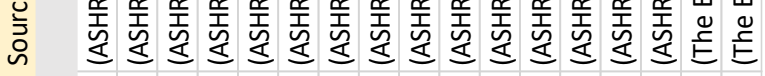

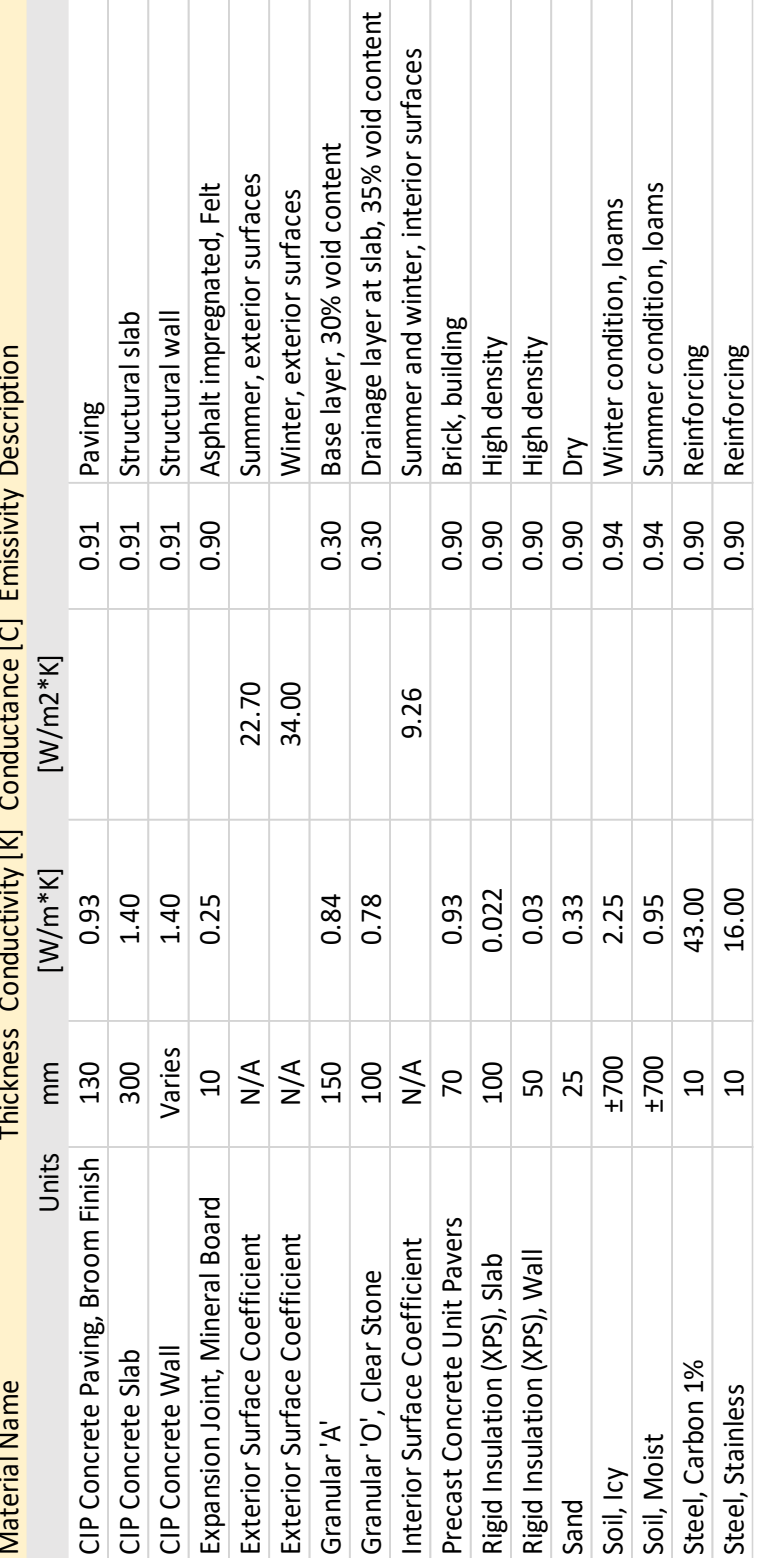




\section{Appendix C - Condition Simulation Model Results}

Table 0-3 - Simulation Model Results

\begin{tabular}{|c|c|c|c|c|c|c|c|}
\hline \multicolumn{8}{|c|}{ THERM Isotherms, U-factor, Winter and Summer } \\
\hline Model & $\begin{array}{l}\text { U-factor, } \\
\text { total }\end{array}$ & $\begin{array}{l}\text { Heat Flux } \\
{[q]}\end{array}$ & $\begin{array}{l}\text { U-factor, } \\
\text { paving }\end{array}$ & $\begin{array}{l}\text { U-factor, } \\
\text { soil }\end{array}$ & Projection & $\begin{array}{c}\text { \% Error } \\
\text { Energy Norm. }\end{array}$ & Description \\
\hline Units & {$\left[\mathrm{W} / \mathrm{m}^{2} \cdot \mathrm{K}\right]$} & {$\left[\mathrm{W} / \mathrm{m}^{2}\right]$} & {$\left[\mathrm{W} / \mathrm{m}^{2} \cdot \mathrm{K}\right]$} & {$\left[\mathrm{W} / \mathrm{m}^{2} \cdot \mathrm{K}\right]$} & & & \\
\hline cond_01-01_s & 0.4464 & -1.7856 & 0.4509 & 0.4419 & Total Length & $8.63 \%$ & Standard \\
\hline cond_01-01_w & 0.4596 & 17.4629 & 0.4593 & 0.4598 & Total Length & $8.87 \%$ & Standard \\
\hline cond_01-02_s & 0.7116 & -2.8462 & 0.7211 & 0.7020 & Total Length & $6.84 \%$ & Standard @ Reinforcing \\
\hline cond_01-02_w & 0.7310 & 27.7761 & 0.7360 & 0.7259 & Total Length & $6.83 \%$ & Standard@ Reinforcing \\
\hline cond_01-03_s & 0.4156 & -1.6622 & 0.4185 & 0.4126 & Total Length & $8.63 \%$ & Standard w/ 125mm Slab Insulation \\
\hline cond_01-03_w & 0.4262 & 16.1937 & 0.4258 & 0.4265 & Total Length & $8.84 \%$ & Standard w/ 125mm Slab Insulation \\
\hline cond_01-04_s & 0.3912 & -1.5648 & 0.3931 & 0.3893 & Total Length & $8.49 \%$ & Standard w/ 150mm Slab Insulation \\
\hline cond_01-04_w & 0.4000 & 15.2000 & 0.3995 & 0.4005 & Total Length & $8.66 \%$ & Standard w/ 150mm Slab Insulation \\
\hline cond_01-05_s & 0.4507 & -1.8026 & 0.4555 & 0.4458 & Total Length & $9.20 \%$ & Standard w/ 25mm Wall Insulation \\
\hline cond_01-05_w & 0.4666 & 17.7308 & 0.4665 & 0.4667 & Total Length & $9.68 \%$ & Standard w/ 25mm Wall Insulation \\
\hline cond_01-06_s & 0.4665 & -1.8660 & 0.4730 & 0.4600 & Total Length & $9.10 \%$ & Standard w/ No Wall Insulation \\
\hline cond_01-06_w & 0.5000 & 18.9981 & 0.5009 & 0.4990 & Total Length & $9.67 \%$ & Standard w/ No Wall Insulation \\
\hline cond_01-07_s & 0.3906 & -1.5622 & 0.3937 & 0.3874 & Total Length & $9.35 \%$ & Standard w/ 200mm Wide Wall \\
\hline cond_01-07_w & 0.4023 & 15.2874 & 0.4008 & 0.4038 & Total Length & $9.51 \%$ & Standard w/ 200mm Wide Wall \\
\hline cond_01-08_s & 0.4191 & -1.6764 & 0.4229 & 0.4153 & Total Length & $8.82 \%$ & Standard w/ 250mm Wide Wall \\
\hline cond_01-08_w & 0.4316 & 16.3989 & 0.4306 & 0.4325 & Total Length & $8.99 \%$ & Standard w/ 250mm Wide Wall \\
\hline cond_01-09_s & 0.4937 & -1.9746 & 0.5014 & 0.4859 & Total Length & $7.96 \%$ & Standard w/ 400mm Wide Wall \\
\hline cond_01-09_w & 0.5078 & 19.2964 & 0.5107 & 0.5049 & Total Length & $8.16 \%$ & Standard w/ 400mm Wide Wall \\
\hline cond_01-10_s & 0.4507 & -1.8026 & 0.4551 & 0.4462 & Total Length & $8.79 \%$ & Standard w/ Precast Conc. Paving \\
\hline cond_01-10_w & 0.4640 & 17.6301 & 0.4637 & 0.4642 & Total Length & $9.02 \%$ & Standard w/ Precast Conc. Paving \\
\hline cond_02-01_s & 0.1742 & -0.6966 & 0.1787 & 0.1696 & Total Length & $6.15 \%$ & Improved \\
\hline cond_02-01_w & 0.1801 & 6.8438 & 0.1806 & 0.1796 & Total Length & $6.06 \%$ & Improved \\
\hline cond_02-02_s & 0.4854 & -1.9414 & 0.4910 & 0.4797 & Total Length & $6.91 \%$ & Improved@ Reinforcing \\
\hline cond_02-02_w & 0.4970 & 18.8841 & 0.4983 & 0.4956 & Total Length & $7.36 \%$ & Improved@ Reinforcing \\
\hline cond_02-03_s & 0.1473 & -0.5892 & 0.1502 & 0.1444 & Total Length & $3.86 \%$ & Improved w/ 125mm Slab Insulation \\
\hline cond_02-03_w & 0.1513 & 5.7494 & 0.1515 & 0.1511 & Total Length & $3.87 \%$ & Improved w/ 125mm Slab Insulation \\
\hline cond_02-04_s & 0.1288 & -0.5150 & 0.1305 & 0.1270 & Total Length & $1.13 \%$ & Improved w/ 150mm Slab Insulation \\
\hline cond_02-04_w & 0.1316 & 5.0008 & 0.1315 & 0.1317 & Total Length & $1.00 \%$ & Improved w/ 150mm Slab Insulation \\
\hline cond_02-05_s & 0.1751 & -0.7002 & 0.1791 & 0.1710 & Total Length & $6.17 \%$ & Improved w/ 25mm Wall Insulation \\
\hline cond_02-05_w & 0.1808 & 6.8704 & 0.1810 & 0.1806 & Total Length & $6.11 \%$ & Improved w/ 25mm Wall Insulation \\
\hline cond_02-06_s & 0.1768 & -0.7070 & 0.1795 & 0.1740 & Total Length & $6.90 \%$ & Improved w/ No Wall Insulation \\
\hline cond_02-06_w & 0.1818 & 6.9084 & 0.1815 & 0.1821 & Total Length & $6.91 \%$ & Improved w/ No Wall Insulation \\
\hline cond_02-07_s & 0.1765 & -0.7060 & 0.1810 & 0.1720 & Total Length & $5.67 \%$ & Improved w/ 200mm Wide Wall \\
\hline cond_02-07_w & 0.1828 & 6.9445 & 0.1831 & 0.1824 & Total Length & $5.60 \%$ & Improved w/ 200mm Wide Wall \\
\hline cond_02-08_s & 0.1753 & -0.7010 & 0.1798 & 0.1707 & Total Length & $6.06 \%$ & Improved w/ 250mm Wide Wall \\
\hline cond_02-08_w & 0.1813 & 6.8894 & 0.1817 & 0.1809 & Total Length & $6.00 \%$ & Improved w/ 250mm Wide Wall \\
\hline cond_02-09_s & 0.1715 & -0.6860 & 0.1761 & 0.1669 & Total Length & $6.12 \%$ & Improved w/ 400mm Wide Wall \\
\hline cond_02-09_w & 0.1772 & 6.7317 & 0.1778 & 0.1765 & Total Length & $6.05 \%$ & Improved w/ 400mm Wide Wall \\
\hline cond_02-10_s & 0.1742 & -0.6968 & 0.1787 & 0.1697 & Total Length & $6.19 \%$ & Improved w/ Precast Conc. Paving \\
\hline cond_02-10_w & 0.1801 & 6.8438 & 0.1805 & 0.1797 & Total Length & $6.08 \%$ & Improved w/ Precast Conc. Paving \\
\hline
\end{tabular}




\section{Simulation Model Results (continued)}

\begin{tabular}{|c|c|c|c|c|c|c|c|}
\hline \multicolumn{8}{|c|}{ THERM Isotherms, U-factor, Winter and Summer } \\
\hline Model & $\begin{array}{l}\text { U-factor, } \\
\text { total }\end{array}$ & $\begin{array}{l}\text { Heat Flux } \\
{[q]}\end{array}$ & $\begin{array}{l}\text { U-factor, } \\
\text { paving }\end{array}$ & $\begin{array}{l}\text { U-factor, } \\
\text { soil }\end{array}$ & Projection & $\begin{array}{c}\text { \% Error } \\
\text { Energy Norm. }\end{array}$ & Description \\
\hline Units & {$\left[\mathrm{W} / \mathrm{m}^{2} \cdot \mathrm{K}\right]$} & {$\left[\mathrm{W} / \mathrm{m}^{2}\right]$} & {$\left[\mathrm{W} / \mathrm{m}^{2} \cdot \mathrm{K}\right]$} & {$\left[\mathrm{W} / \mathrm{m}^{2} \cdot \mathrm{K}\right]$} & & & \\
\hline cond_03-01_s & 0.1815 & -0.7260 & 0.1855 & 0.1775 & Total Length & $1.46 \%$ & Ultimate \\
\hline cond_03-01_w & 0.1874 & 7.1212 & 0.1874 & 0.1874 & Total Length & $1.21 \%$ & Ultimate \\
\hline cond_03-02_s & 0.1835 & -0.7338 & 0.1876 & 0.1793 & Total Length & $1.90 \%$ & Ultimate@ Reinforcing \\
\hline cond_03-02_w & 0.1891 & 7.1839 & 0.1893 & 0.1888 & Total Length & $1.58 \%$ & Ultimate @ Reinforcing \\
\hline cond_03-03_s & 0.1507 & -0.6026 & 0.1532 & 0.1481 & Total Length & $1.29 \%$ & Ultimate w/ $125 \mathrm{~mm}$ Slab Insulation \\
\hline cond_03-03_w & 0.1546 & 5.8729 & 0.1545 & 0.1546 & Total Length & $1.10 \%$ & Ultimate $\mathrm{w} / 125 \mathrm{~mm}$ Slab Insulation \\
\hline cond_03-04_s & 0.1288 & -0.5150 & 0.1305 & 0.1270 & Total Length & $1.18 \%$ & Ultimate $\mathrm{w} / 150 \mathrm{~mm}$ Slab Insulation \\
\hline cond_03-04_w & 0.1316 & 5.0008 & 0.1315 & 0.1317 & Total Length & $1.00 \%$ & Ultimate $\mathrm{w} / 150 \mathrm{~mm}$ Slab Insulation \\
\hline cond_03-05_s & 0.1819 & -0.7276 & 0.1855 & 0.1783 & Total Length & $1.53 \%$ & Ultimate $\mathrm{w} / 25 \mathrm{~mm}$ Wall Insulation \\
\hline cond_03-05_w & 0.1876 & 7.1288 & 0.1875 & 0.1877 & Total Length & $1.09 \%$ & Ultimate $\mathrm{w} / 25 \mathrm{~mm}$ Wall Insulation \\
\hline cond_03-06_s & 0.1827 & -0.7308 & 0.1854 & 0.1800 & Total Length & $1.22 \%$ & Ultimate w/ No Wall Insulation \\
\hline cond_03-06_w & 0.1879 & 7.1383 & 0.1876 & 0.1881 & Total Length & $1.10 \%$ & Ultimate w/ No Wall Insulation \\
\hline cond_03-07_s & 0.1813 & -0.7250 & 0.1853 & 0.1772 & Total Length & $1.29 \%$ & Ultimate $\mathrm{w} / 200 \mathrm{~mm}$ Wide Wall \\
\hline cond_03-07_w & 0.1874 & 7.1212 & 0.1874 & 0.1874 & Total Length & $1.05 \%$ & Ultimate $\mathrm{w} / 200 \mathrm{~mm}$ Wide Wall \\
\hline cond_03-08_s & 0.1813 & -0.7250 & 0.1853 & 0.1772 & Total Length & $2.00 \%$ & Ultimate w/ 250mm Wide Wall \\
\hline cond_03-08_w & 0.1873 & 7.1155 & 0.1873 & 0.1872 & Total Length & $1.99 \%$ & Ultimate $\mathrm{w} / 250 \mathrm{~mm}$ Wide Wall \\
\hline cond_03-09_s & 0.1816 & -0.7264 & 0.1855 & 0.1777 & Total Length & $2.02 \%$ & Ultimate w/ 400mm Wide Wall \\
\hline cond_03-09_w & 0.1872 & 7.1117 & 0.1872 & 0.1871 & Total Length & $2.03 \%$ & Ultimate w/ 400mm Wide Wall \\
\hline cond_03-10_s & 0.1816 & -0.7264 & 0.1855 & 0.1777 & Total Length & $1.52 \%$ & Ultimate w/ Precast Conc. Paving \\
\hline cond_03-10_w & 0.1874 & 7.1212 & 0.1873 & 0.1875 & Total Length & $1.27 \%$ & Ultimate w/ Precast Conc. Paving \\
\hline
\end{tabular}


Appendix D -THERM Simulation Models - Summer

\section{Condition 1 - Standard}

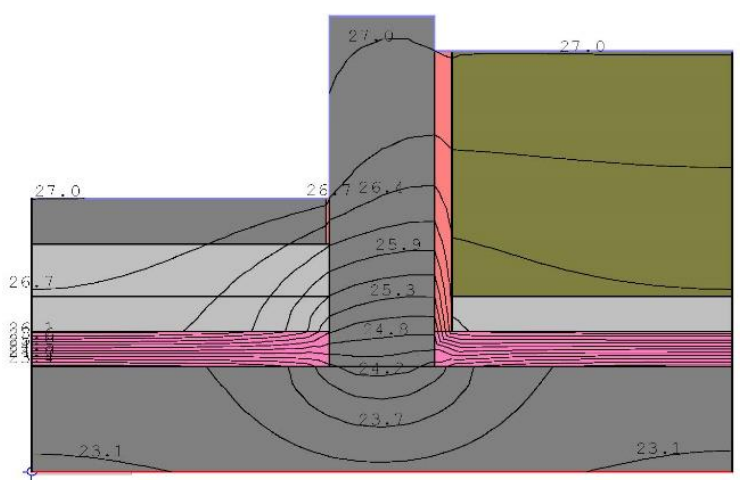

Condition 1.1 - Standard; Isotherms

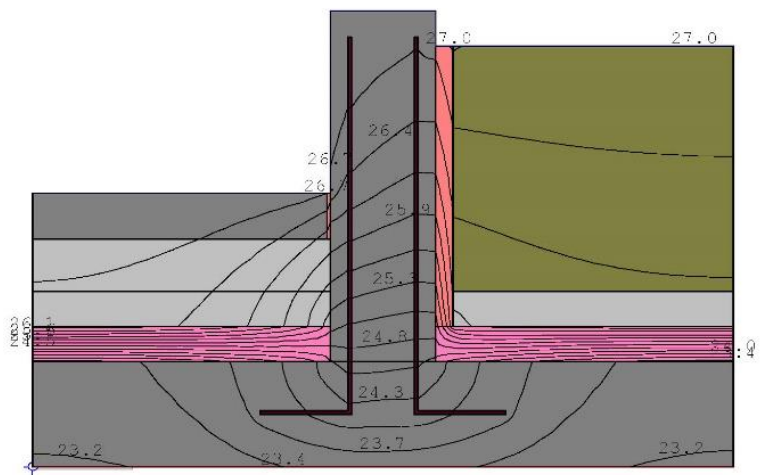

Condition 1.2 -Standard @ Reinforcing; Isotherms

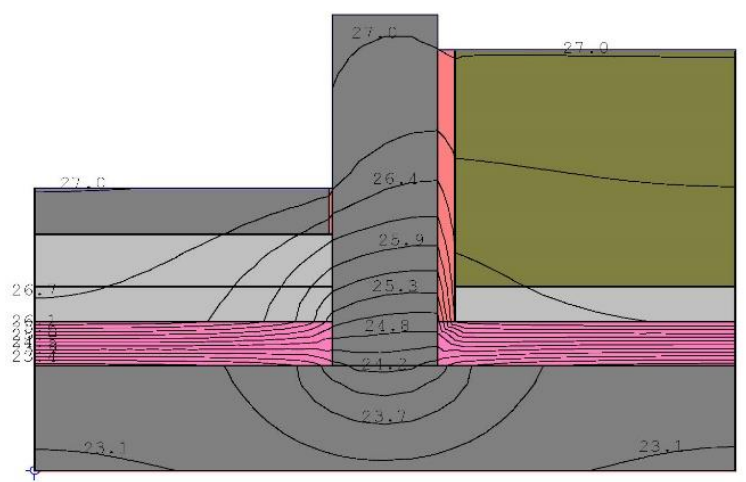

Condition 1.3 - Standard w/ 125mm Slab Insulation; Isotherms

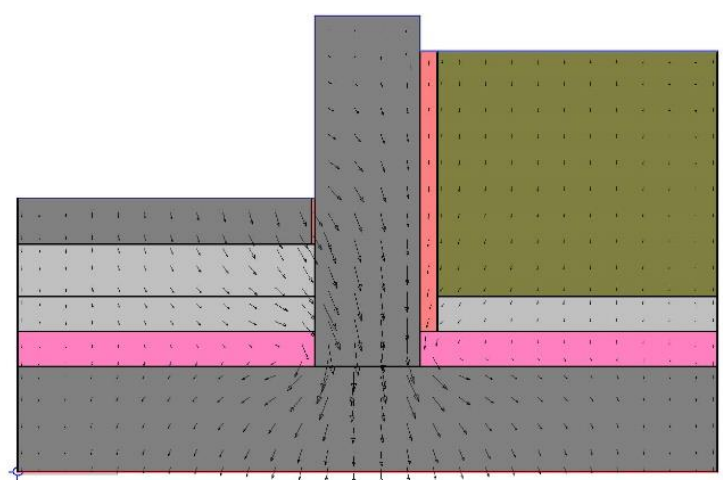

Condition 1.1 - Standard; Flux Vectors

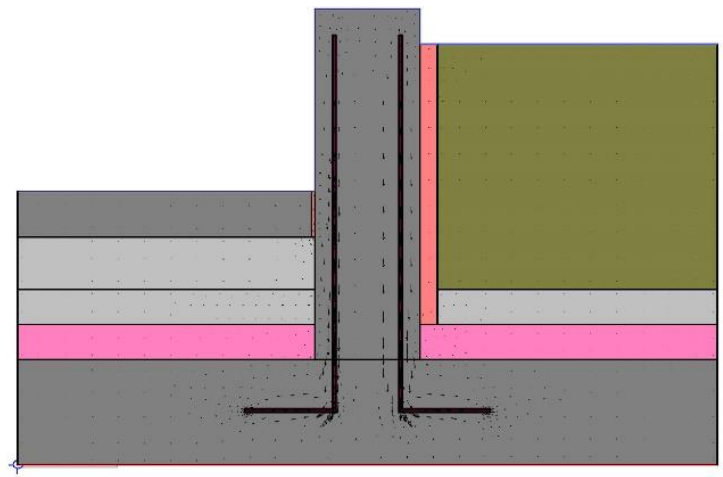

Condition 1.2 - Standard; Flux Vectors

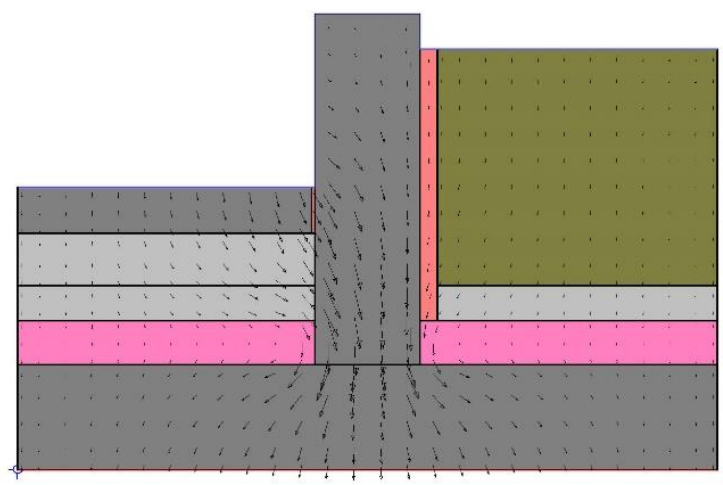

Condition 1.3 - Standard w/ 125mm Slab Insulation; Flux Vectors 


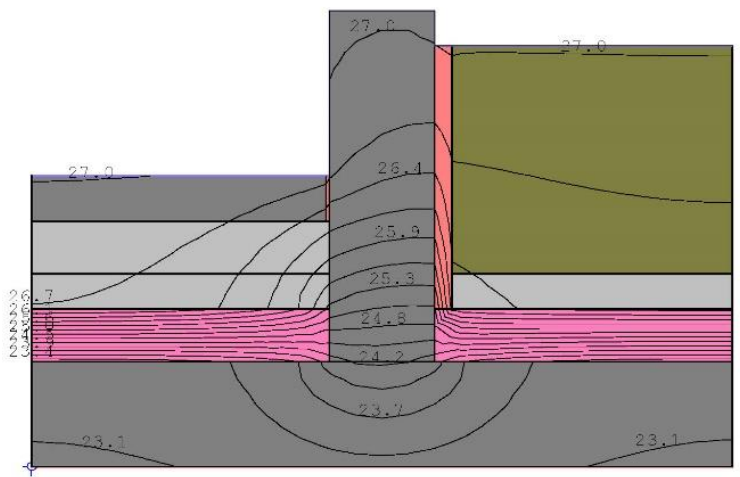

Condition 1.4 - Standard w/ 150mm Slab Insulation; Isotherms

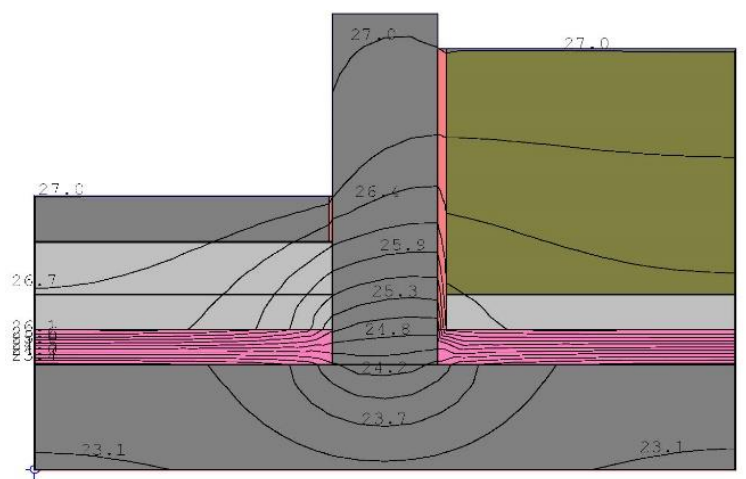

Condition 1.5 - Standard w/ 25mm Wall Insulation; Isotherms

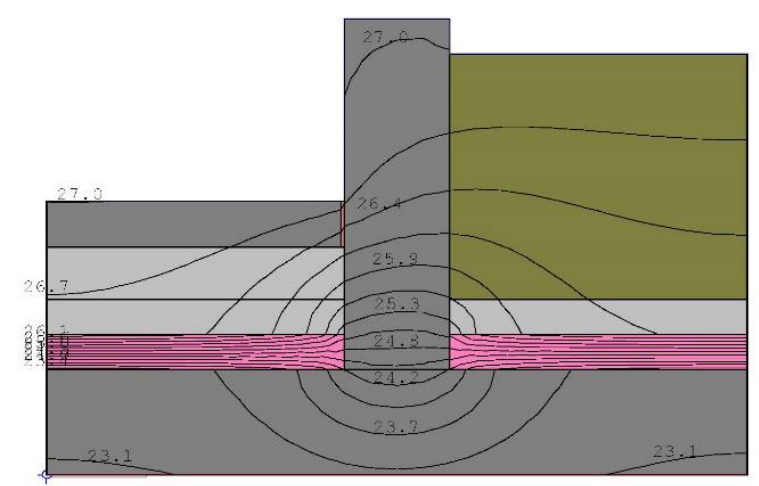

Condition 1.6 - Standard w/ No Wall Insulation; Isotherms

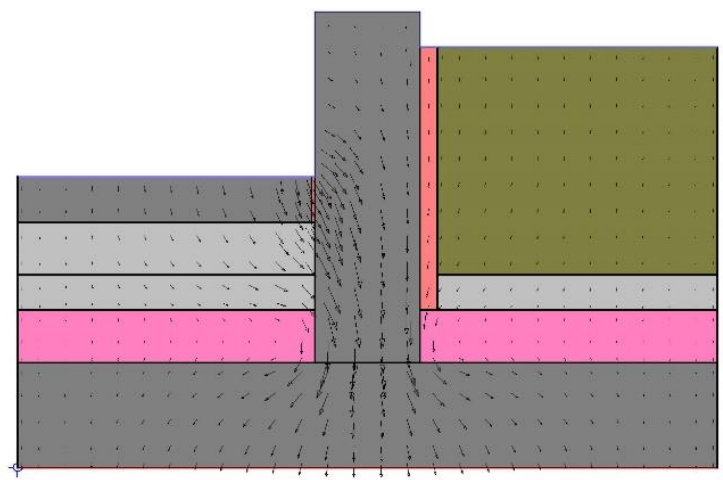

Condition 1.4 - Standard w/ 150mm Slab Insulation; Flux Vectors

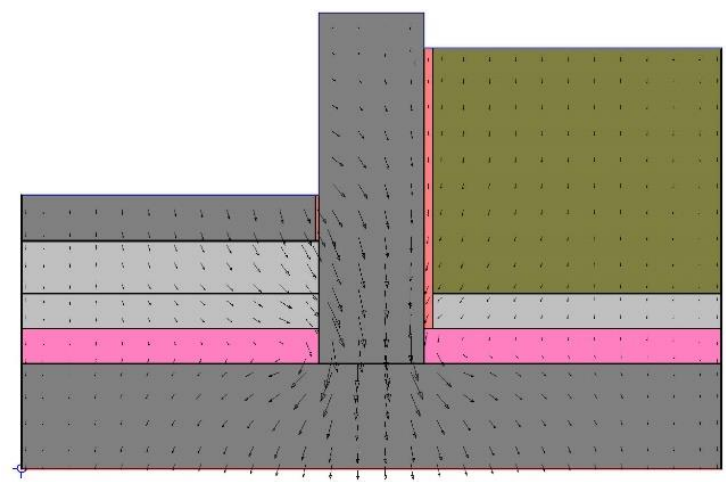

Condition 1.5 - Standard w/ 25mm Wall Insulation; Flux Vectors

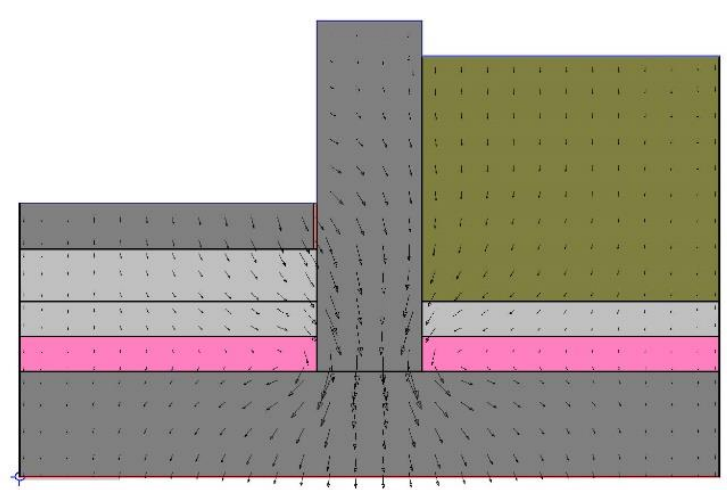

Condition 1.6 - Standard w/ No Wall Insulation; Flux Vectors 


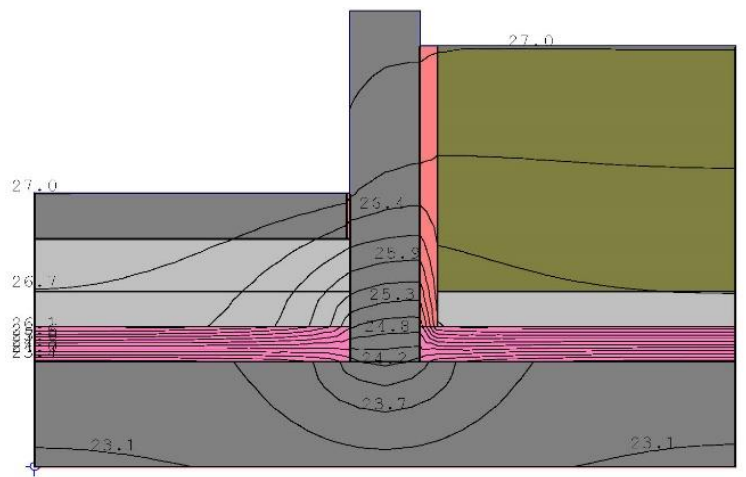

Condition 1.7-Standard w/ 200mm Wide Wall; Isotherms

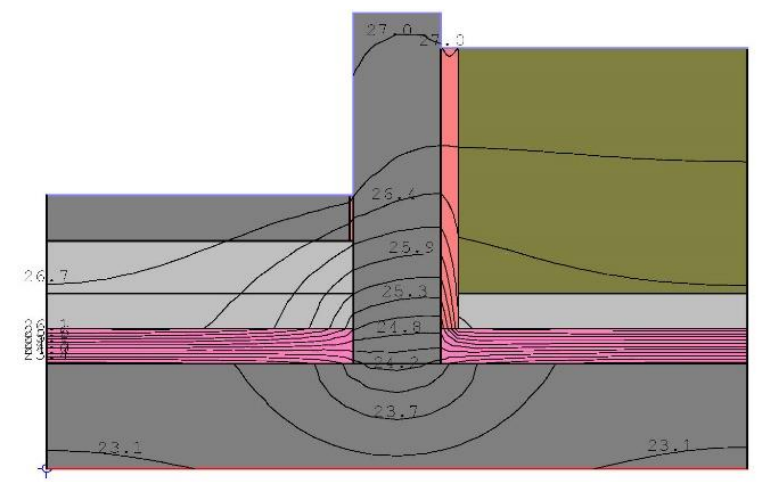

Condition 1.8 - Standard w/ 250mm Wide Wall; Isotherms

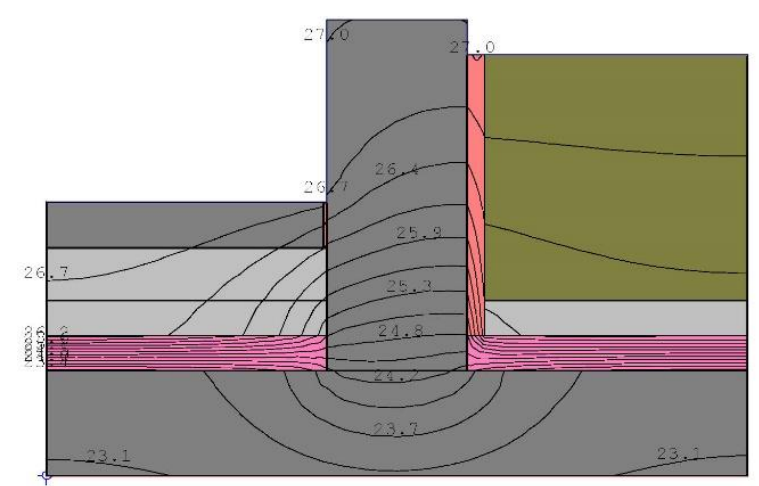

Condition 1.9-Standard w/400mm Wide Wall; Isotherms

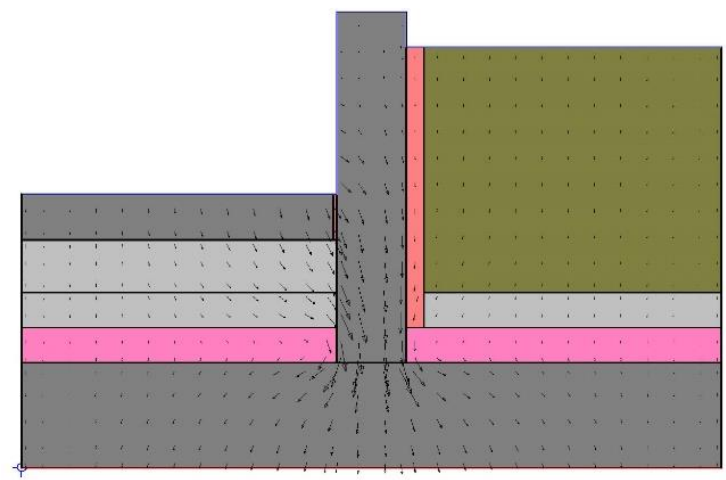

Condition 1.7-Standard w/ 200mm Wide Wall; Flux Vectors

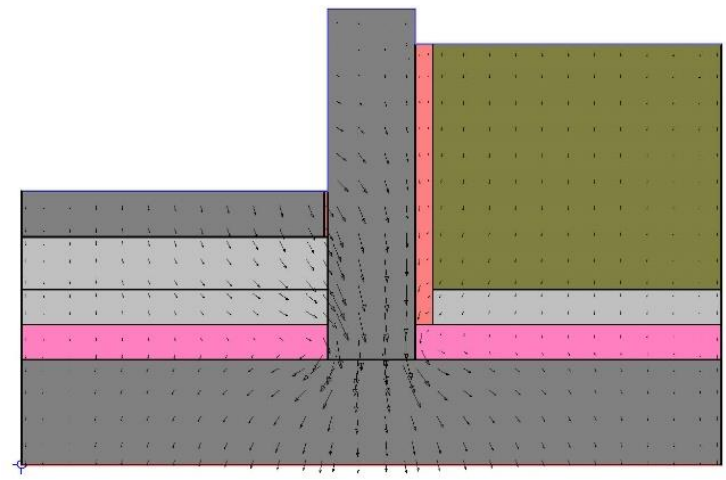

Condition 1.8 - Standard w/ 250mm Wide Wall; Flux Vectors

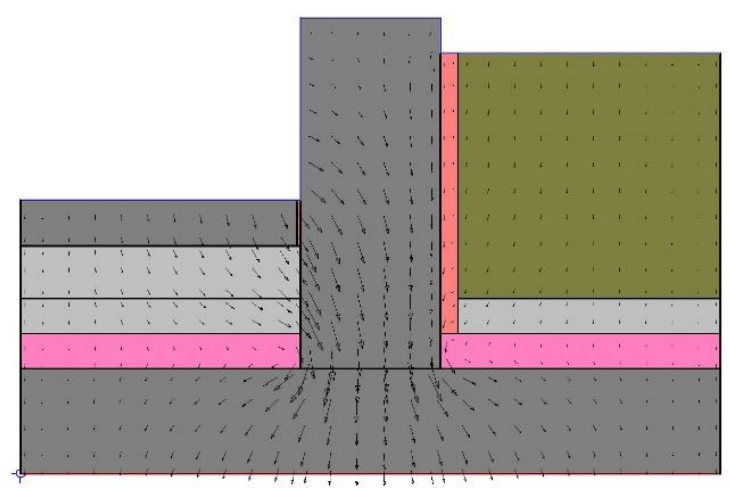

Condition 1.9 - Standard w/400mm Wide Wall; Flux Vectors 


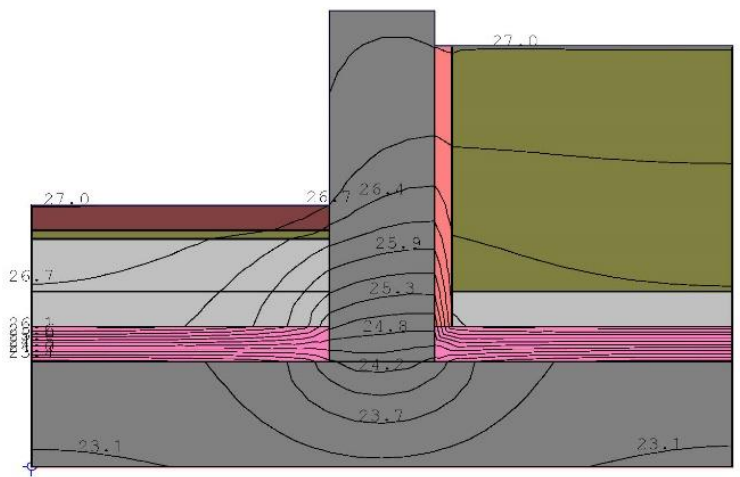

Condition 1.10 - Standard w/Precast Conc. Paving; Isotherms

\section{Condition 2-Improved}

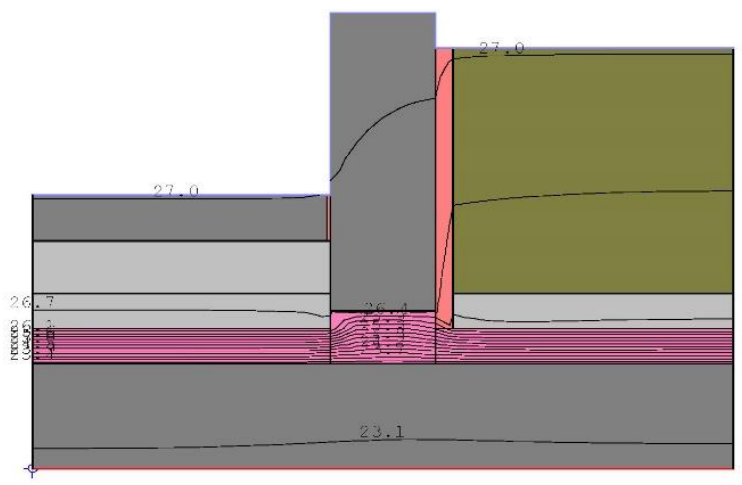

Condition 2.1-Improved; Isotherms

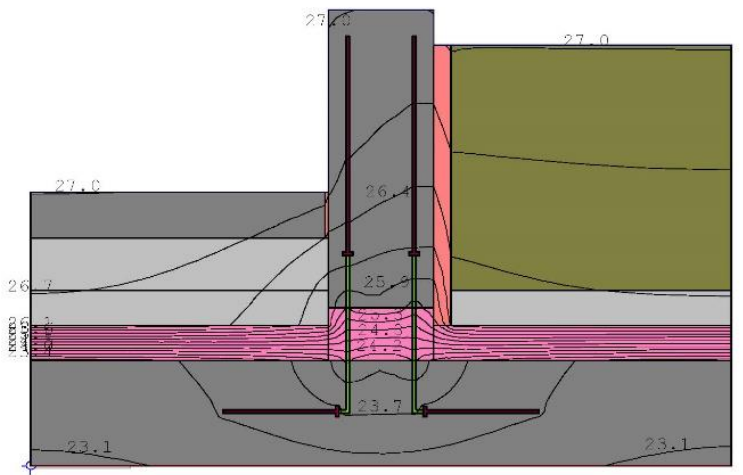

Condition 2.2 - Improved @ Reinforcing; Isotherms

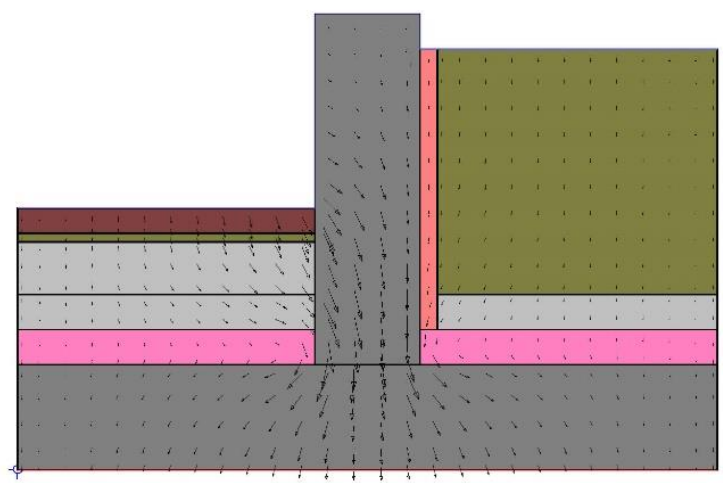

Condition 1.10 - Standard w/ Precast Conc. Paving; Flux Vectors

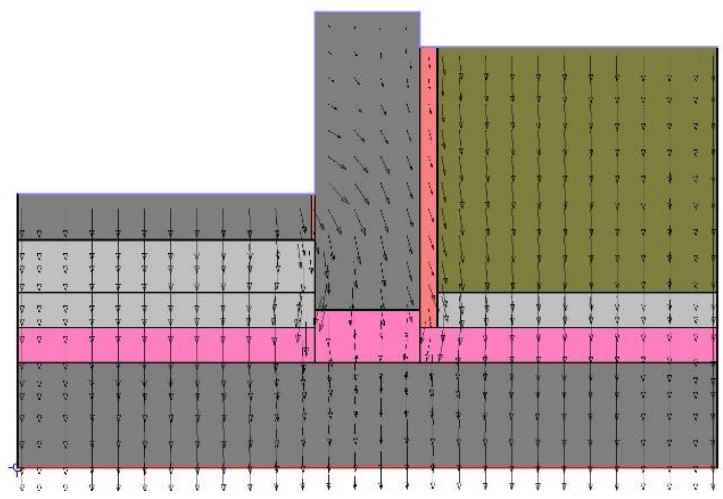

Condition 2.1 - Improved; Flux Vectors

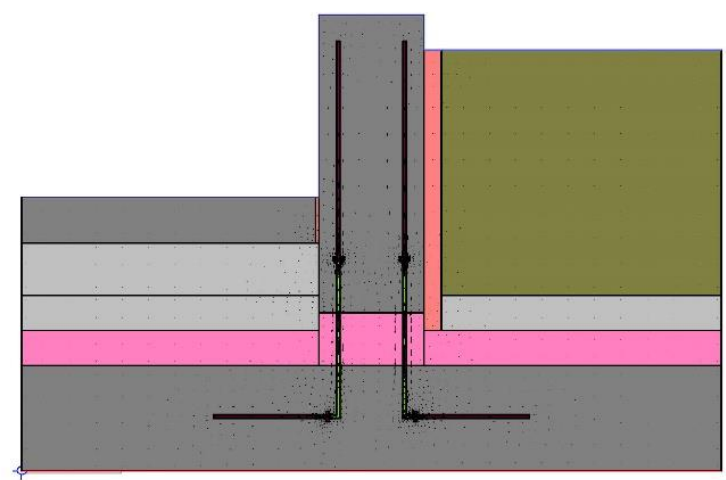

Condition 2.2 -Improved @ Reinforcing; Flux Vectors 


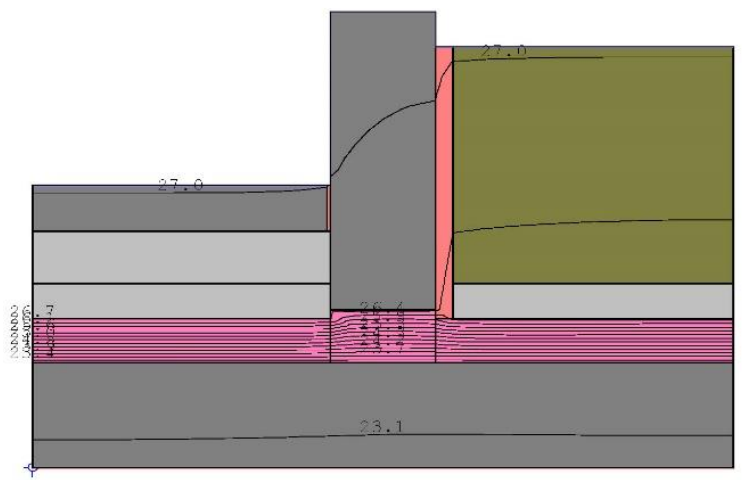

Condition 2.3-Improved $w / 125 \mathrm{~mm}$ Slab Insulation; Isotherms

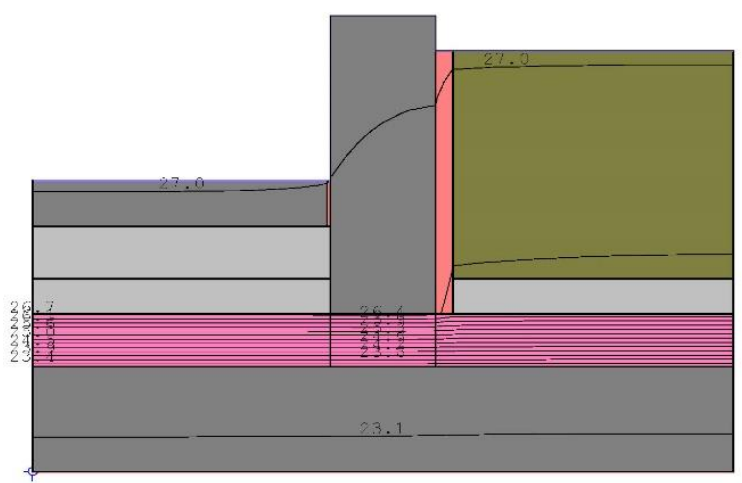

Condition 2.4-Improved w/ 150mm Slab Insulation; Isotherms

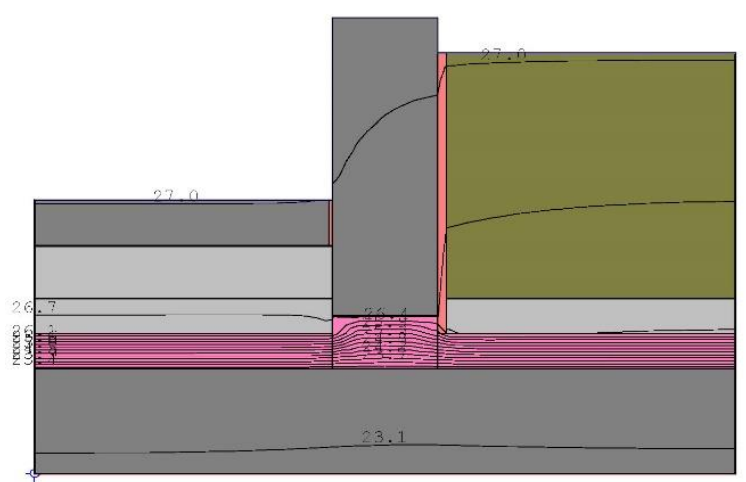

Condition 2.5 - Improved w/ 25mm Wall Insulation; Isotherms

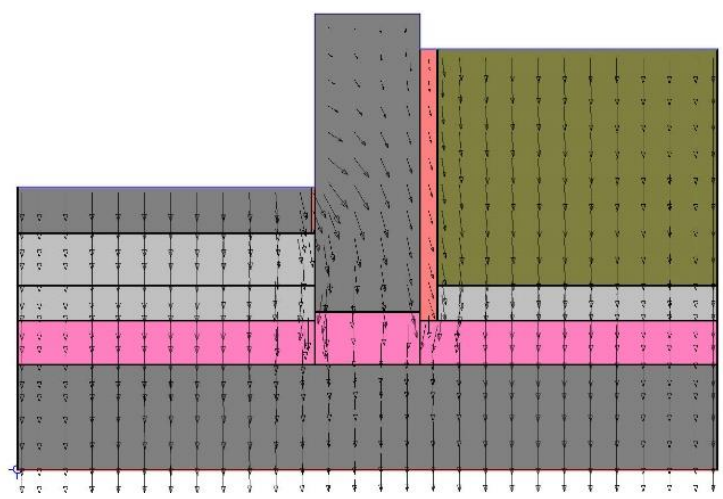

Condition 2.3 - Improved w/ 125mm Slab Insulation; Flux Vectors

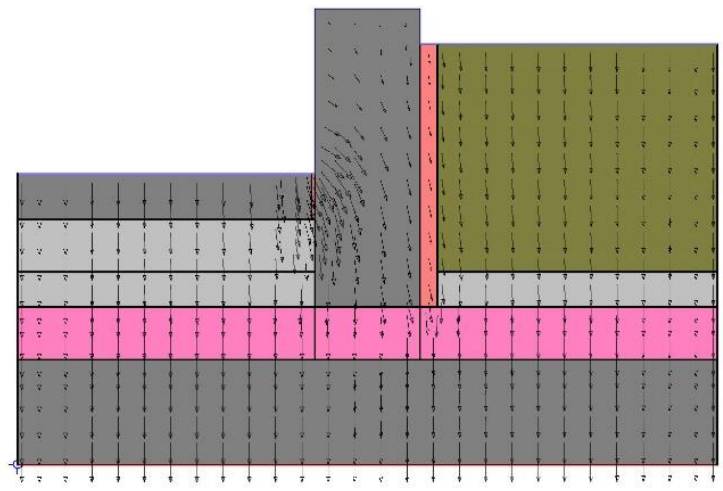

Condition 2.4 - Improved w/ 150mm Slab Insulation; Flux Vectors

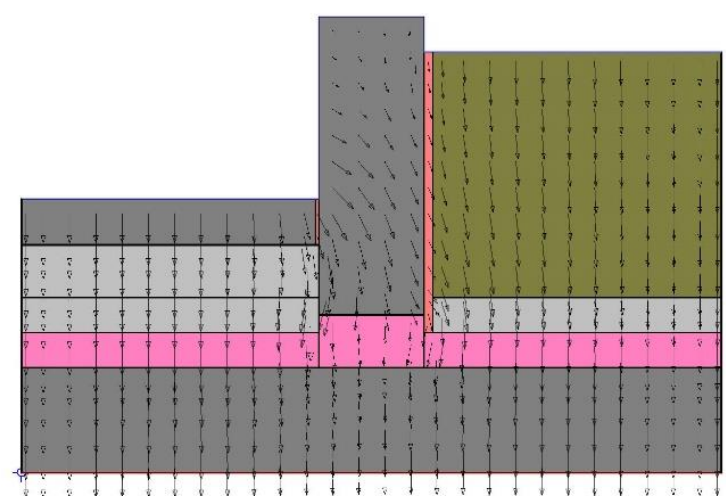

Condition 2.5-Improved $w / 25 \mathrm{~mm}$ Wall Insulation; Flux Vectors 


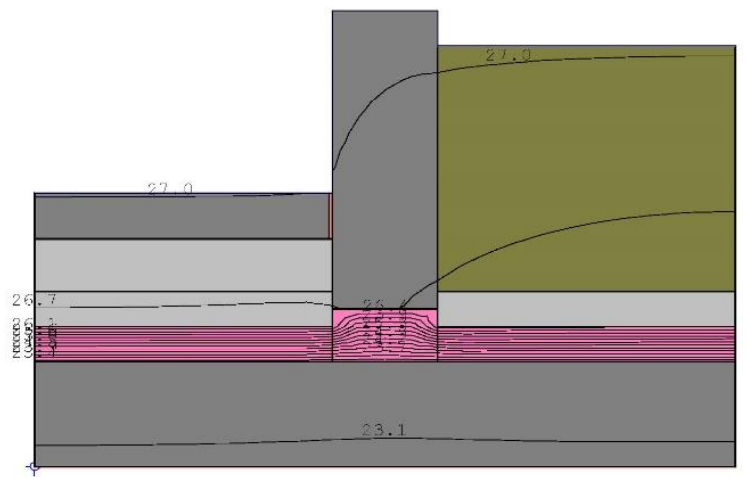

Condition 2.6-Improved w/ No Wall Insulation; Isotherms

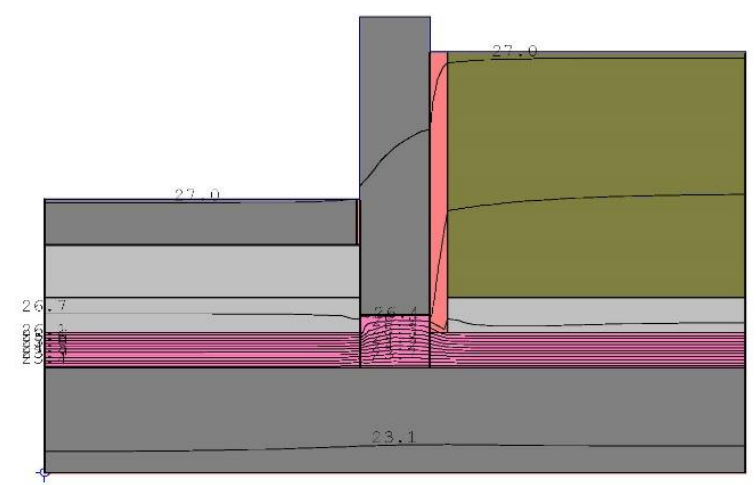

Condition 2.7-Improved w/200mm Wide Wall; Isotherms

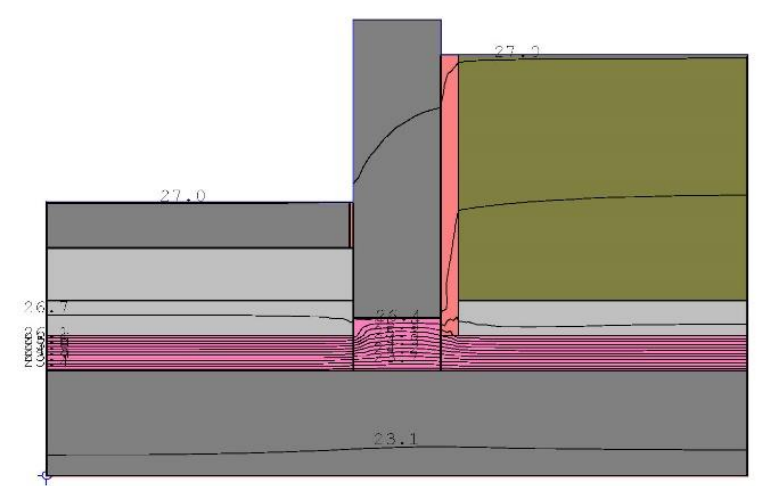

Condition 2.8-Improved w/250mm Wide Wall; Isotherms

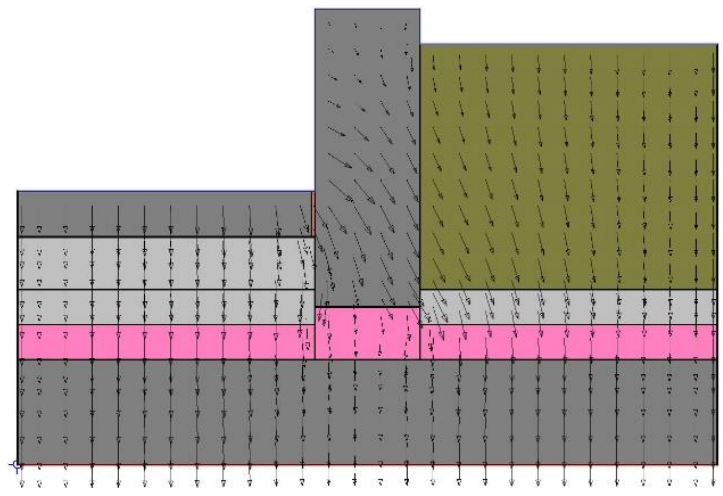

Condition 2.6 - Improved w/ No Wall Insulation; Flux Vectors

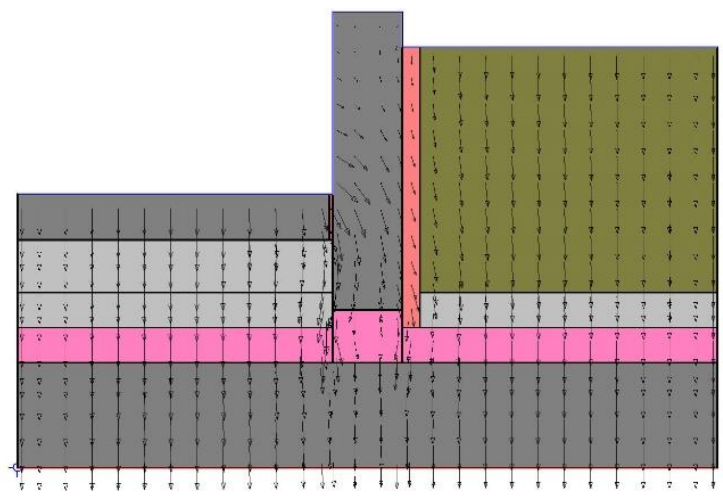

Condition 2.7-Improved $w / 200 \mathrm{~mm}$ Wide Wall; Flux Vectors

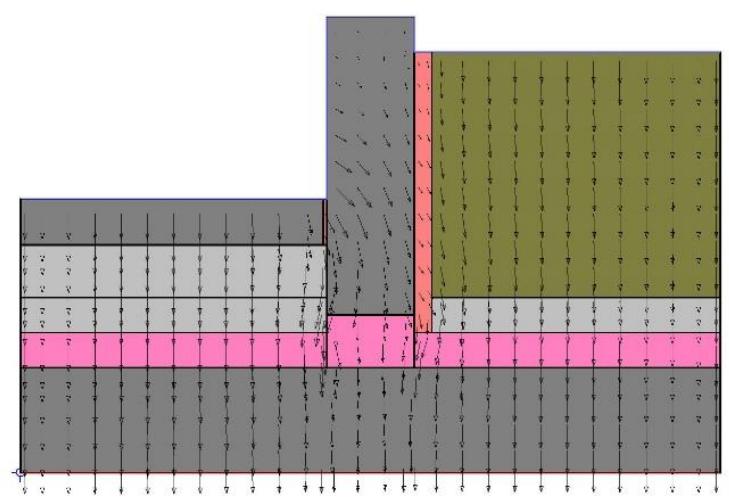

Condition 2.8-Improved w/250mm Wide Wall; Flux Vectors 


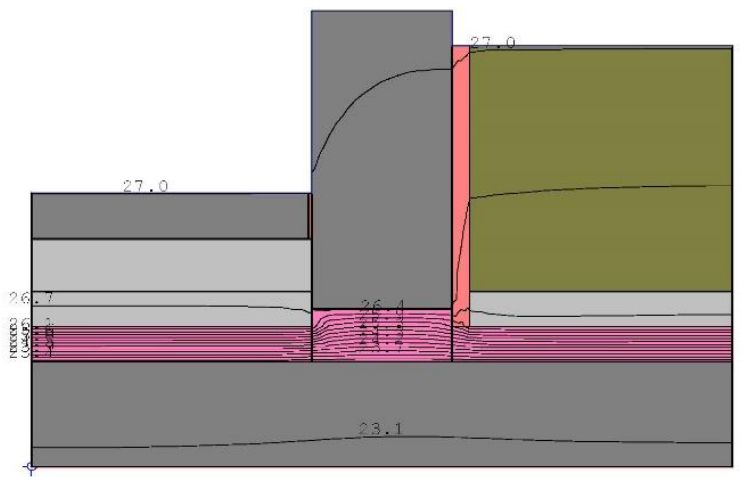

Condition 2.9-Improved $w / 400 \mathrm{~mm}$ Wide Wall; Isotherms

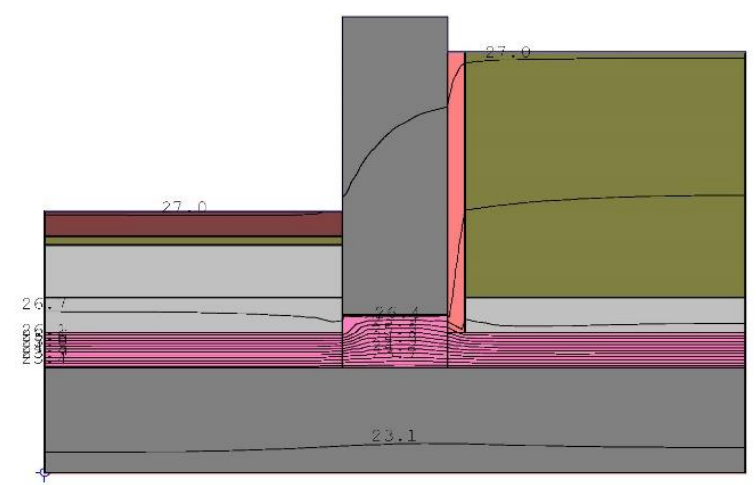

Condition 2.10-Improved w/ Precast Conc. Paving; Isotherms

\section{Condition 3 - Ultimate}

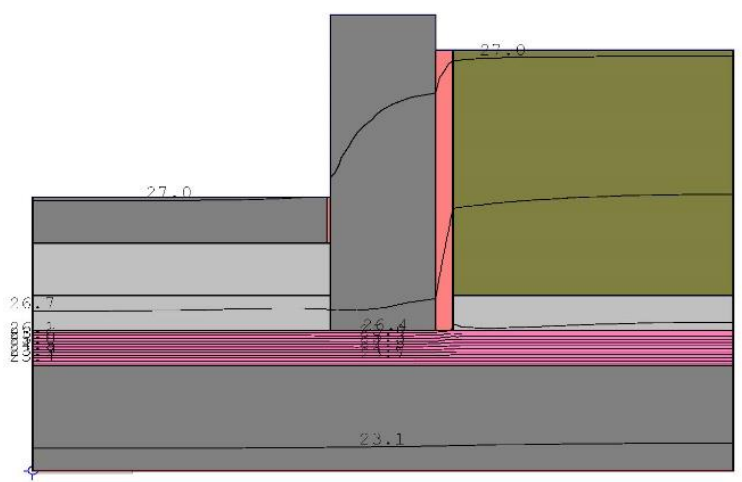

Condition 3.1 - Ultimate; Isotherms

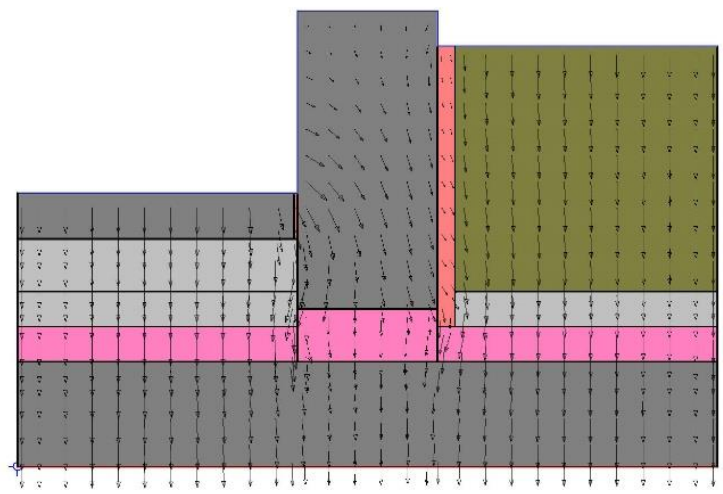

Condition 2.9-Improved w/400mm Wide Wall; Flux Vectors

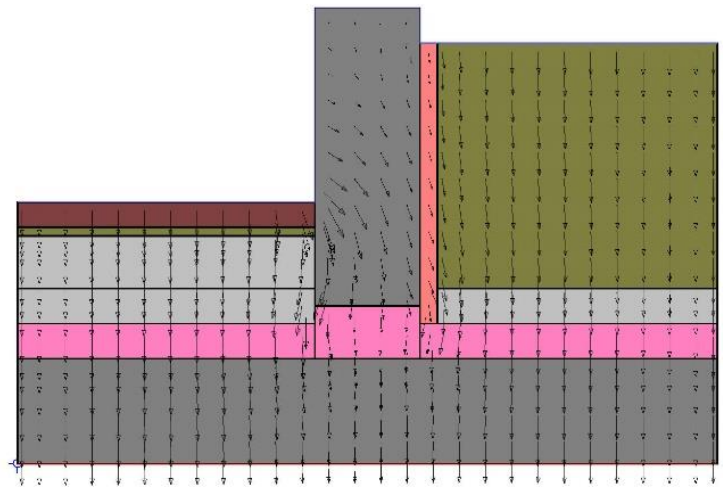

Condition 2.10 - Improved w/ Precast Conc. Paving; Flux Vectors

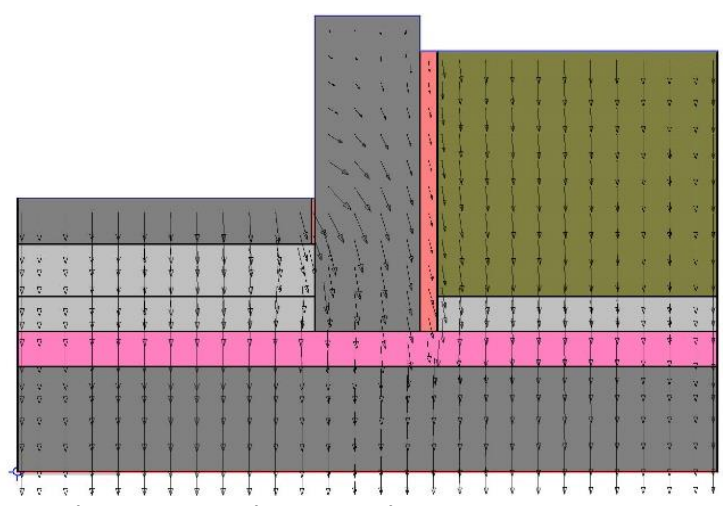

Condition 3.1 - Ultimate; Flux Vectors 


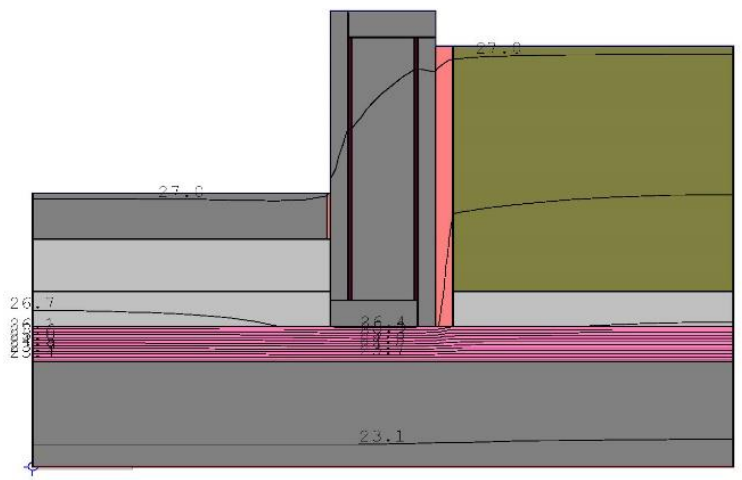

Condition 3.2 -Ultimate @ Reinforcing; Isotherms

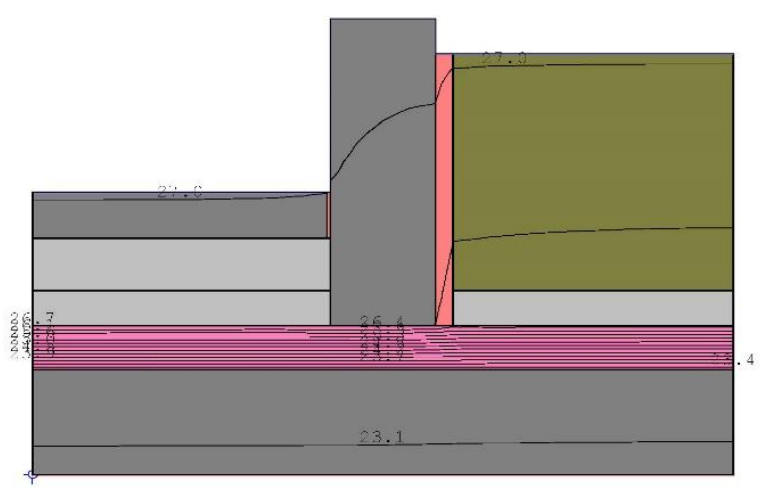

Condition 3.3 - Ultimate $w / 125 \mathrm{~mm}$ Slab Insulation; Isotherms

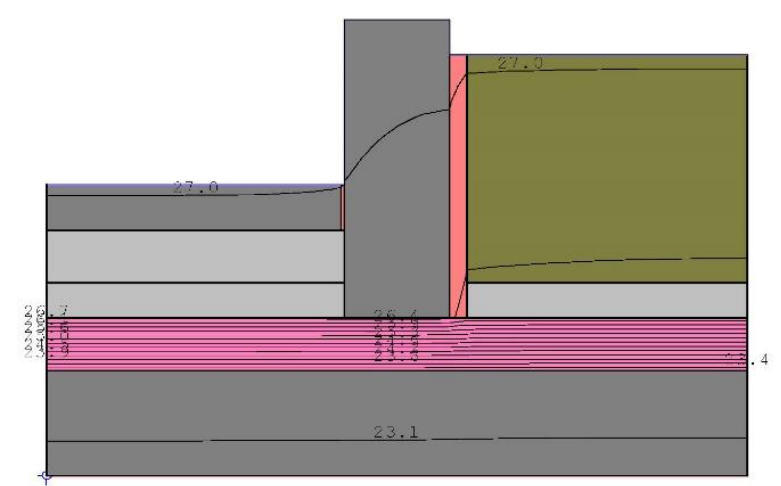

Condition 3.4-Ultimate w/150mm Slab Insulation; Isotherms

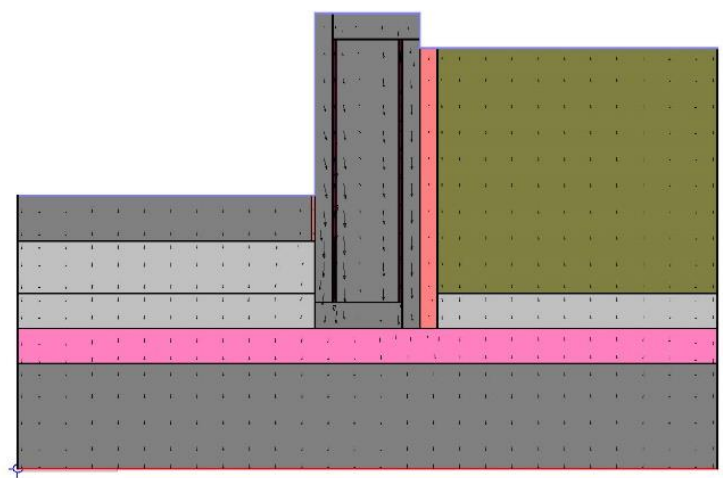

Condition 3.2 -Ultimate @ Reinforcing; Flux Vectors

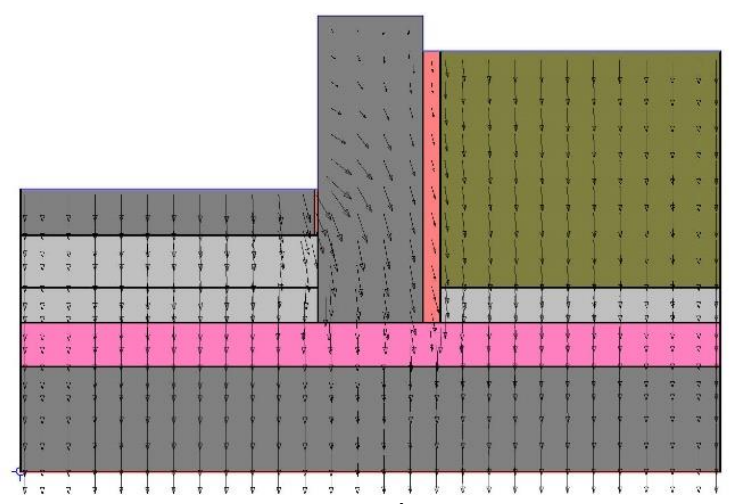

Condition 3.3 - Ultimate $\mathrm{w} / 125 \mathrm{~mm}$ Slab Insulation; Flux Vectors

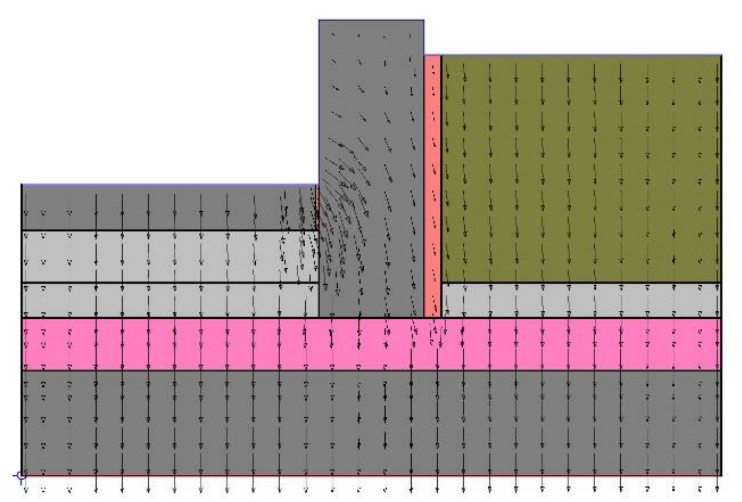

Condition 3.4 - Ultimate w/ 150mm Slab

Insulation; Flux Vectors 


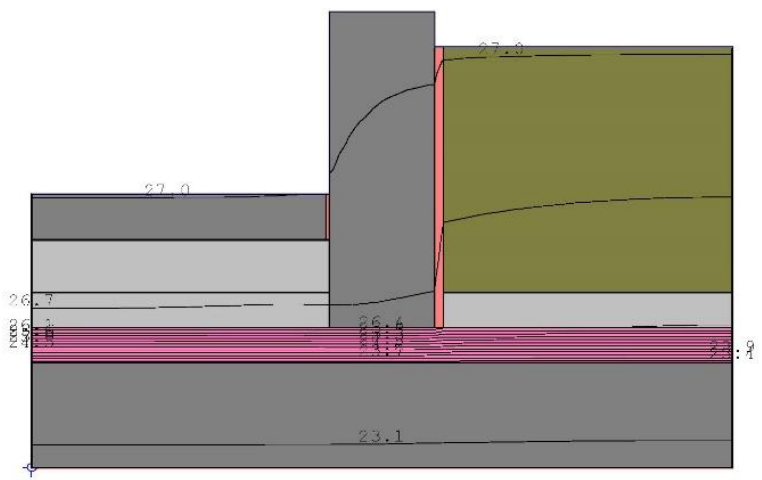

Condition 3.5 - Ultimate $w / 25 \mathrm{~mm}$ Wall Insulation; Isotherms

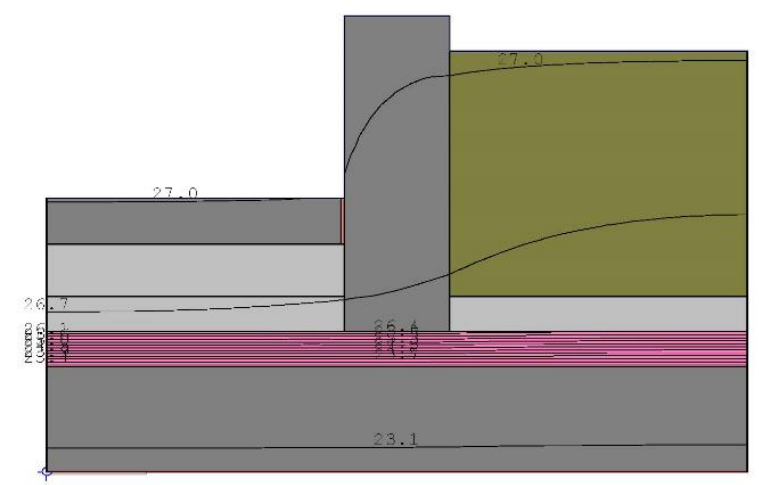

Condition 3.6 - Ultimate w/ No Wall Insulation; Isotherms

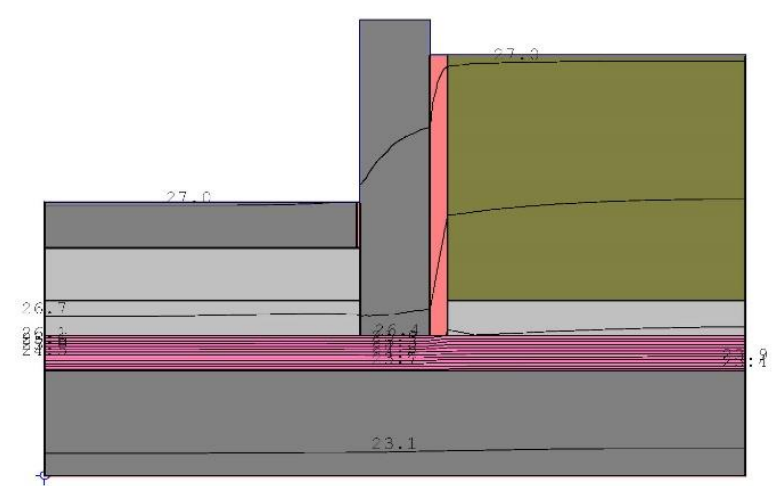

Condition 3.7-Ultimate $w / 200 \mathrm{~mm}$ Wide Wall; Isotherms

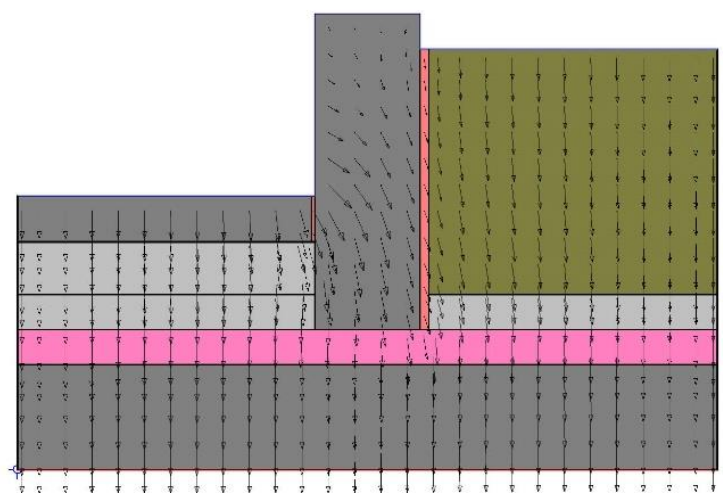

Condition 3.5 - Ultimate $w / 25 \mathrm{~mm}$ Wall Insulation; Flux Vectors

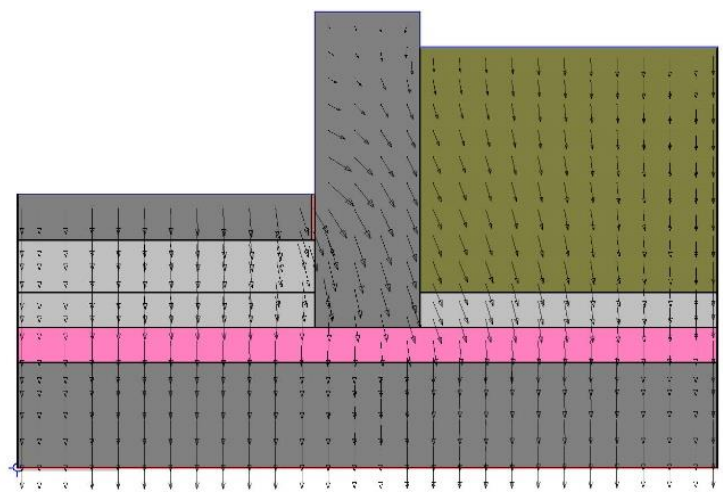

Condition 3.6 - Ultimate w/ No Wall Insulation; Flux Vectors

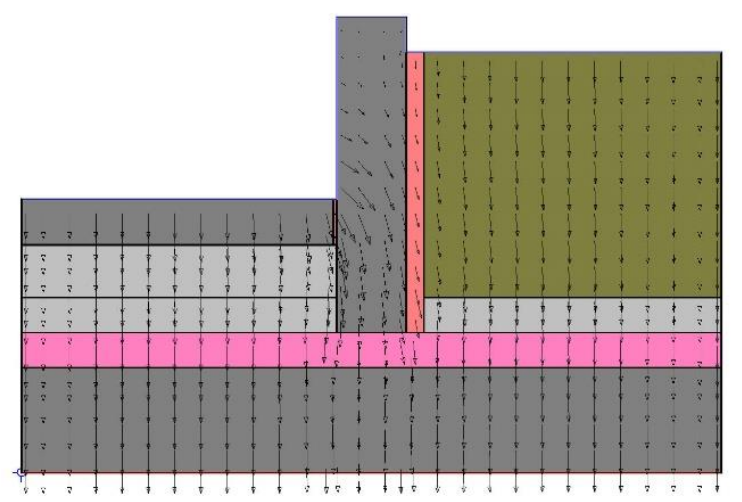

Condition 3.7 - Ultimate w/200mm Wide Wall; Flux Vectors 


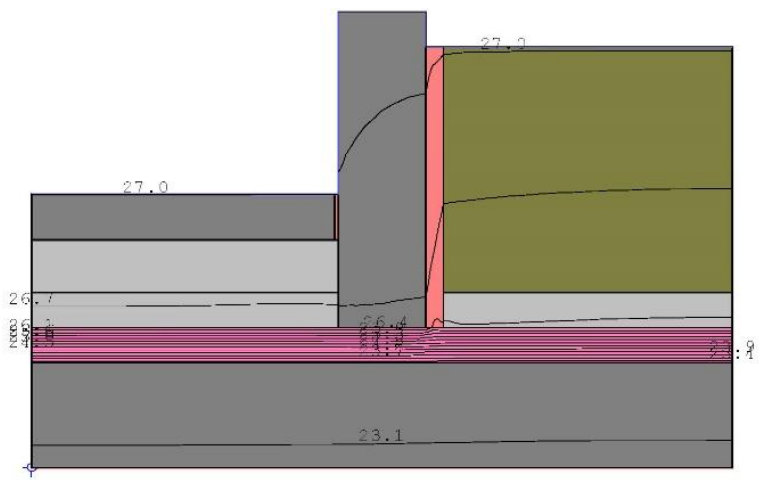

Condition 3.8 -Ultimate $w / 250 \mathrm{~mm}$ Wide Wall; Isotherms

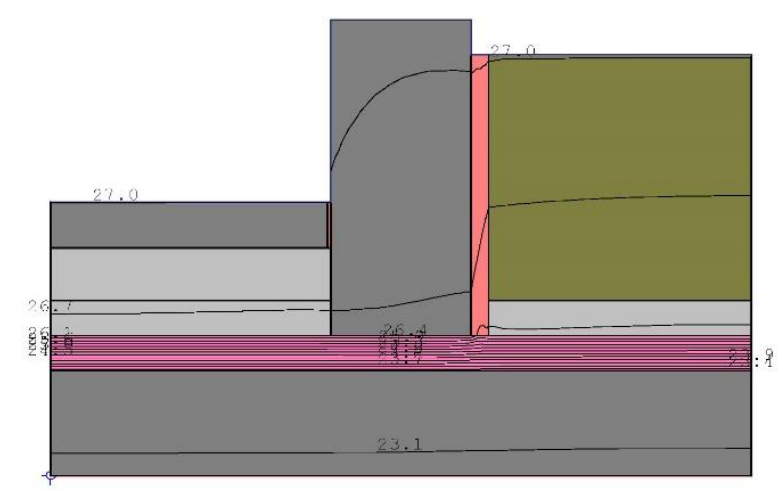

Condition 3.9-Ultimate $w / 400 \mathrm{~mm}$ Wide Wall; Isotherms

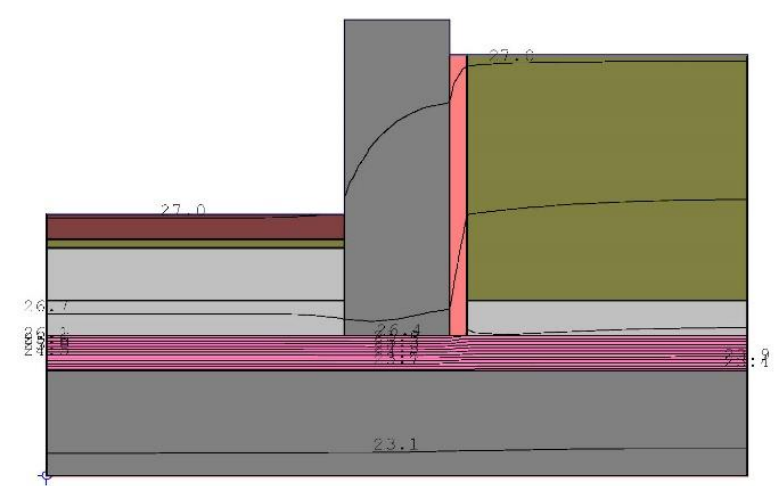

Condition 3.10 - Ultimate w/ Precast Conc. Paving; Isotherms

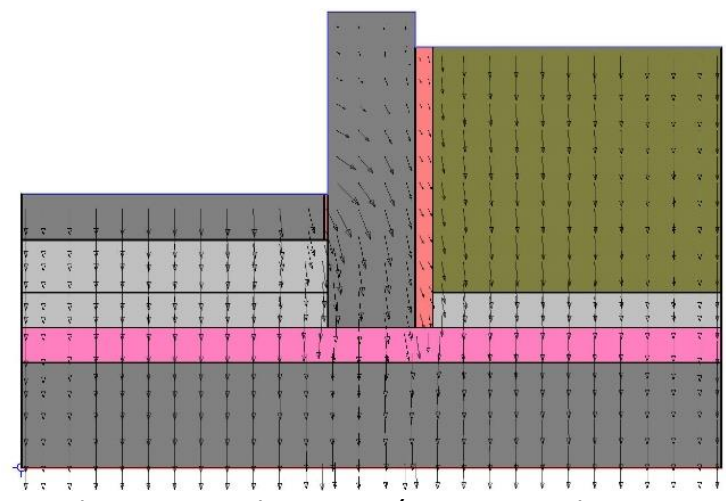

Condition 3.8 - Ultimate $w / 250 \mathrm{~mm}$ Wide Wall; Flux Vectors

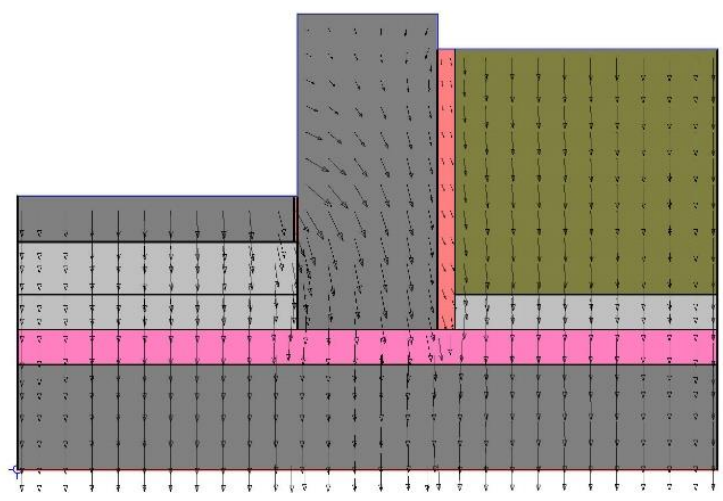

Condition 3.9 - Ultimate $w / 400 \mathrm{~mm}$ Wide Wall; Flux Vectors

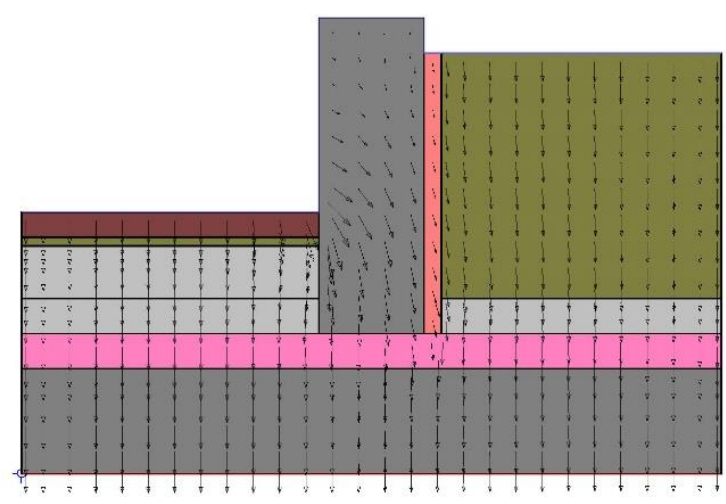

Condition 3.10 - Ultimate w/ Precast Conc.

Paving; Flux Vectors 
Appendix E - THERM Simulation Models - Winter

Condition 1 - Standard

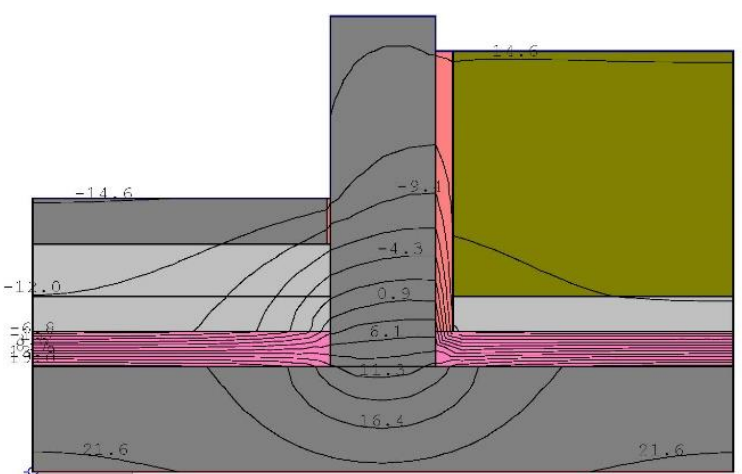

Condition 1.1 - Standard; Isotherms

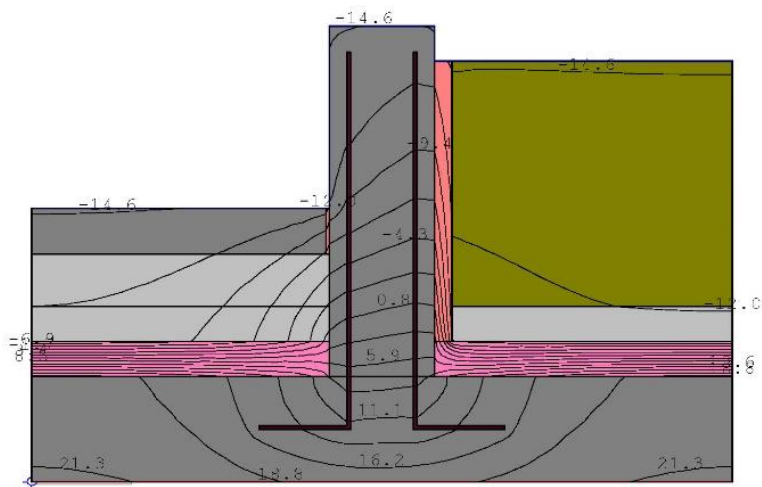

Condition 1.2 -Standard @ Reinforcing; Isotherms

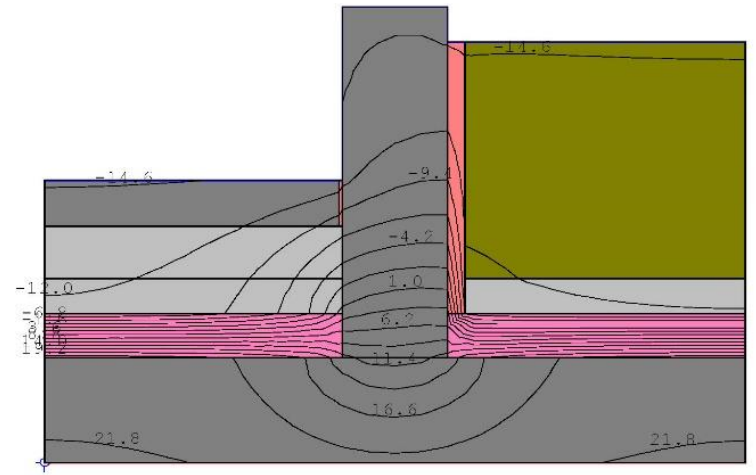

Condition 1.3 - Standard $w / 125 \mathrm{~mm}$ Slab Insulation; Isotherms

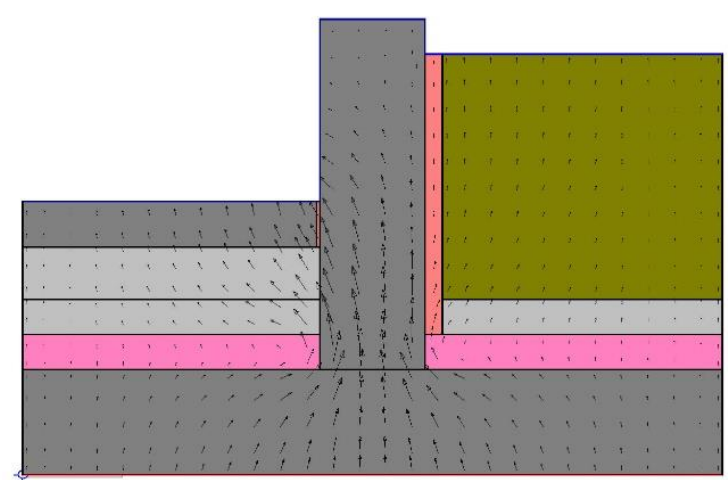

Condition 1.1 - Standard; Flux Vectors

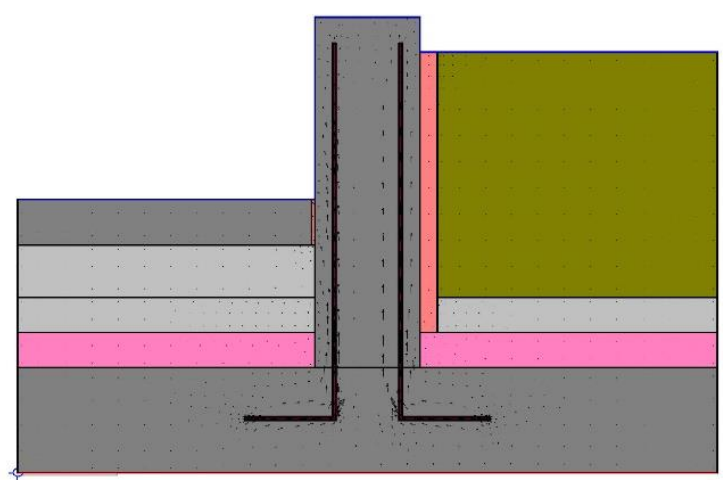

Condition 1.2 - Standard; Flux Vectors

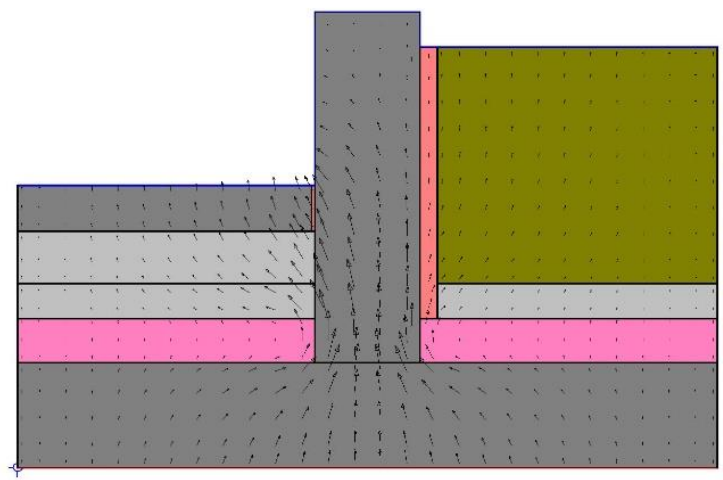

Condition 1.3 - Standard w/ 125mm Slab Insulation; Flux Vectors 


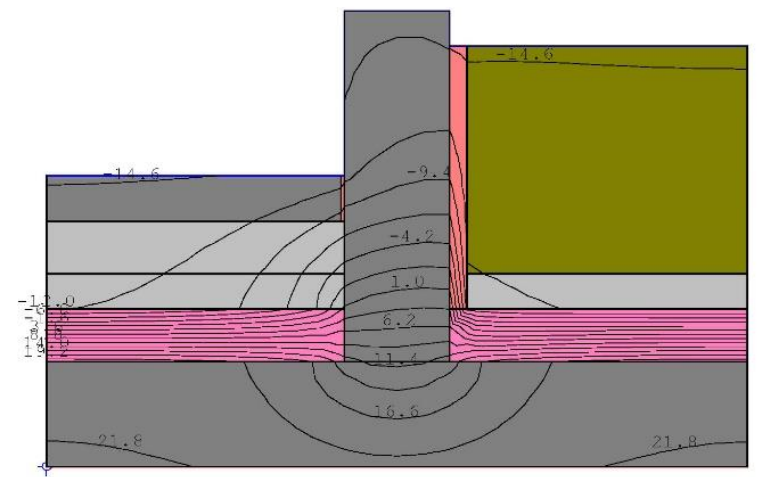

Condition 1.4 - Standard w/ 150mm Slab Insulation; Isotherms

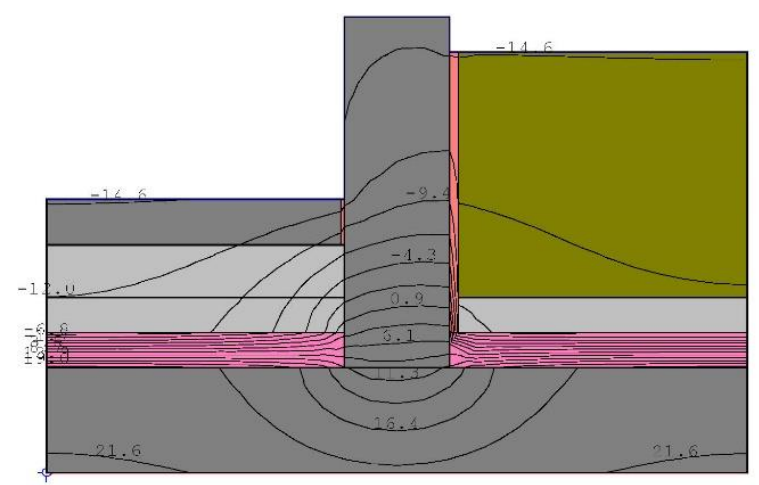

Condition 1.5 - Standard w/ 25mm Wall Insulation; Isotherms

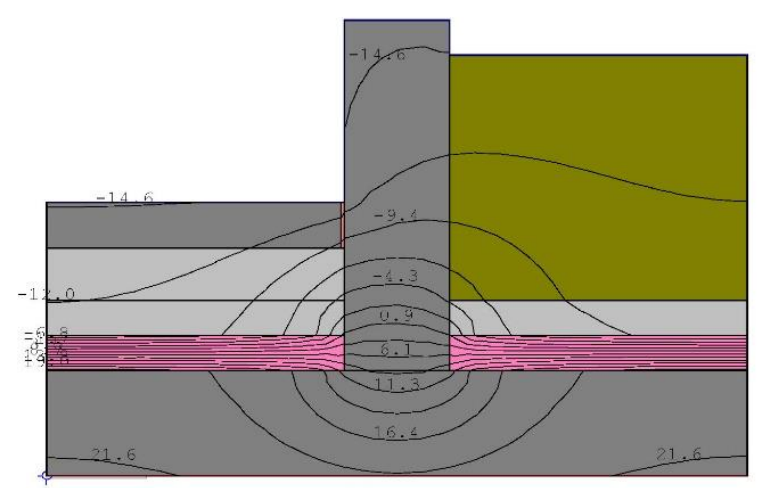

Condition 1.6 - Standard w/ No Wall Insulation; Isotherms

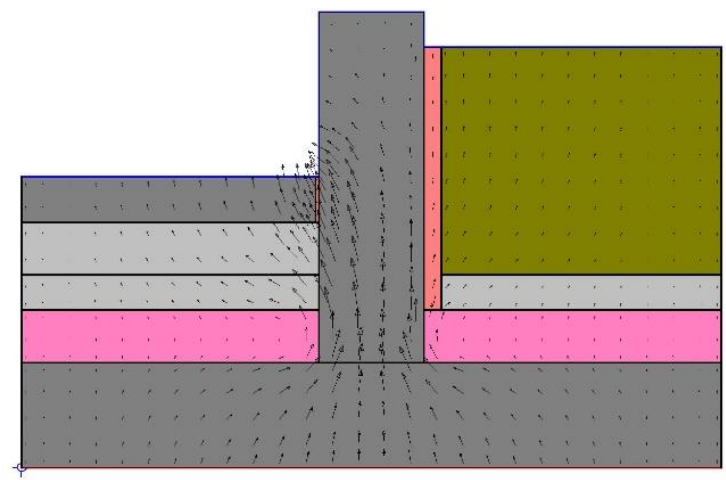

Condition 1.4 - Standard w/ 150mm Slab Insulation; Flux Vectors

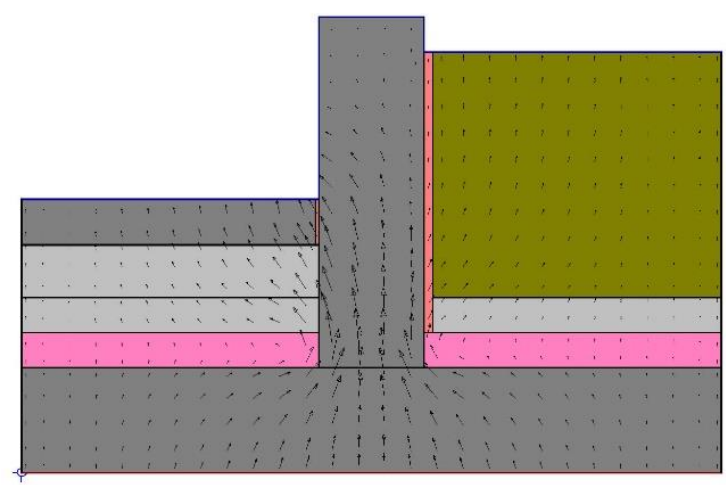

Condition 1.5 - Standard w/ 25mm Wall Insulation; Flux Vectors

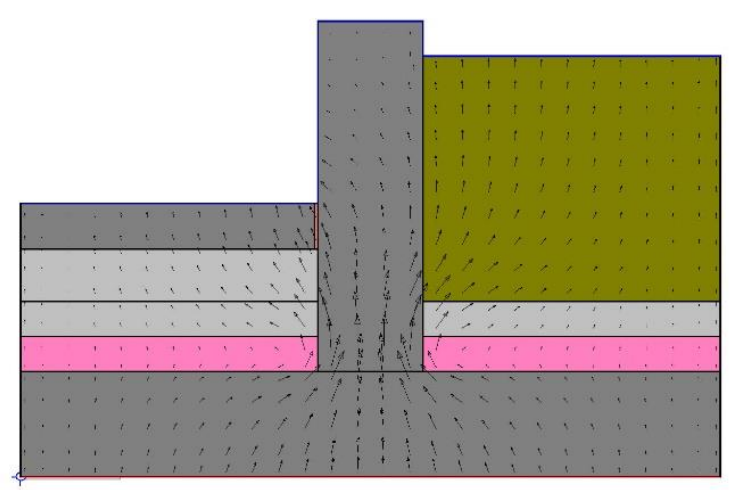

Condition 1.6 - Standard w/ No Wall Insulation; Flux Vectors 


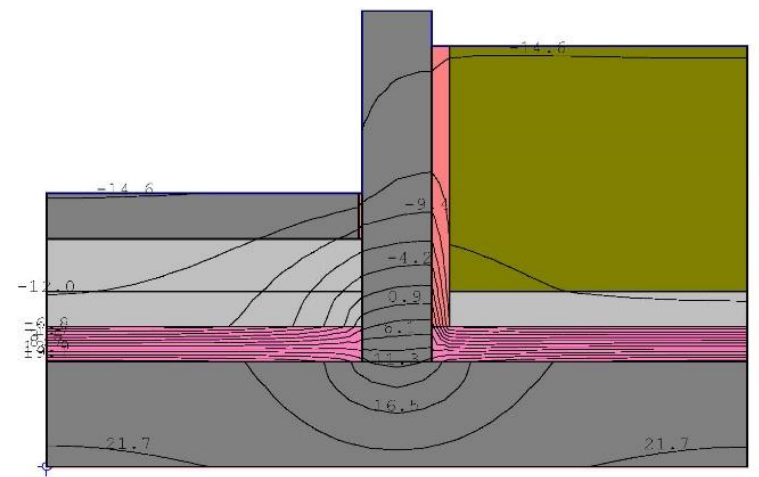

Condition 1.7-Standard w/ 200mm Wide Wall; Isotherms

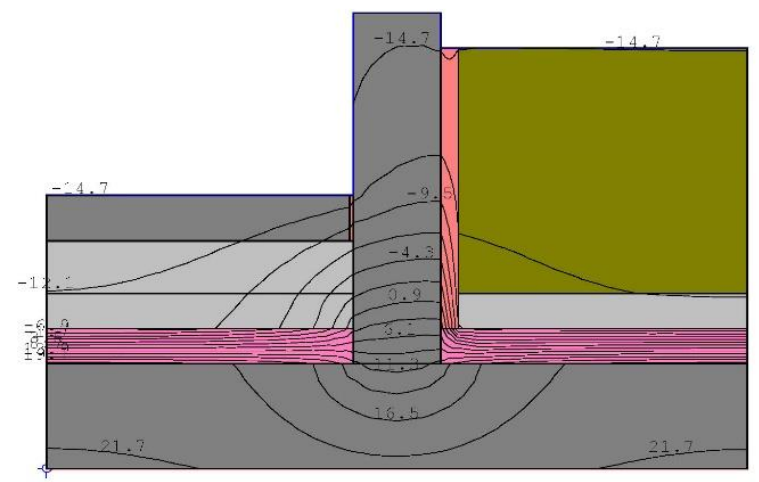

Condition 1.8 - Standard w/ 250mm Wide Wall; Isotherms

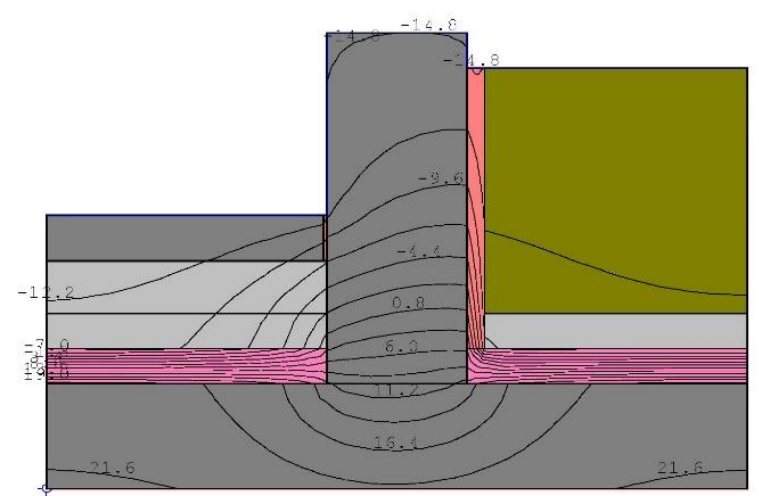

Condition 1.9-Standard w/400mm Wide Wall; Isotherms

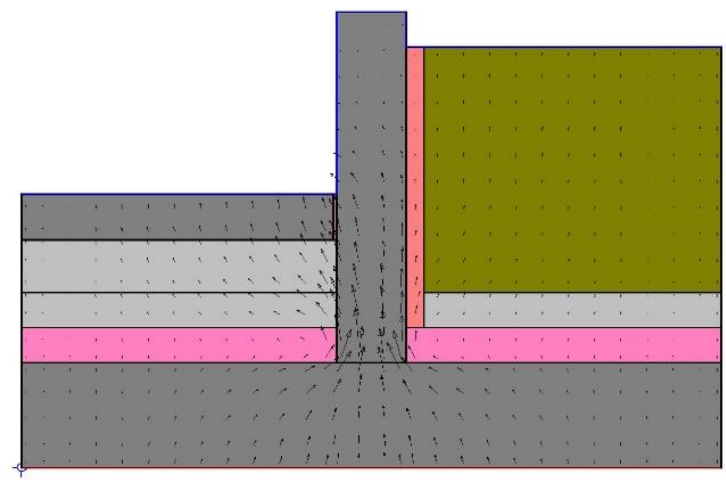

Condition 1.7 - Standard w/ 200mm Wide Wall; Flux Vectors

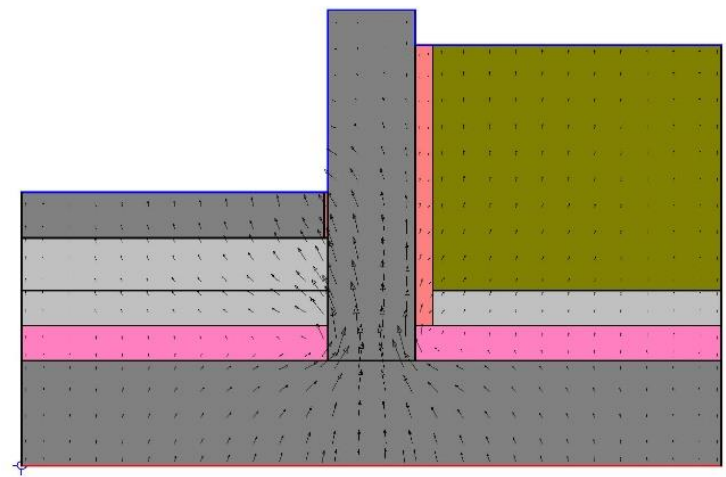

Condition 1.8 - Standard w/ 250mm Wide Wall; Flux Vectors

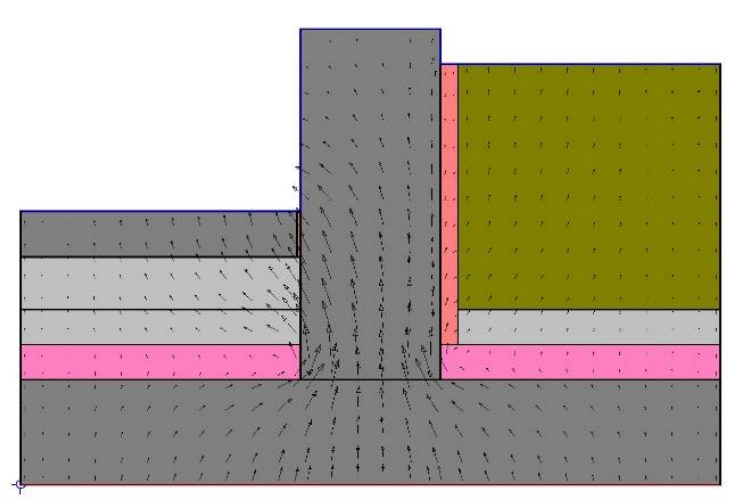

Condition 1.9 - Standard w/400mm Wide Wall; Flux Vectors 


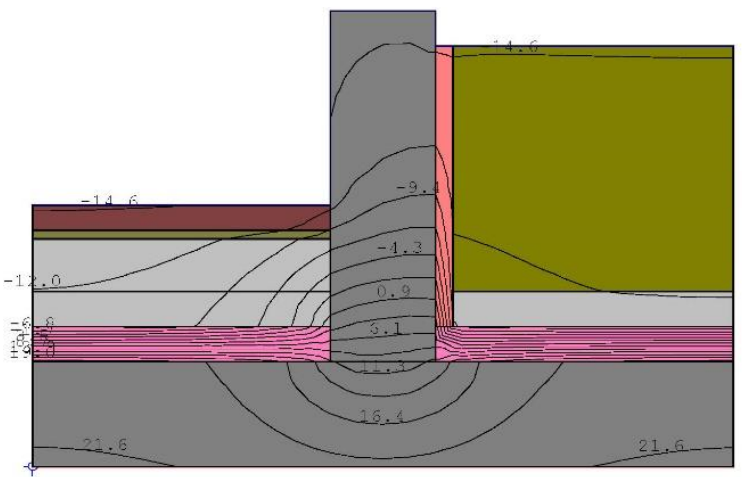

Condition 1.10 - Standard w/Precast Conc. Paving; Isotherms

\section{Condition 2-Improved}

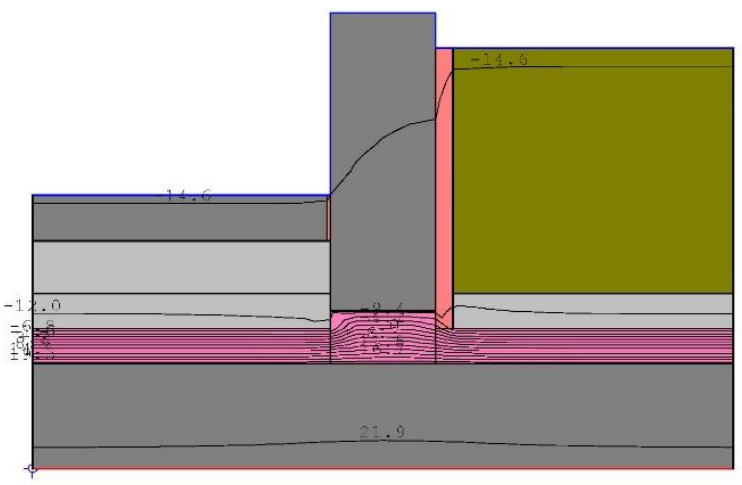

Condition 2.1 - Improved; Isotherms

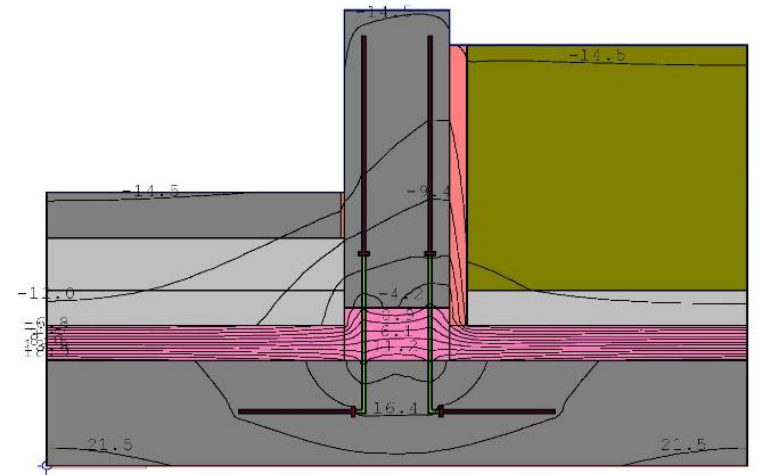

Condition 2.2 - Improved @ Reinforcing; Isotherms

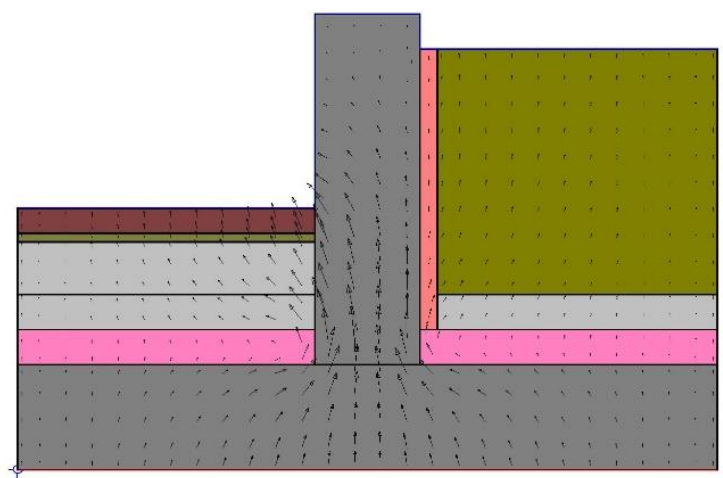

Condition 1.10 - Standard w/ Precast Conc. Paving; Flux Vectors

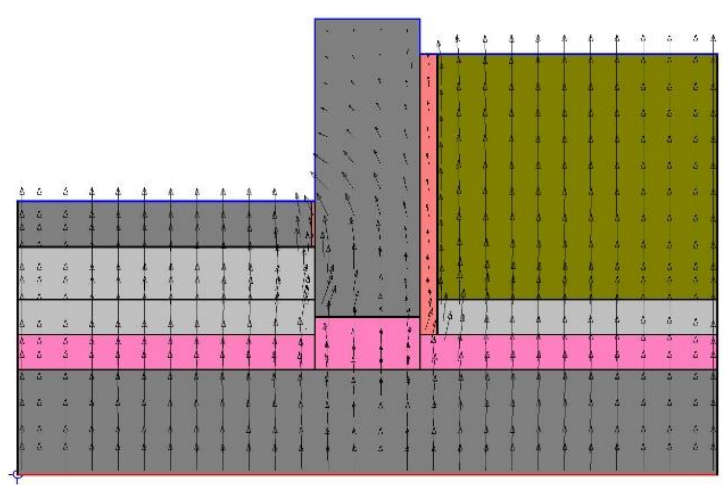

Condition 2.1-Improved; Flux Vectors

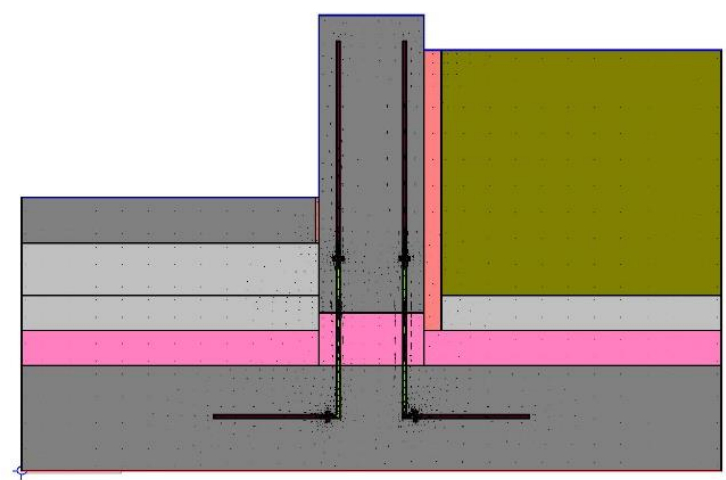

Condition 2.2 - Improved @ Reinforcing; Flux Vectors 


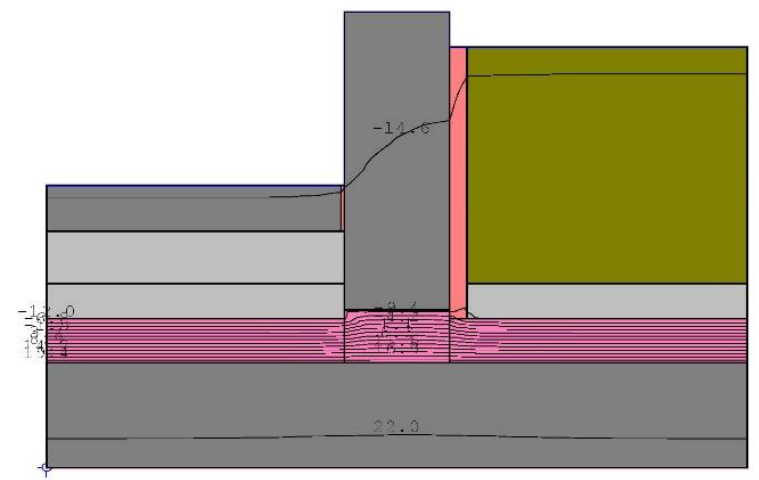

Condition 2.3-Improved $w / 125 \mathrm{~mm}$ Slab Insulation; Isotherms

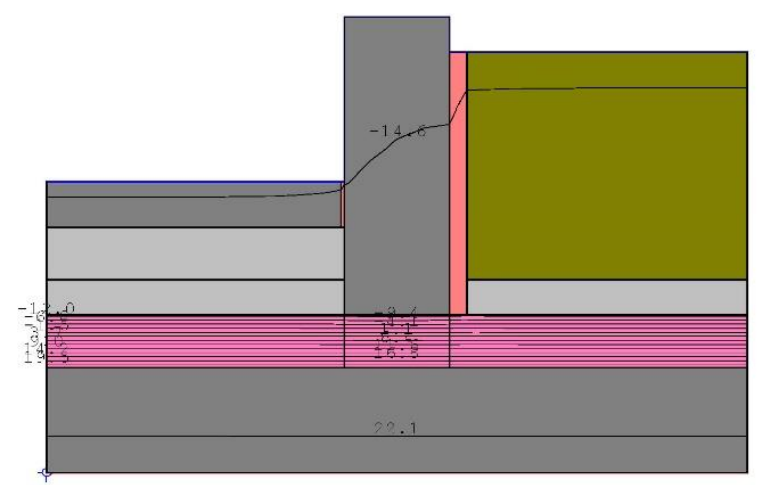

Condition 2.4-Improved w/ 150mm Slab Insulation; Isotherms

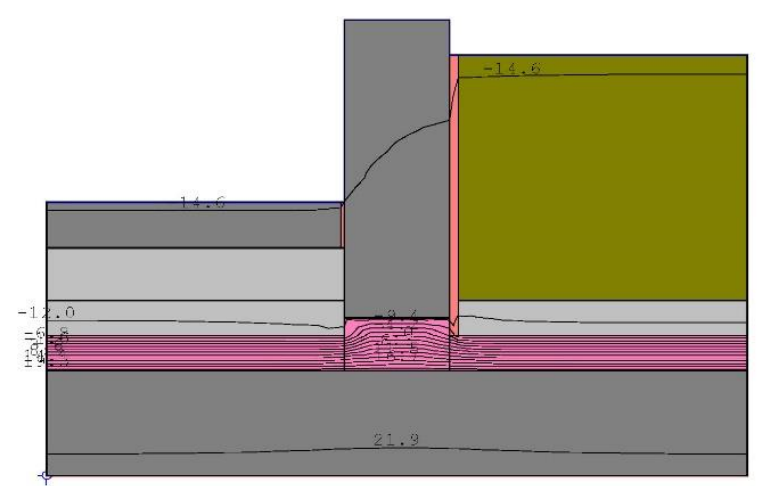

Condition 2.5 - Improved w/ 25mm Wall Insulation; Isotherms

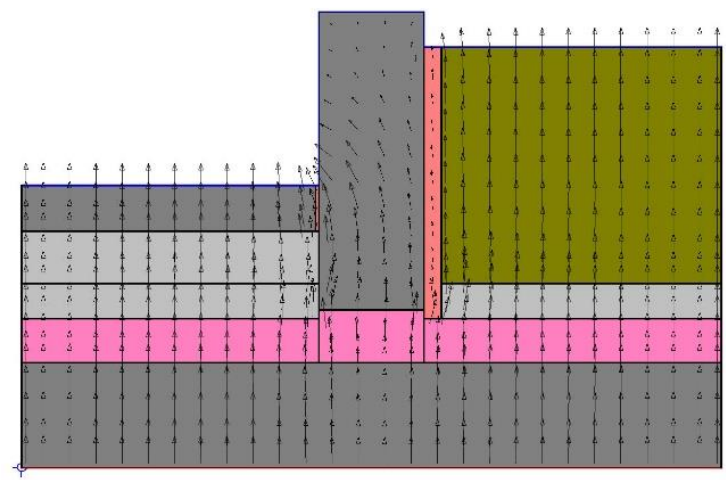

Condition 2.3 - Improved $w / 125 \mathrm{~mm}$ Slab Insulation; Flux Vectors

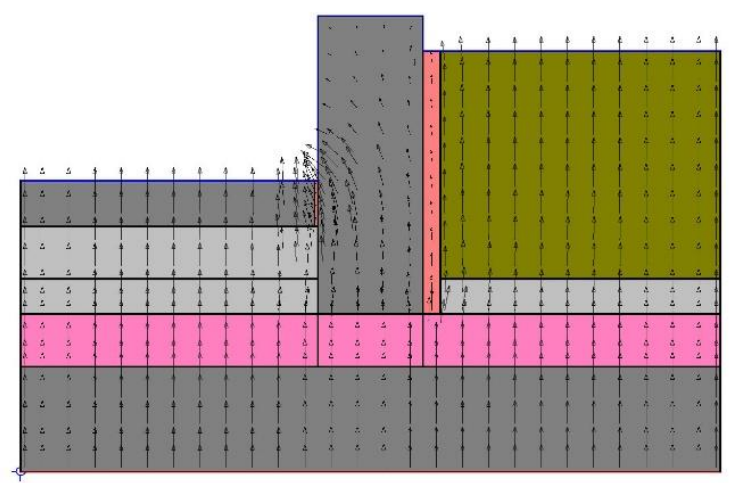

Condition 2.4-Improved w/ 150mm Slab Insulation; Flux Vectors

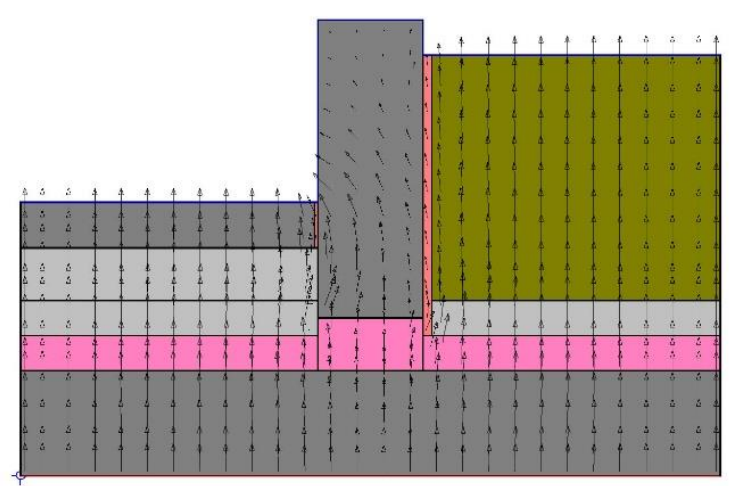

Condition 2.5 - Improved w/ 25mm Wall Insulation; Flux Vectors 


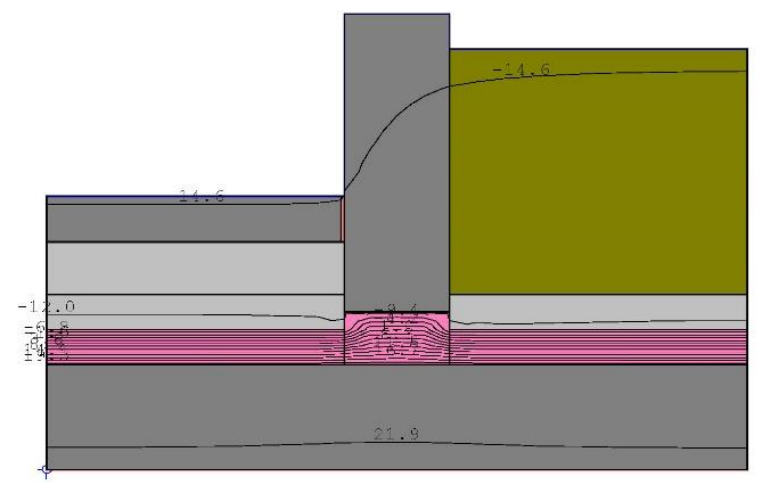

Condition 2.6 - Improved w/ No Wall Insulation; Isotherms

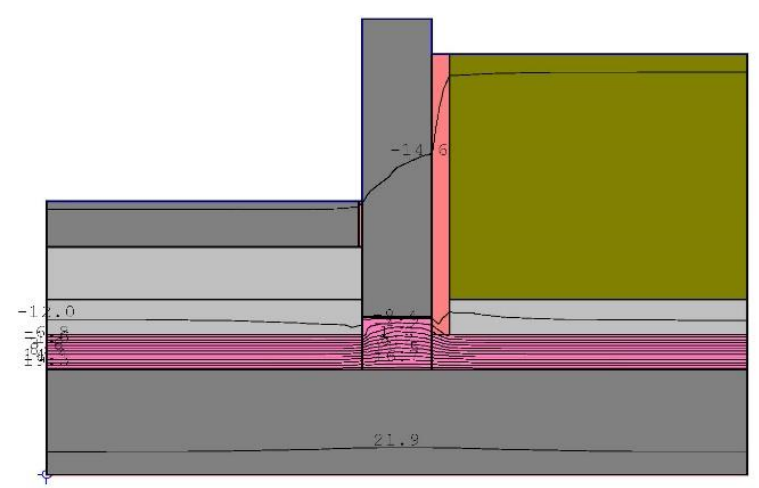

Condition 2.7-Improved w/ 200mm Wide Wall; Isotherms

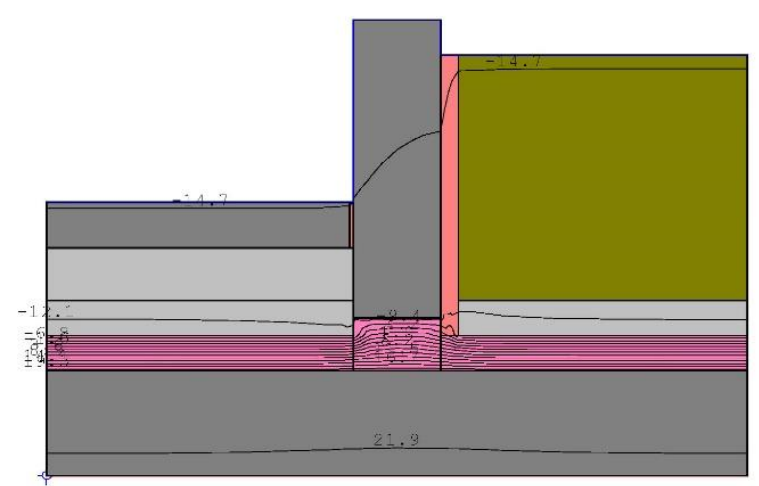

Condition 2.8-Improved w/250mm Wide Wall; Isotherms

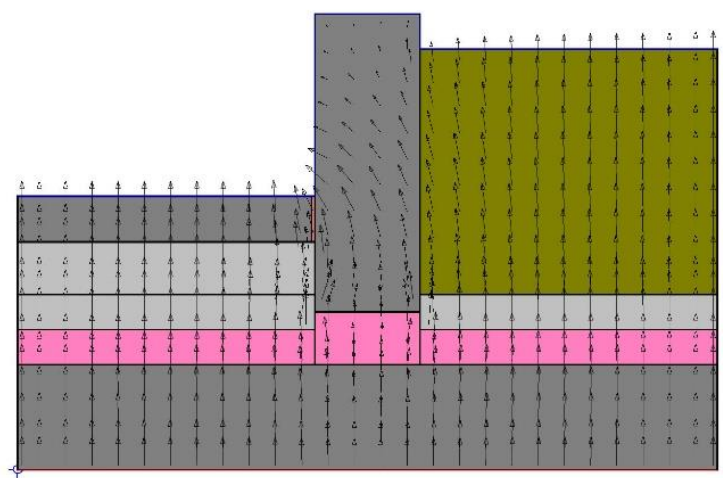

Condition 2.6 - Improved w/ No Wall Insulation; Flux Vectors

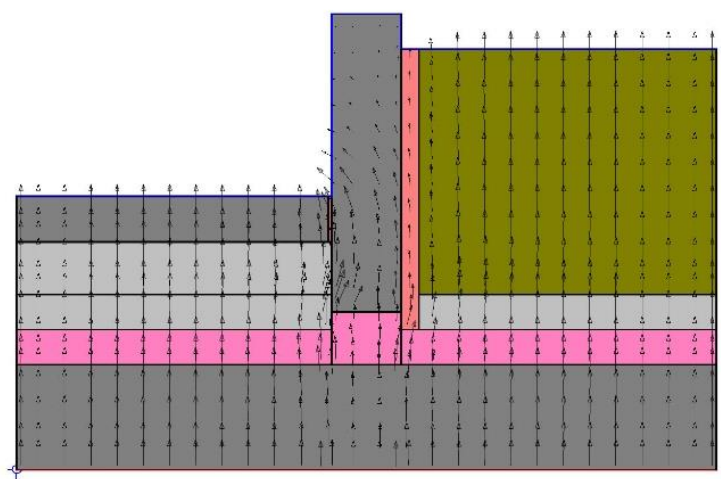

Condition 2.7-Improved w/ 200mm Wide Wall; Flux Vectors

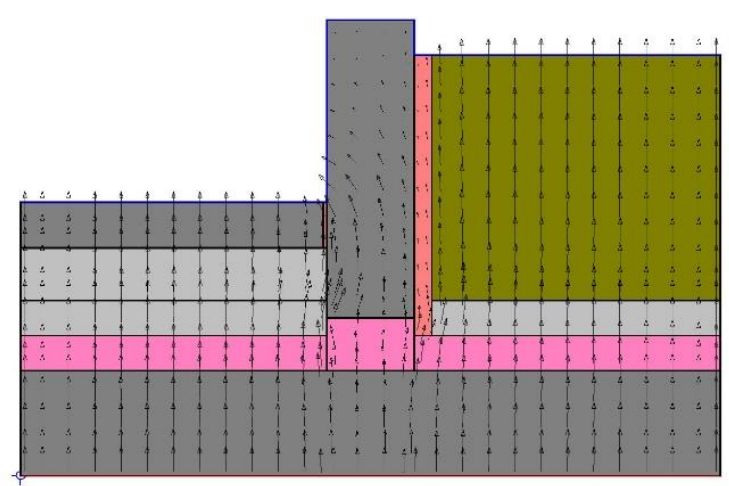

Condition 2.8-Improved w/250mm Wide Wall; Flux Vectors 


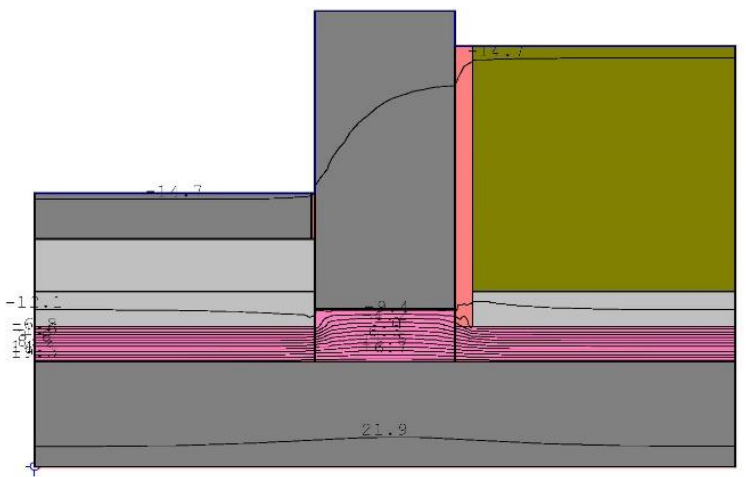

Condition 2.9-Improved $w / 400 \mathrm{~mm}$ Wide Wall; Isotherms

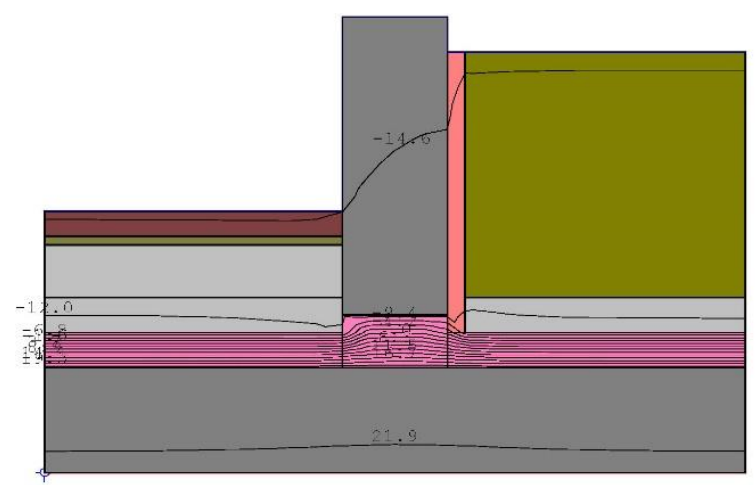

Condition 2.10-Improved w/ Precast Conc. Paving; Isotherms

\section{Condition 3 - Ultimate}

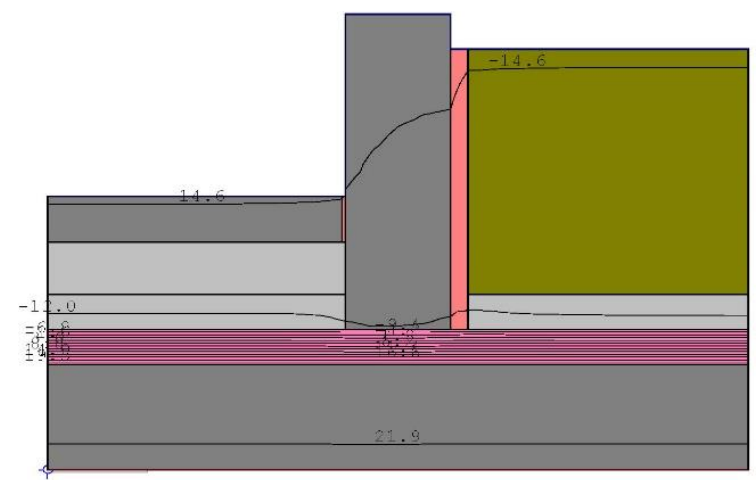

Condition 3.1 - Ultimate; Isotherms

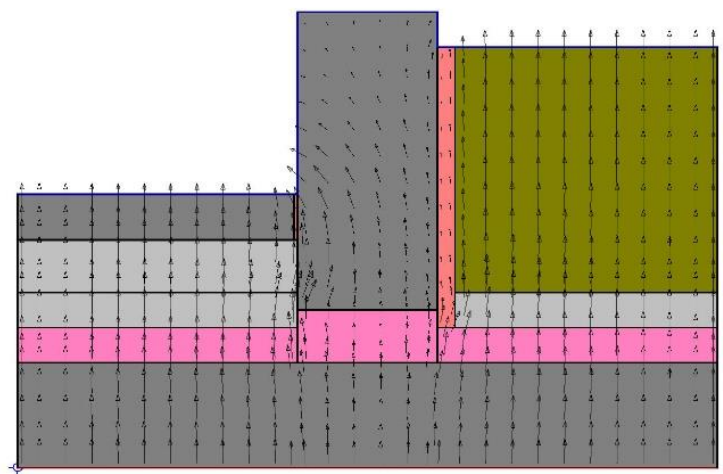

Condition 2.9-Improved w/400mm Wide Wall; Flux Vectors

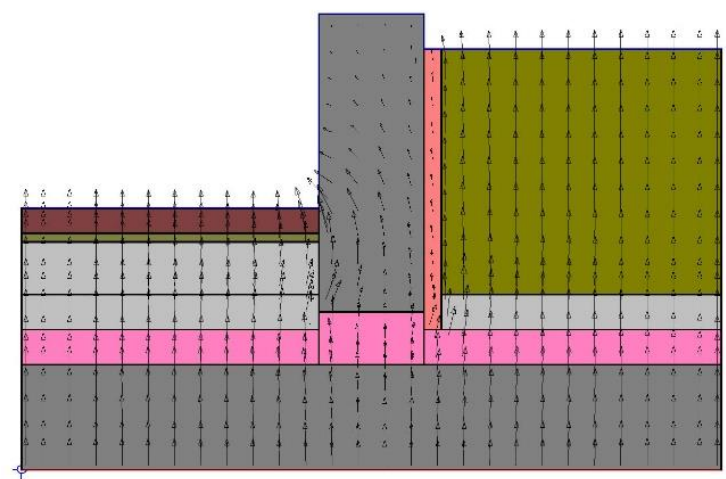

Condition 2.10-Improved w/ Precast Conc. Paving; Flux Vectors

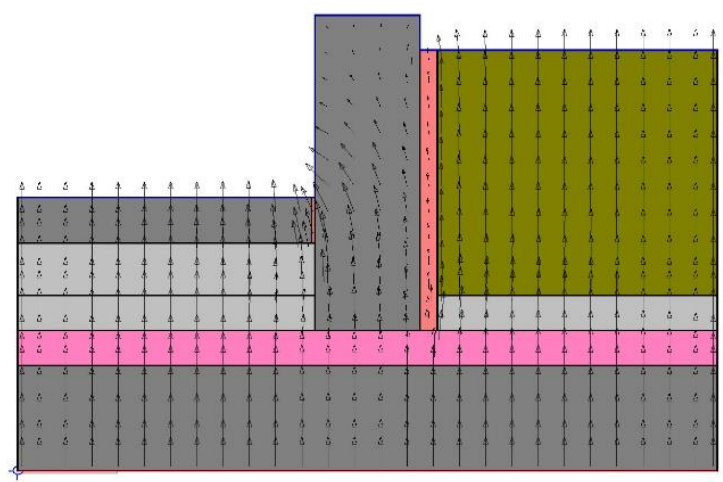

Condition 3.1 - Ultimate; Flux Vectors 


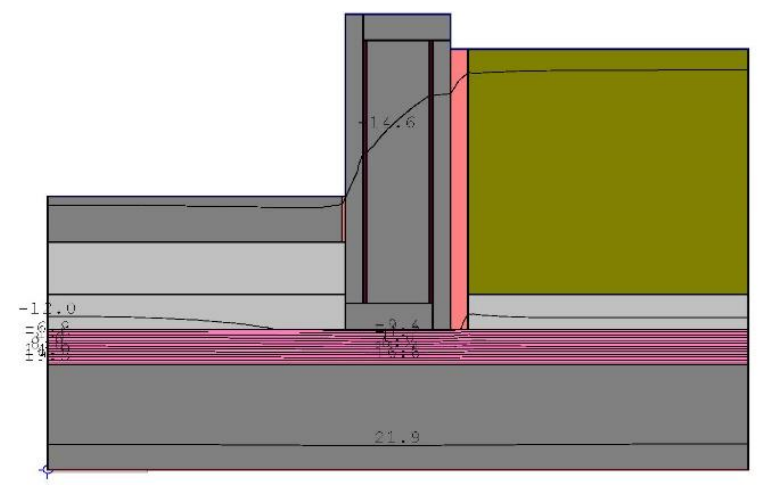

Condition 3.2 -Ultimate @ Reinforcing; Isotherms

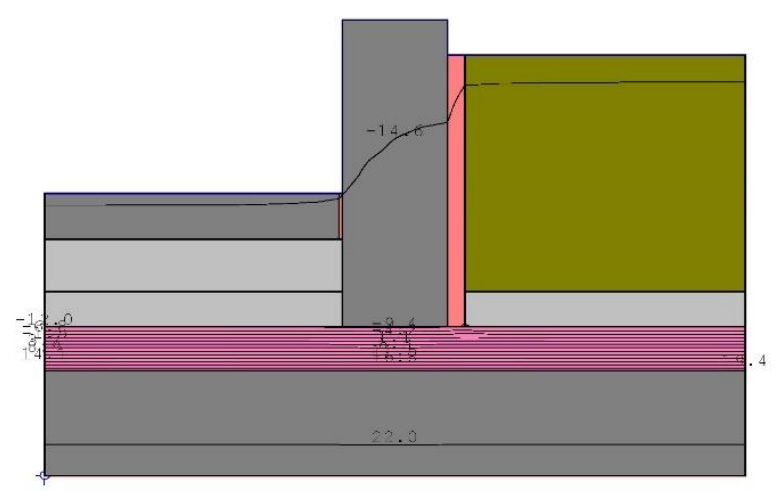

Condition 3.3 - Ultimate $w / 125 \mathrm{~mm}$ Slab Insulation; Isotherms

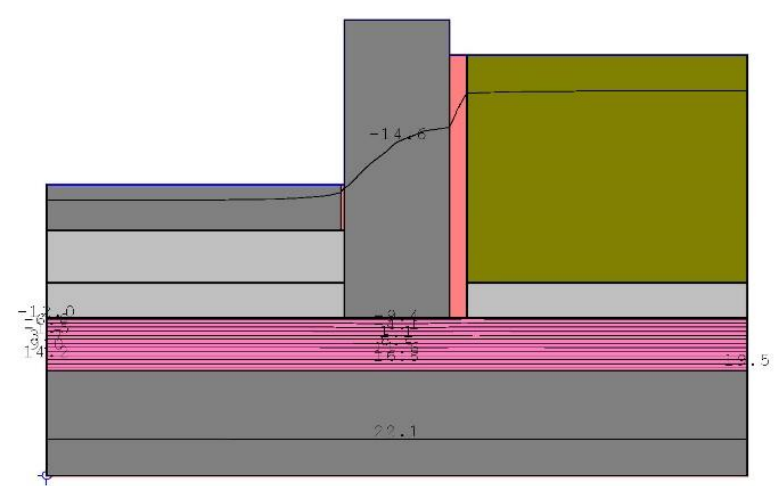

Condition 3.4-Ultimate w/ 150mm Slab Insulation; Isotherms

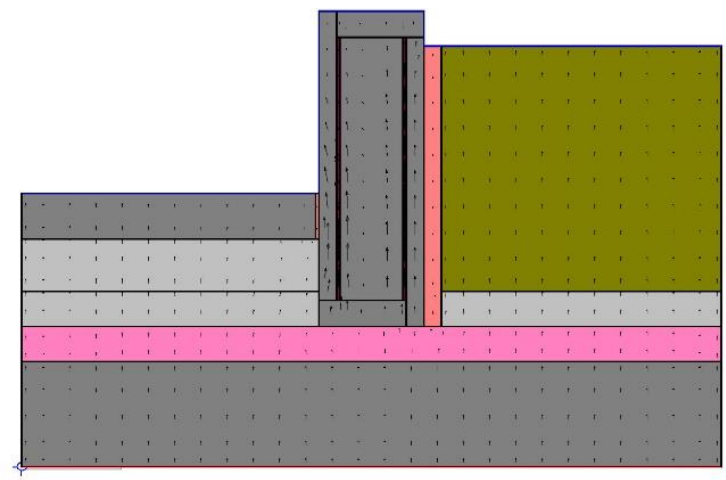

Condition 3.2 -Ultimate @ Reinforcing; Flux Vectors

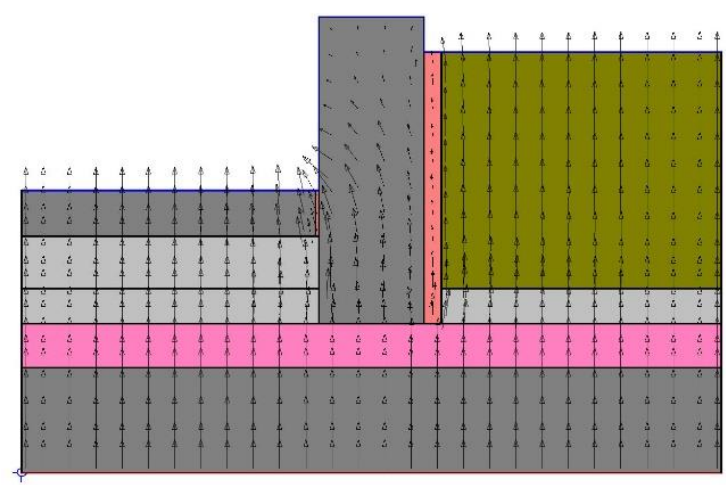

Condition 3.3 - Ultimate $w / 125 \mathrm{~mm}$ Slab Insulation; Flux Vectors

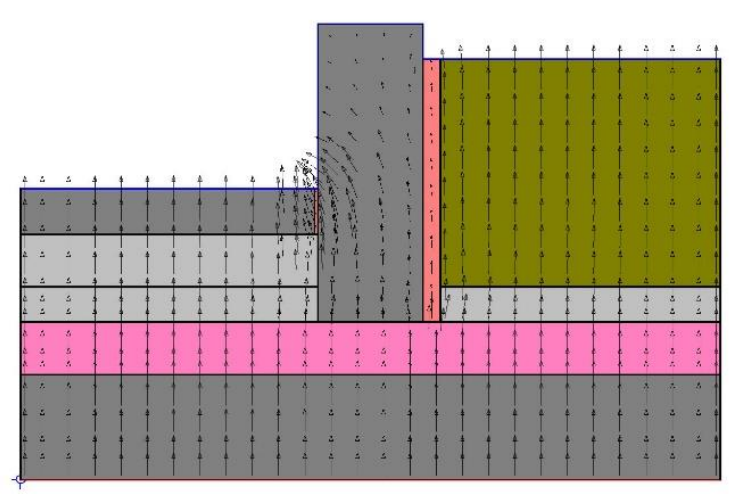

Condition 3.4 - Ultimate $w / 150 \mathrm{~mm}$ Slab Insulation; Flux Vectors 


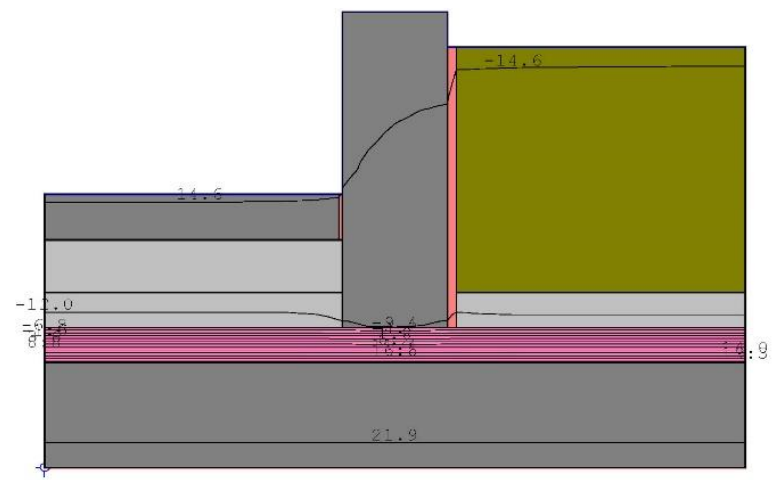

Condition 3.5 - Ultimate $w / 25 \mathrm{~mm}$ Wall Insulation; Isotherms

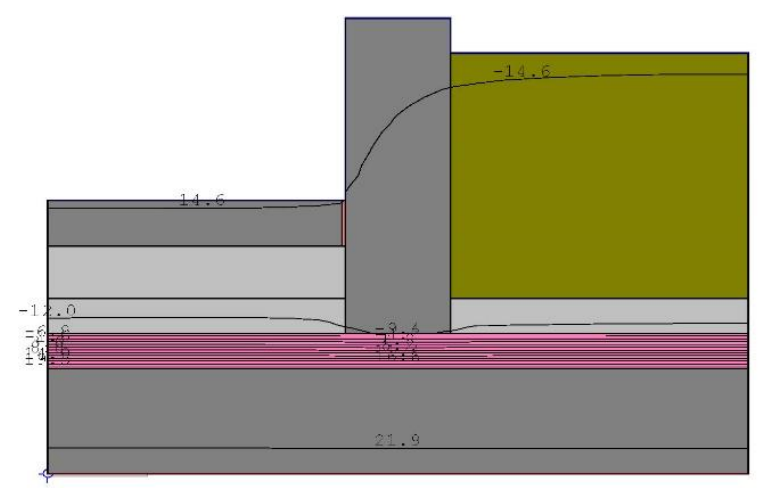

Condition 3.6 - Ultimate w/ No Wall Insulation; Isotherms

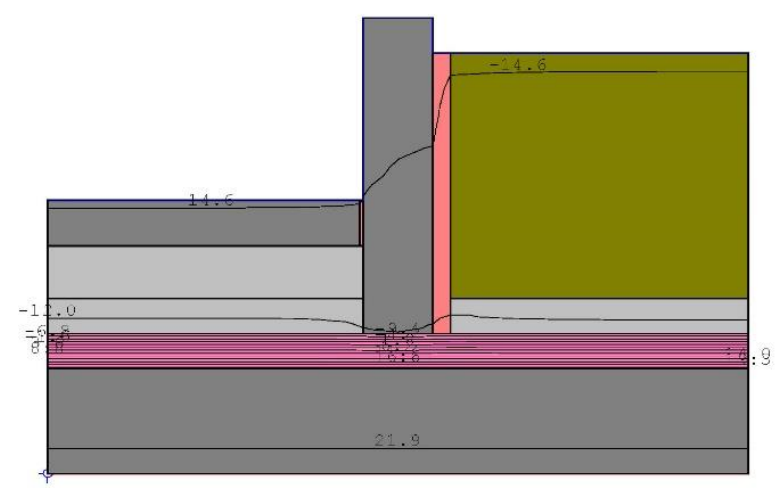

Condition 3.7-Ultimate $\mathrm{w} / 200 \mathrm{~mm}$ Wide Wall; Isotherms

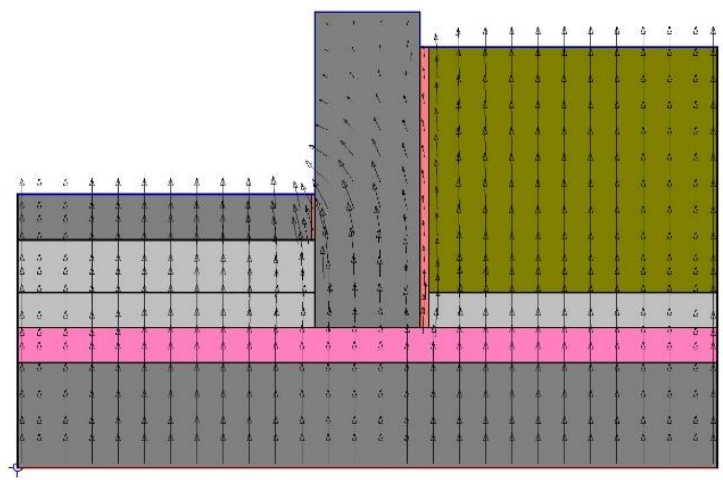

Condition 3.5 - Ultimate $w / 25 \mathrm{~mm}$ Wall Insulation; Flux Vectors

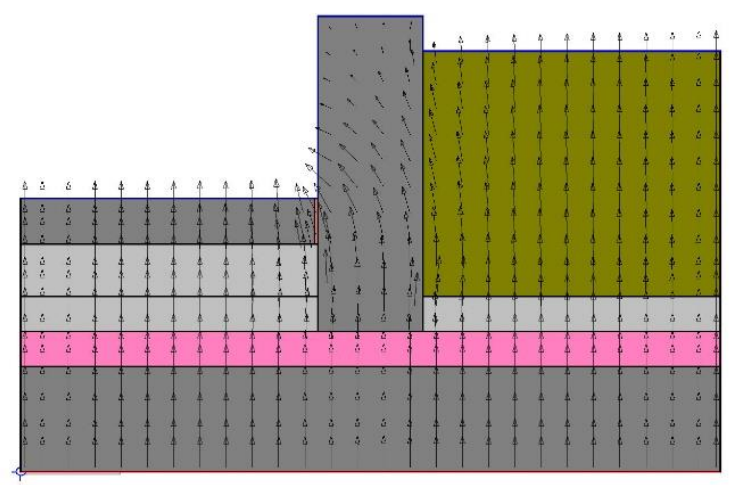

Condition 3.6 - Ultimate w/ No Wall Insulation; Flux Vectors

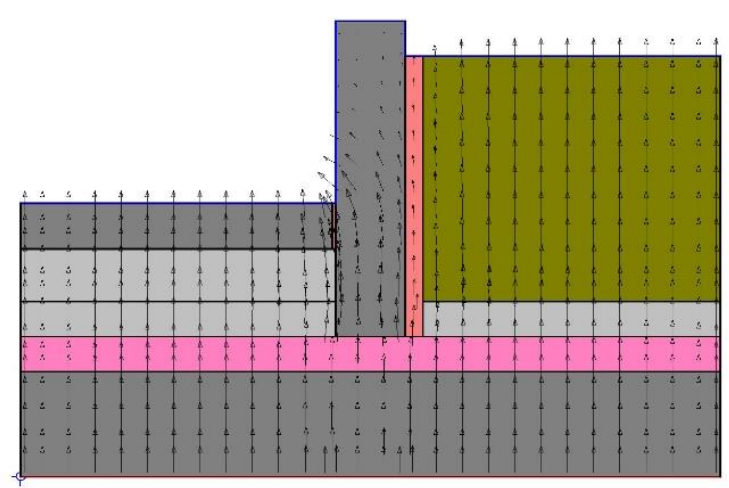

Condition 3.7 - Ultimate w/200mm Wide Wall; Flux Vectors 


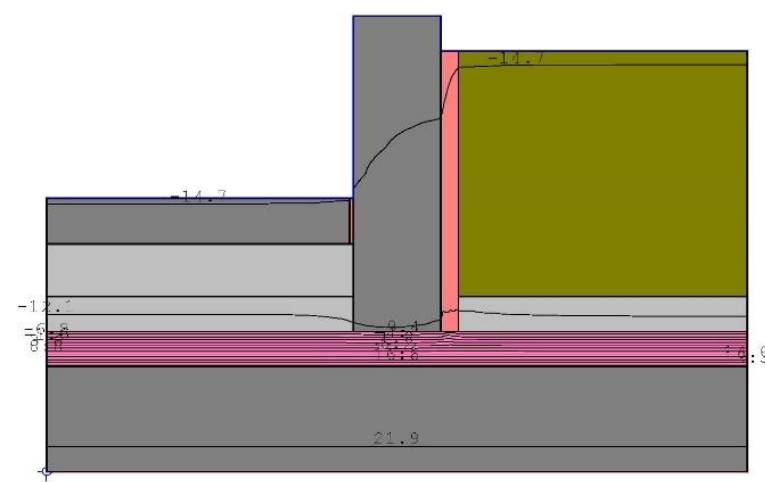

Condition 3.8 -Ultimate $w / 250 \mathrm{~mm}$ Wide Wall; Isotherms

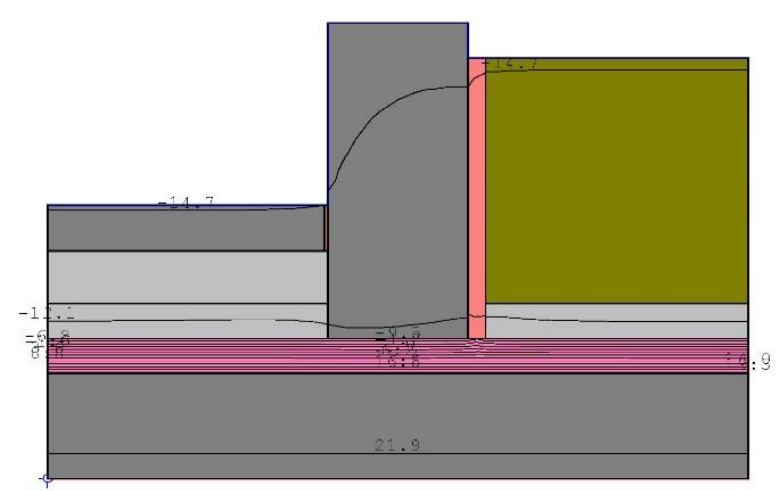

Condition 3.9-Ultimate $w / 400 \mathrm{~mm}$ Wide Wall; Isotherms

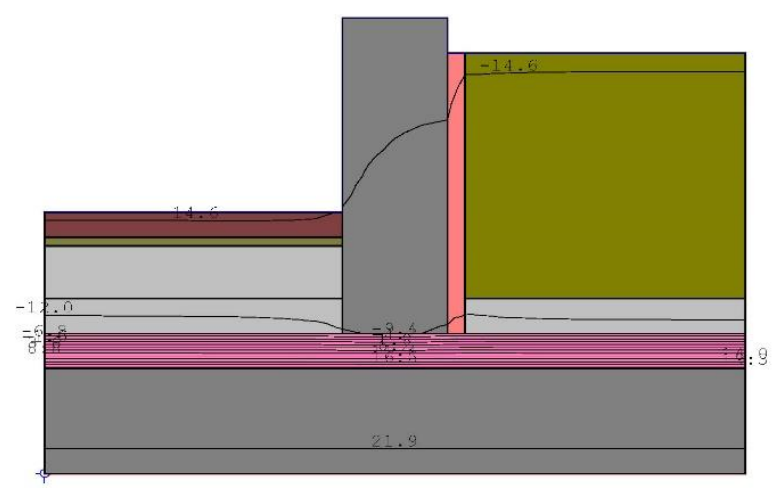

Condition 3.10 - Ultimate w/ Precast Conc. Paving; Isotherms

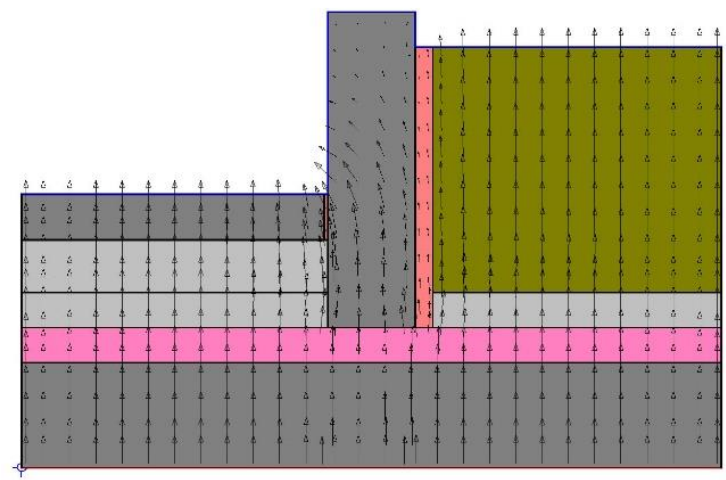

Condition 3.8 - Ultimate $w / 250 \mathrm{~mm}$ Wide Wall; Flux Vectors

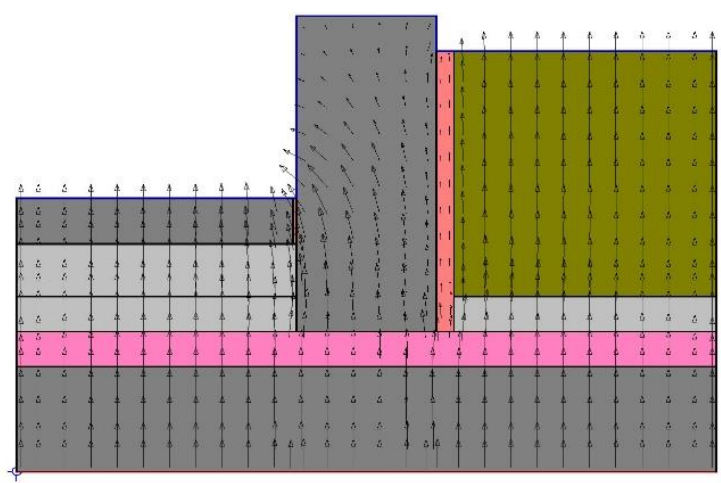

Condition 3.9 - Ultimate $w / 400 \mathrm{~mm}$ Wide Wall; Flux Vectors

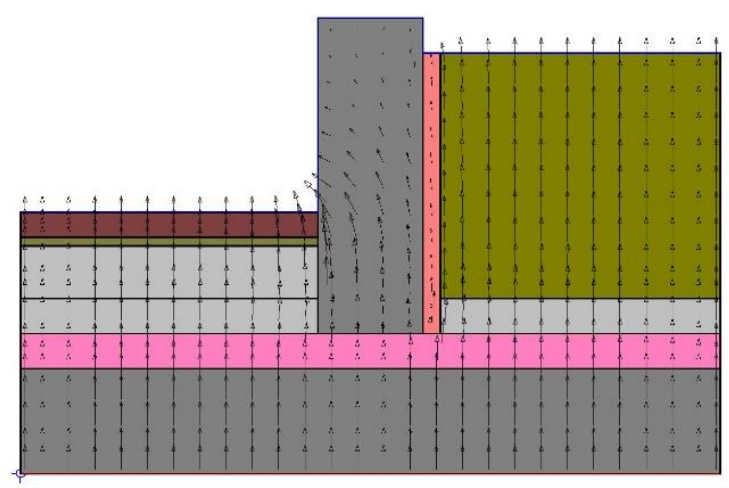

Condition 3.10 - Ultimate w/ Precast Conc. Paving; Flux Vectors 


\section{Appendix F - Condition Simulation Model Results Graph}

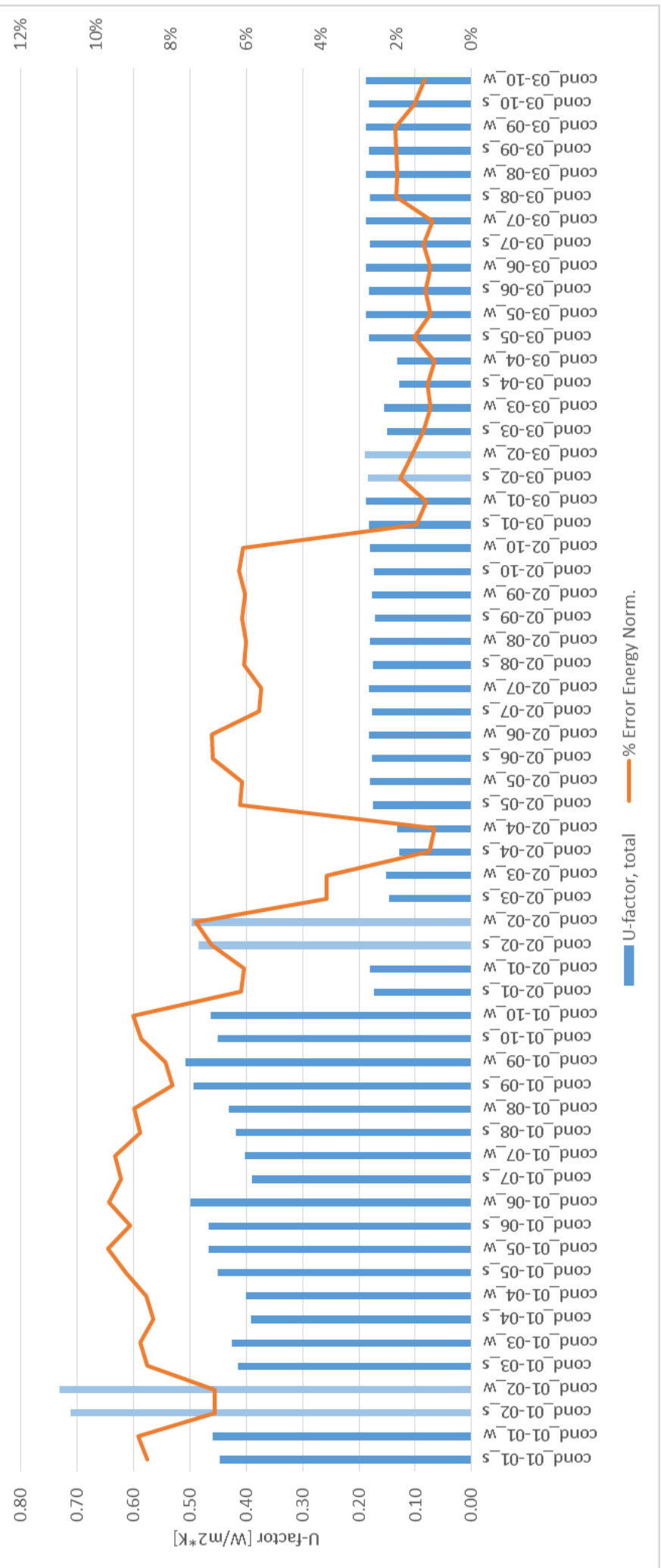


Appendix G - Additional Design Details
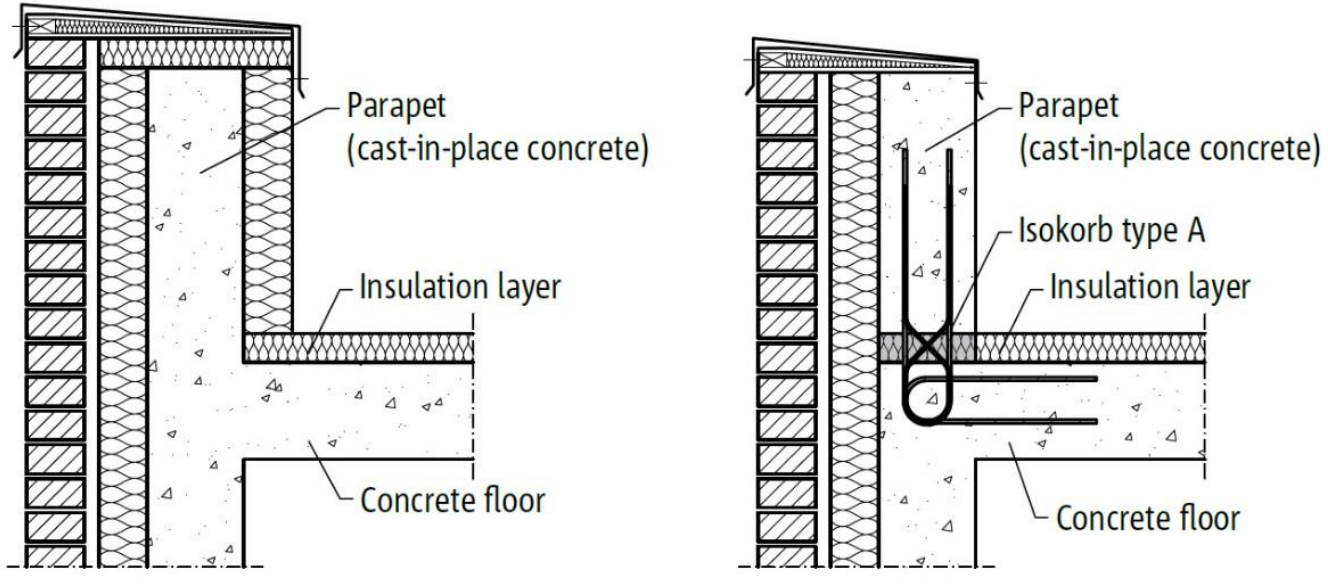

Concrete Parapet Design - Parapet with insulation wrapping causing a thermal bridge in the insulation layer (left), parapet with a thermal break element (right) (Lawton \& Roppel, 2014) 


\section{References}

Almusaed, A. (2011). Biophilic and bioclimatic architecture: Analytical therapy for the next generation of passive sustainable architecture. London: Springer.

ASHRAE. (2009). Handbook - Fundamentals (SI Edition). Atlanta, GA: American Society of Heating, Refrigerating, and Air-Conditioning Engineers, Inc.

Becker, D., \& Wang, D. (2011). Green Roof Heat Transfer and Thermal Performance Analysis (Thesis). Retrieved from Carnegie Mellon University: https://www.cmu.edu/environment/campus-greendesign/green-roofs/documents/heat-transfer-and-thermal-performance-analysis.pdf

Blomberg, T. (1996). Heat conduction in two and three dimensions: Computer modelling of building physics applications (Dissertation). Retrieved March 3, 2016, from http://lup.lub.lu.se/record/17728

Building Science Corporation. (2016). Habitable Space. Retrieved from Building Science Corporation: https://buildingscience.com/glossary/habitable-space

Canada Mortgage and Housing Corporation. (2013, April 30). Canadian Housing Observer 2013 Condominiums: A Chapter from the Canadian Housing Observer. Retrieved from Canada Mortgage and Housing Corporation: https://www.cmhc-

schl.gc.ca/en/hoficlincl/observer/upload/chapter_2_67993_w_acc.pdf

Canada Mortgage and Housing Corporation. (2016). Housing Starts, Completions, and Units Under Construction: Starts, Completions and Under Construction - Census Metropolitan Areas (CMA). Retrieved from Canada Mortgage and Housing Corporation: https://www.cmhcschl.gc.ca/en/hoficlincl/homain/stda/hocoacmu/hocoacmu_001.cfm

Cengel, Y. A. (2007). Introduction To Thermodynamics and Heat Transfer (2nd ed.). New York: McGrawHill.

City of Toronto. (2014, August 19). City of Toronto Zoning By-law 569-2013, as amended (Office Consolidation). Retrieved from City of Toronto: http://www.toronto.ca/zoning/bylaw_amendments/ZBL_NewProvision_Chapter15.htm

Edelsbrunner, H. (2001). Geometry and Topology of Mesh Generation. Cambridge University Press: Cambridge. Retrieved from https://www.cs.duke.edu/ edels/Papers/2001-T-05GeometryTopologyForMeshing.pdf

Green Roof Technology. (2016). Green Roof Types. Retrieved September 15, 2016, from Green Roof Technology: http://www.greenrooftechnology.com/green-roof-types

Gullone, E. (2000). The biophilia hypothesis and life in the 21st century: Increasing mental health or increasing pathology? Journal of Happiness Studies, 1(3), 293-321.

Hens, H. S. (2007). Building Physics - Heat, Air and Moisture: Fundamentals and Engineering Methods with Examples and Exercises. Berlin: Ernst \& Sohn. 
Hutcheon, N. B., \& Handegord, G. O. (1995). Building Science for a Cold Climate. Ottawa: National Research Council of Canada.

International Organization for Standardization (ISO). (2015). ISO/DIS 14683 - Thermal bridges in building construction - Linear thermal transmittance - Simplified methods and default values. Retrieved April 13, 2016, from Chartered Institution of Building Services Engineers: http://www.cibse.org/getmedia/71450291-7486-44f1-a145-f13ce1a44d57/Draft-EN-ISO14683.pdf.aspx

Koliji, A. (2013, 11 16). Geotechdata.info. Retrieved from Geotechdata: http://www.geotechdata.info/parameter/void-ratio.html

Lawrence Berkeley National Laboratory. (2016, April 22). THERM. Retrieved from Windows \& Daylighting: https://windows.lbl.gov/software/therm/therm.html

Lawton, M., \& Roppel, P. (2014). Schöck Isokorb ${ }^{\circledR}$ Design Guide Solutions to Prevent Thermal Bridging. Retrieved from Schöck.ca: http://www.schoeck.ca/upload/files/download/Design_Guide_Schoeck_Isokorb_Solutions_to_P revent_Thermal_Bridging[5752].pdf

Mitchell, R., Kohler, C., Curcija, D., Zhu, L., Vidanovic, S., Czarnecki, S., \& Arasteh, D. (2013). THERM 6.3 / WINDOW 6.3 NFRC Simulation Manual. Berkeley: Lawrence Berkeley National Laboratory. Retrieved from Lawrence Berkeley National Laboratory.

Morrison Hershfield. (2011). Thermal Performance of Building Envelope Details for Mid-and High-Rise Buildings (1365-RP). Atlanta: Morrison Hershfield. Retrieved from http://morrisonhershfield.com/wp-content/uploads/2015/11/MH_1365RP_Final_-small.pdf

Murad, C. (2015). Investigate the impact of a low U-value framing condition and an insulated curb condition at cantileverd concrete balcony slabs in high-rise MURBS. Toronto, Ontario: Retrieved from Ryerson University (RULA) Digital Repository. http://digital.library.ryerson.ca/islandora/object/RULA\%3A3430.

National Fenestration Rating Council. (2016, October 14). National Fenestration Rating Council. Retrieved from National Fenestration Rating Council: http://www.nfrc.org/

Nyberg, H. (2011). Thermal bridges at foundations: Evaluation of heat calculation methods (Thesis). Retrieved March 3, 2016, from http://publications.lib.chalmers.se/records/fulltext/155743.pdf

Oberndorfer, E., Lundholm, J., Bass, B., Coffman, R. R., Doshi, H., Dunnett, N., . . Rowe, B. (2007). Green Roofs as Urban Ecosystems: Ecological Structures, Functions, and Services. BioScience, 57(10), 823-833.

Ontario Ministry of Housing. (2015, October 29). Ontario Building Code 2012. Retrieved from O. Reg. 332/12: BUILDING CODE: https://www.ontario.ca/laws/regulation/120332

Owens Corning. (2011). FOAMULAR ${ }^{\circledR}$ 150: Extruded Polystyrene (XPS) Rigid Foam Insulation. Retrieved from Product Data Sheets: http://www.owenscorning.com/networkshare/eis/23513-hfoamular-150-xps-insulation-product-data-sheet.pdf 
Schöck USA Inc. (2015, August). Schöck Isokorb ${ }^{\circledR}$ Technical Manual, U.S. Edition. Retrieved March 23, 2016, from Schöck USA Inc.: http://www.schock-

us.com/upload/files/download/Technical_Manual_Schoeck_Isokorb_\%5B5185\%5D.pdf

Sheftell, J. (2016). In Queens, the newest amenity is up on the roof. Retrieved 1120, 2016, from Daily News; New York: http://www.nydailynews.com/new-york/queens/queens-buildings-featureparks-sky-article-1.1358016

Straube, J. (2012). High Performance Enclosures. Somerville, MA: Building Science Press.

Sutton, R. K. (2015). Green Roof Ecosystems. (R. K. Sutton, Ed.) Switzerland: Springer International Publishing.

The Engineering Toolbox. (2016). Materials Conductivity. Retrieved October 25, 2016, from The Engineering Toolbox: http://www.engineeringtoolbox.com/thermal-conductivity-d_429.html

Theodosiou, T. (2009). Green Roofs in Buildings: Thermal and Environmental Behaviour. Advances in Buildling Energy Research, 3, 271-288. doi:10.3763/aber.2009.0311

Urban Toronto [a]. (2016). Amenity Space Example. Retrieved October 13, 2016, from http://urbantoronto.ca/sites/default/files/images/projects/8453/urbantoronto-845337882.jpeg

Urban Toronto [b]. (2016). Amenity Space Example. Retrieved October 13, 2016, from http://urbantoronto.ca/sites/default/files/imagecache/displayslideshow/images/articles/2012/03/5223/urbantoronto-5223-16136.jpg

Weiler, S. K., \& Scholz-Barth, K. (2009). Green roof systems: A guide to the planning, design, and construction of landscapes over structure. Hoboken, NJ: John Wiley \& Sons. 